\title{
Funktionelle Charakterisierung von apoplastischen Proteinen in Brassica napus und Arabidopsis thaliana nach Infektion mit Verticillium longisporum
}

\author{
Dissertation \\ zur Erlangung des Doktorgrades \\ „Doctor rerum naturalium“ \\ der Mathematisch-Naturwissenschaftlichen Fakultäten \\ der Georg-August-Universität zu Göttingen
}

vorgelegt von

Christine Drübert

aus Volkmarsen

Göttingen 2011 
Mitglieder des Betreuungsausschusses:

Referentin:

Korreferentin:

Tag der mündlichen Prüfung:
Prof. Dr. Andrea Polle, Prof. Dr. Christiane Gatz Prof. Dr. Andrea Polle Prof. Dr. Christiane Gatz 18.04.2011 




\section{Inhaltsverzeichnis}

\section{Abkürzungsverzeichnis}

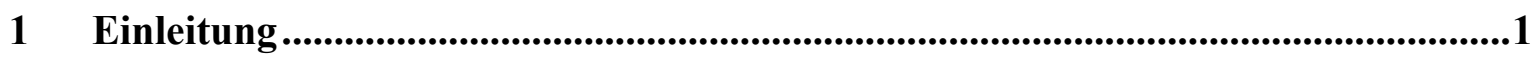

1.1 Das vaskuläre Pathogen Verticillium longisporum ............................................1

1.2 Die Interaktion zwischen Pflanzen und Pathogenen..........................................

1.3 Die Rolle des pflanzlichen Apoplasts bei der Pathogenabwehr gegen vaskuläre Pathogene wie Verticillium longisporum ............................................11

1.4 Zielsetzung der vorliegenden Arbeit ................................................................ 16

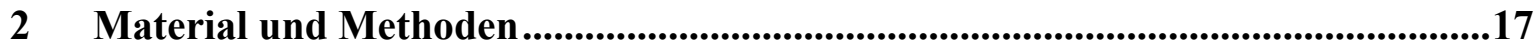

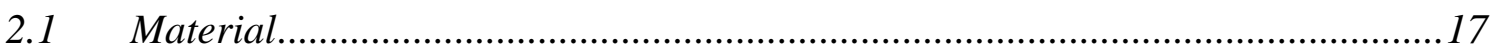

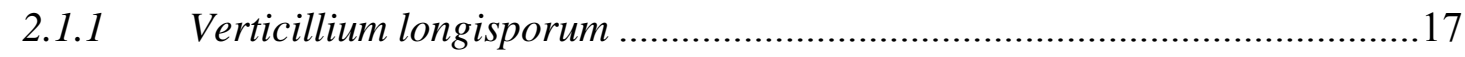

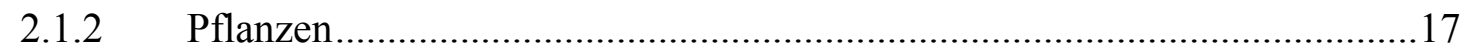

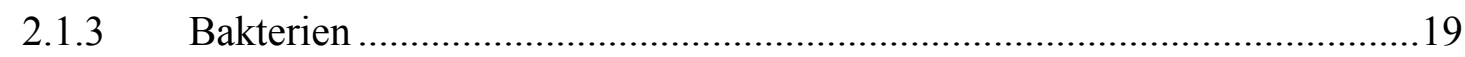

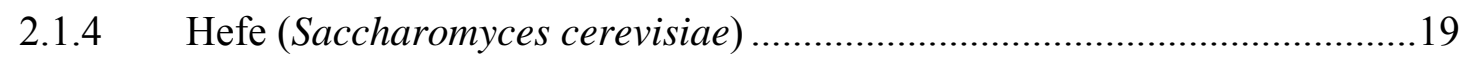

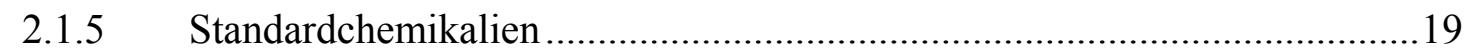

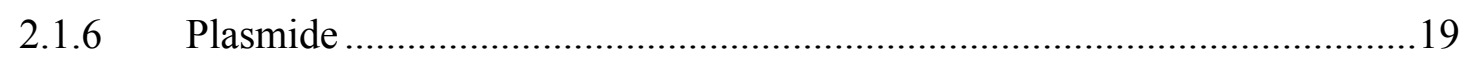

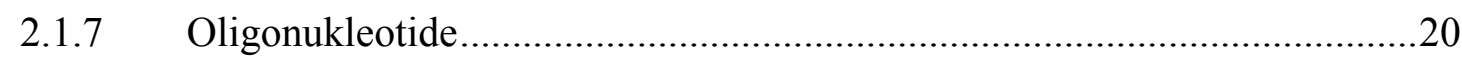

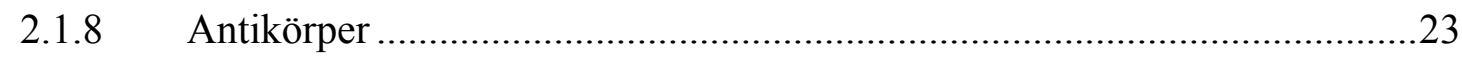



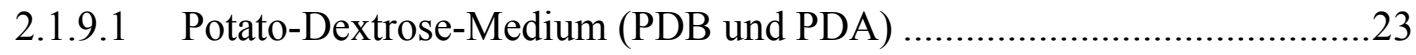

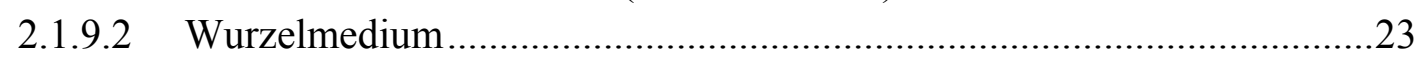

2.1.9.3 Medien für Mikroorganismen ........................................................2

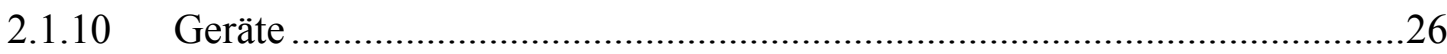

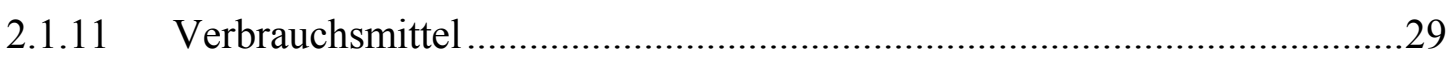

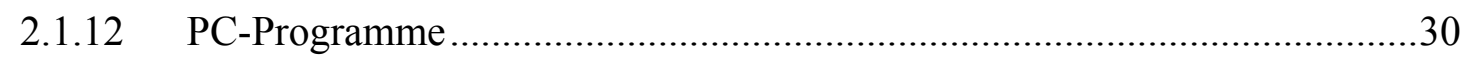

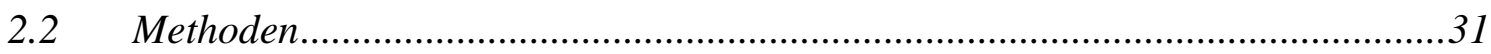

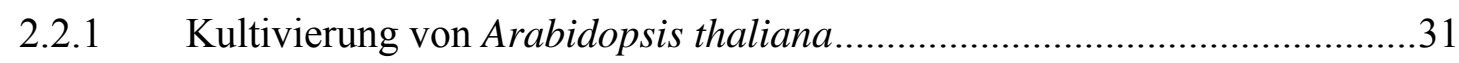

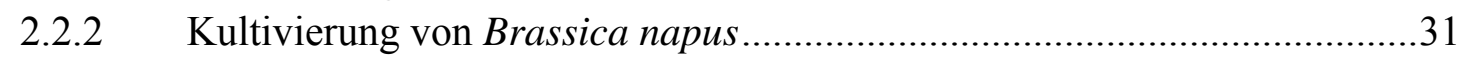

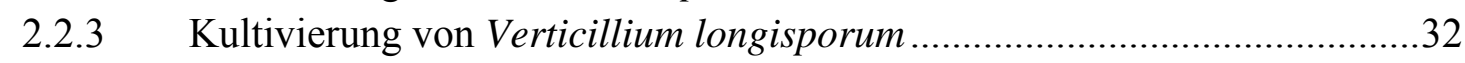

2.2.3.1 Herstellung von Stammkulturen Verticillium longisporum ......................32

2.2.3.2 Herstellung einer Sporenlösung von Verticillium longisporum.................32

2.2.3.3 Wachstum von Verticillium longisporum im Xylemsaft von Brassica napus ............................................................................... 32

2.2.3.4 Wachstum von Verticillium longisporum unter dem Einfluss von GLP3 produzierender Hefe ............................................................33

2.2.4 Infektion der Versuchspflanzen mit Verticillium longisporum.....................34 
2.2.5 Gewinnung von Xylemsaft aus Brassica napus Pflanzen. 34

2.2.6 Messung der Blattfläche von Arabidopsis thaliana ........................................35

2.2.7 Ermittlung der Biomasse von Arabidopsis thaliana .....................................35



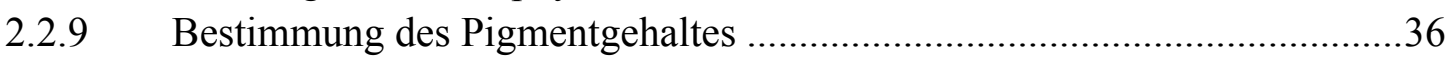

2.2.10 Elementanalyse durch Optische Emissionsspektrometrie mit einem

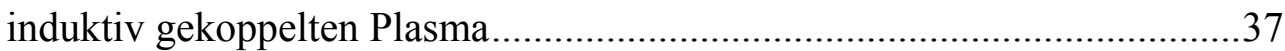

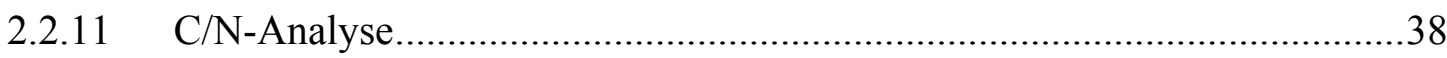

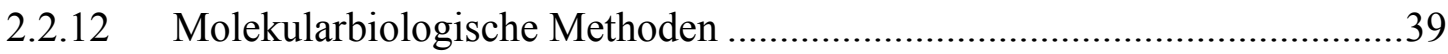

2.2.12.1 Extraktion pflanzlicher und pilzlicher genomischer DNA...................39

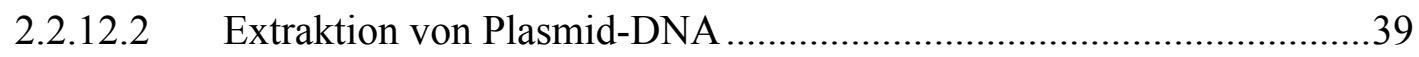

2.2.12.3 Konzentrationsmessung von Nukleinsäuren .....................................40

2.2.12.4 Polymerase-Kettenreaktion (PCR) ................................................40

2.2.12.5 Selektion homozygoter T-DNA-Insertionslinien mittels PCR ............42

2.2.12.6 Agarose-Gelelektrophorese von DNA-Molekülen ..............................43

2.2.12.7 Aufreinigung von DNA durch Gel-Extraktion ....................................44

2.2.12.8 Sequenzierung von PCR-Produkten...................................................44

2.2.12.9 Extraktion pflanzlicher RNA mit Trizol ..........................................46

2.2.12.10 Denaturierende Agarose-Gelelektrophorese von RNA-Molekülen .....46

2.2.12.11 Verdau von genomischer DNA im RNA-Extrakt .............................47

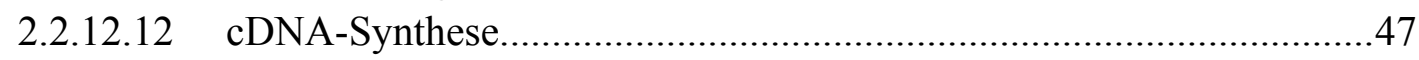

2.2.12.13 Quantitative Real Time PCR (qRT-PCR) .......................................48

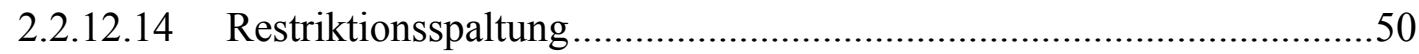

2.2.12.15 Herstellung transgener Arabidopsis-Pflanzen ......................................52

2.2.12.16 Selektion transgener Pflanzen .......................................................53

2.2.12.17 Herstellung eines Vektorkonstrukts für die Überexpression

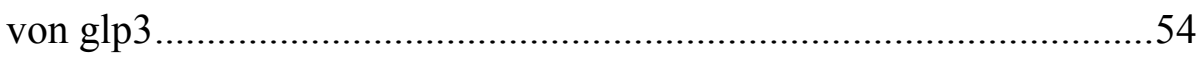

2.2.12.18 Herstellung eines Vektorkonstrukts für die Komplementierung der T-DNA-Insertionslinie FLAG_412D02 ......................................56

2.2.12.19 Herstellung der Vektorkonstrukte für amiRNA-Pflanzen....................56

2.2.12.20 Herstellung des Vektorkonstrukts für die GUS-Reporterpflanzen ......59

2.2.12.21 Kultivierung und Transformation von Escherichia coli ......................61

2.2.12.22 Kultivierung und Transformation von Agrobacterium tumefaciens ....62

2.2.12.23 Heterologe Expression eines pflanzlichen Proteins in Hefe ................63

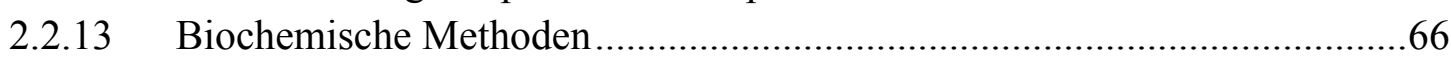

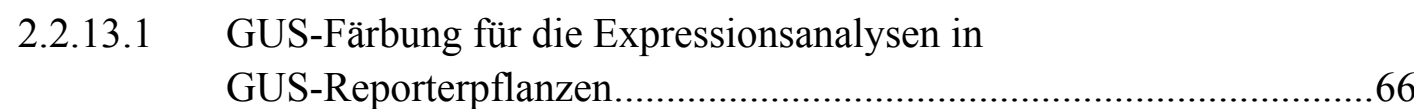

2.2.13.2 Proteinextraktion aus Pflanzen und Gelfiltration................................66

2.2.13.3 Bestimmung der Proteinkonzentration mit Bicinchoninic acid (BCA) ............................................................67

2.2.13.4 Bestimmung der Proteinkonzentration nach Bradford..........................68

2.2.13.5 SDS-Polyacrylamidgelelektrophorese …...........................................68

2.2.13.6 Western Blot ......................................................................... 70 
2.2.13.7 Bestimmung der Aktivität der Guajakolperoxidase .............................71

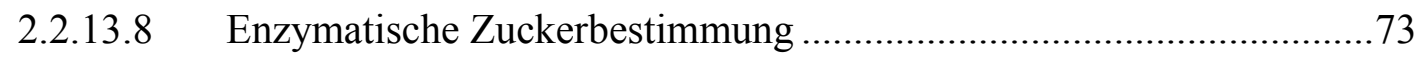

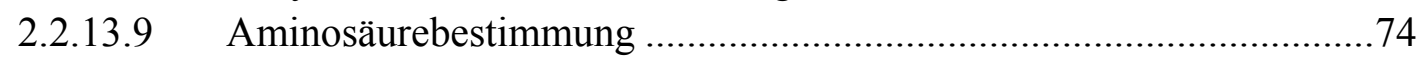

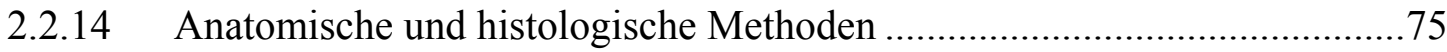

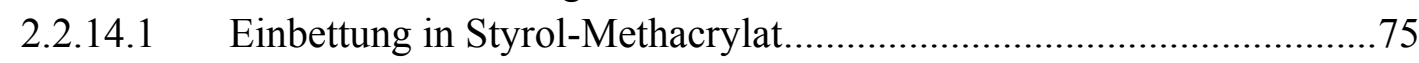

2.2.14.2 Herstellung von Semidünnschnitten mit Hilfe eines Mikrotoms ..........76

2.2.14.3 Herstellung von Schnitten mit dem Gefriermikrotom ..........................77

2.2.14.4 Herstellung von gelatinierten Objektträgern......................................77

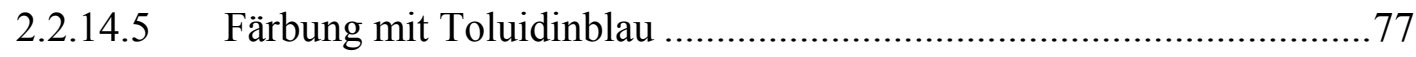

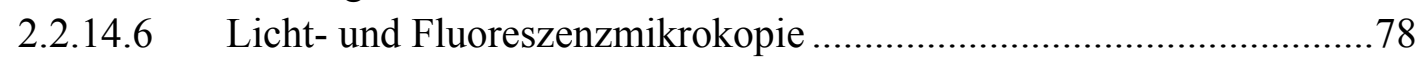

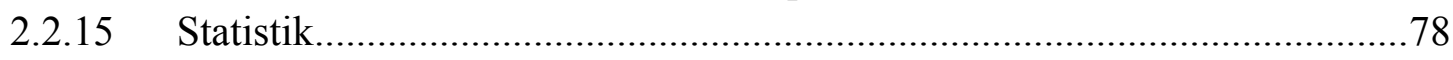

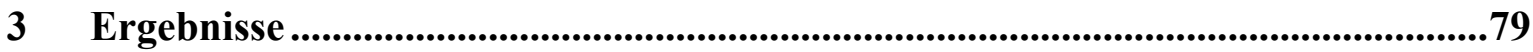

3.1 Analysen des Xylemsaftes von Brassica napus im Bezug auf potentielle antifungale Eigenschaften.....

3.2 Charakterisierung von T-DNA-Insertionsmutanten von Arabidopsis thaliana hinsichtlich ihrer Sensitivität gegenüber Verticillium longisporum

3.3 Charakterisierung von Arabidopsis-Pflanzen mit konstitutiv erhöhter glp3-Expression hinsichtlich ihrer Suszeptibilität gegenüber Verticillium longisporum

3.4 Komplementierung der glp3-Mutante 100

3.5 Charakterisierung von amiRNA-Pflanzen bezüglich der Sensitivität gegenüber Verticillium longisporum

3.6 Anatomische Untersuchungen von Arabidopsis-Wildtyp-Pflanzen sowie der glp3-Mutante hinsichlich Verticillium-induzierter Veränderungen ..... 105

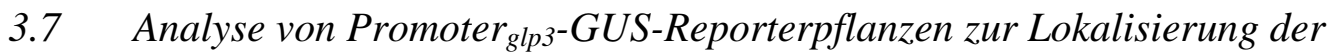
glp3-Expression in Arabidopsis thaliana.....

3.8 Untersuchung des Einflusses von heterolog produziertem GLP3 auf das Wachstum von Verticillium longisporum

4 Diskussion

4.1 Proteine aus dem Xylemsaft von Brassica napus weisen antifungale Eigenschaften auf.

4.2 Eine Infektion mit Verticillium longisporum führt in Arabidopsis thaliana zur Produktion von hyperplastischem Xylem und zu einer Transdifferenzierung von Mesophyllzellen zu Gefäß-ähnlichen Elementen

4.3 GLP3 vermittelt in Arabidopsis thaliana Resistenz gegenüber Verticillium longisporum durch Einschränkung des Pilzwachstums... 


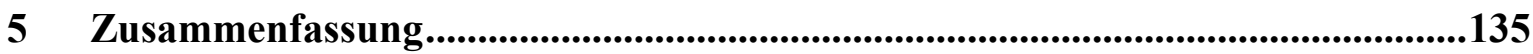

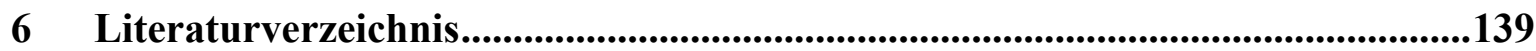

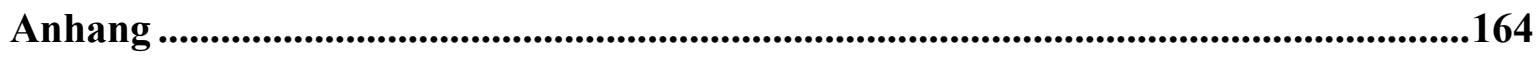

Anhang A: Einfluss einer Infektion mit Verticillium longisporum auf die Aktivität



Anhang B: Zusätzliche Bilder der GUS-Reporterpflanzen, Linie 3 .............................167

Anhang C: Querschnitte der VND7-Repressorlinien.....................................................169

Anhang D: Veröffentlichungen im Rahmen dieser Arbeit...........................................170 


\section{Abkürzungsverzeichnis}

Abb.

Abbildung

ADP

Adenosindiphosphat

APS

Ammoniumpersulfat

ATP

Adenosintriphosphat

BCA

Bicinchoninic acid

BSA

Rinderserumalbumin

bzw.

beziehungsweise

ca.

circa

Col-0

Ökotyp Columbia von Arabidopsis thaliana

ddNTPs

Didesoxyribonukleotide

DMSO

Dimethylsulfoxid

DNA

Desoxyribonukleinsäure

dNTPs

Desoxyribonukleotide

dpi

Days post infection $=$ Tage nach Infektion

E

Extinktion

EDTA

Ethylendiamintetraessigsäure

et al.

und andere (et alii)

ETI

Effector triggered immunity

ETS

Effector triggered susceptibility

FM

Frischmasse

g

Gramm

ggf.

gegebenenfalls

GUS

ß-Glucuronidase

$\mathrm{kDA}$

Kilodalton

1

Liter

M

Molar $=\mathrm{mol} / 1$

MAMP

Microbe associated molecular pattern

$\max$

maximal

$\min$

minimal

$\mathrm{MPa}$

Megapascal 


\section{MW}

$\mathrm{n}$

$\mathrm{NAD}^{+}$/

$\mathrm{NADH}$

$\mathrm{NADP}^{+}$/

$\mathrm{NADPH}$

RNA

$\mathrm{p}$

PAGE

PAMP

PCR

$\mathrm{pH}$

PR-Protein

PS

PTI

qRT-PCR

RNA

rpm

ROS

RT

SDS

$\mathrm{T}$

$\mathrm{T}_{\mathrm{m}}$

Taq-Polymerase

T-DNA

Tris

UV-Licht

VL43

$\mathrm{v} / \mathrm{v}$

Ws-2

WT

$\mathrm{w} / \mathrm{v}$

z. B.
Molekulargewicht

Anzahl der Wiederholungen

Nicotinamid-adenin-dinucleotid, oxidierte/reduzierte Form

Nicotinamid-adenin-dinucleotidphosphat, oxidierte/reduzierte Form

RNA (Ribonukleinsäure)

Irrtumswahrscheinlichkeit

Polyacrylamid-Gelelektrophorese

Pathogen associated molecular pattern

polymerase chain reaction

negativer dekadischer Logarithmus der Protonenkonzentration

Pathogenesis-related Protein

Photosystem

PAMP-triggered immunity

Quantitative Real Time PCR

Ribonukleinsäure

rounds per minute, Umdrehungen pro Minute

Reaktive Sauerstoffspezies (Reactive Oxygen Species)

Raumtemperatur

Natrium-Laurylsulfat (engl. Sodium dodecyl sulfat)

Temperatur

Schmelztemperatur

DNA-Polymerase aus Thermus aquaticus

Transferierte DNA

Tris(hydroxymethyl)aminomethan

Ultraviolettes Licht

Verticillium longisporum, Stamm 43

Volumenprozent (volume per volume)

Ökotyp Wassilewskija von Arabidopsis thaliana

Wildtyp

Gewichtsprozent (weight per volume)

zum Beispiel 
Liste der in dieser Arbeit untersuchten Proteine und deren Abkürzungen

\begin{tabular}{|l|l|l|}
\hline Abkürzung & Vollständiger Name des Proteins & AGI-Nummer \\
\hline GAL & $\alpha$-Galactosidase & At5g08370 \\
\hline GLP3 & Germin-ähnliches Protein 3 & At5g20630 \\
\hline LLP & Lektin-ähnliches Protein & At3g16530 \\
\hline POD34 & Peroxidase 34 & At3g49120 \\
\hline POD37 & Peroxidase 37 & At4g37530 \\
\hline POD52 & Peroxidase 52 & At5g05340 \\
\hline SCP & Serin-Carboxypeptidase & At4g12910 \\
\hline
\end{tabular}




\section{$1 \quad$ Einleitung}

\subsection{Das vaskuläre Pathogen Verticillium longisporum}

\section{Die Gattung Verticillium}

Die verschiedenen Vertreter der Gattung Verticillium, zu denen auch das Pathogen Verticillium longisporum gehört, sind weit verbreitete bodenbürtige Pilze, die besonders in gemäßigten Zonen und in den Subtropen vorkommen (Pegg \& Brady 2002, Fradin \& Thomma 2006). Über 200 Pflanzenarten sind von den durch diese Pilze verursachten Krankheiten betroffen (Fradin \& Thomma 2006). Zu der Gattung Verticillium gehören sechs phytopathogene Arten (Barbara \& Clewes 2003). Hiervon sind V. dahliae Klebahn und V. albo-atrum Reinke \& Berthold am weitesten verbreitet und bislang am besten untersucht. V. albo-atrum kommt beispielsweise an Hopfen, Tomate, Kartoffel und Luzerne vor (Heale 2000). Infektionen durch V. dahliae wurden an Tomate, Paprika, Kopfsalat, Melone, Kartoffel, Baumwolle, Sonnenblume, Artischocke, Weintrauben, Erdbeere, Flachs, aber auch an holzigen Pflanzen wie Olivenbäumen beobachtet (Pegg \& Brady 2002, Gordon et al. 2006). Der im Rahmen dieser Arbeit untersuchte Pilz V. longisporum wurde zunächst als Varietät von $V$. dahliae angesehen (s. unten). Die weiteren Arten, $V$. tricorpus Isaac, $V$. nigrescens Pethybridge, $V$. nubilum Pethybridge und $V$. theobroma Mason \& Hughes sind für die Landwirtschaft nicht so bedeutend, da sie sehr schwach phytopathogen sind oder saprophytisch leben (Barbara \& Clewes 2003).

Aufgrund der vegetativen Strukturen und neuerer genetischer Analysen wird die Gattung Verticillium phylogenetisch den filamentösen Ascomyceten und der Ordnung der Phyllachorales zugeordnet (Barbara \& Clewes 2003, Hibbet et al. 2007). Da jedoch bisher keine Ascosporen, d. h. keine sexuelle Vermehrung, dokumentiert werden konnte, wird Verticillium auch zur Sammelgruppe der Deuteromyceten gezählt (Barbara \& Clewes 2003).

Die Konidiophoren der Verticillium-Arten sind wirtelig angeordnet. Sie bilden längliche Phialiden, an deren Apex die Konidien entstehen (Fradin \& Thomma 2006). Ein weiteres Merkmal von $V$. dahliae und $V$. albo-atrum ist die Produktion von Mikrosklerotien. 
Hierbei handelt es sich um eine Überdauerungsform aus Aggregaten von stark melanisierten, dickwandigen Hyphen (Gordee \& Porter 1985, Klimes \& Dobinson 2006).

\section{Verticillium longisporum}

Seit den 1950er Jahren werden Verticillium-Isolate an Kruziferen beschrieben, die sich mikroskopisch hinsichtlich ihrer Sporenlänge von den anderen unterscheiden (Isaac 1957, Stark 1961). Zunächst wurden diese Isolate als Varietät von V. dahliae eingeordnet (Stark 1961). Aufgrund von morphologischen, physiologischen und molekulargenetischen Unterschieden wurde V. longisporum als neue Art vorgeschlagen (Karapapa et al. 1997, Karapapa \& Typas 2001). Während die Konidiosporen von V. longisporum eine Länge von 7-9 $\mu \mathrm{m}$ aufweisen, sind die von $V$. dahliae mit einer Länge von 3,5 - $6 \mu \mathrm{m}$ deutlich kürzer (Karapapa et al. 1997). Auch die Mikrosklerotien sind bei V. longisporum verlängert (Karapapa et al. 1997). Im Gegensatz zu V. dahliae und V. albo-atrum wurde bei $V$. longisporum zudem eine annähernde Verdopplung der DNA festgestellt (amphihaploid), was auf eine Herkunft der Art durch parasexuelle Hybridisierung von zwei VerticilliumArten schließen lässt (Collins et al. 2003, Barbara et al. 2005, Karapapa et al. 2007). Um welche Arten es sich hierbei handeln könnte, ist noch unklar. Zunächst wurden V. dahliae und V. albo-atrum als Elternteile postuliert (Karapapa et al. 1997, Collins et al. 2003), aber durch Mikrosatellitenanalysen konnte V. albo-atrum als Elternteil ausgeschlossen werden (Barbara \& Clewes 2003, Barbara et al. 2005).

Auch hinsichtlich der Pilz-Pflanze-Interaktion gibt es Unterschiede zwischen $V$. longisporum und V. dahliae bzw. V. albo-atrum. Während für die beiden letztgenannten ein vielfältiges Wirtsspektrum dokumentiert ist, wurde für $V$. longisporum eine Spezifität gegenüber der Pflanzenfamilie der Brassicaceae beschrieben (Karapapa et al. 1997, Zeise \& von Tiedemann 2001, 2002a, 2002b). Auch die zu den Brassicaceae gehörende Modellpflanze A. thaliana kann unter Laborbedingungen von $V$. longisporum infiziert werden (Steventon et al. 2001, Veronese et al. 2003, siehe auch Abb. 1). Bislang ist nur in einer Studie beschrieben worden, dass auch Pflanzen anderer Familien in einem Gewächshausexperiment mit $V$. longisporum infiziert werden konnten (Johansson et al. 2006a). 


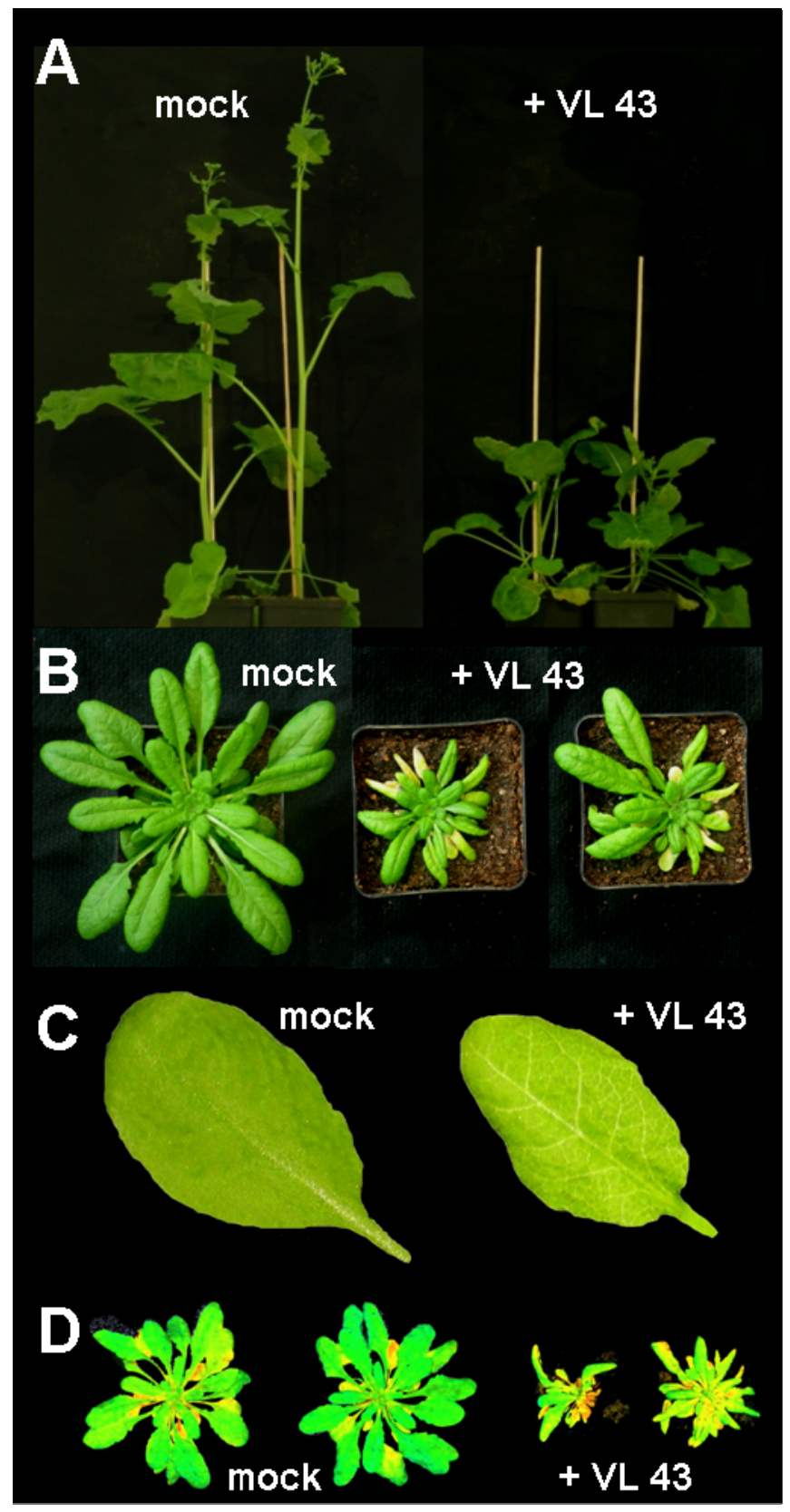

Abb. 1: Symptome durch V. longisporum. Gestauchtes Wachstum von B. napus (A) und $A$. thaliana (B). Bei $A$. thaliana ist nach Infektion neben Chlorosen und assymetrischem Wachstum (B) auch das Ausbleichen der Blattnervatur (C) zu beobachten. Auch hinsichtlich der photosynthetischen Quantenausbeute gibt es geringe Unterschiede zwischen infizierten und mock inokulierten Pflanzen, wie Falschfarbenbilder der Messungen der Quantenausbeute (D) zeigen (weitere Erläuterungen siehe Anhang A). 
Die Symptome, die durch die verschiedenen Arten hervorgerufen werden, sind verschieden. Charakteristisch für Infektionen durch $V$. dahliae und $V$. albo-atrum ist das Auftreten von Welkeerscheinungen, weshalb die durch die genannten Arten verursachte Krankheit auch als Welkekrankheit oder Verticillium-Welke bezeichnet wird. Weiterhin können Chlorosen, Nekrosen, ein Ausbleichen der Blattnervatur sowie braune Verfärbungen im vaskulären Gewebe der Sprossachse auftreten, jedoch ist die Symptomatik und Ausprägung bei den verschiedenen Wirtspflanzen sehr unterschiedlich (Fradin \& Thomma 2006). Bei einer Infektion durch $V$. longisporum konnten wir dagegen weder offensichtliche Anzeichen für ein Welken beobachten, noch wurden Hinweise auf eine eingeschränkte Wasser- und Nährstoffversorgung gefunden (Floerl et al. 2008, 2010, siehe Anhang D). Symptome bei einer Infektion mit V. longisporum sind Chlorosen der Blätter sowie eine verfrühte Seneszenz und ein damit einhergehendes vorzeitiges Abreifen der Pflanze (Karapapa et al. 1997, Eynck et al. 2007, siehe auch Abb. 1). Unter Gewächshausbedingungen ist außerdem ein gestauchtes Wachstum zu beobachten (Floerl et al. 2008, 2010, Häffner et al. 2010). Zudem verändert sich die Chlorophyllfluoreszenz geringfügig (Floerl et al. 2008, 2010, Abb. 1).

\section{Der Lebenszyklus von Verticillium}

Der Lebenszyklus der verschiedenen Verticillium-Arten ist sehr ähnlich (Zhou et al. 2006). Er ist eng gekoppelt an den Lebenszyklus der Wirtspflanze und wird eingeteilt in eine ruhende, eine parasitische und eine saprophytische Phase (Fradin \& Thomma 2006).

Mikrosklerotien im Boden keimen in der Nähe von Pflanzenwurzeln durch Wurzelexsudate aus (Schreiber \& Green 1963, Huisman 1982, Mol et al. 1995, siehe auch Abb. 2). Für $V$. dahliae wurde gezeigt, dass die Keimungsrate mit weiterem Abstand zur Pflanzenwurzel abnimmt (Mol \& van Riessen 1995). Nach der Keimung wachsen die Hyphen des Pilzes gerichtet zur Pflanzenwurzel hin (Eynck et al. 2007). Der Eintritt in die Wurzel, bei dem der Pilz in die parasitische Phase seines Lebenszyklus übergeht, erfolgt durch direktes Penetrieren der Epidermis in der Wurzelhaarzone (Zhou et al. 2006, Eynck et al. 2007). In der Wurzel wächst der Pilz intra- und interzellular durch die Cortexzellen weiter, bis er die Gefäße im Zentralzylinder erreicht. Hier kann V. longisporum zwar durch die Plasmodesmata in benachbarte Gefäße vordringen, jedoch beschränkt sich das Vorkommen des Pilzes meist auf einzelne Gefäße, während benachbarte Xylem-Elemente 
vollständig frei von Hyphen sind (Eynck et al. 2007). Dies ist vermutlich einer der Gründe für das Fehlen der Welkesymptome bei einer Infektion durch $V$. longisporum (Floerl et al. 2008, 2010).

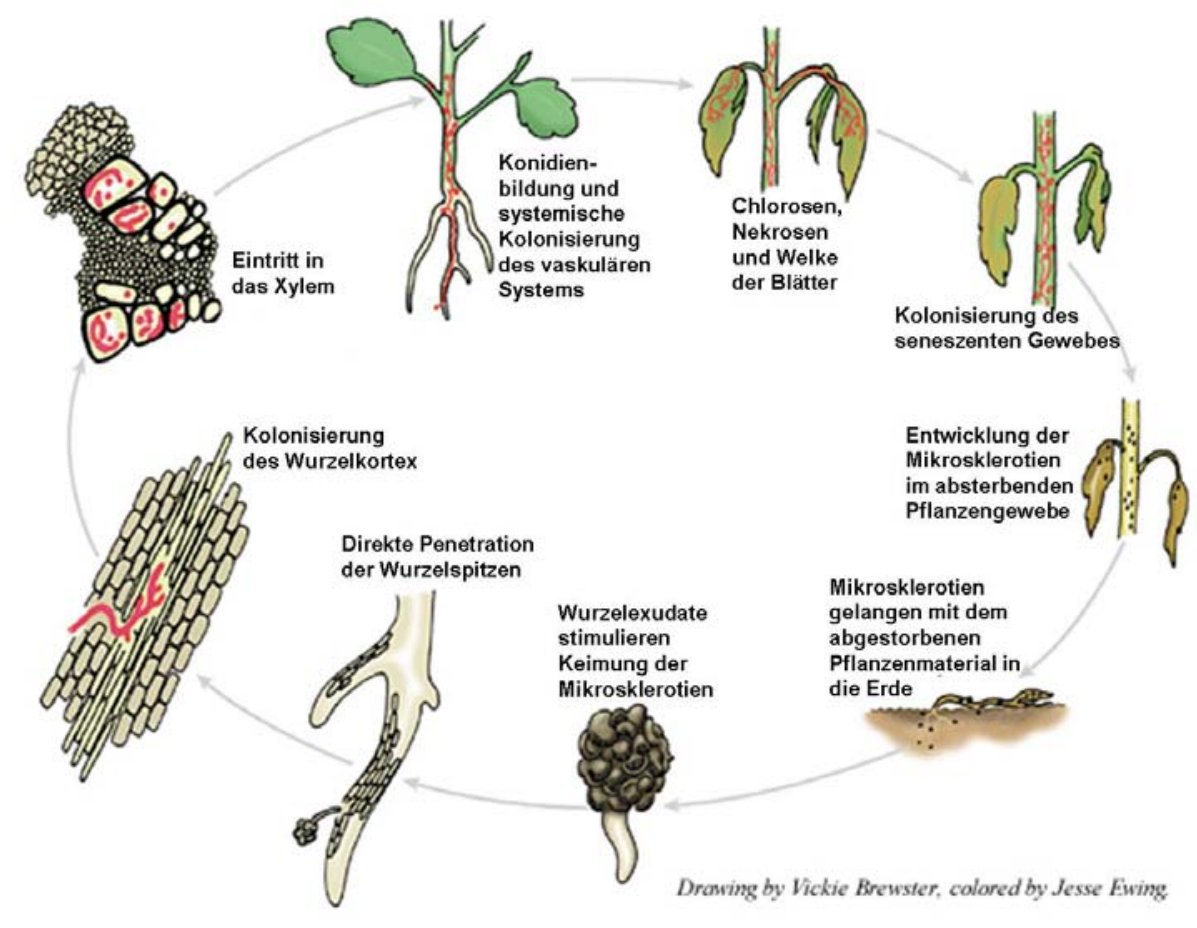

\section{Abb. 2: Lebenszyklus der Verticillium-Arten (verändert nach Berlanger \& Powelson 2000).}

Im Xylem bildet der Pilz Konidiosporen, die sich mit dem Transpirationsstrom akropetal verbreiten (Beckman 1987, Gold et al. 1996). Wenn diese Sporen in Aushöhlungen und an den Enden von Gefäßen, den sogenannten ,trapping sites“ (Heinz et al. 1998), hängen bleiben, keimen sie aus. Die Hyphen dringen in die nächsten Zellen vor, wo wiederum neue Sporen gebildet werden (Beckman 1987, Gold \& Robb 1995, Gold et al. 1996, Heinz et al. 1998, Eynck et al. 2007). Der Pilz tritt in seine sapropytische Phase ein, wenn die Pflanze in die Seneszenz übergeht (Fradin \& Thomma 2006). In diesem Stadium ist er nicht mehr nur auf das Leitgewebe beschränkt, sondern breitet sich in allen Zellen des absterbenden Gewebes aus. Hier bildet das Pathogen Mikrosklerotien, die mit den absterbenden Pflanzenteilen in den Boden gelangen (Schnathorst 1981, Mol \& Scholte 1995, Neumann \& Dobinson 2003). Während Konidien und Myzel des Pilzes nicht lange 
überlebensfähig sind (Menzies \& Griebel 1967, Galanopoulus \& Tribe 1974), kann der Pilz in seiner ruhenden Phase in Form von Mikrosklerotien viele Jahre im Boden überdauern (Wilhelm 1955, Schnathorst 1981, Heale \& Karapapa 1999).

\section{Die Bedeutung von Verticillium longisporum für die Agrarwirtschaft}

$\mathrm{Zu}$ der Familie der Brassicaceae, auf die V. longisporum spezialisiert ist, gehören viele ökonomisch bedeutende Pflanzen, unter anderem Raps (Brassica napus L. oleifera) (Karapapa et al. 1997, Zeise \& von Tiedemann 2001, 2002a, 2002b). Infektionen durch $V$. longisporum an Raps werden in Nordeuropa seit den 1960er Jahren beschrieben (Svenson \& Lerenius 1987, Zielinski \& Sadowski 1995, Dixelius et al. 2005). V. longisporum konnte bisher in Schweden, Deutschland, Frankreich und Polen nachgewiesen werden (Karapapa et al. 1997, Zeise \& von Tiedemann 2002a, 2002b). In Schweden stellt V. longisporum mittlerweile die bedeutendste Gefahr für den Rapsanbau dar (Dixelius et al. 2005). Aber auch in Deutschland nimmt die Bedrohung durch das Pathogen seit den 80er Jahren mit dem Rapsanbau zu (Daebeler et al. 1988, Krüger 1989, Günzelmann \& Paul 1990, Zeise \& Seidel 1990). Die verfrühte Abreife der Pflanzen durch die Infektion mit V. longisporum kann zu Ertragsverlusten zwischen 10 und $50 \%$, bei Einzelpflanzen sogar bis $80 \%$ führen (Daebeler et al. 1988, Günzelmann \& Paul 1990, Dunker et al. 2008). Der Ertragsverlust ist hauptsächlich durch das Aufplatzen der Schoten aufgrund der Notreife bedingt (Dunker \& von Tiedemann 2005).

Aufgrund der Lebensweise im Leitgewebe der Wirtspflanze und der Überdauerung im Boden sind alle Verticillium-Arten schwer zu bekämpfen, da sie Fungiziden keine Angriffsfläche bieten (Fradin \& Thomma 2006). Neben einer Vorbeugung der Krankheit durch eine breite Fruchtfolge (Pegg \& Brady 2002) ist daher die einzige Möglichkeit, der Krankheit entgegen zu wirken, die Züchtung von resistenten Sorten. Für B. napus sind bisher keine resistenten Sorten bekannt, aber bei den nah verwandten Arten B. oleracea und B. rapa konnten resistente Genotypen identifiziert werden (Happstadius et al. 2003, Dixelius et al. 2005, Rygulla et al. 2007). In dieser Arbeit steht die Charakterisierung der pflanzlichen Abwehrreaktionen nach einer Infektion mit V. longisporum im Mittelpunkt. Die Erforschung einer solchen Pflanze-Pathogen-Beziehung kann Beiträge zur gezielten Züchtung von resistenten Pflanzen liefern (,smart breeding“, Collard \& Mackill 2008). 


\subsection{Die Interaktion zwischen Pflanzen und Pathogenen}

Pathogene werden in biotrophe und nekrotrophe Pathogene eingeteilt. Während nekrotrophe Pathogene wie z. B. Botrytis cinerea, die pflanzlichen Zellen abtöten, leben biotrophe Pathogene in der Pflanze, ohne die Zellen gezielt zu töten (Pieterse et al. 2009). Einige Pathogene wechseln im Infektionsverlauf von einer biotrophen $\mathrm{zu}$ einer nekrotrophen Lebensweise. $\mathrm{Zu}$ diesen als hemibiotroph bezeichneten Pathogenen zählen auch die Verticillium-Arten (Fradin \& Thomma 2006).

Des Weiteren wird bei der Pflanze-Pathogen-Beziehung zwischen einer kompatiblen und einer inkompatiblen Interaktion unterschieden. Bei einer inkompatiblen Interaktion kann das nichtadaptierte Pathogen eine Pflanze nicht befallen. Die Pflanze ist resistent gegenüber dem Pathogen und zeigt keine Symptome (Tao et al. 2003). Wenn eine ganze Pflanzenart oder -familie resistent gegenüber allen Isolaten eines Pathogens ist, so wird dies auch als Nicht-Wirts-Resistenz bezeichnet (Lipka et al. 2005). Wenn eine Pflanze suszeptibel gegenüber einem Pathogen ist und Symptome auftreten, handelt es sich um eine kompatible Interaktion (Tao et al. 2003). Daher ist die Interaktion zwischen $V$. longisporum und B. napus bzw. A. thaliana kompatibel.

Um eine Pflanze zu besiedeln und auszubeuten, müssen Pathogene eine Reihe basaler Schutzmechanismen überwinden. Dazu zählen zunächst mechanische Barrieren wie die Cuticula auf der Epidermis der Blätter sowie die Exo- und Endodermis in den Wurzeln. Beide Strukturen erschweren nichtadaptierten Pathogen das Eindringen in das pflanzliche Gewebe. Bei einer kompatiblen Interaktion haben die entsprechenden Pathogene diese ersten Abwehrmechanismen überwunden. Einige Pathogene nutzen zum Eintritt in die Pflanze offene Stellen wie Stomata oder Wunden. Das Auftreten von Nematoden im Boden kann beispielweise eine Infektion durch Verticillium verstärken, was sowohl auf die vermehrte Keimung von Mikrosklerotien durch austretende Wurzelexsudate als auch auf den erleichterten Eintritt des Pathogens in die Wurzel aufgrund der Verletzungen zurückgeführt wird (Fradin \& Thomma 2006). Da solche natürlichen Eintrittsstellen selten sind, haben die Pathogene vielfältige Strategien entwickelt, um die Pflanzen zu penetrieren. Einige Pathogene sekretieren beispielsweise Enzyme, welche die Zellwand lysieren und so den Eintritt in die Zellen ermöglichen (Beliën et al. 2006), während andere sogenannte Appressorien ausbilden, in denen Druck aufgebaut wird, so dass die Epidermis durchbrochen werden kann. Ein bekanntes Beispiel hierfür ist die Gattung Magnaporthe 
(Ebbole 2007). V. longisporum bildet an der Eintrittsstelle an der Wurzel keine Appressorien. Jedoch sind die Hyphen in diesem Bereich leicht geschwollen (Eynck et al. 2007). Die biologische Relevanz dieser Schwellungen ist noch ungeklärt.

Wenn ein Pathogen eine Pflanze penetriert, reagiert diese mit einer Vielzahl von Abwehrreaktionen. Die Pflanze nimmt das Pathogen aufgrund des Auftretens eines sogenannten Pathogen- oder Microben-assoziierten molekularen Musters (Pathogen/Microbe Associated Molecular Pattern, PAMP oder MAMP) wahr (Jones \& Dangl 2006). Die Pflanze bringt also bestimmte Moleküle mit einem Befall durch ein Pathogen in Verbindung. Hierbei handelt es vor allem um Pathogen-eigene Substanzen wie das Chitin und Ergosterol von Pilzen oder das Flagellin von Bakterien, die unter dem Begriff Elicitoren zusammengefasst werden (Schwessinger \& Zipfel 2008). Aber auch pflanzliche Moleküle, die durch den Angriff des Pathogens entstehen, wie z. B. Bestandteile der durch das Eindringen des Pathogens zerstörten Zellwand, zählen zu den PAMPs (Ferrari et al. 2003). Es wird angenommen, dass auch manche Verticillium-Arten Elicitoren und Phytotoxine produzieren (Dubery \& Slater 1997, Wang et al. 2004, Mansoori \& Smith 2005). In V. dahliae wurde ein Nep1-ähnliches Protein identifiziert, das vermutlich als Elicitor fungiert (Wang et al. 2004). V. dahliae produziert außerdem ein Zelltod-auslösendes Phytotoxin, das den Krankheitsverlauf in Baumwollpflanzen maßgeblich beeinflusst (Tian et al. 2010).

Da die PAMPs relativ unspezifisch sind und ganze Gruppen von Pathogenen umfassen, haben sich Pflanzen erfolgreich gegen viele Pathogene durchgesetzt. Man spricht von PAMP-vermittelter Immunität (PAMP-triggered immunity, PTI, Jones \& Dangl 2006). Diese PTI ist darauf zurückzuführen, dass infolge der Wahrnehmung des Pathogens eine Reihe von Abwehrreaktionen in der Pflanze ausgelöst werden, die sich zum Teil überschneiden und sich gegenseitig beeinflussen können. An erster Stelle steht hierbei die Signaltransduktion, die über Kaskaden von Mitogen-aktivierten Protein-Kinasen (MAPKinasen, Tena et al. 2001, Sanabria et al. 2008), durch Calcium (Blume et al. 2000, Boudsocq et al. 2010) sowie durch reaktive Sauerstoffspezies (reactive oxygen species, ROS) wie $\mathrm{H}_{2} \mathrm{O}_{2}$ (Lamb \& Dixon 1997, Apel \& Hirt 2004) oder Stickstoffmonoxid (Beligni \& Lamattina 2001) erfolgen kann. Anschließend kommt es zur Induktion von PRProteinen (pathogenesis-related proteins, van Loon et al. 2006), zum Schließen der Stomata (Melotto et al. 2006) und zur Synthese von Phytoalexinen (Van Etten et al. 1994, 
Williams \& Cooper 2003, Bednarek \& Osbourn 2009). Bei den Phytoalexinen handelt es sich um sekundäre Metabolite des pflanzlichen Stoffwechsels, die antimikrobielle Eigenschaften aufweisen (Van Etten et al. 1994). Auch für Kruziferen wurde eine Vielzahl an Phytoalexinen beschrieben (Pedras et al. 2000), die bei der Interaktion mit $V$. longisporum eine Rolle spielen könnten. Tatsächlich konnte in Raps nach einer Infektion mit $V$. longisporum die Produktion von phenolischen Komponenten nachgewiesen werden (Eynck et al. 2009). Die Konzentration dieser Phenole war in resistenten Kultivaren höher als in suszeptiblen Pflanzen (Eynck et al. 2009). A. thaliana reagierte auf eine Infektion mit V. longisporum mit der Produktion von Camalexin (Iven 2009). Camalexin ist ein A. thaliana-spezifisches Phytoalexin und wurde als Resistenzfaktor gegenüber pilzlichen Pathogenen beschrieben (Thomma et al. 1999, Bednarek \& Osbourn 2009). Da Mutanten, die kein Camalexin mehr bilden können, keine erhöhte Suszeptibilität gegenüber $V$. longisporum aufweisen, müssen bei A. thaliana aber noch andere Faktoren bei der Erlangung einer Resistenz gegen das Pathogen eine Rolle spielen (Johansson et al. 2006b, Iven 2009).

Im Laufe der Evolution haben einzelne Pathogene Strategien entwickelt, um die PTI zu umgehen. Bei einzelnen Stämmen bestimmter Pathogene haben sich die PAMPs evolutiv verändert, so dass diese von den Rezeptoren der Pflanze nicht mehr erkannt werden. In anderen Fällen sekretieren die Pathogene zusätzliche Moleküle, welche den Signalweg und die Abwehrreaktionen stören oder bereits produzierte antimikrobielle Sekundärmetabolite oder ROS degradieren und sie so unschädlich machen. Solche Moleküle werden als Effektoren oder als Virulenz-Faktoren bezeichnet (Sanabria et al. 2008, Boller \& He 2009). Auch in V. dahliae und V. albo-atrum wurden putative Effektoren identifiziert. So vermuteten Lee et al. (1992), dass V. albo-atrum in Tomate die Produktion der Phenylalanin-Ammonium-Lyase (PAL) unterdrücken kann. PAL ist das Schlüsselenzym im Phenylpropanoid-Synthesewegs, von dem ausgehend verschiedene für die Abwehr wichtige Substanzen wie Lignin und Suberin gebildet werden (Do et al. 2007). Bei Untersuchungen des Proteoms von $V$. dahliae wurden in aggressiveren Isolaten mehrere Proteine identifiziert, von denen angenommen wird, dass diese die Abwehr der Wirtspflanze unterdrücken, z.B Thioredoxin, welches ROS degradieren kann, sowie eine Isochorismatase, welche die Bildung von Salicylsäure inhibieren kann (El-Bebany et al. 2010). Des Weiteren kann V. dahliae Zellwand-abbauende Enzyme produzieren (Neumann 
\& Dobinson 2003, Tzima et al. 2010). Ob V. longisporum ebenfalls Effektoren sekretiert, ist bisher nicht bekannt.

Gegen eine durch Effektoren ausgelöste Suszeptibilität (effector triggered susceptibility, ETS) haben sich bei der Pflanze wiederum Resistenz-Gene (R-Gene) entwickelt, die zu einer Effektor-vermittelten Immunität (effector-triggered immunity, ETI) führen können (Jones \& Dangl 2006). Solche Resistenz-Gene wurden auch nach Infektionen mit $V$. dahliae in verschiedenen Pflanzen induziert. In Tomate wurden beispielsweise die Resistenz-Gene Ve1 und Ve2 entdeckt, die u. a. mit Veränderungen im PhenylpropanoidMetabolismus in Verbindung gebracht werden (Gayoso et al. 2010). In Baumwolle wurde GhHb1 als Resistenz-Gen identifiziert, welches durch $V$. dahliae induziert wird und bei Überexpression Resistenz gegenüber verschiedenen Pathogenen vermittelt $(\mathrm{Qu}$ et al. 2006). Ebenfalls in Baumwolle konnte kürzlich gezeigt werden, dass NDR1 und MKK2 zu einer Resistenz gegenüber V. dahliae beitragen (Gao et al. 2011).

Neben den bisher beschriebenen Abwehrreaktionen spielen bei der Immunantwort auch die Pflanzenhormone eine wichtige Rolle. Die Signaltransduktion von Salizylsäure, Jasmonsäure und Ethylen führt zu einer Vielzahl von Abwehrreaktionen, wobei Salizylsäure vor allem mit biotrophen Pathogenen assoziiert wird, während nekrotrophe Pathogene und Herbivore sensitiv gegen Abwehrmechanismen sind, die durch Jasmonsäure und Ethylen hervorgerufen werden (Spoel \& Dong 2008, Bari \& Jones 2009, Pieterse et al. 2009).

Auch die Auxinkonzentration und Auxin-vermittelte Antworten in Pflanzen können durch Pathogene beeinflusst werden. Auxin ist das wichtigste Wachstumshormon in Pflanzen (Vanneste \& Friml 2009). Es wurde nachgewiesen, dass es eine negative Rückkopplung zwischen Salizylsäure und Auxin gibt (Wang et al. 2007). Daher führt die Aktivierung von Abwehrreaktionen durch Salizylsäure häufig zu Wachstumseinschränkungen. Dies wird dadurch erklärt, dass Pflanzen ihre Ressourcen nicht gleichzeitig in Wachstum und in Abwehrprozesse investieren können. Manche Pathogene produzieren selbst Auxin. Dies wirkt sich negativ auf die Salizylsäure-regulierte Immunantwort aus, wodurch die Pflanze anfälliger wird (Wang et al. 2007).

Andere Phytohormone wie Abscisinsäure, Gibberellinsäure oder Cytokinin können sowohl als negative als auch als positive Regulatoren im Hinblick auf die Abwehrreaktionen 
fungieren. Ihre Reaktion ist spezifisch für bestimmte Pflanze-Pathogen-Interaktionen (Bari \& Jones 2009).

Auch durch die verschiedenen Vertreter der Gattung Verticillium wird der Hormonhaushalt beeinflusst. So wurden erhöhte Mengen von Salicylsäure im Xylemsaft von mit $V$. longisporum infizierten Raps-Pflanzen nachgewiesen (Ratzinger et al. 2009). Eine Infektion mit $V$. dahliae führte in Tomate zu einer Veränderung in der Auxin-Antwort (van Esse et al. 2009). Suszeptible Kultivare der Kartoffel produzierten nach Behandlung mit einem aus V. albo-atrum isolierten Toxin mehr Ethylen als resistente Kultivare. Daher wurde angenommen, dass V. albo-atrum den Ethylen-Signalweg induziert (Mansoori \& Smith 2005). Auch bei der Interaktion zwischen A. thaliana und V. longisporum scheint die Symptomausprägung mit Ethylen in Verbindung zu stehen. Die Zusammenhänge des Wirkungsmechanismus konnten bisher jedoch noch nicht im Detail geklärt werden (Veronese et al. 2003, Tjamos et al. 2005, Johansson et al. 2006b, Tappe 2008, Pantelides et al. 2010).

\subsection{Die Rolle des pflanzlichen Apoplasts bei der Pathogenabwehr gegen vaskuläre Pathogene wie Verticillium longisporum}

Der Apoplast ist der extrazelluläre Raum in Pflanzen, in dem die wässrige Phase frei diffundieren kann. Dazu zählen das Zellwandkontinuum ebenso wie das Xylem und der Xylemsaft, nicht aber die Interzellularen. Die offensichtliche Funktion des Apoplastes, vor allem die des Xylems, ist der Transport von Wasser, Nährstoffen und organischen Metaboliten. Zusätzlich spielt der Apoplast eine wichtige Rolle im Bezug auf biotischen und abiotischen Stress (Polle et al. 1995, Bolwell et al. 2002). V. longisporum ist als vaskuläres Pathogen die meiste Zeit seines Lebenszyklus auf das Xylem seiner Wirtspflanzen beschränkt. Daher spielt der Apoplast bei dieser Interaktion eine besonders große Rolle. Auch Abwehrreaktionen seitens der Pflanze werden vor allem im apoplastischen Raum erwartet.

Bei den meisten Interaktionen findet im Apoplast der erste Kontakt zwischen Pflanze und Pathogen statt. An der Grenzfläche zum Apoplast, nämlich in der Plasmamembran, befinden sich die zur Wahrnehmung der PAMPs essentiellen Rezeptoren. Zudem ist der Apolast auch an der Signaltransduktion mittels ROS oder in Form von Pflanzenhormonen beteiligt (Apel \& Hirt 2004, Ratzinger et al. 2009). Auch die Alkalinisierung im Apoplast, 
die als Folge von biotischem Stress gemessen wurde, wird als wichtiges Signal bei der Immunantwort postuliert (Felle et al. 2005).

$\mathrm{Zu}$ den Pathogen-induzierten Abwehrreaktionen gehören Verstärkungen der Zellwand (Lamb \& Dixon 1997, Apel \& Hirt 2004). In Reis wurde beispielsweise Resistenz gegen das vaskuläre, pathogene Bakterium Xanthomonas oryzae durch Verdickung der sekundären Zellwand der Xylem-Gefäße erreicht (Hilaire et al. 2001). Auch der Durchmesser der Xylem-Gefäße scheint in manchen Fällen wichtig für die Resistenz gegen Xylem-besiedelnde Pathogene zu sein. So korrelierte bei Ulmen, die von dem Pilz Ophiostoma novo-ulmi befallen waren, der Durchmesser der Gefäße positiv mit der Suszeptibiltät (Solla \& Gil 2002). Auch bei vielen der frühen Studien an Verticilliuminfizierten Pflanzen standen anatomische und histologische Untersuchungen im Mittelpunkt. So wurde beispielsweise in Hopfen nach Infektion mit V. albo-atrum das Auftreten von Thyllen und die Bildung neuer Gefäße beschrieben (Talboys 1958). Thyllen sind Membranausstülpungen benachbarter parenchymatischer Zellen, welche die Gefäße blockieren können (Talboys 1958). Auch in anderen Pflanzenarten wurden nach Befall durch verschiedene Verticillium-Arten Okklusionen einzelner Xylem-Gefäße gefunden. Das Auftreten dieses Phänomens korreliert positiv mit der Resistenz (Talboys 1958, Bishop \& Cooper 1984, Eynck et al. 2009). Daher wurde vermutet, dass durch den Verschluss der Gefäße eine weitere Kolonisierung durch das Pathogen verhindert wird (Fradin \& Thomma 2006). Die Okklusionen werden nicht nur auf die bereits beschriebene Bildung von Thyllen, sondern auch auf die Produktion von gelartigen Ablagerungen zurückgeführt, die Kallose, Suberin oder Material der primären Zellwand enthalten können (Beckman 1987, Benhamou 1995, Pegg \& Brady 2002, Eynck et al. 2009). So wurden beispielsweise in Tomate Kallose und Suberin in den Xylem-Gefäßen nach Infektion mit V. dahliae und V. albo-atrum gefunden (Beckman 1987, Robb et al. 1989, Gold \& Robb 1995). Kallose-reiche Strukturen wurden auch in Gefäßen von mit V. albo-atrum befallenen Auberginen sowie in Wurzeln von Baumwollpflanzen nach Infektion mit $V$. dahliae beobachtet (Benhamou 1995, Daayf et al. 1997). Smit \& Dubery (1997) fanden mehr Lignin und lignin-ähnliche phenolische Polymere in Baumwollpflanzen, die mit einem aus $V$. dahliae isolierten Elicitor behandelt waren, und vermuteten, dass die Verstärkung der Zellwand der Abwehr diene. Lignin-, Suberin- und Kalloseablagerungen fungieren jedoch nicht nur als mechanische Barrieren, sondern auch als Phytoalexine. 
Elementarer Schwefel zählt aufgrund seiner antifungalen Eigenschaften ebenfalls zu den Phytoalexinen und wurde nach Infektion mit V. dahliae im Xylem von Kakao, Tomate und Baumwolle detektiert (Cooper et al. 1996, Williams et al. 2002, Williams \& Cooper 2003). Neben den Veränderungen der Zellwand und den antimikrobiell wirksamen Phytoalexinen spielen bei der apoplastischen Immunantwort auch Proteine eine wichtige Rolle. Besonders relevant sind in diesem Zusammenhang PR-Proteine, die in den Apoplast sekretiert werden und dort Abwehrfunktionen übernehmen (van Loon et al. 2006). Einige Vertreter dieser Gruppe wie Chitinasen und Peroxidasen sind bereits in unbehandelten Pflanzen im Apoplast vorhanden und scheinen für eine Basis-Resistenz zu sorgen (Buhtz et al. 2004, Alvarez et al. 2005, Boudart et al. 2005, Kehr et al. 2005, Floerl et al. 2008). Bei dem Kontakt mit Pathogenen steigen die Mengen der PR-Proteine meist an. Außerdem werden zusätzliche PR-Proteine induziert. So wurden beispielsweise im Apoplast von Tomate nach Inkubation mit dem interzellulär wachsenden Pilz Cladosporium fulvum Chitinasen und eine 1,3-ß-Glucanase nachgewiesen (Joosten \& De Wit 1989). Nach einer Infektion mit dem vaskulären Pathogen Xanthomonas oryzae wurde in Reis eine Peroxidase in größeren Mengen gefunden (Young et al. 1995). Im Xylemsaft von Tomate wurde eine Änderung der Proteinzusammensetzung nach einer Infektion mit Fusarium oxysporum beobachtet, wobei neben bekannten PR-Proteinen zusätzlich ein neues PR5-Protein entdeckt wurde (Rep et al. 2002). Auch nach dem Kontakt mit Verticillium produzieren die Wirtspflanzen verschiedene Proteine, die mit Abwehrfunktionen assoziiert werden. Blattscheiben von Baumwolle akkumulieren Chitinasen und 1,3-ß-Glucanasen infolge der Behandlung mit Zellwandfragmenten von $V$. dahliae (Dubery \& Slater 1997). Die gleichen Proteine wurden in zwei Baumwoll-Kultivaren mit unterschiedlicher Suszeptibiliät nach Infektion mit V. dahliae induziert (McFadden et al. 2001).

Veränderungen des extrazellulären Proteoms nach einer Infektion mit V. longisporum wurden bisher nur wenig untersucht. Im Xylemsaft und in der apoplastischen Waschflüssigkeit von Raps traten eine Endochitinase, eine basische 1,3-ß-Glucanase, eine Peroxidase sowie ein PR4-Protein nach der Kolonisierung durch das Pathogen in größeren Mengen auf (Floerl et al. 2008). Ähnliche Analysen wurden in A. thaliana durchgeführt. In der apoplastischen Waschflüssigkeit wurden 7 differenziell auftretende Proteine identifiziert. Davon waren drei verschiedene Peroxidasen (POD34, POD37 und POD52), ein Germin-ähnliches Protein (GLP3), eine Serin-Carboxypeptidase (SCP) und eine $\alpha$ - 
Galactosidase nach Infektion mit $V$. longisporum in erhöhten Mengen zu finden, während die Menge eines Lectin-ähnlichen Proteins (LLP) nach Pathogenbefall abnahm (Flörl 2007). Einige dieser Proteine werden mit Abwehrfunktionen und Zellwandmodifikationen in Verbindung gebracht. So können beispielsweise Peroxidasen im Allgemeinen durch die Produktion von Lignin und Suberin, Zellwandverstärkungen, Synthese von Phytoalexinen sowie durch Bildung von reaktiven Sauerstoffspezies (ROS) eine Rolle bei der Pathogenabwehr spielen (Almagro et al. 2009). Die in der Literatur diskutierten putativen Funktionen der einzelnen Proteine sind in Tabelle 1 zusammengestellt.

Tabelle 1: Putative Funktionen der im Apoplast von A. thaliana differenziell auftretenden Proteine nach Infektion mit V. longisporum.

\begin{tabular}{|c|c|c|}
\hline Protein & Beobachtungen und vermutete Funktionen & Referenz \\
\hline \multirow{4}{*}{$\begin{array}{l}\text { Peroxidase } 34 \\
\text { (POD34), } \\
\text { At3g49120 }\end{array}$} & $\begin{array}{l}\text { In Zellwandextrakten von sich streckenden } \\
\text { Hypokotylen gefunden, daher Rolle bei der } \\
\text { Zellstreckung vermutet }\end{array}$ & Irshad et al. 2008 \\
\hline & $\begin{array}{l}\text { Wichtig für die Generierung von ROS bei } \\
\text { Abwehrreaktionen }\end{array}$ & $\begin{array}{l}\text { Bindschedler et al. } \\
2006\end{array}$ \\
\hline & $\begin{array}{l}\text { Katalysiert die Polymerisierung von Coniferyl- } \\
\text { und Sinapylalkoholen in vitro }\end{array}$ & $\begin{array}{l}\text { Demont-Caulet et al. } \\
2010\end{array}$ \\
\hline & $\begin{array}{l}\text { Erhöhte Expression nach Befall durch } \\
\text { Pseudomonas syringae }\end{array}$ & Mohr \& Cahill 2007 \\
\hline $\begin{array}{l}\text { Peroxidase } 37 \\
\text { (POD37), } \\
\text { At4g37530 } \\
\end{array}$ & $\begin{array}{l}\text { In älteren Teilen des Blütenstängels verstärkt } \\
\text { exprimiert, daher Rolle bei der Polymerisierung } \\
\text { von Monolignolen vermutet }\end{array}$ & Ehlting et al. 2005 \\
\hline \multirow{2}{*}{$\begin{array}{l}\text { Peroxidase } 52 \\
\text { (POD52), } \\
\text { At5g05340 } \\
\end{array}$} & $\begin{array}{l}\text { Erhöhte Expression nach Befall durch } \\
\text { Pseudomonas syringae }\end{array}$ & Mohr \& Cahill 2007 \\
\hline & Erhöhte Expression nach Insektenbefall & Little et al. 2007 \\
\hline \multirow{2}{*}{$\begin{array}{l}\alpha \text {-Galactosidase } \\
\text { (GAL), } \\
\text { At5g08370 }\end{array}$} & $\begin{array}{l}\text { Lokalisiert in Zellwand, Rolle bei } \\
\text { Zellwandmodifikationen vermutet }\end{array}$ & Chrost et al. 2007 \\
\hline & $\begin{array}{l}\alpha \text {-Galactosidasen in Reis und Gerste mit } \\
\text { Seneszenz assoziiert }\end{array}$ & $\begin{array}{l}\text { Chrost \& Krupinska } \\
\text { 2000, Lee et al. } 2009\end{array}$ \\
\hline $\begin{array}{l}\text { Serin-Carboxy- } \\
\text { peptidase (SCP), } \\
\text { At4g12910 }\end{array}$ & $\begin{array}{l}\text { keine bekannte Funktion, ähnlich einer JA- } \\
\text { induzierbaren SCP in Tomate, einige SCPs } \\
\text { involviert in der Produktion von } \\
\text { Sekundärmetaboliten }\end{array}$ & Fraser et al. 2005 \\
\hline \multirow{3}{*}{$\begin{array}{l}\text { Lectin-ähnliches } \\
\text { Protein (LLP), } \\
\text { At3g16520 }\end{array}$} & $\begin{array}{l}\text { Chitin-induzierbar, andere LLPs können Chitin } \\
\text { hydrolysieren }\end{array}$ & Ramonell et al. 2005 \\
\hline & Chitin-induzierbar & Zhang et al. 2002 \\
\hline & $\begin{array}{l}\text { Lectine allgemein: können das Wachstum von } \\
\text { Pathogenen in vitro inhibieren }\end{array}$ & $\begin{array}{l}\text { Sharon \& Lis } 2004, \\
\text { Wong et al. } 2010\end{array}$ \\
\hline \multirow{3}{*}{$\begin{array}{c}\text { Germin- } \\
\text { ähnliches Protein } \\
\text { (GLP3), } \\
\text { At5g20630 }\end{array}$} & Induzierbar durch Colletotrichum higginsianum & Narusaka et al. 2004 \\
\hline & Keine Oxalat-Oxidase-Aktivität in vitro & Membré et al. 2000 \\
\hline & $\begin{array}{l}\text { Ektopische Überexpression verschiedener GLPs } \\
\text { aus anderen Pflanzen vermitteln Resistenz }\end{array}$ & $\begin{array}{l}\text { Schlesier et al. 2004, } \\
\text { Knecht et al. } 2010\end{array}$ \\
\hline
\end{tabular}


Bei der Übersicht fällt auf, dass neben den Peroxidasen auch die $\alpha$-Galactosidase mit Zellwandumgestaltungen und Wachstum assoziiert wird. Über die Funktionen der identifizierten Serin-Carboxypeptidase, des Lectin-ähnlichen Proteins und des Germinähnlichen Proteins ist bisher wenig bekannt. Jedoch weisen die wenigen vorhandenen Informationen, vor allem aber die Kenntnisse über die Funktionen von homologen Proteinen, auf eine Rolle bei der Pathogenabwehr hin. Die spezifische Wirkungsweise der verschiedenen Proteine in der Immunantwort gegenüber $V$. longisporum ist bisher unbekannt. 


\subsection{Zielsetzung der vorliegenden Arbeit}

Die Interaktion zwischen Verticillium longisporum und seinen Wirtspflanzen Brassica napus und Arabidopsis thaliana wird innerhalb der DFG Forschergruppe 546 auf physiologischer, zellbiologischer und genetischer Ebene untersucht. Zudem werden sowohl für $V$. longisporum als auch für die Wirtspflanzen Interaktion-induzierte Veränderungen des Transkriptoms, des Proteoms und des Metaboloms analysiert. Die vorliegende Arbeit wurde im Rahmen dieser Forschergruppe durchgeführt.

Ziel dieser Arbeit war die Charakterisierung von apoplastischen Proteinen in B. napus und A. thaliana nach einer Infektion mit $V$. longisporum in Relation $\mathrm{zu}$ anatomischen Veränderungen und Krankheitssymptomen.

Bei A. thaliana wurden dafür T-DNA-Insertionslinien mit einer verringerten Expression der Zielgene überprüft. Dabei wurde eine glp3-Linie mit einer erhöhten Suszeptibilität gegenüber $V$. longisporum identifiziert. Um die Rolle dieses Proteins für die VerticilliumInfektion näher zu untersuchen, wurden Pflanzen mit einer kontitutiv erhöhten und mit einer verringerten Transkriptmenge hergestellt und im Hinblick auf Krankheitssymptome wie die Veränderung der Blattfläche, der Biomasse und des Chlorophyllgehaltes sowie des Gehaltes an Verticillium-DNA im Pflanzengewebe analysiert.

Um zu überprüfen, ob es infolge einer Vertcillium-Infektion in A. thaliana zu anatomischen oder histologischen Veränderungen kommt, sollten Querschnitte infizierter und nicht infizierter Pflanzen miteinander verglichen und auf Unterschiede hin untersucht werden.

Hinsichtlich der Xylemsaft-Proteine von B. napus bestand die Hypothese, dass die durch $V$. longisporum induzierten Proteine das Wachstum von $V$. longisporum direkt beeinflussen. Um diese Hypothese zu testen, sollte die Proliferation von V. longisporum in Xylemsaft von infizierten und nicht infizierten Pflanzen analysiert werden. Des Weiteren sollten die Xylemsaft-Proteine in Bioassays auf ihre wachstumshemmende Aktivität gegen $V$. longisporum hin untersucht werden. 


\section{$2 \quad$ Material und Methoden}

\subsection{Material}

\subsubsection{Verticillium longisporum}

Verticillium longisporum, Stamm 43, wurde aus Brassica napus isoliert und von der AG Tiedemann zur Verfügung gestellt (Zeise \& Tiedemann 2002).

\subsubsection{Pflanzen}

Im Rahmen dieser Arbeit wurde mit Raps (Brassica napus var. napus) und mit Arabidopsis thaliana L. (Ackerschmalwand) gearbeitet.

Bei dem Raps handelte es sich um „rapid cycling“ Raps. Dieser zeichnet sich durch einem kurzen Lebenzyklus aus und wurde speziell für Forschungszwecke gezüchtet (Williams \& Hill 1986). Während die meisten Brassica-Arten einen 0,5 bis 2 Jahre andauernden Lebenszyklus aufweisen und zudem zur Blüh-Induktion eine Vernalisierung notwendig ist, geht der „rapid cycling“ Raps ohne Vernalisierung 3-4 Wochen nach der Keimung in die Blühphase über (Musgrave 2000). Die Samen für diese Pflanzen wurden von der AG Tiedemann zur Verfügung gestellt und stammen ursprünglich von P.H. Williams (University of Wisconsin-Madison, Crucifer Genetics Cooperative).

Bezüglich Arabidopsis thaliana wurden die Ökotypen Columbia und Wassilewskija verwendet. Zusätzlich wurde mit transgenen Pflanzen gearbeitet, in denen jeweils ein bestimmtes Gen oder dessen Promoterbereich mutiert ist (SALK- und FLAG-Linien). Des Weiteren wurden im Rahmen dieser Arbeit verschiedene transgene Pflanzen selbst hergestellt. Alle A. thaliana - Linien sind in der Tabelle 2 aufgeführt. 
Tabelle 2: Liste aller in dieser Arbeit verwendeten A. thaliana - Linien sowie deren Eigenschaften und Herkunft.

\begin{tabular}{|c|c|c|}
\hline Name & Eigenschaften & Herkunft \\
\hline Columbia Col-0 & Wildtyp & \multirow{11}{*}{$\begin{array}{c}\text { Nottingham } \\
\text { Arabidopsis } \\
\text { Stock Centre, } \\
\text { University of } \\
\text { Nottingham, } \\
\text { Loughborough, } \\
\text { UK, Scholl et al. } \\
2000\end{array}$} \\
\hline Wassilewskija Ws-2 & Wildtyp & \\
\hline SALK_022520 & $\begin{array}{l}\text { T-DNA-Insertionsmutante, betroffenes } \\
\text { Gen: At4g37530 (pod37); Kan }{ }^{\mathrm{R}}\end{array}$ & \\
\hline SALK_024708 & $\begin{array}{l}\text { T-DNA-Insertionsmutante, betroffenes } \\
\text { Gen: At4g37530 (pod37); Kan }{ }^{\mathrm{R}}\end{array}$ & \\
\hline SALK_051769 & $\begin{array}{l}\text { T-DNA-Insertionsmutante, betroffenes } \\
\text { Gen: At3g49120 (pod34); Kan }{ }^{\mathrm{R}}\end{array}$ & \\
\hline SALK_055557 & $\begin{array}{l}\text { T-DNA-Insertionsmutante, betroffenes } \\
\text { Gen: At5g20630 (glp3); Kan }{ }^{\mathrm{R}}\end{array}$ & \\
\hline SALK_081257 & $\begin{array}{l}\text { T-DNA-Insertionsmutante, betroffenes } \\
\text { Gen: At5g05340 (pod52); Kan }\end{array}$ & \\
\hline SALK_089515 & $\begin{array}{l}\text { T-DNA-Insertionsmutante, betroffenes } \\
\text { Gen: At4g37530 (pod37); Kan }{ }^{\mathrm{R}}\end{array}$ & \\
\hline SALK_095638 & $\begin{array}{l}\text { T-DNA-Insertionsmutante, betroffenes } \\
\text { Gen: At4g12910 (scp); Kan }{ }^{\mathrm{R}}\end{array}$ & \\
\hline SALK_134497 & $\begin{array}{l}\text { T-DNA-Insertionsmutante, betroffenes } \\
\text { Gen: At5g08370 (gal); Kan }{ }^{\mathrm{R}}\end{array}$ & \\
\hline SALK_147839 & $\begin{array}{l}\text { T-DNA-Insertionsmutante, betroffenes } \\
\text { Gen: At4g12910 (scp); Kan }{ }^{\mathrm{R}}\end{array}$ & \\
\hline FLAG_561D11 & $\begin{array}{l}\text { T-DNA-Insertionsmutante, betroffenes } \\
\text { Gen: At3g16530 (llp); Basta }{ }^{\mathrm{R}}\end{array}$ & \multirow{4}{*}{$\begin{array}{c}\text { Institut Jean- } \\
\text { Pierre Bourgin, } \\
\text { INRA Centre de } \\
\text { Versailles, } \\
\text { Versailles, } \\
\text { Frankreich; } \\
\text { Samson et al. } \\
2002\end{array}$} \\
\hline FLAG_146D08 & $\begin{array}{l}\text { T-DNA-Insertionsmutante, betroffenes } \\
\text { Gen: At5g20630 (glp3); Basta }\end{array}$ & \\
\hline FLAG_412D02 & $\begin{array}{l}\text { T-DNA-Insertionsmutante, betroffenes } \\
\text { Gen: At5g20630 (glp3); Basta }\end{array}$ & \\
\hline FLAG_552G09 & $\begin{array}{l}\text { T-DNA-Insertionsmutante, betroffenes } \\
\text { Gen: At3g16530 (llp); Basta }\end{array}$ & \\
\hline p35s::glp3 (Ws) & $\begin{array}{l}\text { Überexpression von glp3 (At5g20630) } \\
\text { im Ws-2 Ökotyp; Basta }\end{array}$ & \multirow{4}{*}{ diese Arbeit } \\
\hline $\begin{array}{l}\text { p35s::glp3 (glp3), } \\
\text { Kompl., Linie } 1+5\end{array}$ & $\begin{array}{l}\text { Komplementierung der Insertionslinie } \\
\text { FLAG_412D02; } \text { Hyg }^{\mathrm{R}}\end{array}$ & \\
\hline pglp3::GUS & $\begin{array}{l}\text { Promoter::GUS-Reporterlinie, } 3363 \text { bp } \\
\text { vor dem ATG von glp3, in Col- } 0 ; \mathrm{Hyg}^{\mathrm{R}}\end{array}$ & \\
\hline $\begin{array}{c}\text { p35s::amiRNAglp3, } \\
\text { A und B }\end{array}$ & $\begin{array}{l}\text { amiRNA-Linien mit einem Konstrukt } \\
\text { gegen glp3 im Col-0 Ökotyp; Basta }{ }^{\mathrm{R}}\end{array}$ & \\
\hline
\end{tabular}




\subsubsection{Bakterien}

Die bei den Klonierungen sowie die für die Transformation von A. thaliana verwendeten Bakterien sind in der Tabelle 3 aufgelistet.

Tabelle 3: Liste aller in dieser Arbeit verwendeten Bakterien, deren Eigenschaften und Herkunft.

\begin{tabular}{|c|c|c|}
\hline Bakterium + Stamm & Eigenschaften & Referenz \\
\hline $\begin{array}{l}\text { Escherichia coli } \\
\text { Stamm TOP TEN }\end{array}$ & $\begin{array}{c}\mathrm{F}-\text { mcrA } \Delta(\text { mrr-hsdRMS-mcrBC }) \\
\text { Ф80lacZ } \Delta \text { M15 } \Delta \text { lacX74 recA1 } \\
\text { araD139 } \Delta(\text { ara leu }) 7697 \text { galU galK } \\
\text { rpsL (StrR) endA1 nupG }\end{array}$ & $\begin{array}{l}\text { Invitrogen, } \\
\text { Darmstadt, } \\
\text { Deutschland }\end{array}$ \\
\hline $\begin{array}{l}\text { Escherichia coli } \\
\text { Stamm DB 3.1 }\end{array}$ & $\begin{array}{c}\mathrm{F}-\text { gyrA462 endA1 } \Delta(\text { sr1-recA) mcrB } \\
\text { mrr hsdS20(rB-, mB-) supE44 ara-14 } \\
\text { galK2 lacY1 proA2 rpsL20(SmR) } \\
\text { xyl-5 } \lambda-\text { leu mtl1 }\end{array}$ & $\begin{array}{l}\text { Invitrogen, } \\
\text { Darmstadt, } \\
\text { Deutschland }\end{array}$ \\
\hline $\begin{array}{l}\text { Agrobacterium } \\
\text { tumefaciens } \\
\text { Stamm GV3101 }\end{array}$ & $\begin{array}{l}\text { Helferplasmid: pMP90RK } \\
\text { genomisch codiert:Rif }{ }^{\mathrm{R}} \\
\text { auf Helferplasmid codiert: } \mathrm{Gem}^{\mathrm{R}} ; \mathrm{Kan}^{\mathrm{R}}\end{array}$ & $\begin{array}{c}\text { Koncz \& Schell, } \\
1986\end{array}$ \\
\hline
\end{tabular}

\subsubsection{Hefe (Saccharomyces cerevisiae)}

Für die heterologe Expression eines pflanzlichen Proteins wurde Saccharomyces cerevisiae, Stamm INVSc1 (Invitrogen, Darmstadt, Deutschland; Genotyp his3 $\Delta 1 /$ his $3 \Delta 1$, leu2/leu2, trp1-289/trp1-289, ura3-52/ura3-52) verwendet, der auxotroph für Histidin, Leucin, Tryptophan und Uracil ist.

\subsubsection{Standardchemikalien}

Standardchemikalien wurden von den Firmen Merck, Roth, Sigma oder Fluka bezogen und stets mit dem höchstmöglichen Reinheitsgrad bestellt. Abweichungen bei einzelnen Produkten oder Spezifizierungen sind im Text in Klammern angegeben. Das zum Ansetzen von Puffern und Lösungen verwendete demineralisierte Wasser $\left(\mathrm{ddH}_{2} \mathrm{O}\right)$ wurde mit Hilfe des Gerätes Satorius arium ${ }^{\circledR}$ 611VF (Sartorius, Göttingen, Germany) produziert. RNasefreies Wasser wurde von Ambion (Ambion Inc., Austin, USA) bezogen.

\subsubsection{Plasmide}

Die bei den Klonierungen für die spätere Herstellung der transgenen Pflanzen sowie für die heterologe Expression eines pflanzlichen Proteins in Hefe verwendeten Plasmide sind in der Tabelle 4 aufgelistet. 
Tabelle 4: Liste aller in dieser Arbeit verwendeten Plasmide, deren Eigenschaften und deren Herkunft.

\begin{tabular}{|c|c|c|}
\hline Plasmid & Eigenschaften & Herkunft/Referenz \\
\hline pDONR201 & $\begin{array}{l}\text { Gateway-kompatibler Eingangsvektor mit } \\
\text { attL1- und attL2-site, pUC ori, ccdB, } \\
\qquad \mathrm{Cm}^{\mathrm{R}}, \mathrm{Km}^{\mathrm{R}}\end{array}$ & $\begin{array}{l}\text { Invitrogen, } \\
\text { Darmstadt, } \\
\text { Deutschland }\end{array}$ \\
\hline $\mathrm{pE}$ & $\begin{array}{l}\text { Gateway-kompatibler Zielvektor mit } \\
\text { attR1- und attR2-site, 35s Promoter, ccdB, } \\
\mathrm{Cm}^{\mathrm{R}}, \mathrm{Km}^{\mathrm{R}}, \text { Basta }^{\mathrm{R}} \\
\end{array}$ & AG Dröge-Laser \\
\hline pGWB2 & $\begin{array}{l}\text { Gateway-kompatibler Zielvektor mit } \\
\text { attR1- und attR2-site, 35s Promoter, ccdB, } \\
\qquad \mathrm{Cm}^{\mathrm{R}}, \mathrm{Km}^{\mathrm{R}}, \mathrm{Hyg}^{\mathrm{R}}\end{array}$ & Nakagawa et al. 2007 \\
\hline pCAMBIA1391Z & $\begin{array}{l}\text { Vektor zur Herstellung eines } \\
\text { Promoter::GUS-Konstruktes; } \mathrm{Km}^{\mathrm{R}} \text {, } \mathrm{Hyg}^{\mathrm{R}}\end{array}$ & www.cambia.org \\
\hline pRS300 & $\begin{array}{c}\text { Vektor zur Produktion von artifiziellen } \\
\text { microRNAs durch zielgerichtete } \\
\text { Mutagenese, } \mathrm{Amp}^{\mathrm{R}}\end{array}$ & $\begin{array}{c}\text { MPI Tübingen, } \\
\text { Schwab et al. } 2006 \text {, } \\
\text { Ossowski et al. } 2008\end{array}$ \\
\hline pYES2CT & $\begin{array}{c}\text { Expressionsvektor für Hefe, Amp }{ }^{\mathrm{R}} \text {, URA3 } \\
\text { Marker, GAL1 Promoter, V5 epitope, 6x } \\
\text { His-Tag (beides C-terminal) }\end{array}$ & $\begin{array}{l}\text { Invitrogen, } \\
\text { Darmstadt, } \\
\text { Deutschland }\end{array}$ \\
\hline
\end{tabular}

\subsubsection{Oligonukleotide}

Die in dieser Arbeit verwendeten Primer für die verschiedenen PCR-Reaktionen sind der Tabelle $5 \mathrm{zu}$ finden. Sie wurden alle von der Firma Invitrogen (Darmstadt, Deutschland) synthetisiert.

Tabelle 5: Liste aller in dieser Arbeit verwendeten Primer und deren Sequenz.

\begin{tabular}{|l|l|}
\hline Bezeichnung & Sequenz in $\mathbf{5}^{\prime} \mathbf{-} \mathbf{3}^{\prime}$ Richtung \\
\hline LP SALK_022520 & CTAGTTTTGGATTCACGCAGC \\
\hline RP SALK_022520 & TGGATCCCACGATTAACAAAG \\
\hline LP SALK_024708 & GCCAAATAGGCATCAGTATGC \\
\hline RP SALK_024708 & TGGATCCCACGATTAACAAAG \\
\hline LP SALK_051769 & CCAGTAACATCACTGTCGATGAG \\
\hline RP SALK_051769 & TCCGTTAGCGTTCCACATTAG \\
\hline LP SALK_055557 & TCAACCTCGAGAGTGATGGTC \\
\hline RP SALK_055557 & CAGCTAAACTCTGGGAAAGGC \\
\hline LP SALK_081257 & TGTTAGACTATTTCCGGGTCTTG \\
\hline
\end{tabular}




\begin{tabular}{|c|c|}
\hline Bezeichnung & Sequenz in $5^{\prime}-3^{\prime}$ Richtung \\
\hline RP SALK_081257 & TACGACGGAGTCTCTAGCAGC \\
\hline LP SALK_089515 & CCCGCCTATTTTGAATTTAATG \\
\hline RP SALK_089515 & TTCGGAAAGATTCAAGGTGAC \\
\hline LP SALK_095638 & СTTTTCTTTGTAGCGGGGATC \\
\hline RP SALK_095638 & CCTATGTTGATGAAGCTATCAATCAC \\
\hline LP SALK_134497 & TTTGATAGGGGAGTTTGGTTG \\
\hline RP SALK_134497 & ATACTTTTGCCAATGCCCAG \\
\hline LP SALK_147839 & TGCAGTGGGAAACTCTCATTC \\
\hline RP SALK_147839 & ATGGACCACAAAGGCATTATG \\
\hline LP FLAG_561D11 & TGTAGATAGCGGGTCTCCAAAC \\
\hline RP FLAG_561D11 & AACTAGATTTGCTTGAACCACATG \\
\hline LP FLAG_146D08 & TGTTTTCACGAAAATTTGCATC \\
\hline RP FLAG_146D08 & CAGCTAAACTCTGGGAAAGGC \\
\hline LP FLAG_412D02 & TGCTCTTGTGTTCTTGGAGAAG \\
\hline RP FLAG_412D02 & ACTTTGGGTGTACGTACGTGG \\
\hline LP FLAG_552G09 & CATGTTTCTTACCAAAACAACTTG \\
\hline RP FLAG_552G09 & TTCTCTTGTCGCTGAGAAAGC \\
\hline LBb1 & GCGTGGACCGCTTGCTGCAACT \\
\hline FLAG_tDNA_RB4 & TCACGGGTTGGGGTTTCTACAGGAC \\
\hline FLAG_tDNA_Tag3 & CTGATACCAGACGTTGCCCGCATAA \\
\hline FLAG_tDNA_LB4 & CGTGTGCCAGGTGCCCACGGAATAGT \\
\hline FLAG_tDNA_Tag5 & CTACAAATTGCCTTTTCTTATCGAC \\
\hline Act2_DNA_fw & AATTTGGATCTGTGAACCTCCAC \\
\hline Act2_DNA_rev & CGACACTACAAATCCTAAAGTTTCG \\
\hline UBQ5_fw & GACGCTTCATCTCGTCC \\
\hline UBQ5_rev & GTAAACGTAGGTGAGTCC \\
\hline G1_At5g20630_for & CCTCAAAGCCCATCAGGTTA \\
\hline G1_At5g20630_rev & ACCTCAGAAGCACCAGGATG \\
\hline At5g20630_FW & $\begin{array}{l}\text { GGGGACAAGTTTGTACAAAAAAGCAGGCTTC } \\
\text { ATGAAGATGATAATCCAAATTTTCTTC }\end{array}$ \\
\hline At5g20630_RV & $\begin{array}{l}\text { GGGGACCACTTTGTACAAGAAAGCTGGGTC } \\
\text { ATTAGTTCCCCCAAGCACACCC }\end{array}$ \\
\hline Seq-L1-pDON-FW & CTCGCGTTAACGCTAGCATGGATCT \\
\hline
\end{tabular}




\begin{tabular}{|c|c|}
\hline Bezeichnung & Sequenz in $5^{\prime}-3^{\prime}$ Richtung \\
\hline Seq-L1-pDON-RV & GTAACATCAGAGATTTTGAGACAC \\
\hline PstI-PromoterGLP3_fw & $\begin{array}{l}\text { AAAAACTGCAGTTAAACTTTATTATTATTAT } \\
\text { AATCATTATAGCTGTTTCC }\end{array}$ \\
\hline NcoI-PromoterGLP3_rev & $\begin{array}{l}\text { TTTTTCCATGGTTCTTTAGAATGTTTTATAGA } \\
\text { TAAGAGCTTTTG }\end{array}$ \\
\hline Seq_PromoterGLP3_1 & CGAGTTATATATGGACCATAATCACGTG \\
\hline Seq_PromoterGLP3_2 & AAAGTTAGATAGGTTAAGCAATAAAATCG \\
\hline Seq_PromoterGLP3_3 & GAGAGACTGAGGTGTTGTCCATGTC \\
\hline Seq_PromoterGLP3_4 & СTTATCTTTTTAGACATTTAATCTGGGC \\
\hline Seq_PromoterGLP3_5 & GCCTATACTGTAGACTGGATTTGGAG \\
\hline Seq_pCambia1391Z_fw & GTTGTGTGGAATTGTGAGCGG \\
\hline Seq_pCambia1391Z_rev & GGGTCCTAACCAAGAAAATGAAGG \\
\hline amiRNA_GW_PrimerA & $\begin{array}{l}\text { GGGGACAAGTTTGTACAAAAAAGCAGGCTC } \\
\text { TGCAAGGCGATTAAGTTGGGTAAC }\end{array}$ \\
\hline amiRNA_GW_PrimerB & $\begin{array}{l}\text { GGGGACCACTTTGTACAAGAAAGCTGGGTC } \\
\text { GCGGATAACAATTTCACACAGGAAACAG }\end{array}$ \\
\hline amiRNA_At5g20630_A_PrimerI & $\begin{array}{l}\text { GATATGGTAGAATTTGGAGCGCTTCTCTCTT } \\
\text { TTGTATTCC }\end{array}$ \\
\hline amiRNA_At5g20630_A_PrimerII & $\begin{array}{l}\text { GAAGCGCTCCAAATTCTACCATATCAAAGAG } \\
\text { AATCAATGA }\end{array}$ \\
\hline amiRNA_At5g20630_A_PrimerIII & $\begin{array}{l}\text { GAAGAGCTCCAAATTGTACCATTTCACAGGT } \\
\text { CGTGATATG }\end{array}$ \\
\hline amiRNA_At5g20630_A_PrimerIV & $\begin{array}{l}\text { GAAATGGTACAATTTGGAGCTCTTCTACATA } \\
\text { TATATTCCT }\end{array}$ \\
\hline amiRNA_At5g20630_B_PrimerI & $\begin{array}{l}\text { GATCAAATGGTAGAATTTGGGGCTCTCTCTT } \\
\text { TTGTATTCC }\end{array}$ \\
\hline amiRNA_At5g20630_B_PrimerII & $\begin{array}{l}\text { GAGCCCCAAATTCTACCATTTGATCAAAGAG } \\
\text { AATCAATGA }\end{array}$ \\
\hline amiRNA_At5g20630_B_PrimerIII & $\begin{array}{l}\text { GAGCACCAAATTCTAGCATTTGTTCACAGGT } \\
\text { CGTGATATG }\end{array}$ \\
\hline amiRNA_At5g20630_B_PrimerIV & $\begin{array}{l}\text { GAACAAATGCTAGAATTTGGTGCTCTACATA } \\
\text { TATATTCCT }\end{array}$ \\
\hline GLP_Hefe_FW & $\begin{array}{l}\text { TATAAAGCTTATGAAGATGATAATCCAAATT } \\
\text { TTCTTCA }\end{array}$ \\
\hline GLP_Hefe_REV & TATACTCGAGATTAGTTCCCCCAAGCACACC \\
\hline Seq_pYES2-CT_FW & TATACCTCTATACTTTAACGTCAAGGAGA \\
\hline Seq_pYES2-CT_REV & TTAAACTCAATGGTGATGGTGATG \\
\hline
\end{tabular}




\subsubsection{Antikörper}

Für die Western Blot Analyse wurde der Antikörper Anti His (C-term) - AP Antibody von Invitrogen (Darmstadt, Deutschland) verwendet, welcher an Polyhistidin-Tags bindet und an eine alkalische Phosphatase gekoppelt ist.

\subsubsection{Nährmedien}

\subsubsection{Potato-Dextrose-Medium (PDB und PDA)}

Zur Kultivierung von Verticillium longisporum wurde Potato-Dextrose-Medium verwendet (Fahleson et al. 2003). Für flüssiges Medium wurden 6 g PDB (Potato Dextrose Brooth, Sigma, Steinheim, Deutschland) in $250 \mathrm{ml}$ destilliertem Wasser angesetzt. Zur Herstellung von festem Medium wurde $39 \mathrm{~g} / 1$ PDA (Potato Dextrose Agar, Difco Laboratories, Detroit, USA) verwendet. Sowohl flüssiges als auch festes Medium wurde autoklaviert und nach dem Abkühlen mit $0,2 \mu \mathrm{g} / \mathrm{ml}$ steril filtriertem Streptomycin (Duchefa, Haarlem, Niederlande) versetzt.

\subsubsection{Wurzelmedium}

Die Anzucht von Arabidopsis thaliana und Brassica napus erfolgte auf Wurzelmedium. Die Zusammensetzung des Mediums (siehe Tabelle 6) basiert auf den Angaben von Schenk und Hildebrandt (1972) für die Makronährelemente; die Konzentrationen der Mikronährelemente richten sich jedoch nach Gresshoff und Doy (1974), während die der Vitamine und der weiteren Zusätzen nach Murashige und Skoog (1962) verändert sind. Für 1 Liter des Mediums wurden folgende Volumina der bei $4^{\circ} \mathrm{C}$ gelagerten Stammlösungen verwendet: $100 \mathrm{ml}$ der Makroelemente, je $1 \mathrm{ml}$ der Mikroelemente, Vitamine und Glycin sowie je $5 \mathrm{ml}$ Inosit und Eisen. Nach Zugabe der Saccharose wurde der pH-Wert mit $\mathrm{NaOH}$ auf 5,8 eingestellt. Anschließend wurde das Gelrite hinzugefügt, bevor das vollständige Medium autoklaviert wurde. 
Tabelle 6: Zusammensetzung des Wurzelmediums. Die Abkürzungen SH (Schenk und Hildebrandt), GD (Gresshoff und Doy) und MS (Murashige und Skoog) geben an, auf wessen Angaben die Konzentration der jeweiligen Stammlösung basiert (nähere Erläuterungen siehe Text).

\begin{tabular}{|c|c|c|c|}
\hline Stammlösung & Bestandteil & Konzentration Stammlösung & Endkonzentration \\
\hline \multirow{4}{*}{$\begin{array}{c}\text { Makroelemente } \\
\text { SH }\end{array}$} & $\mathrm{KNO}_{3}$ & $247,28 \mathrm{mM}$ & $24,73 \mathrm{mM}$ \\
\hline & $\mathrm{CaCl}_{2} \times 2 \mathrm{H}_{2} \mathrm{O}$ & $13,60 \mathrm{mM}$ & $1,36 \mathrm{mM}$ \\
\hline & $\mathrm{MgSO}_{4} \times 7 \mathrm{H}_{2} \mathrm{O}$ & $16,23 \mathrm{mM}$ & $1,62 \mathrm{mM}$ \\
\hline & $\mathrm{NH}_{4} \mathrm{H}_{2} \mathrm{PO}_{4}$ & $26,08 \mathrm{mM}$ & $2,61 \mathrm{mM}$ \\
\hline \multirow{7}{*}{$\begin{array}{l}\text { Mikroelemente } \\
\text { GD }\end{array}$} & $\mathrm{H}_{3} \mathrm{BO}_{3}$ & $48,52 \mathrm{mM}$ & $48,52 \mu \mathrm{M}$ \\
\hline & $\mathrm{Na}_{2} \mathrm{MoO}_{4}$ & $1,21 \mathrm{mM}$ & $1,21 \mu \mathrm{M}$ \\
\hline & KI & $4,52 \mathrm{mM}$ & $4,52 \mu \mathrm{M}$ \\
\hline & $\mathrm{MnSO}_{4} \times \mathrm{H}_{2} \mathrm{O}$ & $59,16 \mathrm{mM}$ & $59,16 \mu \mathrm{M}$ \\
\hline & $\mathrm{ZnSO}_{4} \times 7 \mathrm{H}_{2} \mathrm{O}$ & $10,43 \mathrm{mM}$ & $10,43 \mu \mathrm{M}$ \\
\hline & $\mathrm{CoCl}_{2} \times 6 \mathrm{H}_{2} \mathrm{O}$ & $1,05 \mathrm{mM}$ & $1,05 \mu \mathrm{M}$ \\
\hline & $\mathrm{CuSO}_{4} \times 5 \mathrm{H}_{2} \mathrm{O}$ & $1,00 \mathrm{mM}$ & $1,00 \mu \mathrm{M}$ \\
\hline \multirow{3}{*}{ Vitamine MS } & $\mathrm{C}_{6} \mathrm{H}_{5} \mathrm{NO}_{2}$ & $4,06 \mathrm{mM}$ & $4,06 \mu \mathrm{M}$ \\
\hline & $\mathrm{C}_{8} \mathrm{H}_{11} \mathrm{NO}_{3} \times \mathrm{HCl}$ & $2,43 \mathrm{mM}$ & $2,43 \mu \mathrm{M}$ \\
\hline & $\mathrm{C}_{12} \mathrm{H}_{18} \mathrm{C}_{12} \mathrm{~N}_{4} \mathrm{OS} \times \mathrm{H}_{2} \mathrm{O}$ & $0,30 \mathrm{mM}$ & $0,30 \mu \mathrm{M}$ \\
\hline Glycin MS & $\mathrm{C}_{2} \mathrm{H}_{5} \mathrm{NO}_{2}$ & $26,64 \mathrm{mM}$ & $26,64 \mu \mathrm{M}$ \\
\hline Inosit MS & $\mathrm{C}_{6} \mathrm{H}_{12} \mathrm{O}_{6}$ & $110,99 \mathrm{mM}$ & $554,94 \mu \mathrm{M}$ \\
\hline \multirow[t]{3}{*}{ Eisen MS } & $\mathrm{C}_{10} \mathrm{H}_{12} \mathrm{FeN}_{2} \mathrm{NaO}_{8}$ & $29,99 \mathrm{mM}$ & $99,97 \mu \mathrm{M}$ \\
\hline & Saccharose & & $25 \mathrm{~g} / 1$ \\
\hline & $\begin{array}{l}\text { Gelrite (Duchefa, } \\
\text { Haarlem, Niederlande) }\end{array}$ & & $2,8 \mathrm{~g} / 1$ \\
\hline
\end{tabular}

\subsubsection{Medien für Mikroorganismen}

Für die Kultur der verschiedenen Mikroorganismen wurden folgende Medien hergestellt:

LB-Medium

$10 \mathrm{~g} / 1$ Bacto $^{\text {TMT}}$ Trypton

$5 \mathrm{~g} / 1$ Bacto $^{\text {TM}}{ }^{2}$ efeextrakt

$10 \mathrm{~g} / 1 \mathrm{NaCl}$

ggf. $15 \mathrm{~g} / 1$ Bacto ${ }^{\text {TM }}$ Agar für festes Medium

$\mathrm{pH}$ auf 7,4 einstellen und bei $121^{\circ} \mathrm{C}$ sterilisieren 
SOB-Medium $20 \mathrm{~g} / 1$ Bacto $^{\mathrm{TM}}$ Trypton

$5 \mathrm{~g} / 1$ Bacto $^{\text {TM}}{ }^{2}$ efeextrakt

$0,6 \mathrm{~g} / 1 \mathrm{NaCl}$

$0,2 \mathrm{~g} / 1 \mathrm{KCl}$

ggf. $15 \mathrm{~g} / 1$ Bacto ${ }^{\mathrm{TM}}$ Agar für festes Medium

$\mathrm{pH}$ auf 7,0 einstellen und bei $121^{\circ} \mathrm{C}$ sterilisieren; getrennt autoklavieren und nach dem Abkühlen hinzufügen:

$10 \mathrm{ml} / 11 \mathrm{M} \mathrm{MgCl}_{2}$

$10 \mathrm{ml} / 11 \mathrm{M} \mathrm{MgSO}_{4}$

SOC-Medium SOB-Medium $+40 \mathrm{ml} / 1$ 0,5 M Glucose

Glucose-Lösung getrennt autoklavieren und nach dem Abkühlen zum Medium geben

YEB-Medium $5 \mathrm{~g} / \mathrm{l}$ Fleischextrakt

$1 \mathrm{~g} / 1$ Bacto ${ }^{\text {TM}}$ Hefeextrakt

$5 \mathrm{~g} / 1$ Bacto $^{\text {TMPepton }}$

$5 \mathrm{~g} / 1$ Saccharose

ggf. $15 \mathrm{~g} / 1$ Bacto ${ }^{\text {TM}}$ Agar für festes Medium

YPD-Medium $1 \%$ Bact $^{\mathrm{TM}}$ Hefeextrakt

$2 \%$ Bacto $^{\text {TMPepton }}$

$2 \%$ Dextrose (D-Glucose)

ggf. $2 \%$ Bacto $^{\text {TM}}$ Agar für festes Medium

SD-Medium $\quad 0,67 \%$ Yeast nitrogen base (YNB) ohne Aminosäuren, mit Ammoniumsulfat

$2 \%$ Zucker (Glucose, Galactose oder Raffinose)

0,077 \% CSM (Complete Supplement Mixture) ohne Uracil; entspricht einer Endkonzentration von je 0,01 \% Adenin, Arginin,Cystein, Leucin, Lysin, Theonin und Tryptophan sowie je $0,005 \%$ Aspartat, Histidin, Isoleucin, Methionin, Phenylalanin, Prolin, Serin, Tyrosin und Valin

ggf. $2 \%$ Bacto-Agar für festes Medium 
Bacto $^{\mathrm{TM}}$ Trypton, Bacto ${ }^{\mathrm{TM}}$ Hefeextrakt, Bacto ${ }^{\mathrm{TM}}$ Agar und Bacto ${ }^{\mathrm{TM}}$ Pepton wurden von der Firma Becton, Dickinson and Company (Sparks, USA), Fleischextrakt von Difco Laboratories (Detroit, USA), YNB von Sigma (Steinheim, Deutschland) und CSM von der Firma Mobitec (Göttingen, Deutschland) bezogen.

$\mathrm{Zu}$ Selektionszwecken wurden den Medien unterschiedliche Antibiotika zugesetzt (Tabelle 7). Dafür wurden Stammlösungen hergestellt und steril filtriert. Für Rifampicin wurde DMF als Lösungsmittel verwendet, während alle anderen Antibiotika in Wasser angesetzt wurden. Dem autoklavierten Medium wurde die entsprechende Menge des Antibiotikums nach dem Abkühlen zugesetzt. Alle Antibiotika wurden von der Firma Duchefa (Haarlem, Niederlande) erworben.

Tabelle 7: Liste mit den in dieser Arbeit verwendeten Antibiotika.

\begin{tabular}{|l|l|l|}
\hline Zusatz & Stammlösung & Endkonzentration \\
\hline Ampicillin Natriumsalz & $100 \mathrm{mg} / \mathrm{ml}$ & $100 \mu \mathrm{g} / \mathrm{ml}$ \\
\hline Gentamycin-Sulfat & $10 \mathrm{mg} / \mathrm{ml}$ & $15 \mu \mathrm{g} / \mathrm{ml}$ \\
\hline Hygromycin B & $40 \mathrm{mg} / \mathrm{ml}$ & $40 \mu \mathrm{g} / \mathrm{ml}$ \\
\hline Kanamycin Monosulfat & $50 \mathrm{mg} / \mathrm{ml}$ & $50 \mu \mathrm{g} / \mathrm{ml}$ \\
\hline Streptomycin-Sulfat & $100 \mathrm{mg} / \mathrm{ml}$ & $0,2 \mu \mathrm{g} / \mathrm{ml}$ \\
\hline Rifampicin & $100 \mathrm{mg} / \mathrm{ml}$ (in DMF) & $50 \mu \mathrm{g} / \mathrm{ml}$ \\
\hline Tetracyclin $\mathrm{HCl}$ & $15 \mathrm{mg} / \mathrm{ml}$ & $15 \mu \mathrm{g} / \mathrm{ml}$ \\
\hline
\end{tabular}

\subsubsection{Geräte}

Im Folgenden sind alle in dieser Arbeit benutzten Geräte aufgeführt:

\begin{tabular}{|l|l|l|}
\hline Gerät & Modell & Hersteller \\
\hline Autoklav & HST 6x6x6 & Zirbus, Osterode, Deutschland \\
\hline Binokular & M205FA; Kamera: DFC420C & Leica, Solms, Deutschland \\
\hline $\begin{array}{l}\text { Chlorophyllfluoreszenz- } \\
\text { Messgerät }\end{array}$ & Imaging Pam & Walz, Effeltrich, Deutschland \\
\hline Digitalkamera & Coolpix S4 & $\begin{array}{l}\text { Nikon, Düsseldorf, } \\
\text { Deutschland }\end{array}$ \\
\hline Eismaschine & AF 100 & Scotsman, Mailand, Italien \\
\hline
\end{tabular}




\begin{tabular}{|c|c|c|}
\hline Gerät & Modell & Hersteller \\
\hline Elektroporationsgerät & & Bio-Rad, Hercules, USA \\
\hline Gefriermikrotom & 2800 Frigocut N & $\begin{array}{l}\text { Reichert-Jung, Heidelberg, } \\
\text { Deutschland }\end{array}$ \\
\hline $\begin{array}{l}\text { Geldokumentationsanlage für } \\
\text { Agarose-Gele }\end{array}$ & Fluor-S Multi Imager & Bio-Rad, Hercules, USA \\
\hline $\begin{array}{l}\text { Geldokumentationsanlage für } \\
\text { SDS-Gele }\end{array}$ & FLA-5100 & $\begin{array}{l}\text { Fujifilm, Düsseldorf, } \\
\text { Deutschland }\end{array}$ \\
\hline $\begin{array}{l}\text { Gelelektrophoresekammer } \\
\text { horizontal, für Agarose-Gele }\end{array}$ & & Bio-Rad, Hercules, USA \\
\hline $\begin{array}{l}\text { Gelelektrophoresekammer } \\
\text { vertikal, für SDS-Gele }\end{array}$ & & Bio-Rad, Hercules, USA \\
\hline Glasmesserbrecher & Knifemaker 7800 & LKB, Stockholm, Schweden \\
\hline Heizblock + Schüttler & Thermomixer comfort & $\begin{array}{l}\text { Eppendorf, Hamburg, } \\
\text { Deutschland }\end{array}$ \\
\hline Heizplatte & & Schütt, Göttingen, Deutschland \\
\hline Klimakammer & HN 1166073 & $\begin{array}{l}\text { Karl Weiss, Giessen, } \\
\text { Deutschland }\end{array}$ \\
\hline Klimaschrank & AR-75L & Percival Scientific, Perry, USA \\
\hline Laborschüttler & 3015 und 3017 & $\begin{array}{l}\text { Gesellschaft für Labortechnik, } \\
\text { Burgwedel, Deutschland }\end{array}$ \\
\hline Lampen Klimakammer & Osram HQL-R $400 \mathrm{~W}$ & Osram, München, Deutschland \\
\hline \multirow[t]{2}{*}{ Lampen Klimaschrank } & $\begin{array}{l}\text { Leuchtstoffröhren } \\
\text { F32T8/TL741, } 700 \text { series, } 32 \\
\text { Watt }\end{array}$ & Philips, Hamburg, Deutschland \\
\hline & Glühbirnen $230 \mathrm{~V} 25 \mathrm{Watt}$ & Osram, München, Deutschland \\
\hline Magnetrührer & MR 2002 & $\begin{array}{l}\text { Heidolph Instruments, } \\
\text { Schwabach, Deutschland }\end{array}$ \\
\hline Mikroskop & Axioskop & $\begin{array}{l}\text { Zeiss, Oberkochen, } \\
\text { Deutschland }\end{array}$ \\
\hline $\begin{array}{l}\text { Mikrotom für } \\
\text { Semidünnschnitte }\end{array}$ & Autocut & $\begin{array}{l}\text { Reichert-Jung, Heidelberg, } \\
\text { Deutschland }\end{array}$ \\
\hline Mikrowelle & & Siemens, Berlin, Deutschland \\
\hline PCR-Gerät & Mastercycler gradient & $\begin{array}{l}\text { Eppendorf, Hamburg, } \\
\text { Deutschland }\end{array}$ \\
\hline $\begin{array}{l}\text { PCR-Gerät für quantitative } \\
\text { Real Time PCR }\end{array}$ & Light Cycler 480 & $\begin{array}{l}\text { Roche, Grenzach-Whylen, } \\
\text { Deutschland }\end{array}$ \\
\hline
\end{tabular}




\begin{tabular}{|c|c|c|}
\hline Gerät & Modell & Hersteller \\
\hline pH-Meter & pH 526 & WTW, Weilheim, Deutschlanc \\
\hline Photometer & DU 640 & $\begin{array}{l}\text { Beckman Coulter, Fullerton, } \\
\text { USA }\end{array}$ \\
\hline Photometer & Bio Photometer & $\begin{array}{l}\text { Eppendorf, Hamburg, } \\
\text { Deutschland }\end{array}$ \\
\hline Photometer & Specord 205 & $\begin{array}{l}\text { Analytic Jena, Jena, } \\
\text { Deutschland }\end{array}$ \\
\hline Retschmühle & & Retsch, Haan, Deutschland \\
\hline Scanner & CanoScan4400F & Canon, Krefeld, Deutschland \\
\hline Sequenziergerät & $\begin{array}{l}\text { ABI Prism } 3100 \text { Genetic } \\
\text { Analyser, } 36 \mathrm{~cm} \text { Kapillare } \\
\text { Matrix, Pop6 }\end{array}$ & $\begin{array}{l}\text { Applied Biosystems, Foster } \\
\text { City, USA }\end{array}$ \\
\hline $\begin{array}{l}\text { Spannungsgeber für } \\
\text { Elektrophorese }\end{array}$ & Power Pac 200 & Bio-Rad, Hercules, USA \\
\hline Sterilbank & $\begin{array}{l}\text { Microflow Biological Safety } \\
\text { Cabinet }\end{array}$ & $\begin{array}{l}\text { Nunc, Wiesbaden-Biebrich, } \\
\text { Deutschland }\end{array}$ \\
\hline Tischzentrifuge & Biofuge pico & Heraeus, Schütt, Göttingen \\
\hline Tischzentrifuge mit Kühlung & 5417 R, Rotor F 45-30-11 & $\begin{array}{l}\text { Eppendorf, Hamburg, } \\
\text { Deutschland }\end{array}$ \\
\hline Ultraschallbad & Sonorex Super RK $510 \mathrm{H}$ & Bandelin, Berlin, Deutschland \\
\hline Ultrazentrifuge & $\begin{array}{l}\text { J2-HS; Rotoren: JA-20.1, JA- } \\
\text { 20, JLA-16.250 }\end{array}$ & $\begin{array}{l}\text { Beckman Coulter, Fullerton, } \\
\text { USA }\end{array}$ \\
\hline UV-Handlampe & & $\begin{array}{l}\text { Krannich, Göttingen, } \\
\text { Deutschland }\end{array}$ \\
\hline UV-Tisch & MW 312 nm & $\begin{array}{l}\text { Intas Science Imaging } \\
\text { Instruments, Göttingen, } \\
\text { Deutschland }\end{array}$ \\
\hline Vakuumzentrifuge & Concentrator 5301 & $\begin{array}{l}\text { Eppendorf, Hamburg, } \\
\text { Deutschland }\end{array}$ \\
\hline Vortexer & REAX 2000 & $\begin{array}{l}\text { Heidolph Instruments, } \\
\text { Schwabach, Deutschland }\end{array}$ \\
\hline Waage, fein & BP $210 \mathrm{D}$ & $\begin{array}{l}\text { Sartorius, Göttingen, } \\
\text { Deutschland }\end{array}$ \\
\hline Waage, grob & LA 6205 & $\begin{array}{l}\text { Sartorius, Göttingen, } \\
\text { Deutschland }\end{array}$ \\
\hline $\begin{array}{l}\text { Waage für Einwaage der C/N- } \\
\text { Proben }\end{array}$ & Supermicro & $\begin{array}{l}\text { Sartorius, Göttingen, } \\
\text { Deutschland }\end{array}$ \\
\hline
\end{tabular}




\begin{tabular}{|l|l|l|}
\hline Gerät & Modell & Hersteller \\
\hline Wärmeschrank & $\begin{array}{l}\text { Memmert, Büchenbach, } \\
\text { Deutschland }\end{array}$ \\
\hline Wasseraufbereitungsanlage & arium ${ }^{\circledR} 611$ & $\begin{array}{l}\text { Sartorius, Göttingen, } \\
\text { Deutschland }\end{array}$ \\
\hline Wasserbad & & $\begin{array}{l}\text { Gesellschaft für Labortechnik, } \\
\text { Burgwedel, Deutschland }\end{array}$ \\
\hline Western Blot Anlage & $\begin{array}{l}\text { Mini Trans-Blot }{ }^{\circledR} \\
\text { Electrophoretic Transfer Cell }\end{array}$ & Bio-Rad, Hercules, USA \\
\hline $\begin{array}{l}\text { Zentrifuge für } \\
\text { Mikrotiterplatten }\end{array}$ & $5430 \mathrm{R}$ & $\begin{array}{l}\text { Eppendorf, Hamburg, } \\
\text { Deutschland }\end{array}$ \\
\hline Zinnkapseln & $\begin{array}{l}\text { HEKAtech GmbH, Wegberg, } \\
\text { Deutschland }\end{array}$ \\
\hline
\end{tabular}

\subsubsection{Verbrauchsmittel}

Im Folgenden sind alle in dieser Arbeit verwendeten Verbrauchsmittel aufgelistet:

\begin{tabular}{|l|l|}
\hline Produkt & Hersteller \\
\hline Aluminiumfolie & Roth, Karlsruhe, Deutschland \\
\hline Deckgläschen, 24 x 40 mm, Stärke 1 & Menzel, Braunschweig, Deutschland \\
\hline Erde T25 & Fruhstorfer, Vechta, Deutschland \\
\hline Fließpapier & Whatman, Kent, UK \\
\hline Filter Vivaspin 6, 3000 MWCO & Sartorius, Göttingen, Deutschland \\
\hline Gelatine-Kapseln (Größe 0) & Plano, Wetzlar, Deutschland \\
\hline $\begin{array}{l}\text { Glasmaterialien (Bechergläser, Flaschen, } \\
\text { Erlmeyerkolben etc.) }\end{array}$ & Brand, Wertheim; Schott, Mainz \\
\hline Glasmesser, 25 mm & Leica, Solms, Deutschland \\
\hline Glasperlen, 0,5 mm (Soda Lime) & BioSpec Products, Bartlesville, USA \\
\hline Handschuhe & VWR, Darmstadt, Deutschland \\
\hline $\begin{array}{l}\text { Kleber (Pattex Sekundenkleber } \\
\text { Blitzkleber Gel) }\end{array}$ & Henkel, Düsseldorf, Deutschland \\
\hline $\begin{array}{l}\text { Kunststoff-Einwegmaterial } \\
\text { (Pipettenspitzen, Reaktionsgefäße, } \\
\text { Spritzen, Petrischalen, Rührspatel etc.) }\end{array}$ & $\begin{array}{l}\text { Brand, Wertheim; Eppendorf, Hamburg; } \\
\text { Küvetten für Photometer }\end{array}$ \\
\hline
\end{tabular}




\begin{tabular}{|l|l|}
\hline Produkt & Hersteller \\
\hline Küvetten für Elektroporation & Bio-Rad, Hercules, USA \\
\hline Multiwell Plates + Folie & Roche, Grenzach-Whylen, Deutschland \\
\hline $\begin{array}{l}\text { Nitrocellulose-Membran (Protran, } \\
\text { Porengröße von 0,2 } \mu \text { m, BA 83) }\end{array}$ & Whatman, Kent, UK \\
\hline Objektträger, geschnitten, 76 x 26 mm & Menzel, Braunschweig, Deutschland \\
\hline Parafilm "M" & Pechiney Plastic Packaging, Chicago, USA \\
\hline $\begin{array}{l}\text { Sand/Quarzkies weiß, Körnung fein 1-2 } \\
\text { mm, Farbcode 220 }\end{array}$ & Vitakraft, Bremen, Deutschland \\
\hline Sephadex G-25 Säulen NAP 5 & Amersham Biosciences, Uppsala, Schweden \\
\hline Töpfe (7 x 7 x 8 cm und 11 x 11 x 12 cm) & Meyer, Rellingen, Deutschland \\
\hline Zentrifugenbecher & Nalgene, New York, USA \\
\hline
\end{tabular}

\subsubsection{PC-Programme}

Mit den folgenden PC-Programme wurde gearbeitet:

\begin{tabular}{|l|l|}
\hline Software & Hersteller \\
\hline Adobe Reader 9.2.0 & Adobe, Burlington, USA \\
\hline Axioplan & Zeiss, Oberkochen, Deutschland \\
\hline Bildanalyseprogramm 1.0.2.4 & Datinf GmbH, Tübingen, Deutschland \\
\hline Chromas Lite, Version 2.01 & Technelysium, USA \\
\hline Image J, Version 1.43 & $\begin{array}{l}\text { Rasband, U.S. National Institutes of Health, } \\
\text { Bethesda, USA, 1997 - 2009; } \\
\text { http://rsb.info.nih.gov/ij/ }\end{array}$ \\
\hline Imaging Win Version 2.32 & Walz, Effeltrich, Deutschland \\
\hline Light Cycler 480 Real Time Software & Roche, Grenzach-Whylen, Deutschland \\
\hline Multi Analyst & Bio-Rad, Hercules, USA \\
\hline Office 2007 & Microsoft, Unterschleißheim, Deutschland \\
\hline Origin 7G & OriginLab Corp., Northampton, USA \\
\hline Photoshop Elements 2.0 & Adobe, Burligton, USA \\
\hline Statgraphics Plus 2.1 & Manugistics, Rockville, USA \\
\hline Vector NTI & Invitrogen, Darmstadt, Deutschland \\
\hline
\end{tabular}




\subsection{Methoden}

\subsubsection{Kultivierung von Arabidopsis thaliana}

Die Anzucht von Arabidopsis thaliana für die spätere Infektion mit V. longisporum erfolgte unter sterilen Bedingungen auf Wurzelmedium. Hierfür wurden die Samen zunächst oberflächensterilisiert, indem sie in einem $2 \mathrm{ml}$ Reaktionsgefäß in einer Calciumhypochlorid-Lösung (5\% Ca(OCl $)_{2}, 0,02 \%$ Triton X-100) für 15 Minuten inkubiert wurden. Nach drei Waschschritten mit sterilem Wasser wurden die einzelnen Samen mit Hilfe einer zuvor durch Autoklavieren sterilisierte Pipettenspitze auf das Medium gelegt. Zur Stratifizierung wurden die Samen 3 Tage im Dunkeln bei $4^{\circ} \mathrm{C}$ inkubiert, bevor bei $20^{\circ} \mathrm{C}, 60 \%$ relativer Luftfeuchte und einer Lichtintensität von 120 $\mu \mathrm{mol} \mathrm{m} \mathrm{m}^{-2} \mathrm{~s}^{-1}$ unter Kurztag-Bedingungen (8 Stunden Licht/16 Stunden Dunkelheit) in einem Klimaschrank (AR-75L, Percival Scientific, Perry, USA) die Keimung induziert wurde. Samen des Ökotyps Columbia und die hiervon abstammenden transgenen Linien wurden 4 Wochen vor Infektion, Samen des Ökotyps Wassilewskija sowie die hiervon abstammenden transgenen Linien 3 Wochen vor Infektion ausgelegt und kultiviert.

Zur Samenvermehrung und Basta ${ }^{\circledR}$-Selektion wurden die Samen unsteril direkt auf Erde (Typ T25, Fruhstorfer, Vechta, Deutschland) ausgelegt und nach 3tägiger Stratifizierung bei $4^{\circ} \mathrm{C}$ unter Langtag-Bedingungen (16 Stunden Licht/ 8 Stunden Dunkelheit) bei $20^{\circ} \mathrm{C}$, $60 \%$ relativer Luftfeuchte und einer Lichtintensität von $120 \mu \mathrm{mol} \mathrm{m}^{-2} \mathrm{~s}^{-1}$ kultiviert.

\subsubsection{Kultivierung von Brassica napus}

Brassica napus wurde wie A. thaliana auf Wurzelmedium vorkultiviert. Die Samen wurden sterilisiert und ausgelegt wie unter Punkt 2.2.1 beschrieben. Die Platten wurden direkt in den Klimaschrank überführt, wo die Keimlinge für 2 Wochen bei KurztagBedingungen (8 Stunden Licht/16 Stunden Dunkelheit) bei $20^{\circ} \mathrm{C}, 60 \%$ relativer Luftfeuchte und einer Lichtintensität von $120 \mu \mathrm{mol} \mathrm{m} \mathrm{m}^{-2} \mathrm{~s}^{-1}$ wuchsen, bevor sie mit $V$. longisporum infiziert, in ein Sand/Erde-Gemisch umgesetzt und unter LangtagBedingungen (16 Stunden Licht/ 8 Stunden Dunkelheit) weiterkultiviert wurden. 


\subsubsection{Kultivierung von Verticillium longisporum}

\subsubsection{Herstellung von Stammkulturen Verticillium longisporum}

Zur Herstellung von Stammkulturen von Verticillium longisporum wurden $2 \mathrm{ml}$ Aliquots einer Sporen enthaltenden Flüssigkultur des Pilzes (Konzentration: 2 x $10^{6}$ Sporen pro ml) mit steriler Glycerin-Lösung (Endkonzentration: $20 \%$ Glycerin) in einem Reaktionsgefäß vermischt, eingefroren und bei $-80^{\circ} \mathrm{C}$ gelagert.

\subsubsection{Herstellung einer Sporenlösung von Verticillium longisporum}

Zum Animpfen von Verticillium Flüssigkulturen wurden $250 \mu \mathrm{l}$ der GlycerinStammkulturen (siehe Punkt 2.2.3.1) in $250 \mathrm{ml}$ flüssiges PDB-Medium gegeben. Die Sporenlösung wurde unter leichtem horizontalen Schütteln (80 rpm, G10 Gyrotory Shaker, New Brunswick Scientific, New Brunswick, USA) bei $22^{\circ} \mathrm{C}$ im Dunkeln kultiviert (Fahleson et al. 2003). Die Sporen keimten und Pilzmyzel wuchs heran, bevor sich nach ca. 14 Tagen neue Sporen in der Kultur entwickelten. Zur Isolierung der Sporen wurden die Flüssigkulturen zunächst durch ein Haushaltssieb mit einer Maschenweite von 0,5 mm (VWR, Darmstadt, Deutschland) gegeben, wodurch das Myzel von der Sporenlösung getrennt wurde. Das Medium, welches die Sporen enthielt, wurde 10 min bei $900 \mathrm{x}$ g (Rotanta 96 R, Hettich, Tuttlingen, Deutschland) zentrifugiert. Nach dem Verwerfen des Überstandes wurden die Sporen in Leitungswasser resuspendiert und bis zu der gewünschten Konzentration verdünnt. Die Sporenkonzentration wurde mit Hilfe einer Thoma-Zählkammer (VWR, Darmstadt, Deutschland) bestimmt, indem zunächst die Sporen in den Kleinquadraten der Zählkammer am Mikroskop gezählt wurden. Anschließend wurde die Anzahl der Sporen durch das Volumen der gezählten Quadrate dividiert. Das Ergebnis wurde mit 1000 multipliziert, um die Sporenanzahl bezogen auf 1 $\mathrm{ml}$ zu erhalten.

\subsubsection{Wachstum von Verticillium longisporum im Xylemsaft von Brassica napus}

Xylemsaft von Brassica napus wurde während eines Zeitraums von 25 bis 28 dpi gewonnen wie unter Punkt 2.2.4 beschrieben. $900 \mu$ Xylemsaft wurde in $2 \mathrm{ml}$ Reaktionsgefäße gegeben, mit $100 \mu \mathrm{l}$ einer Verticillium-Sporenlösung $\left(\begin{array}{llll}1,8 & \mathrm{x} & 10^{5}\end{array}\right.$ Sporen $/ \mathrm{ml}$ ) angeimpft und 3 Tage bei $20^{\circ} \mathrm{C}$ im Dunkeln unter leichtem horizontalem Schütteln bei 80 rpm (G10 Gyrotory Shaker, New Brunswick Scientific, New Brunswick, 
USA) inkubiert. Das Experiment wurde mit dem Xylemsaft von infizierten und mit dem von mock inokulierten Pflanzen sowie mit Xylemsaft und PDB-Medium, dem $3 \mu \mathrm{M}$ Salicylsäure (Sigma, Steinheim, Deutschland) zugegeben wurde, durchgeführt. Des Weiteren wurde Xylemsaft, aus dem alle Makromoleküle größer als 3 kDa gefiltert (Filter Vivaspin 6, 3000 MWCO, Sartorius, Göttingen, Deutschland) wurden, für den Versuch verwendet. In einem weiteren Ansatz wurde die Sporenlösung in PDB-Medium gegeben, welches $15 \mu \mathrm{g} / \mathrm{ml}$ der herausgefilterten Xylemsaft-Proteine enthielt.

Nach der 3tägigen Inkubationszeit wurde das gewachsene Pilmyzel durch 20 minütige Zentrifugation bei $18000 \mathrm{x}$ g und $4^{\circ} \mathrm{C}$ von dem Xylemsaft bzw. dem PDB-Medium Pilzmaterial getrennt. Der Überstand wurde abgenommen und für weitere Analysen (Zucker, Aminosäuren) bei $-80^{\circ} \mathrm{C}$ aufbewahrt. Aus dem Pellet wurde nach dem Aufmörsern des Materials die Pilz-DNA extrahiert (siehe Punkt 2.2.12.1). Die Quantifizierung der DNA erfolgt durch quantitative Real Time PCR (siehe Punkt 2.2.12.13).

\subsubsection{Wachstum von Verticillium longisporum unter dem Einfluss von GLP3 produzierender Hefe}

Um den Einfluss von GLP3 produzierender Hefe auf das Wachstum von V. longisporum zu untersuchen, wurden die Hefezellen aus einer Vorkultur (flüssiges SD-Medium ohne Uracil mit Glucose) in selektives Expressionsmedium (flüssiges SD-Medium ohne Uracil mit Galaktose) überführt. Das Volumen des Expressionsmediums wurde so gewählt, dass die Kultur nach dem Überimpfen eine $\mathrm{OD}_{600}$ von 0,8 aufwies. Die Hefe wurde bei $25^{\circ} \mathrm{C}$ unter leichtem Schütteln im Dunkeln einige Stunden inkubiert, bis sie eine $\mathrm{OD}_{600}$ von 1,5 erreicht hatte. Die Hefezellen aus dieser Kultur wurden auf festes SD-Medium (ohne Uracil mit Galaktose) aufgebracht, indem ein sterilisierter Glastrichter mit einem Durchmesser von $6 \mathrm{~cm}$ in die Kultur eingetaucht und leicht auf das Medium gedrückt wurde. In die Mitte der Agarplatten wurde eine runde Myzelscheibe von V. longisporum mit einem Durchmesser von $2 \mathrm{~cm}$, welche einer vier Wochen alten Kultur des Pilzes auf Potato-Dextrose-Agar entnommen wurde, übertragen. Neben der GLP3 exprimierenden Hefe wurde auf zusätzlichen Platten der Einfluss von Hefe, die mit dem leeren Vektor (ohne glp3) transformiert worden war, getestet. Außerdem wurde das Wachstum von $V$. longisporum ohne Hefe-Ring untersucht. Die Platten wurden dazu bei $25^{\circ} \mathrm{C}$ im Dunkeln inkubiert und regelmäßig mit Hilfe eines Scanners (CanoScan4400F, Canon, Krefeld, 
Deutschland) dokumentiert. Zur Quantifizierung des Wachstums wurde die Fläche des Pilzmyzels auf den digitalen Bildern mit Hilfe der Software Image J gemessen.

\subsubsection{Infektion der Versuchspflanzen mit Verticillium longisporum}

Die Infektion wurde während des Pikierens der Pflanzen durchgeführt. Die zuvor unter sterilen Bedingungen heran gewachsenen Keimlinge wurden vorsichtig mit einer Pinzette aus dem Agar gezogen. Um das Eindringen des Pilzes in die Pflanze gezielt zu verbessern und somit eine gleichmäßigere Infektion zu gewährleisten, wurden die Wurzeln mit einer Schere um 1/3 gekürzt. Dann wurden die Pflanzen mit ihren Wurzeln 5 Minuten in eine Sporenlösung mit einer Konzentration von 2 × $10^{6}$ Sporen $/ \mathrm{ml}$ (siehe Punkt 2.2.3.2) getaucht, so dass die Wurzeln mit der Sporenlösung benetzt waren. Anschließend wurden die Pflanzen in Töpfe ( 7 × 7 × $8 \mathrm{~cm}$ für A. thaliana, 11 × 11 × $12 \mathrm{~cm}$ für Raps) mit Erde ( $A$. thaliana) bzw. in ein Gemisch aus $50 \%$ Erde und $50 \%$ Sand (v/v) (Raps) überführt, indem die Wurzeln mit $10 \mathrm{ml}$ der Sporenlösung vorbereitete Pflanzlöcher gespült wurden. Die Sporenanzahl pro Topf betrug somit $2 \times 10^{7}$. Für die Kontrollpflanzen wurde statt der Sporenlösung Leitungswasser verwendet.

Die Pflanzen wurden nach Inokulation bei $20^{\circ} \mathrm{C}, 60 \%$ relativer Luftfeuchte und einer Lichtintensität von $120 \mu \mathrm{mol} \mathrm{m} \mathrm{m}^{-2} \mathrm{~s}^{-1}$ weiter kultiviert. Bei A. thaliana handelte es sich hierbei um Kurztag-Bedingungen (8 Stunden Licht/16 Stunden Dunkelheit), während Raps unter Langtag-Bedingungen (16 Stunden Licht/8 Stunden Dunkelheit) wuchs.

\subsubsection{Gewinnung von Xylemsaft aus Brassica napus Pflanzen}

Der Xylemsaft wurde mit Hilfe einer Scholander-Bombe gewonnen (Scholander 1965; Kruse et al. 2003). Dafür wurden die Wurzeln der Pflanzen zunächst 1 - 2 Minuten unter Leitungswasser ausgewaschen, um sie von Sand und Erde zu befreien. Anschließend wurden Wurzel und Spross jeder Pflanze oberhalb des Hypokotyls mit einer Rasierklinge voneinander getrennt. Die Schnittfläche wurde mit destilliertem $\mathrm{H}_{2} \mathrm{O}$ abgespült. Die Pflanzenwurzel wurde locker in Aluminiumfolie eingehüllt und in den Zylinder der Druckbombe gehängt. Wenn die Kammer gut verschlossen und abgedichtet war, wurde der Druck in der Kammer langsam bis auf 2 bar erhöht. Der austretende Xylemsaft wurde abgenommen und über einen Zeitraum von 15 Minuten in einem sterilen Reaktionsgefäß auf Eis gesammelt, dann in flüssigem Stickstoff eingefroren und bis zur weiteren Verwendung bei $-80^{\circ} \mathrm{C}$ gelagert. 


\subsubsection{Messung der Blattfläche von Arabidopsis thaliana}

Um die Fläche der Blattrosetten von A. thaliana zu quantifizieren, wurde wöchentlich die Blattfläche der Pflanzen gemessen. Hierfür wurden die Pflanzen mit einer Digitalkamera von oben fotografiert (Coolpix S4, Nikon, Düsseldorf, Deutschland). Die digitalen Bilder wurden mit einer speziell für diesen Zweck entwickelten Software (DatInf GmbH, Tübingen, Deutschland) analysiert. Die Software nimmt alle Pixel des Fotos eines zuvor gewählten Farbtons sowie bestimmter Helligkeit und Sättigung auf. So lässt sich die grüne Blattfläche von dem Hintergrund unterscheiden und anhand eines Maßstabs (Topfgröße) messen.

\subsubsection{Ermittlung der Biomasse von Arabidopsis thaliana}

Für die Bestimmung der frischen Biomasse wurde die Blattrosette direkt über der Erde mit einer Rasierklinge abgeschnitten und gewogen.

\subsubsection{Messung der Chlorophyllfluoreszenz}

Lichtenergie, die auf die Chlorophyllmoleküle in Photosystem I (PS I) und Photosystem II (PS II) trifft, kann im Bereich der Wellenlänge von 380 bis $700 \mathrm{~nm}$ (PAR = Photosynthetic Active Radiation) für die Photosynthese genutzt werden. Ein Teil der absorbierten Energie geht jedoch in Form von Wärme verloren oder wird als Fluoreszenz wieder emittiert. Dabei korreliert die Chlorophyll-Fluoreszenz negativ mit der Photosyntheserate (Maxwell \& Johnson 2000). Anhand der Chlorophyll-Fluoreszenz können daher Rückschlüsse über die Photosyntheseleistung gezogen werden. Die Messung der Chlorophyllfluoreszenz kann auch zur Detektion von biotischem oder abiotischem Stress verwendet werden (Maxwell \& Johnson 2000).

Bei der Messung der maximalen Fluoreszenz mit einem IMAGING PAM (Walz, Effeltrich, Deutschland) wird ein 3 us andauernder, starker Lichtimpuls auf die Blattrosette appliziert. Dadurch sind die Photosysteme für einen kurzen Moment lichtgesättigt. Die weiter auftreffende Energie kann nicht mehr photosynthetisch genutzt werden, so dass die gesamte Energie in Form von Fluoreszenz emittiert wird. Aus der Differenz der maximalen Fluoreszenz $\mathrm{F}_{\mathrm{m}}$, die kurz nach dem Lichtblitz gemessen wird, und der Grundfluoreszenz im Dunkeln $\mathrm{F}_{0}$ lässt sich die variable Fluoreszenz $\left(\mathrm{F}_{\mathrm{v}}=\right.$ 
$\left.\mathrm{F}_{\mathrm{m}}-\mathrm{F}_{0}\right)$ sowie die maximale photosynthetische Aktivität, die auch als maximale Quantenausbeute vom Photosystem II oder kurz als „,Yield“ bezeichnet wird, berechnen:

Gleichung $1 \Phi(\max )=\left(F_{m}-F_{0}\right) / F_{m}=F_{v} / F_{m}$

(Kitajima \& Butler 1975, Roháček 2002)

Im Licht ist die Grundfluoreszenz größer, die maximale Fluoreszenz aufgrund der aktiven Photosynthese kleiner, die Differenz zwischen den Werten daher auch geringer. Die Quantenausbeute nimmt also in der Regel mit zunehmender Lichtintensität ab. Die Fluoreszenzwerte werden dann als $\mathrm{F}_{0}^{\prime}$ (Grundfluoreszenz) und $\mathrm{F}_{\mathrm{m}}^{\prime}$ (maximale Fluoreszenz) bezeichnet, mit denen sich analog zur Gleichung 1 die aktuelle Quantenausbeute ermitteln lässt:

Gleichung $2 \Phi($ aktuell $)=\left(\mathrm{F}_{\mathrm{m}}^{\prime}-\mathrm{F}^{\prime}{ }_{0}\right) / \mathrm{F}_{\mathrm{m}}$ (Maxwell \& Johnson 2000)

In dieser Arbeit wurde die aktuelle und die maximale Quantenausbeute von infizierten und nicht infizierten Pflanzen anhand von Lichtkurven miteinander verglichen. Für die Erstellung von Lichtkurven wurde die Chlorophyllfluoreszenz bei Lichtintensitäten von 0, 20, 50, 100, 500 und $1000 \mu \mathrm{mol} \mathrm{m} \mathrm{m}^{-2}$ gemessen. Die Messungen wurden im Abstand von 5 Minuten durchgeführt, um eine Adaption der Pflanzen an die veränderten Lichtverhältnisse zu gewährleisten. Neben der Illustration anhand von Falschfarbenbildern, bei denen die Chlorophyllfluoreszenz der gesamten Rosette abgebildet wurde, wurde die mittlere Quantenausbeute (Yield) gegen die Lichtintensität aufgetragen und so als Kurve dargestellt.

\subsubsection{Bestimmung des Pigmentgehaltes}

Zur Bestimmung des Chlorophyll- und des Carotinoidgehaltes wurde das gefrorene Material gemahlen (Kugelmühle Typ MM 2, Retsch, Haan, Deutschland). 50 bis $60 \mathrm{mg}$ Blattpulver wurden in Reagenzgläser eingewogen, mit je $4 \mathrm{ml} 80$ \% (v/v) Acetonlösung versetzt, 30 Sekunden gemischt (Heidolph Reax 2000, Schwabach, Deutschland) und nach einer Inkubationszeit von 20 Minuten im Dunkeln auf Eis 10 Minuten bei $4500 \mathrm{x}$ g und 
$4^{\circ} \mathrm{C}$ zentrifugiert (Hettich Rotanta $96 \mathrm{R}$, Tuttlingen, Deutschland). Der Überstand wurde in 1,6 ml Halbmikroküvetten aus Polystyrol (Sarstedt, Nürnbrecht, Deutschland) überführt. Die Absorption wurde bei den Wellenlängen $\lambda=663 \mathrm{~nm}$ für Chlorophyll a, $\lambda=646 \mathrm{~nm}$ für Chlorophyll $\mathrm{b}$ und $\lambda=470 \mathrm{~nm}$ für die Carotinoide photometrisch (Beckman DU 640, Fullerton, USA) bestimmt. Als Leerwert diente $80 \%$ (v/v) Aceton. Um methodische Fehler auszuschließen, wurden drei technische Wiederholungen pro Probe durchgeführt.

Die Konzentrationen der Pigmente wurden mittels der Gleichungen 3 bis 6 mit den Extinktionskoeffizienten von Lichtenthaler \& Wellburn (1983) berechnet:

Gleichung 3 Chlorophyll a $[\mu \mathrm{g} / \mathrm{ml}]=12,21 \cdot \mathrm{A}_{663}-2,81 \cdot \mathrm{A}_{646}$

Gleichung 4 Chlorophyll $\mathrm{b}[\mu \mathrm{g} / \mathrm{ml}]=20,13 \cdot \mathrm{A}_{646}-5,03 \cdot \mathrm{A}_{663}$

Gleichung 5 Carotinoide $[\mu \mathrm{g} / \mathrm{ml}]=\left(1000 \cdot \mathrm{A}_{470}-3,27 \cdot \mathrm{Chl} \mathrm{a}-104 \cdot \mathrm{Chl} \mathrm{b}\right) / 229$

Um die Pigmentmenge pro g Frischmasse zu bestimmen, müssen Extraktvolumen und die genaue Einwaage des Blattpulvers berücksichtigt werden:

Gleichung 6 Pigmentgehalt $[\mu \mathrm{g} / \mathrm{g}$ Frischmasse $]=$ Pigment $[\mu \mathrm{g} / \mathrm{ml}$ Extrakt $] \cdot \mathrm{V}_{\mathrm{e}}[\mathrm{ml}] / \mathrm{FM}[\mathrm{g}]$

$\mathrm{A}_{\mathrm{x}}=$ Absorption bei der Wellenlänge $\mathrm{x}$

Chl a $=$ Konzentration an Chlorophyll a $[\mu \mathrm{g} / \mathrm{ml}$ Extrakt $]$

$\mathrm{Chl} \mathrm{b}=$ Konzentration an Chlorophyll $\mathrm{b}[\mu \mathrm{g} / \mathrm{ml}$ Extrakt $]$

Carotinoide $=$ Konzentration der Carotinoide $[\mu \mathrm{g} / \mathrm{ml}$ Extrakt $]$

$\mathrm{V}_{\mathrm{e}} \quad=$ Extraktvolumen [ml]

FM = eingewogene Frischmasse $[\mathrm{g}]$

\subsubsection{Elementanalyse durch Optische Emissionsspektrometrie mit einem induktiv gekoppelten Plasma}

Die Bestimmung der Konzentration verschiedener Elemente im Myzel von V. longisporum sowie im Xylemsaft aus Raps-Pflanzen erfolgte durch Optische Emissionsspektrometrie mit einem induktiv gekoppelten Plasma (Inductively Coupled Plasma - Optical Emission 
Spectrometry, ICP-OES; Spectroflame, Spectro Analytical Instruments, Kleve, Deutschland). Um die Elemente aus dem Pilz-Myzel zu messen, wurden die Proben mittels Druckaufschluss vorbereitet. Hierbei wurden $50 \mathrm{mg}$ des getrockneten Materials mit $2 \mathrm{ml}$ einer $65 \%$ igen $\mathrm{HNO}_{3}$-Lösung versetzt und in einem Trockenschrank 12 Stunden bei $137^{\circ} \mathrm{C}$ inkubiert. Die abgekühlten Proben wurden mit destilliertem Wasser auf $50 \mathrm{ml}$ aufgefüllt. Der Xylemsaft wurde ohne weitere Vorbereitung für die Messung benutzt.

Während der ICP-OES wird die Probe atomisiert, gleichzeitig in einen angeregten Zustand versetzt und ionisiert. Diese Vorgänge finden in mehrere Tausend Kelvin heißem ArgonPlasma statt, d.h. in einem ionisierten Gas, in dem sich positiv geladene Argon-Ionen und negativ geladene Elektronen durch ein angelegtes elektromagnetisches Feld gegenläufig bewegen. Die Bestandteile der zugegebenen Probe folgen der Bewegungsrichtung der anderen Ladungsträger durch die verschieden heißen Zonen des Plasmas. Ein angeschlossenes Spektrometer detektiert die dabei von der Probe emittierten Lichtquanten. Da die Wellenlänge dabei für jedes Element spezifisch ist, lassen sich Rückschlüsse über die stoffliche Zusammensetzung der Probe und Anteile der einzelnen Bestandteile ziehen.

Die Messungen wurden von der Abteilung Ökopedologie der gemäßigten Zonen im Büsgen-Institut der Universität Göttingen durchgeführt.

\subsubsection{C/N-Analyse}

Für die Bestimmung des Kohlenstoff- und des Stickstoff-Gehaltes im Myzel von $V$. longisporum wurden 650 bis $900 \mu \mathrm{g}$ des getrockneten, gemahlenen Materials in eine Zinnkapsel (HEKAtech GmbH, Wegberg, Deutschland) eingewogen (Supermicro, Sartorius, Göttingen, Deutschland) und in einem Elementanalysator (Elemental Analyser EA-1108, Carlo Erba Instruments, Rodano, Italien) gemessen. In diesem Gerät werden die Moleküle bei $1020{ }^{\circ} \mathrm{C}$ und in Anwesenheit eines Oxidationskatalysators (Chrom-III-Oxid) unter Zugabe von Sauerstoff aufgespalten und $\mathrm{zu} \mathrm{N}_{2}, \mathrm{CO}_{2}$ und $\mathrm{H}_{2} \mathrm{O}$ reduziert, während im Verbrennungsrohr befindliches reduziertes Kupfer oxidiert wird. Die entstandenen Verbindungen werden anschließend chromatographisch aufgetrennt. An die Säule angeschlossen ist ein Wärmeleitfähigkeitsdetektor, der elektrische Signale an einen Integrator weiterleitet. Die durchlaufenden Elemente verändern die Temperatur und somit die Leitfähigkeit dieses Detektors, was sich auch in den abgegebenen Signalen widerspiegelt. Durch Integration der Flächen unter den aufgezeichneten Kurven konnte die 
Gesamtkonzentration der Elemente Stickstoff und Kohlenstoff in der Probe berechnet werden. Als Standard diente Acetanilid $\left(\mathrm{C}_{8} \mathrm{H}_{9} \mathrm{NO}\right.$, HEKAtech $\mathrm{GmbH}$, Wegberg, Deutschland).

\subsubsection{Molekularbiologische Methoden}

\subsubsection{Extraktion pflanzlicher und pilzlicher genomischer DNA}

Für die Extraktion genomischer DNA wurden in dieser Arbeit zwei unterschiedliche Methoden verwendet.

Die DNA-Extraktion von gemahlenen Proben von A. thaliana Pflanzen für die spätere Messung der Verticilliium-DNA erfolgte mittels quantitativer Real Time PCR (siehe Punkt 2.2.12.13) mit dem DNeasy Plant Mini Kit (Qiagen, Hilden, Germany) nach den Anweisungen des Herstellers.

Für die DNA-Extraktion aller anderen Proben wurde die Methode von Schneidereit (2005, abgewandelt nach Aitchitt et al. 1993) verwendet. Hierbei wurden zwischen 100 und 200 mg des gefrorenen Pflanzenmaterial bzw. das Pilzmyzel nach dem Mahlen mit $400 \mu 1$ Extraktionspuffer (200 mM Tris-HCl, pH 7,5, $250 \mathrm{mM} \mathrm{NaCl}, 25 \mathrm{mM}$ EDTA, 0,5 \% (v/v) SDS) versetzt. Nach gründlichem Durchmischen wurden die Proben für 3 Minuten bei 20000 x g zentrifugiert (5417 R, Eppendorf, Hamburg, Deutschland). $300 \mu 1$ des Überstands wurden in ein neues 1,5 ml Reaktionsgefäß überführt. Nach Zugabe von $300 \mu 1$ Isopropanol wurden die Proben einige Male invertiert und anschließend 2 Minuten bei RT inkubiert. Nach einem weiteren Zentrifugationsschritt bei 20000 x g für 5 Minuten wurde der Überstand vollständig abgenommen und das Pellet unter Vakuum für 5 Minuten bei 37 ${ }^{\circ} \mathrm{C}$ (Eppendorf Concentrator 5301) getrocknet. Die DNA wurde in der Regel in $100 \mu 1 \mathrm{TE}-$ Puffer (10 mM Tris-HCl, pH 7,5, 1 mM EDTA) resuspendiert. Nur die aus V. longisporum extrahierte DNA, die mittels qRT-PCR quantifiziert werden sollte (siehe Punkt 2.2.12.13), wurde in destilliertem Wasser gelöst. Alle Proben wurden bis zur weiteren Bearbeitung bei $-20^{\circ} \mathrm{C}$ gelagert.

\subsubsection{Extraktion von Plasmid-DNA}

Zur Isolation von Plasmid-DNA aus E. coli wurde das QIAprep Spin Miniprep Kit (Qiagen, Hilden, Deutschland) verwendet. Die Zellen werden bei dieser Methode basierend auf dem Prinzip der alkalischen Lyse (Le Gouill et al. 1994) aufgeschlossen. 
Anschließend wird die DNA in mehreren Schritten über eine DNA-affine Säule konzentriert und gesäubert, bevor sie eluiert wird. Die Ausbeute an DNA lag mit dieser Methode unter Verwendung einer $5 \mathrm{ml}$ Übernachtkultur bei etwa 200 - 400 ng/ $\mu 1$ DNA.

\subsubsection{Konzentrationsmessung von Nukleinsäuren}

Die Konzentration von Nukleinsäuren (DNA und RNA) wurden mit Hilfe eines Photometers (Bio Photometer, Eppendorf, Hamburg, Deutschland) bestimmt. Nach der Eichung des Geräts auf die Absorption von Wasser wurde die 1:50 mit Wasser verdünnte Probe bei einer Wellenlänge von $\lambda=260 \mathrm{~nm}$ gemessen. Eine optische Dichte (optical density $=$ OD) von 1,0 entspricht hierbei einer Nukleinsäurekonzentration von $50 \mu \mathrm{g} / \mathrm{ml}$ $\mathrm{H}_{2} \mathrm{O}$ für doppelsträngige DNA, $33 \mu \mathrm{g} / \mathrm{ml} \mathrm{H}_{2} \mathrm{O}$ für einzelsträngige DNA sowie $40 \mu \mathrm{g} / \mathrm{ml}$ $\mathrm{H}_{2} \mathrm{O}$ für RNA. Da die aromatischen Seitenketten einiger Aminosäuren bei einer Wellenlänge von $\lambda=280 \mathrm{~nm}$ ihr Absorptionsmaximum haben, kann durch eine zusätzliche Messung der Absorption bei dieser Wellenlänge und anschließender Bildung des Quotienten $\mathrm{OD}_{260} / \mathrm{OD}_{280}$ zudem eine Aussage über die Reinheit der Probe getroffen werden. Bei sauberen DNA-Extrakten liegt der Wert zwischen 1,8 und 2,0. Bei Messungen der RNA-Konzentration sollte der Wert für $\mathrm{OD}_{260} / \mathrm{OD}_{280}$ größer als 2 sein.

Für die Messung der Nukleinsäuren wurden $2 \mu 1$ der Probe in $98 \mu 1$ steriles, destilliertes Wasser gegeben. Nur Proben, bei denen die Reinheit durch Bestimmung des Quotienten $\mathrm{OD}_{260} / \mathrm{OD}_{280}$ nachgewiesen werden konnte, wurden weiter verwendet.

\subsubsection{Polymerase-Kettenreaktion (PCR)}

Die Polymerase-Kettenreaktion $($ Polymerase Chain Reaction $=$ PCR) ist eine Methode, mit der DNA-Fragmente in vitro amplifiziert werden können (Mullis \& Faloona 1987). Bei dieser Methode wird eine thermostabile DNA-Polymerase (taq-Polymerase) eingesetzt, die einzelsträngige DNA zu einem Doppelstrang verlängern kann, wenn ein kurzer doppelsträngiger Startbereich vorliegt. Die Startpunkte werden durch Zugabe bestimmter Oligonukleotide, sogenannter Primer, definiert, welche mit der einzelsträngigen DNAMatrize hybridisieren. Die Zusammensetzung für eine PCR-Reaktion ist der Tabelle $8 \mathrm{zu}$ entnehmen. 
Tabelle 8: Allgemeiner Ansatz für eine PCR. Bei der Taq-Polymerase, dem zugehörigen PCR-Puffer, $\mathrm{MgCl}_{2}$ sowie den dNTPs handelt es sich um Produkte der Firma Fermentas (St. Leon-Rot, Deutschland).

\begin{tabular}{|l|l|l|}
\hline Substanz & Volumen $[\boldsymbol{\mu}]$ ] & $\begin{array}{l}\text { Konzentration der } \\
\text { Stammlösungen }\end{array}$ \\
\hline PCR-Puffer & 2,5 & $10 \mathrm{x}$ \\
\hline dNTP-Mix & 0,5 & $100 \mathrm{mM}$ \\
\hline $\mathrm{MgCl}_{2}$ & 2,0 & $25 \mathrm{mM}$ \\
\hline Primer 1 & 1,0 & $10 \mathrm{pmol} / \mu 1$ \\
\hline Primer 2 & 1,0 & $10 \mathrm{pmol} / \mu 1$ \\
\hline Taq-Polymerase rec. & 0,5 & $5 \mathrm{u} / \mu 1$ \\
\hline $\mathrm{H}_{2} \mathrm{O}$ & 16,5 & \\
\hline DNA/Probe & 1,0 & $300-500 \mathrm{ng} / \mu 1$ \\
\hline Gesamt & $\mathbf{2 5 , 0}$ & \\
\hline
\end{tabular}

Für die Amplifizierung der DNA werden die beiden Stränge der DNA zunächst durch Erhitzen voneinander getrennt (Denaturierung). Während einer kurzen Abkühlungsphase lagern sich die Primer an den codierenden oder codogenen Strang des aufgeschmolzenen DNA-Fragmentes (Annealing). Anschließend werden durch die Taq-Polymerase komplementäre desoxy-Nukleotidtriphosphate (dNTPs) an die Primer gehängt, was zu einer Verlängerung des neuen DNA-Stücks in 3'-Richtung führt (Elongation). Durch mehrfache Wiederholung dieser Schritte (Zyklus) wird die vorhandene DNA vervielfältigt. In der Regel wurde die DNA durch folgendes PCR-Programm amplifiziert:

1. Initiale Denaturierung: $1 \min$ bei $93^{\circ} \mathrm{C}$

2. Denaturierung: $30 \mathrm{~s}$ bei $93^{\circ} \mathrm{C}$

3. Primer-Annealing: $30 \mathrm{~s}$ bei $\mathrm{T}_{\mathrm{m}}-3^{\circ} \mathrm{C}$

4. Elongation: $30 \mathrm{~s}$ bei $72^{\circ} \mathrm{C}$

5. Finale Elongation: $1 \mathrm{~min}$ bei $72^{\circ} \mathrm{C}$

6. Hold $4^{\circ} \mathrm{C}$

Der Ablauf des PCR-Programms muss bei jeder PCR überprüft werden, da die AnnealingTemperatur und die Elongationszeit angepasst werden müssen. 
Die Annealing-Temperatur ist abhängig von den benutzten Primern und ist deshalb variabel. Im Allgemeinen ist sie $3^{\circ} \mathrm{C}$ geringer als die Schmelztemperatur $\mathrm{T}_{\mathrm{m}}$. Diese ist definiert als die Temperatur, bei der 50\% des Primer-DNA-Komplexes dissoziiert sind. Ist die Annealing-Temperatur zu hoch, kann der Primer nicht an die DNA binden, wodurch die Amplifizierung inhibiert wird. Bei einer zu geringen Annealing-Temperatur kommt es $\mathrm{zu}$ unspezifischen Hybridisierungen und somit $\mathrm{zu}$ unspezifischen Produkten. Bei der Berechnung der Schmelztemperatur spielt die Länge des Primers und das Verhältnis der Nukleobasen Guanin und Cytosin zu Adenin und Thymin eine Rolle: Guanin und Cytosin sind über 3 Wasserstoffbrücken verbunden, Adenin und Thymin nur durch 2. Daher nimmt die Schmelztemperatur mit einem steigenden Anteil an Guanin und Cytosin zu. Die Annealing-Temperatur kann mit folgender Formel berechnet werden:

$\mathrm{T} \mathrm{m}\left[{ }^{\circ} \mathrm{C}\right]=69,3+0,41 \times(\% \mathrm{GC})-650 / \mathrm{n}$ (Bolton \& McCarthy 1962)

Die Elongationszeit ist abhängig von der Länge des zu vervielfältigenden DNA-Stückes und der Effizienz der benutzten Polymerase. In der Regel werden 1000 desoxyNukleotidtriphosphate pro Minute durch die Polymerase angehängt. Daher reicht für die meisten PCRs eine Elongationszeit von 20-30 Sekunden aus. Für die Isolierung von cDNAs oder Promotern für die anschließende Klonierung wird die Zeit verlängert, da DNA-Fragmente von mehreren Kilobasen amplifiziert werden. Die Temperatur während der Denaturierung und der Elongation ist ebenfalls abhängig von der verwendeten Polymerase und ist den Angaben des Herstellers des Enzyms zu entnehmen.

Bei der PCR zur Selektion von homozygoten T-DNA-Insertionslinien (siehe Punkt 2.2.12.5) sowie bei der Kontroll-PCR nach dem Verdau von genomischer DNA in RNAExtrakten (siehe Punkt 2.2.12.11) wurde mit einer Annealing-Temperatur von $57^{\circ} \mathrm{C}$ gearbeitet. Die PCR für die Isolierung von glp3 für die Klonierung (siehe Punkt 2.2.12.17) lief mit einer Annealing-Temperatur von $49^{\circ} \mathrm{C}$ für die ersten fünf Zyklen, während der restlichen Zyklen wurde die Annealing-Temperatur auf $70^{\circ} \mathrm{C}$ erhöht. Abweichend vom oben angegebenen Programm wurde hierbei auch die Elongationszeit auf 1,5 Minuten verlängert.

\subsubsection{Selektion homozygoter T-DNA-Insertionslinien mittels PCR}

Die T-DNA-Insertionslinien (Herkunft siehe Tabelle 2) wurden auf Erde unter Langtagbedingungen angezogen. Zur Selektion von homozygoten Pflanzen der 
verwendeten T-DNA-Insertionslinien wurden nach der Extraktion genomischer DNA (siehe Punkt 2.2.12.1) zwei PCR-Reaktionen mit unterschiedlichen Primer-Kombinationen durchgeführt. Für den ersten PCR-Ansatz wurden genspezifische Primer verwendet, die rechts (RP) und links (LP) von der T-DNA Insertionsstelle binden. War die untersuchte Pflanze heterozygot oder Wildtyp, so wurde bei der PCR ein Amplikon um 1000 bp produziert. War die Insertion homozygot, entstand bei der PCR dagegen kein Produkt. In der zweiten PCR-Reaktion wurde der RP Primer mit einem weiteren Primer kombiniert, der mit der inserierten T-DNA hybridisiert, so dass die entsprechende Sequenz nur amplifiziert wird, wenn die getestete Pflanze homozygot oder heterozygot ist.

Die für die verschiedenen T-DNA Insertionslinien spezifischen RP- und LP-Primer wurden mit Hilfe des Primerdesign-Tools der SIGnAL-Webpage (http://signal.salk.edu/tdnaprimers.2.html) konzipiert und sind in der Tabelle 5 aufgelistet. Welcher Primer für die T-DNA verwendet wurde, ist abhängig von der jeweiligen Linie. Für alle SALK-Linien wurde der Primer LBb1 verwendet. Da die FLAG-Linien mit einem anderen Plasmid transformiert worden sind, müssen für diese Linien andere Primer, nämlich RB4 oder Tag3 (Right Border) bzw. LB4 oder Tag5 (Left Border), verwendet werden (siehe Tabelle 5).

\subsubsection{Agarose-Gelelektrophorese von DNA-Molekülen}

Die Agarose-Gelelektrophorese dient der Auftrennung von DNA-Molekülen nach ihrer Größe (McDonell et al. 1977, Southern 1979). Da das Zucker-Phosphat-Rückgrat von DNA negativ geladen ist, wandern diese im elektrischen Feld in Richtung der Anode. Je kleiner die DNA-Fragmente sind, desto schneller bewegen sie sich im elektrischen Feld vorwärts. Als Gelmatrix dient Agarose (Agarose Seakem LE, Cambrex, Rockland, USA), ein gelierfähiges Polysaccharid. Die Agarosekonzentration beeinflusst die Porengröße: je höher die Agarosekonzentration, desto kleiner die Poren, desto besser werden kleine Moleküle aufgetrennt. Zur Auftrennung großer DNA-Fragmente (z. B. Plasmide) wurde in dieser Arbeit daher ein 1\%iges Gel benutzt, während kleine DNA-Moleküle (z.B. PCRProdukte) in höherprozentigen Gelen separiert wurden. Als Lösungsmittel für die Agarose sowie als Laufpuffer diente 1 x TBE-Puffer ( $89 \mathrm{mM}$ Tris ultra, $89 \mathrm{mM}$ Borsäure, $2 \mathrm{mM}$ EDTA; pH 8,0-8,3). 
Für ein Gel wurde die entsprechende Menge Agarose in TBE-Puffer in einer Mikrowelle bei 600 Watt so lange erwärmt, bis sie gelöst war. Die Lösung wurde mit $1 \mu 1$ Ethidiumbromid (3,8-Diamino-6-ethyl-5-phenylphenantridiumbromid) versetzt und in die vorgesehenen Gelträger gegossen. Ethidiumbromid dient der späteren Visualisierung der DNA, da es an DNA-Moleküle bindet, wodurch diese nach Anregung mit ultraviolettem Licht fluoreszieren.

Das polymerisierte Gel wurde in einer Elektrophorese-Kammer plaziert (Bio-Rad, Hercules USA) und mit den Proben beladen, welche zuvor mit Ladepuffer (57,5 \% (w/v) Glycerin, 1\% (w/v) SDS, $100 \mathrm{mM}$ EDTA, $89 \mathrm{mM}$ Tris ultra, $89 \mathrm{mM}$ Borsäure, $2 \mathrm{mM}$ EDTA, $0,01 \%(\mathrm{w} / \mathrm{v})$ Bromphenolblau) versetzt wurden. Durch den Farbstoff Bromphenolblau im Puffer konnte die Fortbewegung der Proben im Gel nachvollzogen werden. Neben den Proben wurde auch ein Marker mitgeführt, der als Größenvergleich diente, so dass die Größe der DNA-Fragmente aus den Proben abgeschätzt werden konnte (Gene Ruler, Gene Ruler Plus oder 1kbLadder von Fermentas, je nach der zu erwartenden Größe der DNA-Fragmente). Die Elektrophorese erfolgte bei $100 \mathrm{~V}$ für 20 bis 40 Minuten. Danach wurde das Gel unter UV-Licht dokumentiert (Fluor-S Multi Imager, Bio-Rad, Hercules, USA).

\subsubsection{Aufreinigung von DNA durch Gel-Extraktion}

Um verschiedene DNA-Fragmente voneinander $\mathrm{zu}$ trennen und von Primern oder Enzymen zu befreien, wurde die Probe über ein Agarose-Gel bei $100 \mathrm{~V}$ aufgetrennt (siehe Punkt 2.2.12.6). Die gewünschten Banden wurden mit Hilfe einer UV-Handlampe (Krannich, Göttingen, Deutschland) visualisiert, mit einem Skalpell ausgeschnitten und aufgereinigt (Extraction Kit 50 QIAquick, Qiagen, Hilden, Deutschland).

\subsubsection{Sequenzierung von PCR-Produkten}

Für die Sequenzierung der DNA wurde ein Verfahren verwendet, das auf dem kontrollierten Abbruch der DNA-Replikation während einer modifizierten PCR-Reaktion beruht (Sanger et al. 1977). Im Vergleich zu der üblichen PCR werden bei dieser Methode neben den desoxy-Nukleotidtriphosphaten (dNTPs) auch didesoxy-Nukleotidtriphosphate (ddNTPs), welchen die freie $3{ }^{`}-\mathrm{OH}-$ Gruppe fehlt und in die eine fluoreszierende Substanz eingebaut ist, in geringer Konzentration eingesetzt. Normalerweise werden die dNTPs von der DNA-Polymerase unter Abspaltung von zwei Phosphatgruppen jeweils an das freie 3`- 
OH-Ende des wachsenden, synthetisierten DNA-Strangs geknüpft. Wird bei dieser Synthese allerdings ein ddNTP in die Kette eingebaut, können keine weiteren Nukleotide mehr angefügt werden und die Synthese stoppt. Die ddNTPs werden daher auch als Abbruchnukleotide bezeichnet. Da dieser Kettenabbruch aus statistischen Gründen an jeder beliebigen Position des DNA-Moleküls vorkommen kann, liegen nach der Reaktion im Ansatz viele Fragmente des Matrizenstrangs vor, die sich in ihrer Länge in nur einem Nukleotid unterscheiden. Über die unterschiedliche Länge der neu entstandenen DNAStränge lässt sich die Basenabfolge nach einer gelelektrophoretischen Auftrennung ermitteln. Längenunterschiede von einem Basenpaar können aufgelöst werden.

Für eine Sequenzier-Reaktion wurden $1 \mu 1$ Big Dye Terminator und 1,5 $\mu 1$ des zugehörigen Puffers (Applied Biosystems, Foster City, USA) mit $1 \mu 1$ des Primers (10 pmol/ $\mu$ l) und 100 bis 400 ng DNA gemischt und mit $\mathrm{H}_{2} \mathrm{O}$ auf $10 \mu \mathrm{l}$ aufgefüllt. Nach einer initialen Denaturierung für 1 Minute bei $95^{\circ} \mathrm{C}$ verlief die Reaktion über 30 Zyklen mit den folgenden Bedingungen: 10 Sekunden bei $95^{\circ} \mathrm{C}$ (Denaturierung), 10 Sekunden bei $50^{\circ} \mathrm{C}$ (Primer-Annealing) und $4 \mathrm{~min}$ bei $60{ }^{\circ} \mathrm{C}$ (Elongation). Um die Ergebnisse abzusichern, werden komplementäre Sequenzen separat amplifiziert.

Nach der Sequenzierreaktion wurden die PCR-Ansätze in ein 1,5 ml Reaktionsgefäß überführt und mit 9,5 $\mu 1$ Wasser sowie $31 \mu 1$ 100\% EtOH gemischt. Anschließend wurden die Proben 1 Stunde bei RT oder mehrere Stunden bei $-20^{\circ} \mathrm{C}$ inkubiert. Danach wurden die Proben bei 18000 x g 30 min zentrifugiert (5417 R, Eppendorf, Hamburg, Deutschland). Der Überstand wurde verworfen, und die Proben wurden mit $125 \mu 1 \quad 70 \%$ EtOH gewaschen. Nach einem erneuten 15minütigen Zentrifugationsschritt bei 18000 x g wurde der Überstand vollständig abgenommen. Um zu gewährleisten, dass sich kein restliches EtOH in den Proben befindet, wurden diese für 2 min bei $50^{\circ} \mathrm{C}$ auf dem Heizblock getrocknet. Das Pellet wurde in $15 \mu \mathrm{Hi}-\mathrm{Di}^{\mathrm{TM}}$ Formamide (Applied Biosystems, Foster City, USA) wieder aufgenommen und über ein Kapillargel (ABI Prism 3100 Genetic Analyser, $36 \mathrm{~cm}$ Kapillare Matrix, Pop 6, Applied Biosystems, Foster City, USA) aufgetrennt. Diese Auftrennung und die Auswertung des Kapillargels wurde in der Abteilung Forstgenetik und Forstpflanzenzüchtung des Büsgen-Instituts der Universität Göttingen durchgeführt. Die Sequenzen wurden mit Hilfe der Software Chromas Lite und Vector-NTI ausgewertet. 


\subsubsection{Extraktion pflanzlicher RNA mit Trizol}

Für die Extraktion von RNA aus Pflanzengewebe wurden ein Trizol-Extraktionspuffer sowie Chloroform verwendet. Durch die beiden Thiocyanat-Salze im Extraktionspuffer wird die Aktivität von RNAsen inhibiert, wodurch eine Degradation der RNA vermieden wird (Chomczynski \& Sacchi 1987, Chomczynski 1993).

Zur Isolation der RNA wurden $200 \mathrm{mg}$ unter Stickstoff gemörsertes Blattmaterial in einem $2 \mathrm{ml}$ Reaktionsgefäß mit 1,5 ml Trizol-Extraktionspuffer (380 ml/1 mit 0,1 M Citratlösung gesättigte Phenollösung, 0,8 M Guanidiumthiocyanat, 0,4 M Ammoniumthiocyanat, 33,4 $\mathrm{ml} / 13 \mathrm{M}$ Natrium-Acetat, $\mathrm{pH} 5,5 \%(\mathrm{v} / \mathrm{v})$ Glycerin) versehen und 5 Minuten stark geschüttelt. Danach wurden $300 \mu$ Chloroform in den Ansatz gegeben und dieser erneut 5 Minuten geschüttelt. Während der anschließenden 30minütigen Zentrifugation bei $18000 \mathrm{x}$ $\mathrm{g}$ und $4^{\circ} \mathrm{C}$ (5417 R, Eppendorf, Hamburg, Deutschland) wurden die polare und die unpolare Phase voneinander getrennt. Kleine, polare Nukleinsäuren reichern sich in der wässrigen Phase an, während unpolare Substanzen wie Chlorophyll in der Chloroformphase zu finden sind. Die genomische DNA sowie Zelltrümmer sammeln sich an der Phasengrenze als braune Platte. Um die gelöste RNA zu isolieren, wurde der Überstand aus der oberen, wässrigen Phase in ein neues steriles $2 \mathrm{ml}$ Eppendorfgefäß überführt, mit $420 \mu \mathrm{l}$ Fällungspuffer (1,2 M NaCl, 0,8 M tri-Natrium-Citrat-Dihydrat) versetzt und invertiert. Anschließend wurde die Probe mit $420 \mu 1$ Isopropanol versehen und nochmals invertiert. Nach einer 10 minütigen Inkubationszeit bei RT wurden die Proben erneut bei $4^{\circ} \mathrm{C}$ und 18000 x g 20 Minuten zentrifugiert. Das entstandene Pellet der ausgefällten RNA wurde anschließend mit $250 \mu 1$ 70\%igem Ethanol gewaschen. Nach erneuter Zentrifugation bei $4^{\circ} \mathrm{C}$ und 18000 x g für 20 Minuten wurde das Pellet von jeglichem Ethanol befreit und in $50 \mu 1$ nukleasefreiem Wasser aufgenommen. Eine längere Lagerung der RNA erfolgte bei mindestens $-20^{\circ} \mathrm{C}$.

\subsubsection{Denaturierende Agarose-Gelelektrophorese von RNA-Molekülen}

Wie DNA-Fragmente können auch RNA-Moleküle gelelektrophoretisch nach ihrer Größe aufgetrennt werden. Da RNA Sekundärstrukturen bildet, die das Laufverhalten im Gel beeinflussen können, findet die RNA im Unterschied zur DNA unter denaturierenden Bedingungen statt. Dazu wurde ein Gel aus 1,2 \% (w/v) Agarose, MEA-Puffer (0,02 M MOPS, 1 mM EDTA, 5 mM Natrium-Acetat) und 7,4 \% (v/v) Formaldehyd gegossen, 
indem zunächst die Agarose in der Mikrowelle in MEA-Puffer gelöst und nach dem Abkühlen Formaldehyd zugegeben wurde. Für ein Gel mit $0,5 \mathrm{~cm}$ breiten Taschen wurde 1 $\mu \mathrm{g}$ der aufzutragenden RNA mit Wasser auf ein Volumen von $3 \mu 1$ gebracht, mit $3 \mu \mathrm{l}$ Ladepuffer (66 \% (v/v) Formamid, 0,3 \% (v/v) Formaldehyd, $10 \%$ (v/v) 10x MEA-Puffer, $0,01 \%(\mathrm{w} / \mathrm{v})$ Bromphenolblau, 0,05 \% (w/v) Ethidiumbromid) versetzt und zur Denaturierung 10 Minuten bei $70^{\circ} \mathrm{C}$ inkubiert. Danach wurden die Proben auf Eis gekühlt, bis sie auf das Gel aufgetragen wurden. Der Marker (High Range RNA Ladder RiboRuler, Fermentas, St.-Leon-Rot, Deutschland) wurde genauso behandelt. Die Elektrophorese erfolgt bei $100 \mathrm{~V}$ für 30 bis 40 Minuten. Anschließend wurde das Gel unter UV-Licht dokumentiert (Fluor-S Multi Imager, Bio-Rad, Hercules, USA).

\subsubsection{Verdau von genomischer DNA im RNA-Extrakt}

Da es möglich ist, dass mit der RNA auch geringe Mengen genomischer DNA extrahiert werden, muss die DNA beseitigt werden, bevor die mRNA in cDNA umgeschrieben wird. Im Ansatz vorhandene genomische DNA wird in der anschließenden qRT-PCR (siehe Punkt 2.2.12.13) ebenfalls amplifiziert wird und kann somit die Ergebnisse verfälschen.

Für die Degradation der genomischen DNA wurde $1 \mu \mathrm{g}$ RNA mit $1 \mu 1$ DNAseI und der gleichen Menge des zugehörigen Puffers (Fermentas, St.-Leon-Rot, Deutschland) in einem $10 \mu \mathrm{l}$ Ansatz für 30 Minuten bei $37^{\circ} \mathrm{C}$ inkubiert. Anschließend wurde die Reaktion nach Zugabe von $50 \mathrm{mM}$ EDTA während einer 10 minütigen Inkubationszeit bei $65^{\circ} \mathrm{C}$ abgestoppt.

Im Anschluss wurde mit einer PCR verifiziert, ob die gesamte DNA in der Probe verdaut wurde. Für diese PCR wurden Primer eingesetzt, die genomische DNA von Actin amplifizieren (Act2_DNA_fw und Act2_DNA_rev, Sequenzen siehe Tabelle 5). Die PCR wurde wie unter Punkt 2.2.12.4 beschrieben durchgeführt.

\subsubsection{2 cDNA-Synthese}

Die Synthese komplementärer DNA (cDNA) aus isolierter mRNA wird durch eine Reverse Transkriptase vermittelt. Dieses Enzym bindet Desoxy-Nukleotide an einen Oligo-dTPrimer, der an das polyadenylierte Ende jeder mRNA hybridisiert. Die Menge der dabei entstehenden, komplementären cDNA ist direkt proportional zur Menge der Transkripte. Deshalb können anhand der Menge der cDNA, die mit quantitativer Real Time PCR 
gemessen werden kann, auch Rückschlüsse über die Menge der mRNA in der Probe gezogen werden.

Die cDNA-Synthese wurde mit Hilfe des First Strand cDNA Synthesis Kit (Fermentas, St.Leon-Rot, Deutschland) nach Anleitung durchgeführt. Hierbei wurde $1 \mu \mathrm{g}$ RNA zunächst 5 Minuten bei $65^{\circ} \mathrm{C}$ inkubiert. Nach Zugabe von dNTPs, RiboLockRNAse Inhibitor und Reverser Transkriptase folgte eine 60 minütige Inkubation bei $37^{\circ} \mathrm{C}$. Abschließend wurde jede Probe zum Abstoppen der Reaktion für 10 Minuten bei $70^{\circ} \mathrm{C}$ inkubiert.

\subsubsection{Quantitative Real Time PCR (qRT-PCR)}

Bei der quantitativen Real Time PCR (qRT-PCR) handelt es sich um eine modifizierte PCR, die aufgrund der Verwendung eines fluoreszierenden Farbstoffs (SYBR Green) die Quantifizierung der DNA in einer Probe ermöglicht. SYBR Green ist ein Molekül, das sequenzunspezifisch in doppelsträngige DNA eingebaut wird und dann fluoresziert. Aufgrund der Amplifizierung der DNA-Moleküle während der PCR steigt auch die Fluoreszenzintensität, welche von einer speziellen Detektionseinheit des Geräts erfasst wird. Eine korrekte Quantifizierung ist allerdings nur in der exponentiellen Phase der PCR, in der optimale Reaktionsbedingungen herrschen, möglich, denn nur dann ist die Zunahme der DNA-Moleküle proportional zu der Fluoreszenzintensität. Hierfür wird der Ct-Wert (engl. Cycle Threshold) ermittelt. Der Ct-Wert bezeichnet den Zyklus, bei dem ein Schwellenwert zu Beginn der exponentiellen Phase überschritten wird und die Fluoreszenz erstmals signifikant über die Hintergrund-Fluoreszenz ansteigt. Je mehr DNA in einer Probe vorhanden ist, desto weniger PCR-Zyklen werden benötigt, um den Ct-Wert zu erreichen. Daher können aufgrund der Messung des Ct-Wertes die DNA-Menge verschiedener Proben miteinander verglichen werden.

Da die qRT-PCR eine sehr sensitive Methode ist, werden bei der Reaktion verschiedene Kontrollen mitgeführt. Zum Einen werden 3 technische Replikate gemessen, um Ungenauigkeiten beim Pipettieren erkennen zu können. Als Negativ-Kontrolle wird Wasser statt Probe in den Ansatz gegeben, um mögliche Verunreinigungen zu detektieren. Des Weiteren muss für jede Probe ein Abgleich mit einem sogenannten Haushaltsgen durchgeführt werden. Als Haushaltsgen (Housekeeping-Gen) wird ein Gen bezeichnet, dessen Produkt für grundlegende zelluläre Funktionen gebraucht wird. Viele dieser Haushaltsgene werden konstitutiv exprimiert, weshalb deren mRNA/cDNA in allen Proben 
in der gleichen Menge vorhanden sein sollte. Die Expression mancher Haushaltsgene kann jedoch abhängig vom Zelltyp, Stadium und äußeren Einflüssen (Kultivierungsbedingungen, Infektion mit Pathogenen) schwanken. Deshalb muss für jedes Experiment erneut überprüft werden, ob die Expression des gewählten Haushaltsgens bei den gegebenen Bedingungen konstant ist (Czechowski et al. 2005, Udvardi et al. 2008). Bekannte und häufig benutzte Haushaltsgene sind beispielsweise Ubiquitin (UBQ), Actin (ACT), $\alpha$-Tubulin (TUA) oder $\beta$-Tubulin (TUB) (Czechowski et al. 2005). In dieser Arbeit wurde Ubiquitin (UBQ) als Haushaltsgen verwendet. Über die Ct-Werte des Haushaltsgens kann die Qualität bzw. die Ausbeute der cDNA nach einer Reversen Transkriptase-PCR beurteilt werden. Eine vergleichbare Ausbeute an cDNA in allen Proben ist dann gegeben, wenn der Unterschied zwischen dem größten und dem kleinsten Ct-Wert des Haushaltsgens nicht größer als 1 ist (Udvardi et al. 2008). Außerdem dient das Haushaltsgen als Vergleichsgen bei der relativen Quantifizierung.

Für die PCR wurden Mikrotiterplatten für 96 Reaktionen (96 well Platten, Roche, Grenzach-Whylen, Deutschland) verwendet. Für eine einzelne Reaktion wurden $10 \mu 12 x$ Mastermix (LightCycler ${ }^{\circledR} 480$ SYBR Green I Mastermix, Roche, Grenzach-Whylen, Deutschland), $2 \mu \mathrm{l}$ des Forward Primers, $2 \mu$ des Reverse Primers sowie $3 \mu 1$ nukleasefreies Wasser gemischt und in eine der Vertiefungen einer Mikrotiterplatte pipettiert, bevor $3 \mu \mathrm{l}$ der Proben, die nach der cDNA-Synthese 1:10 verdünnt wurden, hinzugegeben wurden. Nach dem Ansetzen aller durchzuführenden PCR-Reaktionen wurde die Platte mit einer Folie verschlossen (Roche, Grenzach-Whylen, Deutschland) und für 1 Minute bei 400 x g zentrifugiert (5430 R, Eppendorf, Hamburg, Deutschland). Die anschließende PCR-Reaktion fand im LightCycler ${ }^{\circledR} 480$ (Roche, Grenzach-Whylen, Deutschland) statt. Nach einer initialen Denaturierung für 5 min bei $95^{\circ} \mathrm{C}$ folgten 45 Zyklen mit folgenden Bedingungen: 10 Sekunden bei $95^{\circ} \mathrm{C}$ (Denaturierung), 10 Sekunden bei $57^{\circ} \mathrm{C}$ (Primer-Annealing), 20 Sekunden bei $72^{\circ} \mathrm{C}$ (Elongation).

Nach der Amplifizierung der DNA folgte zudem eine Schmelzkurvenanalyse. Hierbei wurde die Temperatur langsam $\left(0,11^{\circ} \mathrm{C} \mathrm{s}^{-1}\right)$ kontinuierlich von $65^{\circ} \mathrm{C}$ auf $97^{\circ} \mathrm{C}$ erhöht, so dass die DNA aufgeschmolzen (denaturiert) wurde. Hierbei trennt sich die doppelsträngige DNA zu zwei Einzelsträngen auf, wodurch SYBR Green nicht gebunden werden kann und die Fluoreszenz abnimmt. Die Schmelztemperatur von doppelsträngiger DNA spezifischer PCR-Produkte ist höher als die von unspezifischen Produkten oder Primerdimeren. Vor der 
Auswertung wurde daher zunächst die Schmelzkurve begutachtet. Wenn nur ein Peak und dieser bei der richtigen Temperatur zu sehen war, wurde die Probe weiter berücksichtigt. Gab es einen zweiten Peak, handelte es sich um Nebenprodukte oder Primerdimere, die Probe wurde in dem Fall nicht weiter ausgewertet, weil bei der Berechnung der DNAMenge die Nebenprodukte nicht ausgeschlossen werden können.

Für die Auswertung wurde anhand der Ct-Werte die relative Expression des Zielgens im Vergleich zu dem verwendeten Housekeeping-Gen mittels folgender Formeln (Guénin et al. 2008) berechnet:

\section{Gleichung 7:}

Relative Expression $=2^{(\mathrm{Ct} \text { Zielgen }-\mathrm{Ct} \text { Housekeeping-Gen })}$

\section{Gleichung 8:}

Relative Expression im Vergleich zur Referenz $=\underline{2^{(\mathrm{Ct} \text { Zielgen VL }-\mathrm{Ct} \text { Housekeeping-Gen VL) }}}$

$2^{\text {(Ct Zielgen Kontrolle - Ct Housekeeping-Gen Kontrolle) }}$

Die Quantifizierung der Verticillium-DNA im Pflanzenmaterial sowie im Xylemsaft erfolgte ebenfalls mittels quantitativer Real Time PCR und wurde von der AG Karlovsky durchgeführt. Nach der Extraktion der genomischen DNA (siehe Punkt 2.2.12.1) wurde die DNA-Konzentration in der Probe mit Hilfe eines Standards aus isolierter DNA von Verticillium longisporum bestimmt. Zur Amplifizierung wurden die Primer 5'cagcgaaacgcgatatgtag-3' und 5'-ggcttgtagggggtttaga-3', die spezifisch für Verticillium sp. sind, verwendet (Eynck et al. 2007, Floerl et al. 2008, 2010).

\subsubsection{Restriktionsspaltung}

Restriktionsendonukleasen (Desoxyribonukleasen) des Typs II sind bakterielle Enzyme, die Phosphodiester-Bindungen doppelsträngiger DNA spalten können. Die verschiedenen Restriktionsendonukleasen erkennen und hydrolysieren spezifische Sequenzen in DNAMolekülen. Je nach Enzym entstehen glatte DNA-Enden (,,blunt ends“) oder 5'- bzw. 3'überhängende Enden (,sticky ends“), die mit anderen Fragmenten mit komplementären Enden reassoziieren können (Smith \& Wilcox 1970, Roberts 1985). 
Mit Hilfe eines Restriktionsverdaus können DNA-Fragmente sowie Vektoren so gespalten werden, dass sie im Anschluss daran mittels Ligation gezielt mit anderen Fragmenten zusammen gefügt werden können.

Für eine Restriktionsspaltung wurden allgemein $0,5-5 \mu \mathrm{g} / \mu \mathrm{l}$ DNA, $1 \mu \mathrm{l}$ der Restriktionsendonuklease sowie $2 \mu$ des passenden Puffers (10fach konzentriert) gemischt. Der Ansatz wurde mit $\mathrm{H}_{2} \mathrm{O}$ auf $20 \mu \mathrm{l}$ aufgefüllt und inkubiert. Die optimale Inkubationszeit und -temperatur ist für jedes Enzym anders und wird vom Hersteller vorgegeben. Auch die Pufferbedingungen müssen an das jeweilige Enzym angepasst werden. Für jedes Enzym gibt es einen speziell abgestimmten Puffer, der jeweils die bestmögliche Effizienz und Spezifität der Endonuklease gewährleisten soll. Das Volumen der zugegebenen Enzymlösung sollte 10\% des Endvolumens nicht überschreiten, da die Enzyme in einer Glycerinlösung vorliegen, welche in höheren Konzentrationen die Spezifität des Enzyms für die vorgesehene Schnittstelle herabsetzen kann. Kontaminationen der DNA durch hohe Salzkonzentrationen, EDTA oder organische Lösungsmittel können sich ebenfalls negativ auf die Enzymaktivität auswirken.

Nach der Inkubation werden die Restriktionsendonukleasen durch eine Inkubation bei hohen Temperaturen inaktiviert. Auch hier sind Dauer und die genaue Temperatur abhängig von dem verwendeten Enzym und wird vom Hersteller vorgegeben. Ist eine Hitzeinaktivierung nicht möglich, muss die DNA gelelektrophoretisch von den Enzymen getrennt und aufgereinigt werden.

Die in dieser Arbeit verwendeten Restriktionsenzyme, deren Inkubationszeit und Temperatur sowie die Art der Inaktivierung sind in der Tabelle 9 aufgeführt.

Tabelle 9: Liste aller verwendeten Restriktionsenzyme mit Angaben zu den Inkubationsbedingungen und der Inaktivierung. Alle aufgeführten Enzyme wurden von der Firma Fermentas (St. Leon-Rot, Deutschland) bezogen.

\begin{tabular}{|c|c|c|}
\hline Enzym & $\begin{array}{c}\text { Bedingungen für die } \\
\text { Restriktionsspaltung }\end{array}$ & $\begin{array}{c}\text { Inaktivierung des } \\
\text { Enzyms }\end{array}$ \\
\hline Bsp1407I & $1-12$ Std. bei $37^{\circ} \mathrm{C}$ & 20 min bei $65^{\circ} \mathrm{C}$ \\
\hline HindIII & $1-12$ Std. bei $37^{\circ} \mathrm{C}$ & 20 min bei $80^{\circ} \mathrm{C}$ \\
\hline NcoI & $1-12$ Std. bei $37^{\circ} \mathrm{C}$ & 20 min bei $65^{\circ} \mathrm{C}$ \\
\hline PstI & $1-12$ Std. bei $37^{\circ} \mathrm{C}$ & Gelelektrophorese \\
\hline XhoI & $1-12$ Std. bei $37^{\circ} \mathrm{C}$ & 20 min bei $80^{\circ} \mathrm{C}$ \\
\hline
\end{tabular}




\subsubsection{Herstellung transgener Arabidopsis-Pflanzen}

Ein klassischer Weg zur Transformation von dikotylen Pflanzen ist der Agrobakterienvermittelte Gentransfer. Das gramnegative, zu den alpha-Proteobakterien zählende Bodenbakterium Agrobacterium tumefaciens tritt in der Natur als Pathogen auf und verursacht unkontrolliertes Wachstum der Pflanzenzellen und Tumorbildung. Ursache für die Infektiösität ist die Fähigkeit des Pathogens, die Pflanzenzellen umzuprogrammieren, indem sie einen durch zwei Border-Sequenzen flankierten DNA-Abschnitt in die Pflanzenzelle transportieren und dort ungerichtet in das Genom einfügen (Herrera-Estrella et al. 1992). Die für dieses Phänomen verantwortlichen Elemente sind die auf dem sogenannten Ti-Plasmid lokalisierten vir-Gene. Diese codieren für Ausschneide- und Integrationsproteine. Erstere schneiden an spezifischen Bordersequenzen der T-DNA, die dann durch letztere zufällig, d.h. an einer beliebigen Stelle in das Pflanzengenom integriert werden. Die integrierte T-DNA enthält wiederum Gene für die Synthese der Phytohormone Auxin und Cytokinin, die beim Ablesen zu einer übermäßigen Zellteilung und so zum sichtbaren Tumor führen. Des Weiteren codiert die T-DNA für Proteine der Opinsynthese und des -abbaus. Opine sind Verbindungen aus Aminosäuren mit Ketosäuren bzw. Zuckern, die von den Bakterien katabolisch genutzt werden können.

Die Eigenschaft des Bakteriums, die T-DNA in das pflanzliche Genom einzuschleusen, hat man sich für die für die gezielte Transformation von Pflanzen zunutze gemacht. Für diese gezielte Integration von Genen in das pflanzliche Genom wurde Agrobacterium tumefaciens so modifiziert, dass die für den T-DNA-Transfer notwendigen Funktionen auf zwei Plasmide aufgeteilt sind. Auf dem als Helferplasmid bezeichneten Vektor werden die zur Übertragung wichtigen vir-Gene codiert, das rekombinierte Ti-Plasmid enthält die TDNA-Bordersequenzen, die nicht mehr die Gene für die Opin-, Cytokinin- und Auxinsynthese, sondern das zu übertragende Gen sowie Resistenzgene, die wichtig für die spätere Selektion sind, einschließen. Diese Aufteilung der wichtigen Gene auf 2 Plasmide wird als binäres System bezeichnet. Der Vorteil besteht vor allem darin, dass das TiPlasmid relativ klein bleibt und so besser transformierbar und stabiler ist.

Für eine Transformation von A. thaliana muss also zunächst ein Ti-Plasmid mit den gewünschten Informationen (gewünschtes Gen/Promoter, Resistenzgene, Promoter) konstruiert werden (siehe Punkte 2.2.12.17 bis 2.2.12.20). Die Selektion und Vermehrung des Konstruktes erfolgt zu Beginn in E. coli Zellen (siehe Punkt 2.2.12.21), bevor das 
Plasmid isoliert, in A. tumefaciens Zellen transferiert (siehe Punkt 2.2.12.22) und diese für die Transformation von Pflanzen benutzt werden.

Für die Agrobakterien-vermittelte Transformation von Arabidopsis thaliana wurde in dieser Arbeit die Methode von Clough und Bent (1998) durchgeführt. Dazu wurden die Agrobakterien zunächst 3 Tage in $400 \mathrm{ml}$ selektivem YEB-Medium (siehe Punkt 2.1.9.3) auf dem Schüttler bei $200 \mathrm{rpm}$ und $28^{\circ} \mathrm{C}$ vorkultiviert. Anschließend wurden die Zellen durch Zentrifugation für 20 Minuten bei $2500 \mathrm{x}$ g und $4{ }^{\circ} \mathrm{C}$ vom Medium getrennt. Diese Zellen wurden in so viel Transformationsmedium (5 \% (w/v) Saccharose und 0,02\% (v/v) Silwet L-77 (Lehle Seeds, Round Rock, USA) resuspendiert, bis eine OD $_{600}$ von 0,8 erreicht war. Die Infloreszenzen der Pflanzen wurden für 10 bis 20 Sekunden in diese zucker- und benetzungsmittelhaltige Lösung getaucht, 16 bis 24 Stunden unter der Sterilbank inkubiert und anschließend unter Langtagbedingungen weiterkultiviert.

Durch das Abschneiden der ersten Blütenstände lässt sich die Bildung vieler sekundärer Blütenstände anregen. Dies erhöht die Ausbeute an transgenen Samen.

\subsubsection{Selektion transgener Pflanzen}

Da bei der Floral-Dip Transformation von Arabidopsis thaliana produktive Transformationsereignisse hauptsächlich in den sich entwickelnden Eizellen vorkommen (Bent 2000), entstehen zunächst nur heterozygot transgene Samen (T1), aus denen über mehrere Generationen homozygote Linien selektiert werden müssen. Eine Selektion ist aufgrund spezifischer Resistenzen des eingebrachten Vektors möglich. Die Pflanzen der T2-Generation können heterozygot oder homozygot bezüglich der integrierten T-DNA sein. Des Weiteren ist es möglich, dass diese Pflanzen die T-DNA bereits nicht mehr enthalten. Sie entsprechen somit den Wildtyp-Pflanzen. Um homozygote Pflanzen zu identifizieren, wurden mit den Samen der T2-Pflanzen Segregationsanalysen durchgeführt: wenn $100 \%$ der Samen, die von einer Pflanze der T2-Generation gewonnen wurden, resistent gegenüber dem Selektionsmarker waren, war die entsprechende Mutterpflanze homozygot und wurde weiter verwendet.

\section{Selektion transgener Pflanzen mittels Phosphinothricin}

Vektoren, die das bar-Gen tragen, vermittelt eine Resistenz gegenüber Phosphinothricin. Phosphinothricin (auch Glufosinat = L-Homoanalin-4-yl-(methyl)-phosphinsäure) inhibiert die Glutaminsynthetase. Wildtyp-Pflanzen, die mit Phosphinothricin behandelt werden, 
können Glutamat nicht mehr in Glutamin umwandeln, wodurch Ammonium in letalen Konzentration in der Pflanze akkumuliert wird. Zusammen mit dem Glutaminmangel führt dies zum Absterben der behandelten Keimlinge, während Pflanzen, die das bar-Gen als Resistenzmarker tragen, überleben (White et al. 1990).

Phosphinothricin ist in dem Herbizid Basta ${ }^{\circledR}$ enthalten. Zur Selektion wurden auf Erde gekeimte, 7-10 Tage alte Keimlinge, die 2-4 vegetative Blätter gebildet haben, mit einer 2mM Basta ${ }^{\circledR}$-Lösung, die zur besseren Benetzung 0,02 \% Silwet (Lehle Seeds, Round Rock, USA) enthält, besprüht und Licht ausgesetzt. Da es möglich ist, dass trotz Stratifizierung bei $4^{\circ} \mathrm{C}$ einige Samen verspätet keimen, wurden die Pflanzen insgesamt $3 \mathrm{x}$ im Abstand von 2-3 Tagen besprüht, um auszuschließen, das nicht resistente Pflanzen überleben.

\section{Selektion transgener Pflanzen mittels Hygromycin}

Die Selektion von Pflanzen, die mit Hygromycin-Resistenz vermittelnden Vektoren transformiert worden waren, erfolgte unter sterilen Bedingungen auf 1/4 MS-Medium, dem $40 \mu \mathrm{g} / \mathrm{ml}$ Hygromycin zugesetzt wurde. Das MS-Medium bestand aus 4,4 g/l Murashige und Skoog-Medium (Duchefa, Haarlem, Niederlande), 7,4 g/l SELECT Agar ${ }^{\circledR}$ (Invitrogen, Darmstadt, Deutschland) und 2,5 g/l Saccharose. Nach einer 3 tägigen Stratifizierung bei $4^{\circ} \mathrm{C}$ im Dunkeln wurde die Keimung während einer 6 stündigen Lichtphase bei $120 \mu \mathrm{mol} \mathrm{m} \mathrm{m}^{-2}$ und $22^{\circ} \mathrm{C}$ induziert. Es folgte eine 2 tägige Inkubation im Dunkeln, während der sich das Hypokotyl resistenter Keimlinge streckte. Anschließend wurden die Pflanzen unter Langtag-Bedingungen (16 Stunden Licht/8 Stunden Dunkelheit) weiter kultiviert.

Sowohl resistente als auch Wildtyp-Pflanzen keimten auf dem Selektionsmedium. Die nicht resistenten wuchsen jedoch schlechter als die resistenten. Nach der 2tägigen Dunkelheit waren die resistenten Keimlinge deutlich gestreckt, während die nicht resistenten kurz blieben.

\subsubsection{Herstellung eines Vektorkonstrukts für die Überexpression von glp3}

Zur Herstellung von Arabidopsis-Pflanzen, die glp3 (At5g20630) konstitutiv überexprimieren, wurde der Gateway ${ }^{\circledR}-$ Vektor $\mathrm{pE}$ verwendet.

Das Gateway®-System (Invitrogen, Darmstadt, Deutschland) basiert auf dem DNARekombinationsmechanismus des Bakteriophagen Lambda in das Genom von E.coli, bei 
dem DNA-Segmente über ortsspezifische Rekombination zwischen verschiedenen Plasmiden transferiert werden können. Für diese Rekombination sind bestimmte Erkennungssequenzen (att-sites) nötig. Um ein gewünschtes DNA-Fragment in einen Gateway ${ }^{\circledR}-$ Vektor zu klonieren, wird dieses mittels PCR mit Primern amplifiziert, die an den 5'-Enden die Erkennungssequenzen (att-sites) enthalten. Das Gateway ${ }^{\circledR}$-kompatible DNA-Segment wird über zwei Reaktionen in den Expressionsvektor transferiert. Während der sogenannten BP-Reaktion wird das PCR-Produkt in einen Eingangs-Vektor (z.B. pDONR201) eingebracht. Mittels einer LR-Reaktion wird das DNA-Fragment in den jeweiligen Ziel-Vektor (z.B. pE) transferiert.

Für die Isolierung der glp3-cDNA wurde zunächst aus pflanzlichen RNA-Extrakten die komplementäre cDNA synthetisiert. Während einer PCR wurde aus diesem Gemisch unter Zugabe der Primer Atg5g20630_FW und At5g20630_RV (Primersequenzen siehe Tabelle 5) die Gateway®-kompatible cDNA von glp3 isoliert.

Um das Produkt mittels BP-Reaktion in den Entry-Vektor pDONR201 klonieren zu können, wurde das PCR-Produkt aufgereinigt. Dazu wurden $150 \mu 1$ TE-Puffer $(\mathrm{pH} 8)$ und $100 \mu 130 \%$ PEG 8000, 30mM $\mathrm{MgCl}_{2}$ zu einem $50 \mu$ PCR-Ansatz gegeben, gut gemischt und 15 Minuten bei $10000 \mathrm{~g}$ bei RT zentrifugiert. Der Überstand wurde verworfen. Das Pellet wurde in $50 \mu 1$ TE-Puffer wieder aufgenommen und für eine BP-Reaktion weiter verwendet.

Bei der BP-Reaktion gelangt das mit attB-sites modifizierte DNA-Fragment durch das Zusammenwirken verschiedener Enzyme in den kompatiblen Donor-Vektor mit attP-sites. Durch den Integrationsvorgang werden die Sequenzen der Attachment-sites so verändert, dass die Reaktion nahezu irreversibel ist. Es entsteht ein Plasmid mit attL-sites (EntryVektor) (Hartley et al. 2000).

Für eine BP-Reaktion wurden 100 ng des PCR-Produktes $(2-10 \mu 1)$ mit $2 \mu 1$ des DonorVektors pDONR201 (150 ng/ $\mu \mathrm{l})$ und $2 \mu \mathrm{l}$ 5x BP-Clonase Reaktionspuffer auf $2 \mu \mathrm{l}$ des aliquotierten BP-Clonase-Enzymmixes (Invitrogen, Darmstadt, Deutschland) gegeben und mit TE-Puffer (10 mM Tris-HCl, pH 8, 1 mM EDTA) auf $10 \mu l$ aufgefüllt. Die Proben wurden über Nacht bei $25^{\circ} \mathrm{C}$ inkubiert.

Mit den Produkten der BP-Reaktion wurden E. coli Zellen transformiert (siehe Punkt 2.2.12.21). Positive Klone wurden nach einer Kontroll-Restriktionsspaltung mit Hilfe der Primer Seq-L1-pDON-FW und Seq-L1-pDON-RV (siehe Tabelle 5) sequenziert. War die 
Sequenz des eingefügten DNA-Fragments exakt, wurde das Plasmid mit attL-sites mittels LR-Reaktion in den Gateway-kompatiblen Destination-Vektor pE mit attR-sites kloniert.

Für eine LR-Reaktion wurden 300 ng des Eingangs-Vektors, 100 - 300 ng des ZielVektors pE, $2 \mu 1$ 5x LR-Clonase Reaktionspuffers und $2 \mu 1$ des LR-Clonase-Enzymmixes (Invitrogen, Darmstadt, Deutschland) gemischt und mit TE-Puffer (10 mM Tris-HCl, pH 8, $1 \mathrm{mM}$ EDTA) auf $10 \mu \mathrm{l}$ aufgefüllt. Die Proben wurden über Nacht bei $25^{\circ} \mathrm{C}$ inkubiert.

Mit dem entstandenen Expressions-Vektor wurde zunächst E. coli transformiert (2.2.12.21). Nach der Kanamycin-Selektion wurde A. tumefaciens mit dem Plasmid transformiert (Punkt 2.2.12.22), bevor das Plasmid mittels Floral-Dip (Punkt 2.2.12.15) in die Pflanze überführt wurde.

\subsubsection{Herstellung eines Vektorkonstrukts für die Komplementierung der T-DNA- Insertionslinie FLAG_412D02}

Um eine T-DNA-Insertionslinie zu komplementieren, wird jenes Gen wieder in die Pflanze eingebracht, dessen Expression durch die Insertion des T-DNA-Fragments beeinträchtigt oder vollständig inhibiert wird.

Für die Komplementierung der T-DNA-Insertionslinie FLAG_412D02 wurde der Vektor pGWB2 benutzt, der eine Hygromycin-Resistenz als Selektionsmarker codiert. Es handelt sich hierbei um einen Gateway-kompatiblen Destination-Vektor mit att-R Sites. Die für die Überexpressionspflanzen vorbereitete Gateway®-kompatible cDNA von glp3wird mittels einer LR-Reaktion vom Eingangs-Vektor pDONR201-glp3 in den Vektor pGWB2 gebracht. Die Methoden wurde wie unter Punkt 2.2.12.17 beschrieben durchgeführt. Das Plasmid wird nach der Vermehrung und Selektion in E. coli (2.2.12.21) und A. tumefaciens (Punkt 2.2.12.22) mittels Floral-Dip in die Pflanze transferiert.

\subsubsection{Herstellung der Vektorkonstrukte für amiRNA-Pflanzen}

Als microRNAs (miRNAs) werden einzelsträngige RNAs mit einer Länge von 19 - 24 Basenpaaren bezeichnet, die als negative Regulatoren fungieren können. Diese miRNAs entstehen aus längeren, nicht-kodierenden, doppelsträngigen RNAs, die von RNAsen der sogenannten Dicer Familie zerschnitten werden. Die entstehenden miRNAs binden an komplementäre mRNAs, die wiederum zerschnitten und abgebaut werden und so nicht mehr in ein Protein translatiert werden können (Bartel 2004, Filipowicz 2005, Chen 2005, Jones-Rhoades et al. 2006). 
Dieses natürlich in der Pflanze vorkommende Phänomen kann genutzt werden, um gezielt die Menge eines bestimmtes Transkriptes zu reduzieren. $\mathrm{Zu}$ diesem Zweck wird eine artifizielle miRNA (artificial microRNA = amiRNA) in der Pflanze überexprimiert, die an das Transkript eines Zielgens bindet. Die entstandene doppelsträngige RNA wird abgebaut. Dies führt zu einer Reduzierung der RNA-Menge des Zielgens.

Die Konstruktion geeigneter amiRNA-Sequenzen für die Reduzierung der Transkriptmenge von glp3 sowie zu deren Synthese benötigte Primer erfolgte mit Hilfe des Web microRNA-Design-Tools (www.weigelworld.org, Tabelle 10). Da die Wahrscheinlichkeit, dass ein amiRNA-Konstrukt tatsächlich zu einer Verringerung des Expressionslevels führt, ca. $75 \%$ beträgt (www.weigelworld.org), wurden zwei verschiedene Konstrukte gegen glp3 hergestellt.

Tabelle 10: amiRNA-Konstrukte und die für deren Herstellung verwendete Primer.

\begin{tabular}{|c|c|c|c|}
\hline \multicolumn{3}{|c|}{ amiRNA-Konstrukt } & \multirow{2}{*}{$\begin{array}{l}\text { Bezeichnung der für die PCR } \\
\text { verwendeten Primer } \\
\text { (Sequenzen siehe Tabelle 5) }\end{array}$} \\
\hline Bezeichnung & Konstrukt & Sequenz & \\
\hline \multirow{4}{*}{ amiRNA_GLP3_A } & \multirow{4}{*}{ A } & \multirow{4}{*}{$\begin{array}{l}\text { TATGGTA } \\
\text { GAATTTG } \\
\text { GAGCGCT }\end{array}$} & amiRNA_At5g20630_A_PrimerI \\
\hline & & & amiRNA_At5g20630_A_PrimerII \\
\hline & & & amiRNA_At5g20630_A_PrimerIII \\
\hline & & & amiRNA_At5g20630_A_PrimerIV \\
\hline \multirow{4}{*}{ amiRNA_GLP3_B } & \multirow{4}{*}{ B } & \multirow{4}{*}{$\begin{array}{l}\text { TCAAATG } \\
\text { GTAGAAT } \\
\text { TTGGGGC }\end{array}$} & amiRNA_At5g20630_B_PrimerI \\
\hline & & & amiRNA_At5g20630_B_PrimerII \\
\hline & & & amiRNA_At5g20630_B_PrimerIII \\
\hline & & & amiRNA At5g20630 B PrimerIV \\
\hline
\end{tabular}

Zur Generierung der amiRNA-Sequenzen wurden in jeweils 3 parallelen PCR-Läufen mit verschiedenen Primern Teile des Plasmids pRS300 vervielfältigt und währenddessen mutiert. Für die Reaktion (a) wurden die Primer amiRNA_GW_PrimerA und IV verwendet, während für die Reaktion (b) die Primer III und II und für die Reaktion (c) die Primer I und amiRNA_GW_PrimerB eingesetzt wurden. Die Primer A und B (siehe Tabelle 5) waren für jedes Konstrukt gleich, während die Primer I bis IV spezifisch für die einzelnen Konstrukte waren. Die PCR startete mit einer Initialen Denaturierung für 2 
Minuten bei $95^{\circ} \mathrm{C}$ und verlief anschließend über 25 Zyklen wie folgt: 30 Sekunden bei $95^{\circ} \mathrm{C}, 30$ Sekunden bei $55^{\circ} \mathrm{C}$ und 40 Sekunden bei $72^{\circ} \mathrm{C}$. Am Ende schloss ein finaler, 7 Minuten dauernder Elongationsschritt die Reaktion ab. Für die PCR wurde Pfu-DNAPolymerase (Fermentas, St. Leon-Rot, Deutschland) benutzt, die keine Korrekturfunktion aufweist und so beabsichtigte Mutationen zulässt.

Die PCR-Reaktionen (a), (b) und (c) zur Generierung der amiRNA-Konstrukte wurden wie folgt angesetzt:

$5 \mu 1$ 10x PCR Puffer

$5 \mu \mathrm{dNTPs}(2 \mathrm{mM})$

$2 \mu \mathrm{l}$ je Primer $(10 \mu \mathrm{M})$

$2 \mu 1$ Plasmid DNA (200 ng)

$0,5 \mu 1$ Pfu-DNA-Polymerase

$\underline{33,5 \mu 1 \text { Wasser }}$

$50 \mu$ l gesamt

Die Produkte der verschiedenen PCR-Reaktionen wurden mittels Gelektrophorese aufgetrennt, die Banden ausgeschnitten und die DNA aufgereinigt (siehe Punkt 2.2.12.7). Bei einer weiteren PCR wurden die zuvor erhaltenen PCR-Produkte zusammen gefügt. Nach einer initialen Denaturierung für 2 Minuten bei $95^{\circ} \mathrm{C}$ verlief die Reaktion über 25 Zyklen mit den folgenden Bedingungen: 30 Sekunden bei $95^{\circ} \mathrm{C}$ (Denaturierung), 30 Sekunden bei $55^{\circ} \mathrm{C}$ (Primer-Annealing) und 1:30 Minuten bei $72{ }^{\circ} \mathrm{C}$ (Elongation). Beendet wurde die PCR durch eine finale Elongation von 7 Minuten.

Ansatz für die PCR-Reaktion:

$5 \mu 1$ 10x PCR Puffer

$5 \mu 1 \mathrm{dNTPs}(2 \mathrm{mM})$

$2 \mu \mathrm{l}$ je Primer $(10 \mu \mathrm{M})$

$0,5 \mu 1$ PCR (a)

$0,5 \mu 1 \mathrm{PCR}(\mathrm{b})$

$0,5 \mu 1$ PCR (c)

$0,5 \mu 1$ Pfu-DNA-Polymerase

\section{$\underline{34,5 \mu 1 \text { Wasser }}$}

$50 \mu 1$ gesamt 
Erneut wurden die PCR-Produkte über ein Agarose-Gel separiert, ausgeschnitten und aufgereinigt. Die DNA-Extrakte wurden mittels BP-Reaktion in den Donor-Vektor pDONR201, anschließend durch eine LR-Reaktion in den Destination-Vektor pE kloniert (siehe Punkt 2.2.12.17). Der entstandene Expressions-Vektor wurde zunächst nach E. coli, (Punkt 2.2.12.21), dann nach A. tumefaciens (Punkt 2.2.12.22) transferiert, bevor er mittels Floral-Dip in die Pflanze überführt wurde (Punkt 2.2.12.15).

\subsubsection{Herstellung des Vektorkonstrukts für die GUS-Reporterpflanzen}

Um das Expressionsmuster eines bestimmten Gens $\mathrm{zu}$ untersuchen, können Reporterpflanzen hergestellt werden. Ein bekanntes Gen, das häufig als Reportergen benutzt wird, ist das uidA-Gen aus E.coli, welches für die ß-Glucuronidase (GUS) kodiert. Wird vor dieses Gen der Promoter des Zielgens kloniert, so kann mit Hilfe der Aktivitätsmessung des GUS-Enzyms die Induktion des vorgeschalteten Promoters nachgewiesen werden.

Für die Herstellung des Promoter(glp3)::GUS-Konstruktes wurde das gesamte, 3363 bp große DNA-Stück, das zwischen dem ATG des glp3-Gens und dem Stopcodon des in 5'Richtung folgenden Gens liegt, aus einem Gemisch genomischer DNA aus ColumbiaWildtyp-Pflanzen isoliert. Da der Promoter mittels klassischer Ligation mit Hilfe der Restriktionsendonukleasen NcoI und PstI in den Vektor pCAMBIA1391Z transferiert werden sollte, wurden während der PCR die Basenabfolge ctgcag an das 5'-Ende und ccatgg an das 3'-Ende der Sequenz gehängt (Primer PstI-PromoterGLP3_fw und NcoIPromoterGLP3_rev, Sequenzen siehe Tabelle 5). Das PCR-Produkt wurde über ein Gel aufgetrennt, die Banden ausgeschnitten und aufgereinigt (siehe Punkt 2.2.12.7). Sowohl der über PCR amplifizierte Promoter als auch der Vektor pCAMBIA1391Z wurden mit PstI und NcoI während einer 2stündigen Inkubation bei $37^{\circ} \mathrm{C}$ gespalten. Anschließend wurden die Restriktionsenzyme für 20 min bei $75^{\circ} \mathrm{C}$ inaktiviert. Der verdaute Promoter und die Vektor-Fragmente wurden für einen Ligationsansatz verwendet.

Bei einer Ligation werden DNA-Fragmente, die zuvor durch Restriktionsendonukleasen gespalten worden sind und komplementäre Enden besitzen, miteinander verknüpft. Für diese Reassoziierung wird das Enzym T4-DNA-Ligase verwendet, welches in Anwesenheit von ATP die Bildung einer Phosphodiesterbindung zwischen der 3'-OH- 
Gruppe am Ende eines DNA-Stranges und der 5'-Phosphatgruppe am Ende eines anderen katalysiert.

\section{Ligationsansatz:}

Einzufügende DNA (Insert)

$20-100 \mathrm{ng}$

Linearisiertes Vektor-Fragment

$50-500 \mathrm{ng}$

T4-DNA-Ligase 10x-Puffer (Fermentas)

$2 \mu 1$

ATP

$2 \mu 1$

T4-DNA-Ligase (Fermentas)

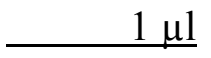

mit $\mathrm{H}_{2} \mathrm{O}$ auffüllen auf $20 \mu 1$

Nach einer Inkubation von 4 Stunden bei $22^{\circ} \mathrm{C}$ wurden E. coli Zellen mit den Produkten transformiert (Punkt 2.2.12.21). Zusätzlich zu der Selektion mittels Antibiotika, mit der nach einer Transformation ausgeschlossen wurde, dass E. coli - Zellen wachsen, die kein Plasmid aufgenommen haben, wurde eine Blau-Weiß-Selektion durchgeführt. Dadurch kann festgestellt werde, ob das richtige Plasmid mit dem gewünschten DNA-Fragment in das Bakterium transferiert worden ist.

Bei der Blau-Weiß-Selektion liegt die Klonierungsstelle innerhalb des lacZ-Gens. lacZ codiert für die ersten 146 aminoterminalen Aminosäuren der $\beta$-Galaktosidase. Der lacZ Promoter wird durch IPTG induziert. Die Bakterien selbst können nur eine funktionslose $\beta$-Galaktosidase, der die Aminosäuren 11 bis 41 fehlen, herstellen. Wenn ein Plasmid in die Bakterien eingebracht wird, der den $\mathrm{C}$-Terminus produziert, bildet sich zusammen mit dem bakterieneigenen Enzym eine funktionierende $\beta$-Galaktosidase ( $\alpha$-Komplementation). Das aktive Enzym hydrolysiert das Substrat X-Gal (5-Brom-4-chlor-3-indoxyl- $\beta$-Dgalactopyranosid) zu Galaktose und dem blauen Farbstoff 5-Brom-4-Chloro-3-Indol. Wird die Sequenz des lacZ-Gens jedoch durch den Einbau von fremder DNA in das Plasmid unterbrochen, so wird kein funktionsfähiges Enzym gebildet, wodurch das Substrat nicht mehr umgesetzt werden kann. Die Bakterienkolonie bleibt weiß.

Für die Blau-Weiß-Selektion wurde die Bakteriensuspension nach der Transformation auf Platten ausgestrichen, die kurz vor der Verwendung mit $60 \mu 1$ einer X-Gal-Stammlösung (20 mg/ml, Roth, Karlsruhe, Deutschland) und $60 \mu \mathrm{l}$ 0,1 M IPTG-Lösung (Roth, Karlsruhe, Deutschland) bestrichen wurden. 
Nach 24 Stunden waren die positiven Klone gut von den blauen Kolonien unterscheidbar. Von weißen Klonen wurde die Plasmid-DNA isoliert. Deren Sequenz wurde durch Sequenzierung mit Hilfe der Primer Seq_pCambia1391Z_fw, Seq_pCambia1391Z_rev sowie Seq_PromoterGLP3_1 bis 5 (siehe Tabelle 5) verifiziert. Plasmide mit der exakten Sequenz wurden in Agrobakterien transferiert (Punkt 2.2.12.22) und für eine Pflanzentransformation verwendet (Punkt 2.2.12.15).

\subsubsection{Kultivierung und Transformation von Escherichia coli}

E. coli wurde auf LB-Medium kultiviert (siehe Punkt 2.1.9.3). Nach der Transformation wurden die Zellen auf festem Medium ausgestrichen, während Zellen, aus denen PlasmidDNA gewonnen werden sollte, in Flüssigkultur angezogen wurden.

Für eine längere Lagerung der Bakterien wurden $750 \mu 1$ einer Flüssigkultur 12 Stunden nach dem Animpfen mit der gleichen Menge einer 30\%igen sterilen Glycerinlösung versetzt und nach dem Einfrieren in flüssigem Stickstoff bei $-80^{\circ} \mathrm{C}$ gelagert.

Für die Herstellung von elektrokompetenten Zellen wurde festes selektives SOB-Medium (siehe Punkt 2.1.9.3) mit E. coli - Zellen angeimpft und 24 Stunden bei $37^{\circ} \mathrm{C}$ inkubiert. Dann wurde eine einzelne Kolonie in $50 \mathrm{ml}$ flüssiges, selektives SOB-Medium überführt und 12 Stunden bei $37{ }^{\circ} \mathrm{C}$ inkubiert. Von dieser Vorkultur wurden $5 \mathrm{ml}$ entnommen und in $500 \mathrm{ml}$ flüssigem SOB-Medium (ohne Antibiotika) bei $37^{\circ} \mathrm{C}$ so lange geschüttelt, bis eine optische Dichte von 0,46 - 0,48 bei $578 \mathrm{~nm}$ erreicht war. Dann wurden die Kolben 10 Minuten auf Eis gestellt, um weitere Zellteilungen zu inhibieren. Anschließend wurden die Zellen durch mehrere Zentrifugations- und Waschschritte von dem Medium getrennt. Dazu wurden die Zellen jeweils für 15 Minuten bei 3600 x g und $4^{\circ} \mathrm{C}$ (Beckman J2-HS, Beckman Coulter, Fullerton, USA) pelletiert, der Überstand verworfen und nacheinander in $250 \mathrm{ml}$ und $125 \mathrm{ml}$ eiskaltem, sterilem, destillierten Wasser resuspendiert. Zuletzt wurden die Zellen in 12,5 ml 10\%iger steriler Glycerinlösung wiederaufgenommen, nach einem abschließenden Zentrifugationsschritt in $1 \mathrm{ml}$ 10\%igem sterilem Glycerin gelöst und in $40 \mu 1$ Aliquots in Stickstoff eingefroren, welche bis zur weiteren Verwendung bei $-80^{\circ} \mathrm{C}$ gelagert wurden.

Die Transformation der E. coli Zellen erfolgte mittels Elektroporation. Hierbei wird durch Gabe kurzer Spannungspulse die Membran kompetenter Bakterienzellen vorübergehend permeabilisiert, wodurch die Aufnahme freier DNA aus dem Medium ermöglicht wird. 
Für die Elektroporation wurden die aliquotierten elektrokompetenten Bakterien auf Eis aufgetaut. Ca. 100 ng Plasmid-DNA wurden $\mathrm{zu}$ den Zellen gegeben. Nach einer Inkubationszeit von 30 bis 60 Sekunden auf Eis wurde die Suspension in den Elektrodenzwischenraum einer sterilen Elektroporationsküvette (Bio-Rad, Hercules, USA) gefüllt. Diese wurde anschließend in den GenePulser (Bio-Rad, Hercules, USA) geschoben, wo kurzzeitig eine Spannung von 1,8 kV (bei $25 \mu \mathrm{F}$ und $400 \Omega$ ) angelegt wurde. Der Transformationsansatz wurde sofort mit $1 \mathrm{ml}$ SOC-Medium (siehe Punkt 2.1.9.3) versehen, in ein Reaktionsgefäß überführt, und im Thermomixer (Eppendorf, Hamburg, Deutschland) bei $37^{\circ} \mathrm{C}$ und $250 \mathrm{rpm}$ inkubiert. Dies diente der Regeneration der Zellen und der Ausbildung der Resistenzen. Die Dauer war abhängig von dem verwendeten Antibiotikum. Zur Entwicklung der Resistenz gegen Ampicillin wurden die Zellen 30 Minuten, zur Resistenzausbildung gegen Kanamycin 1 Stunde inkubiert. Abschließend wurden 50 bis $100 \mu 1$ der Bakterienkultur auf festem, selektivem LBMedium ausgestrichen. Wenn eine geringe Ausbeute von Transformanten zu erwarten war, wurde die Bakteriensuspension vor dem Ausplattieren zunächst konzentriert, indem nach einem Zentrifugationsschritt bei 18000 x g für 20 Sekunden $800 \mu 1$ des Überstandes verworfen wurden und das Pellet mit in dem zurückgelassenem Medium wieder aufgenommen wurde.

Nach 14 bis 16 Stunden bei $37^{\circ} \mathrm{C}$ wurden einzelne Kolonien mit einem sterilen Zahnstocher oder einer Pipettenspitze in 3 bis $5 \mathrm{ml}$ flüssiges, selektives LB-Medium überführt. Nach einer Inkubationszeit von 12 bis 16 Stunden bei $37^{\circ} \mathrm{C}$ unter leichtem Schütteln wurden die Zellen in einem Reaktionsgefäß für 1 Minute bei $10000 \mathrm{x} g$ abzentrifugiert. Der Überstand wurde verworfen. Das Pellet wurde für die Extraktion der Plasmid-DNA (siehe Punkt 2.2.12.2) weiter verwendet.

\subsubsection{Kultivierung und Transformation von Agrobacterium tumefaciens}

Die Kultivierung von Agrobakterien erfolgte auf festem oder flüssigem LB- oder YEBMedium (siehe Punkt 2.1.9.3). Zur Selektion wurden in Abhängigkeit von dem verwendeten Stamm und Helferplasmid verschiedene Antibiotika hinzugefügt, da es andernfalls zum verstärkten Wachstum von Agrobakterien ohne Helferplasmid kommen kann, die ihre Infektiösität eingebüßt haben. Der in dieser Arbeit verwendete Agrobakterien-Stamm GV 3101 weist das Gen für die Resistenz gegenüber Rifampicin auf, zudem vermittelt das Helferplasmid pMP 90 die Resistenz gegenüber Gentamycin. 
Daher wurden die Agrobakterien in Anwesenheit der genannten Antibiotika angezogen. Bei transformierten A. tumefaciens Zellen wurde ein zusätzliches Antibiotikum zum Medium gegeben, für dessen Resistenz das transferierte Plasmid codierte.

Die Transformation von Agrobakterien erfolgte wie bei E. coli durch Elektroporation. Für die Herstellung elektrokompetenter Zellen wurden Agrobakterien auf Platten kultiviert. Von diesen Platten wurde eine einzelne Kolonie in $10 \mathrm{ml}$ selektives, flüssiges YEBMedium überführt und 12-16 Stunden auf dem Schüttler bei $28^{\circ} \mathrm{C}$ inkubiert. Die vollständige Kultur wurde zum Animpfen von $250 \mathrm{ml}$ flüssigem YEB-Medium verwendet. Die Kultur wurde auf dem Schüttler bei $28^{\circ} \mathrm{C}$ inkubiert, bis eine $\mathrm{OD}_{600}$ von $0,5-0,6$ erreicht war. Anschließend wurden die Zellen 15 Minuten auf Eis abgekühlt und dann durch Zentrifugation bei $3000 \mathrm{x}$ g und $4^{\circ} \mathrm{C}$ für 10 Minuten in einer vorgekühlten Zentrifuge vom Medium getrennt. Die vom Überstand befreiten Zellpellets wurden in 200 $\mathrm{ml}$ eiskaltem, sterilem Wasser aufgenommen und wieder für 10 Minuten $3000 \mathrm{x}$ g und $4^{\circ} \mathrm{C}$ zentrifugiert. Danach wurde das Pellet in $100 \mathrm{ml}$ kaltem, sterilem Wasser aufgenommen und nach einem weiteren Zentrifugationsschritt in $50 \mathrm{ml}$ sterilem $10 \%$ (v/v) Glycerin gelöst. Nach einem letzten Zentrifugationsschritt wurden die Zellen in $1 \mathrm{ml}$ kalter, steriler $10 \%$ iger Glycerinlösung resuspendiert, in $50 \mu$ 1 Aliquots in flüssigen Stickstoff eingefroren und bis zur weiteren Verwendung bei $-80^{\circ} \mathrm{C}$ gelagert.

Für die Transformation wurden $100 \mathrm{ng}$ DNA zu $50 \mu \mathrm{l}$ Aliquots auf Eis aufgetauter kompetenter Zellen gegeben. Dieses Gemisch wurde anschließend in den Elektrodenzwischenraum einer sterilen Elektroporationsküvette (Bio-Rad, Hercules, USA) gegeben und im GenePulser (Bio-Rad, Hercules, USA) einem Spannungsimpuls von 2,5 $\mathrm{kV}$ bei $25 \mu \mathrm{F}$ und $400 \Omega$ unterzogen. Diese Suspension wurde sofort mit $2 \mathrm{ml} \mathrm{SOC-oder}$ LB-Medium versehen, in ein Reaktionsgefäß überführt und 2 Stunden bei $28^{\circ} \mathrm{C}$ unter leichtem Schütteln inkubiert. $100 \mu \mathrm{l}$ dieses Transformationsansatzes wurden auf selektivem YEB- oder LB-Medium (siehe Punkt 2.1.9.3) ausgestrichen. Nach 3 (YEBMedium) bzw. 4 (LB-Medium) Tagen wurden die Kolonien zum Animpfen von Flüssigkulturen benutzt.

\subsubsection{Heterologe Expression eines pflanzlichen Proteins in Hefe}

Um GLP3 näher zu charakterisieren, wurde das pflanzliche Protein in Hefe (Saccharomyces cerevisiae, Stamm INVSc1, siehe auch Punkt 2.1.4) exprimiert. Hierzu 
wird die cDNA von glp3 zunächst in den Vektor pYES2/CT kloniert, nach der Vermehrung und Selektion in E. coli isoliert und in die Hefe eingebracht.

Für die Konstruktion des Vektors wurde zunächst die Sequenz von glp3 während einer PCR unter Zugabe der Primer GLP_Hefe_FW sowie GLP_Hefe_REV aus einem Gemisch aus cDNAs, die aus pflanzlichen RNA-Extrakten synthetisiert wurde, isoliert. Das PCRProdukt sowie der Vektor pYES2/CT wurden während einer Inkubation über Nacht bei $37^{\circ} \mathrm{C}$ mit den Restriktionsendonukleasen HindIII und XHoI gespalten. Nach der Auftrennung der DNA-Fragmente über ein Gel und der anschließenden Aufreinigung erfolgte die Ligation (siehe Punkt 2.2.12.20). Mit dem Ligationsansatz wurden elektrokompetente E. coli-Zellen transformiert, die nach einer Inkubationszeit von 45 Minuten bei $37^{\circ} \mathrm{C}$ in SOC-Medium auf festem LB-Medium mit Ampicillin ausgestrichen wurden. Der verwendete Vektor pYES2/CT vermittelt eine Ampicillin-Resistenz. Nur die Zellen, die den Vektor aufgenommen haben, können auf dem Selektionsmedium wachsen. Die aus positiven Klonen isolierte Plasmid-DNA wurde mittels Restriktionsspaltung und Sequenzierung (Primer: Seq_pYES2-CT_FW und Seq_pYES2-CT_REV, siehe Tabelle 5) verifiziert und für die Transformation von Hefe verwendet.

Für die Transformation der Hefe wurden zunächst kompetente Zellen hergestellt. Dafür wurden Hefezellen einer einzelnen Kolonie von festem YPD-Medium in $20 \mathrm{ml}$ flüssiges YPD-Medium (siehe Punkt 2.1.9.3) überführt. Nach einer Inkubation über Nacht bei $30{ }^{\circ} \mathrm{C}$ unter leichtem Schütteln wurde eine neue $20 \mathrm{ml}$ Flüssigkultur mit einem so großen Volumen dieser Vorkultur angeimpft, dass die OD600 dieser neuen Kultur zwischen 0,3 und 0,4 lag. Es folgte eine erneute Inkubation bei $30^{\circ} \mathrm{C}$ unter leichtem Schütteln, bis die Kultur eine OD600 von 0,8 - 1,2 erreicht hatte. $10 \mathrm{ml}$ dieser Kultur wurden 3 Minuten bei 1500 x g zentrifugiert. Nach einem Waschschritt mit $\mathrm{H}_{2} \mathrm{O}$ und erneuter Zentrifugation wurde der Überstand verworfen und das Pellet in $400 \mu$ LITE-Puffer (100 mM Lithiumacetat, 10 $\mathrm{mM}$ Tris-HCl, $\mathrm{pH}$ 7,5, 1 mM EDTA) resuspendiert.

Für die Transformation wurden $200 \mu 1$ kompetente Hefezellen mit $1-3 \mu$ g Plasmid-DNA sowie $800 \mu \mathrm{l}$ PEG-Lösung (LITE-Puffer mit 40 \% w/v PEG 4000) versetzt und gut gemischt. Nach einer 30 minütigen Inkubation bei $30^{\circ} \mathrm{C}$ erfolgte ein Hitzeschock bei $42{ }^{\circ} \mathrm{C}$ für 25 Minuten. Anschließend wurden die Zellen durch Zentrifugation bei $1700 \mathrm{x} g$ für 1 Minute vom Transformationsmedium getrennt, in $100 \mu \mathrm{l}$ Wasser resuspendiert, und auf Selektionsmedium (SD-Medium ohne Uracil, siehe Punkt 2.1.9.3) ausgestrichen. Nach 3 
bis 5 Tagen bei $30^{\circ} \mathrm{C}$ wurden einzelne Kolonien auf neue Selektionsplatten überführt. Nur Zellen von diesen Sekundärplatten wurden weiter berücksichtigt.

Für die Expression von glp3 wurde die Hefe in Expressionsmedium angezogen. Der verwendete Vektor pYES2/CT enthält den Galaktose-induzierbaren Promotor GAL1. Das eingefügte Gen wird dadurch nach Zugabe von Galaktose exprimiert, während Glukose die Expression reprimiert (West et al. 1984, Giniger et al. 1985, Flick \& Johnston 1990, Gancedo 1998). Damit die transformierten Hefezellen glp3 herstellen, wurden diese nach einer Vorkultur in flüssigem, Glukose-haltigen Selektionsmedium in Expressionsmedium überführt. Hierfür wurden die Zellen durch einen Zentrifugationsschritt ( 2 min bei $1500 \mathrm{x}$ g) von dem alten Medium getrennt und in neuem SD-Medium, welches statt Glukose Galaktose enthielt, wieder aufgenommen und bei $25^{\circ} \mathrm{C}$ unter leichtem Schütteln kultiviert. Wenn die Kultur eine $\mathrm{OD}_{600}$ zwischen 0,8 und 1,5 erreicht hatte, wurden die Zellen geerntet, indem $15 \mathrm{ml}$ der Kultur 5 Minuten bei $1500 \mathrm{x}$ g und $4^{\circ} \mathrm{C}$ zentrifugiert wurden. Anschließend wurde der Überstand verworfen, und die Zellen wurden mit $500 \mu 1$ Wasser gewaschen. Nach erneuter Zentrifugation für 30 Sekunden bei maximaler Geschwindigkeit wurden die Zellen lysiert. Dafür wurden $500 \mu$ Lyse-Puffer $(50 \mathrm{mM}$ NatriumphosphatPuffer, $\mathrm{pH}$ 7,4, 1 mM EDTA, $5 \%$ v/v Glycerin), dem ein Protease-Inhibitor-Mix (Complete Mini, Roche, Grenzach-Whylen, Deutschland) zugesetzt wurde, auf das Pellet gegeben. Erneut wurden die Zellen für 5 Minuten bei $1500 \mathrm{x} \mathrm{g}$ und $4{ }^{\circ} \mathrm{C}$ zentrifugiert und der Überstand verworfen. Danach wurde so viel Lyse-Puffer auf die Proben gegeben, dass eine optische Dichte von 50 - 100 erreicht war. Außerdem wurde das gleiche Volumen Glasperlen (0,5 mm Glass Beads Soda Lime, BioSpec Products, Bartlesville, USA) dazugegeben. Die Proben wurden dann 30 Sekunden gemischt (Vortexer), anschließend folgte eine Inkubation von 30 Sekunden auf Eis. Nach 4maliger Wiederholung der letztgenannten zwei Schritte wurden die Proben 10 Minuten bei maximaler Geschwindigkeit bei $4^{\circ} \mathrm{C}$ zentrifugiert. Der erhaltene Überstand wurde bis zur weiteren Verwendung bei $-80^{\circ} \mathrm{C}$ gelagert. Um nachzuweisen, dass das gewünschte Protein tatsächlich von der Hefe hergestellt wurde, wurde nach der Auftrennung der Gesamtproteine über ein SDS-Gel (siehe Punkt 2.2.13.5) ein Western Blot durchgeführt (siehe Punkt 2.2.13.6). 


\subsubsection{Biochemische Methoden}

\subsubsection{GUS-Färbung für die Expressionsanalysen in GUS-Reporterpflanzen}

Das uidA-Gen aus E.coli, welches die ß-Glucuronidase (GUS) kodiert, ist eines der häufig benutzen Reportergene (Jefferson et al. 1987). Das gebildete Enzym hydrolisiert ßglucosidische Bindungen von Glucuroniden. Für den sichtbaren Nachweis der GUSAktivität wird das synthetische Substrat 5-Bromo-4-Chloro-3-Indolyl- $\beta$-D-Glucuronid (XGluc) verwendet. Wenn Pflanzen mit einer X-Gluc enthaltenden Lösung infiltriert werden, spaltet das GUS-Enzym den Glucuronsäure-Rest von X-Gluc ab. Die freien Indolylderivate dimerisieren und werden oxidiert, wodurch ein blauer Farbstoff entsteht.

Um Pflanzenteile zu färben, wurden diese nach der Ernte sofort in eiskaltes $90 \%(\mathrm{v} / \mathrm{v})$ Aceton gegeben und 20 Minuten bei RT inkubiert. Anschließend wurden die Proben mit GUS-Puffer $\left(50 \mathrm{mM} \mathrm{Na} \mathrm{HPO}_{4} / \mathrm{NaH}_{2} \mathrm{PO}_{4}(\mathrm{pH} \quad 7,2), \quad 0,5 \mathrm{mM} \quad \mathrm{K}_{3} \mathrm{Fe}(\mathrm{CN})_{6}, \quad 0,5 \mathrm{mM}\right.$ $\mathrm{K}_{4} \mathrm{Fe}(\mathrm{CN})_{6}$ ) gewaschen, bevor die Färbelösung (GUS-Puffer mit $2 \mathrm{mM} \mathrm{X-Gluc)} \mathrm{auf} \mathrm{die}$ Proben gegeben wurde. Der Zusatz von $\mathrm{K}_{3} \mathrm{Fe}(\mathrm{CN})_{6}$ und $\mathrm{K}_{4} \mathrm{Fe}(\mathrm{CN})_{6}$ führt zu einem schnelleren Ausfallen des Indol-Farbstoffes und damit $\mathrm{zu}$ präziser abgegrenzten Färbungen. $\mathrm{Zu}$ hohe Konzentrationen hemmen allerdings die Enzymaktivität, so dass die Intensität der Färbung abnimmt.

Die Proben wurden mit der Färbelösung infiltriert, indem in einem Exsikator langsam ein Unterdruck von 200 mbar erzeugt und für 2 Minuten gehalten wurde. Nach dem langsamen Ablassen des Vakuums wurden die Proben 3 Stunden (junge Pflanzen) oder über Nacht (ältere Pflanzen) bei $37^{\circ} \mathrm{C}$ inkubiert. Anschließend wurde die Färbelösung entfernt. Die Proben wurden nacheinander mit $65 \%$ (v/v) Ethanol, $80 \%$ (v/v) Ethanol und 96 \% (v/v) Ethanol bei RT gewaschen. Dadurch wurden die Blätter entfärbt, das Gewebe wurde weiß. Durch das GUS-Enzym gefärbte Stellen blieben hingegen blau. Zur Lagerung wurden die Proben in FAE (37 \% (v/v) Formaldehyd, $100 \%$ (v/v) Eisessig, 70 \% (v/v) Ethanol, $5: 5: 90, \mathrm{v} / \mathrm{v} / \mathrm{v})$ überführt.

\subsubsection{Proteinextraktion aus Pflanzen und Gelfiltration}

Für die Proteinextraktion aus Pflanzen wurden 200 mg Polyvinylpolypyrrolidon (PVPP) in Zentrifugenröhrchen mit $4 \mathrm{ml}$ Extraktionspuffer $\left(0,1 \mathrm{M} \mathrm{KH}_{2} \mathrm{PO}_{4} / \mathrm{K}_{2} \mathrm{HPO}_{4}\right.$-Puffer mit 0,5\% Triton X-100, $\mathrm{pH} 7,8$ ) versetzt und über Nacht bei $4^{\circ} \mathrm{C}$ inkubiert. Anschließend wurden $200 \mathrm{mg}$ des gefrorenen, gemahlenen Pflanzenmaterials mit der Lösung vermischt. Nach 
einer 15 minütigen Inkubationszeit auf Eis wurden die Proben 30 Minuten bei $4^{\circ} \mathrm{C}$ und 25000 x g zentrifugiert (Beckman J2-HS, Rotor JA 20.1, Beckman Coulter, Fullerton, USA). Dabei wurden Zelltrümmer, durch PVPP gebundene Phenole sowie aufgrund der Verwendung von Triton X-100 nicht mehr lösliche Phospholipide von den im Überstand gelösten Proteinen getrennt. Der Proteinextrakt wurde über Gelfiltration weiter aufgereinigt, um niedermolekulare Substanzen aus der Lösung zu entfernen. Dazu wurden $500 \mu 1$ des Überstandes aus dem Zentrifugationsschritt auf zuvor mit Elutionspuffer (0,1 M $\mathrm{KH}_{2} \mathrm{PO}_{4} / \mathrm{K}_{2} \mathrm{HPO}_{4}$-Puffer, $\mathrm{pH}$ 7,0) äquilibrierten Sephadex G-25 Säulen (NAP 5 Säulen, Amersham Biosciences, Uppsala, Schweden) gegeben. Anschließend wurden die Proteine durch Zugabe von $1 \mathrm{ml}$ Elutionspuffer aus der Säule eluiert.

\subsubsection{Bestimmung der Proteinkonzentration mit Bicinchoninic acid (BCA)}

Die Proteinbestimmung mit Bicinchoninic acid (BCA) basiert auf dem Prinzip, dass $\mathrm{Cu}^{2+}-$ Ionen aus Kupfersulfat in alkalischem Medium von Proteinen $\mathrm{zu} \mathrm{Cu}^{1+}$-Ionen reduziert werden. Diese wiederum reagieren mit BCA und bilden einen purpurfarbenen Komplex, dessen Absorption bei einer Wellenlänge von $562 \mathrm{~nm}$ photometrisch gemessen werden kann (Smith et al. 1985).

Der BCA-Test wurde mit Hilfe eines Kits (BCA-Test, Uptima, Montelucon, Frankreich) durchgeführt. Wie vom Hersteller angegeben wurden die Reagenzien A und B im Verhältnis 50:1 gemischt. $600 \mu \mathrm{l}$ des Gemischs wurden mit $30 \mu \mathrm{l}$ der Probe versetzt und 30 Minuten bei $60^{\circ} \mathrm{C}$ inkubiert. Nach Abkühlung auf Raumtemperatur wurde die Absorption der Probe bei $\lambda=562 \mathrm{~nm}$ gemessen (DU 640, Beckman Coulter, Fullerton, USA). Als Leerwert (Blank) wurde der Puffer, der in der Probe enthalten war, benutzt. Als Standard wurde Rinderserumalbumin (BSA, Uptima, Montelucon, Frankreich) verwendet, welcher in verschiedenen Verdünnungsstufen gemessen wurde. Die ermittelte Extinktion wurde gegen die bekannte Konzentration aufgetragen. Mit Hilfe der Steigung aus der resultierenden Eichgeraden wurde die Proteinkonzentration nach folgender Formel berechnet:

Gleichung 9 Proteinkonzentration der Probe $(\mu \mathrm{g} / \mathrm{ml})=\left(\mathrm{E}_{\text {Probe }}-\mathrm{E}_{\text {Blank }}\right) /$ Steigung

$E_{\text {Probe }}=$ Extinktion der Probe

$\mathrm{E}_{\text {Blank }}=$ Extinktion des Leerwertes (Blank)

Steigung $=$ Steigung der Eichgerade aus den Messungen des Standards 
Falls die Probe während der Proteinextraktion oder vor der Messung verdünnt wurde, wurde die entsprechenden Verdünnungsfaktoren in die Berechnung einbezogen. Um die Proteinkonzentration auf die Frischmasse zu beziehen, wurde das Ergebnis mit dem Volumen des bei der Proteinextraktion verwendeten Extraktionspuffers multipliziert und das Produkt durch die Frischmasse dividiert.

\subsubsection{Bestimmung der Proteinkonzentration nach Bradford}

Die Proteinbestimmung nach Bradford wurde mit Hilfe des Coomassie PLUS Assay Kit (Thermo Fisher Scientific, Waltham, USA) durchgeführt. In der sauren Lösung bindet Coomassie-Farbstoff an Proteine. Dies führt zu einer Farbänderung von rotbraun zu blau. Für die Messung wurden Probe und Bradford-Reagenz im Verhältnis 1:30 gemischt. Nach einer 10 minütigen Inkubationszeit bei RT wurde die Extinktion bei einer Wellenlänge von 595 nm (Bio Photometer, Eppendorf, Hamburg, Deutschland) gemessen. Als Leerwert (Blank) wurde der in den Proben enthaltene Puffer zu der Reagenz gegeben und wie die Probe behandelt. Wie bei der Proteinbestimmung mit BCA (siehe Punkt 2.2.13.3) wurde auch hier Rinderserumalbumin (BSA, Uptima, Montelucon, Frankreich) für die Erstellung einer Eichreihe und verwendet. Die Proteinkonzentration wurde mit Hilfe der unter Punkt 2.2.13.3 angegebenen Formel berechnet.

\subsubsection{SDS-Polyacrylamidgelelektrophorese}

Mittels SDS-Polyacrylamidgelelektrophorese (SDS-PAGE) werden Proteine unter denaturierenden Bedingungen anhand ihrer Größe aufgetrennt (Laemmli 1970). Die Gelmatrix besteht aus Acrylamid und Methylenbisacrylamid, wobei die Porengröße von der Konzentration der genannten Bestandteile sowie deren Verhältnis zueinander bestimmt wird. Zur Polymerisation wird Ammoniumpersulfat (APS) und der Katalysator Tetramethylethylendiamin (TEMED) zugegeben. In dieser Arbeit wurden Gele aus einem 12,5 \%igen Trenngel sowie einem 5 \%igem Sammelgel verwendet (Tabelle 11).

Vor dem Beladen des Gels mit den Proteinextrakten wurden diese mit Ladepuffer $(0,125$ M Tris, $4 \%$ (w/v) SDS, $20 \%$ (v/v) Glycerol, 0,02 \% Bromphenolblau, 0,2 M Dithiothreitol; pH 6,8) versetzt und für 10 min bei $70^{\circ} \mathrm{C}$ inkubiert. Das im Ladepuffer enthaltene Dithiothreitol zerstört Disulfidbrücken und sorgt so für eine Entfaltung der Proteine. Außerdem wurde dem Ladepuffer SDS zugesetzt, welches sich an die 
denaturierten Proteinmoleküle lagert und deren Ladung überdeckt, so dass alle Proteine negativ geladen sind und daher im Gel in die gleiche Richtung wandern.

Tabelle 11: Zusammensetzung eines Trenngels und eines Sammelgels zur SDSPolyacrylamidgelelektrophorese.

\begin{tabular}{|l|l|l|l|}
\hline Stammlösung & $\begin{array}{l}\text { Volumen für } \\
\text { ein 5\% } \\
\text { Sammelgel } \\
{[\mathbf{m l}]}\end{array}$ & Stammlösung & $\begin{array}{l}\text { Volumen für } \\
\text { ein 12,5 \% } \\
\text { Trenngel [mI] }\end{array}$ \\
\hline $30 \%$ Polyacrylamid & 0,85 & $30 \%$ Polyacrylamid & 6,25 \\
\hline 1 M Tris, pH 6,8 & 0,625 & $1,5 \mathrm{M}$ Tris, pH 8,8 & 3,75 \\
\hline $10 \%$ Ammoniumpersulfat & 0,05 & $10 \%$ Ammoniumpersulfat & 0,15 \\
\hline $10 \%$ SDS & 0,05 & $10 \%$ SDS & 0,15 \\
\hline TEMED & 0,005 & TEMED & 0,006 \\
\hline $\mathrm{H}_{2} \mathrm{O}$ & 3,4 & $\mathrm{H}_{2} \mathrm{O}$ & 4,7 \\
\hline Gesamtvolumen & 5 & Gesamtvolumen & 15 \\
\hline
\end{tabular}

Nach dem Beladen des Gels wurde zunächst für 20 Minuten eine Spannung von 15 mA angelegt, bis die Proteine die Grenze zwischen Sammelgel und Trenngel erreicht hatten. Anschließend erfolgte die weitere Auftrennung für 1,5 - 2 Stunden bei $25 \mathrm{~mA}$. Als Laufpuffer während der Elektrophorese diente 1x SDS-Puffer (0,025 M Tris, 0,192 M Glycin, 0,1 \% SDS; pH 8,3). Wenn das Gel für einen Western Blot weiter verwendet werden sollte, wurde der vorgefärbte Low-Range Rainbow Molecular Weight Marker (Amersham Biosciences, Uppsala, Schweden) benutzt. Sollte das Gel angefärbt werden, wurde als Größenabgleich dagegen ein ungefärbter Low Molecular Weight Marker (Amersham Biosciences, Uppsala, Schweden) mit aufgetragen.

Für die Färbung des Gels wurde der Farbstoff RuBP [Ruthenium (II) tris (bathophenantrolin disulfat)] verwendet, der einen sensitiveren Nachweis von Proteinen im Vergleich zu Coomassie ermöglicht (Rabilloud et al. 2001). Der Farbstoff wurde vorbereitet wie in Lamanda et al. (2004) beschrieben. Die Gele wurden zunächst über Nacht in einer Fixierlösung (40\% (v/v) Ethanol, $10 \%$ (v/v) Eisessig) unter leichtem Schwenken inkubiert. Anschließend wurde die Fixierlösung ausgetauscht. Der frischen Lösung wurde $50 \mu 1 / 1$ RuBP zugesetzt. Nach einer Inkubation von einer Stunde wurde die 
Färbelösung durch frische Fixierlösung ersetzt. Nach einer weiteren Inkubation von 20 Minuten wurde das Gel zwei Mal für jeweils 10 Minuten in destilliertem Wasser gewaschen. Das Gel wurde anschließend mit Hilfe einer Dokumentationsanlage (FLA5100, Fuji Photo Film, Düsseldorf, Deutschland) visualisiert.

\subsubsection{Western Blot}

Bei einem Western Blot werden die über ein SDS-Gel aufgetrennten Proteine auf eine Membran übertragen. In dieser Arbeit wurde für den Western Blot das Tank Blot System verwendet. Dafür wurden das Gel, eine Nitrocellulose-Membran (Protran BA 83, Whatman ${ }^{\circledR}$ ), Filterpapier und Schwämme in Transferpuffer (25 mM Tris, 192 mM Glycin, $20 \%$ (v/v) Methanol) äquilibriert und luftblasenfrei in folgender Reihenfolge aufeinander

geschichtet: Schwamm, Filterpapier, Gel, Membran, Filterpapier, Schwamm. Die Übertragung auf die Membran erfolgte in gekühltem Transferpuffer über Nacht bei $30 \mathrm{~V}$ und $40 \mathrm{~mA}$ (Mini Trans-Blot ${ }^{\circledR}$ Electrophoretic Transfer Cell, Bio-Rad). Vor der weiteren Verwendung wurde die Membran in TBS-Puffer (20 mM Tris, $140 \mathrm{mM} \mathrm{NaCl}, \mathrm{pH}$ 7,5) gewaschen, um Reste des Transferpuffers zu entfernen.

Zur Detektion bestimmter Proteine auf der Membran werden Antikörper verwendet. Der eingesetzte Antikörper erkennt spezifische Regionen (Epitope) des nachzuweisenden Proteins oder ein an dieses fusioniertes Proteinfragment und bindet daran. In dieser Arbeit wurde das nachzuweisende Protein mit einem Polyhistidine-(6x His)-Tag versehen. Zur Detektierung wurde daher ein gegen den Polyhistidine-Tag gerichteten Antikörper verwendet (Anti His (C-term) - AP Antibody). Der Antikörper war direkt an eine alkalische Phosphatase gekoppelt. Dies ermöglicht die spätere Sichtbarmachung des Proteins mittels einer Farbreaktion. Die alkalische Phosphatase katalysiert die Umsetzung von 5-Brom-4-Chlor-3-Indolylphosphat (BCIP, Roth, Karlsruhe, Deutschland) zu einem schwach blauen Farbstoff. Außerdem wird Nitroblau-Tetrazoliumsalz (NBT, Roth, Karlsruhe, Deutschland) zu einem dunkelvioletten Farbstoff umgesetzt.

Da die Membran unspezifisch alle Proteine fixiert, würde sich bei direkter Zugabe des Antikörpers auch dieser an alle freien Bindungsstellen haften und einen spezifischen Nachweis verhindern. Daher müssen die freien Bindungsstellen auf der Membran zunächst mit einem für den Antikörper nicht erkennbaren Protein blockiert werden. Dafür wurde die Membran mit TBS-Puffer, der $5 \%$ (w/v) Milchpulver (Roth, Karlsruhe, Deutschland) 
enthielt, für 2 Stunden bei Raumtemperatur unter Schwenken inkubiert. Anschließend wurde die Membran 2 Stunden mit dem 1:2000 in TBST-Puffer (TBS mit 0,1\% (v/v) Tween-20) verdünnten Antikörper inkubiert. Die Lösung enthielt zusätzlich $1 \%$ (w/v) Milchpulver, um den Hintergrund so gering wie möglich zu halten. Zur Entfernung von überschüssigem Antikörper wurde die Membran danach 4mal für jeweils 5 Minuten mit TBST, anschließend einmal für 5 Minuten mit TBS gewaschen. Danach folgte die Umpufferung für die enzymatische Reaktion. Die Membran wurde dafür 2 mal für jeweils 10 Minuten mit AP-Puffer (100 mM Tris, $100 \mathrm{mM} \mathrm{NaCl}, 5 \mathrm{mM} \mathrm{MgCl}$, pH 9,5) gewaschen. Anschließend wurde die Membran mit der Substratlösung (AP-Puffer mit 66 $\mu 1 / 10 \mathrm{ml}$ NBT-Stammlösung sowie $33 \mu 1 / 10 \mathrm{ml}$ BCIP-Stammlösung; Stammlösungen: 50 $\mathrm{mg} / \mathrm{ml}$ in $100 \% \mathrm{DMF}$ ) inkubiert. Nach 10 bis 30 Minuten waren purpurfarbene Banden dort zu erkennen, wo der Antikörper an das Epitop gebunden hat.

\subsubsection{Bestimmung der Aktivität der Guajakolperoxidase}

Guajakolperoxidasen sind Enzyme, die $\mathrm{H}_{2} \mathrm{O}_{2}$ mit Hilfe von Guajakol (2-Methoxyphenol) als Kosubstrat umsetzen können. Durch photometrische Messung der Zunahme des rotbraunen tetrameren Substrates während einer solchen Reaktion kann die Aktivität von Guajakolperoxidasen ermittelt werden (Polle et al. 1990). Hierzu wurden gelfiltrierte Proteinextrakte (siehe Punkt 2.2.13.2) mit Guajakol und $\mathrm{H}_{2} \mathrm{O}_{2}$ versetzt (Zusammensetzung eines Testansatzes siehe Tabelle 12). Die Extinktionszunahme wurde bei $\lambda=436 \mathrm{~nm}$ und $25{ }^{\circ} \mathrm{C}$ über eine Dauer von 5 Minuten gemessen (Specord 205, Analytic Jena, Jena, Deutschland).

Tabelle 12: Zusammensetzung eines Ansatzes für die Messung der Aktivität der Guajakolperoxidase. Die Guajakol- sowie die $\mathrm{H}_{2} \mathrm{O}_{2}$-Lösung wurde vor jeder Messung frisch angesetzt und lichtgeschützt auf Eis aufbewahrt.

\begin{tabular}{|l|l|l|}
\hline Substanz & Volumen $[\boldsymbol{\mu l}]$ & Endkonzentration $[\mathbf{m M}]$ \\
\hline $0,1 \mathrm{M} \mathrm{KPP}, \mathrm{pH} 5,25$ & 500 & 50 \\
\hline $\begin{array}{l}0,1 \mathrm{M} \mathrm{KPP}, \mathrm{pH} 7,0 \\
\text { (Elutionspuffer) }\end{array}$ & $50-\mathrm{X}$ & \\
\hline Probe & $\mathrm{X}$ & \\
\hline $0,1 \mathrm{M} \mathrm{Guajakol}$ & 400 & 40 \\
\hline $0,2 \mathrm{M} \mathrm{H}_{2} \mathrm{O}_{2}$ & 50 & 10 \\
\hline Gesamt & $\mathbf{1 0 0 0}$ & \\
\hline
\end{tabular}


Die Extinktionsänderung $\Delta \mathrm{E}$ wurde über eine Regressionsgerade mit Hilfe der Messpunkte bestimmt. Die Berechnung der Aktivität der Guajakolperoxidase basiert auf dem LambertBeerschen-Gesetz nach folgender Formel:

Gleichung 10: Aktivität (nkat/l Extrakt) $=\left(\Delta \mathrm{E} * \mathrm{~V}_{\mathrm{T}} * \operatorname{Verd}_{\mathrm{G}} * \operatorname{Verd}_{\mathrm{P}} * \mathrm{c}\right) /\left(\varepsilon * \mathrm{~V}_{\mathrm{E}}\right)$

$\Delta \mathrm{E}=$ Extinktionsänderung $(1 / \mathrm{min})$

$\varepsilon=$ molarer Extinktionskoeffizient (für Guajakolperoxidase $=25,5 \mathrm{mM}^{-1} \mathrm{~cm}^{-1}$ )

$\mathrm{V}_{\mathrm{T}}=$ Gesamtvolumen des Tests $(\mu \mathrm{l})$

$\mathrm{V}_{\mathrm{E}}=$ Volumen Extrakt im Test $(\mu \mathrm{l})$

$\operatorname{Verd}_{\mathrm{G}}=$ Verdünnung Gelfiltration (siehe Punkt 2.2.7.2)

$\operatorname{Verd}_{\mathrm{P}}=$ Verdünnung der Probe im Test

$\mathrm{c}=$ Umrechnungsfaktor zur Umrechnung in nkat $(16666,67)$

Um die Aktivität auf die Proteinkonzentration zu beziehen, wurde zunächst die Aktivität pro g Frischmasse (FM) berechnet:

Gleichung 11: Aktivität [nkat/g FM] $=\underline{\text { (Aktivität [nkat]) }}$

(FM $[\mathrm{g}])$

Mit Hilfe der bestimmten Proteinkonzentration (siehe Gleichung 9 unter Punkt 2.2.13.3) wurde die Aktivität pro mg Protein berechnet:

Gleichung 12: Aktivität [nkat/mg Protein] = (Aktivität [nkat/g FM])

(Proteinkonzentration $[\mathrm{mg} / \mathrm{gFM}]$ ) 


\subsubsection{Enzymatische Zuckerbestimmung}

Die Quantifizierung von Glukose, Fruktose und Saccharose im Xylemsaft von Raps erfolgte enzymatisch (Beutler 1978, Schopfer 1989). Bei dieser Methode werden die Zuckermetabolite durch Zugabe von Enzymen zunächst zu Fruktose-6-Phosphat umgewandelt. Diese wird über eine aktivierte Zwischenstufe zu Gluconat-6-Phosphat umgesetzt. Dabei wird NADP ${ }^{+}$zu NADPH reduziert, dessen Absorption photometrisch bestimmt werden kann. Mit Hilfe des Lambert-Beerschen-Gesetzes kann daraus die in der Probe vorhandene Konzentration der einzelnen Zuckermetabolite berechnet werden.

Für die Messung wurden $200 \mu 1$ des Xylemsaftes mit dem gleichen Volumen $50 \mu \mathrm{M}$ Citratpuffer (Natriumcitrat-Dihydrat, $\mathrm{pH} 4,6$ ) gemischt und auf Eis gestellt. $100 \mu \mathrm{l}$ von diesem Ansatz wurden in 1,6 ml Halbmikroküvetten aus Polystyrol (Sarstedt, Nürnbrecht, Deutschland) mit $250 \mu \mathrm{l}$ einer Reaktionslösung (4 mM NADP ${ }^{+}, 10 \mathrm{mM}$ ATP, $9 \mathrm{mM}$ $\mathrm{MgSO}_{4}, 0,75 \mathrm{M}$ Triethanolamin, $\mathrm{pH}$ 7,6) sowie $400 \mu \mathrm{H}_{2} \mathrm{O}$ versetzt. Nach 2minütiger Inkubationszeit wurde die Extinktion (E1) bei einer Wellenlänge von $\lambda=340 \mathrm{~nm}$ mit einem Spectrophotometer (DU 640, Beckman Coulter, Fullerton, USA) gemessen. Anschließend wurden $10 \mu 1$ Hexokinase/Glukose-6P-Dehydrogenase (Roche, GrenzachWhylen, Deutschland) hinzugefügt. Während der 5 minütigen Inkubationszeit wird Glukose durch ATP in Gegenwart der Hexokinase zu Glukose-6-phosphat phosphoryliert, welches wiederum durch die Glukose-6-phosphat-Dehydrogenase oxidiert wird, wobei die Elektronen auf $\mathrm{NADP}^{+}$übertragen werden. Dadurch entstehen Gluconat-6-phosphat und $\mathrm{NADPH}+\mathrm{H}^{+}$. Die Extinktion von NADPH wurde nach einer Inkubationszeit photometrisch bei $340 \mathrm{~nm}$ gemessen, wobei die gebildete Menge des NADPH zur ursprünglichen Menge der Glukose äqivalent ist.

Fruktose wird gleichzeitig mit Glukose durch ATP in Gegenwart von Hexokinase zu Fruktose-6-phosphat phosphoryliert. Nach der Glukosebestimmung wurde dieses durch Zugabe von $5 \mu$ l Phosphoglukose-Isomerase (PGI, Roche, Grenzach-Whylen, Deutschland) zunächst zu Glukose-6-phosphat, anschließend zu Gluconat-6-phosphat umgewandelt. 5 Minuten nach Zugabe des Enzyms wurde die Probe zur Bestimmung der Fruktose-Konzentration photometrisch gemessen (E3).

Im letzten Schritt wurde durch Zugabe von $10 \mu 1 \quad \beta$-Fruktosidase-Lösung (60 mg Fructosidase (Roche, Grenzach-Whylen, Deutschland)/1 ml 0,32 M Citratpuffer, pH 4,6) während einer 15 minütigen Inkubationszeit Saccharose zu Glukose und Fruktose 
hydrolisiert. Beides wurde über die oben beschriebenen Zwischenschritte zu Gluconat-6phosphat umgewandelt und die Zunahme des NADPH gemessen (E4), um Rückschlüsse über die Menge von Saccharose in der Probe zu ziehen.

Während sämtlicher Inkubationszeiten wurden die Proben abgedunkelt und bei Raumtemperatur aufbewahrt. Nach Zugabe der jeweiligen Enzyme wurden die Proben mit Rührspatel (Sarstedt, Nürnbrecht, Deutschland) gut vermischt. Um methodische Fehler auszuschließen, wurden 3 Wiederholungen durchgeführt. Außerdem wurden parallel zu den Proben jeweils ein Leerwert (Wasser statt Probe) sowie eine Standard-Zuckerlösung (je $100 \mathrm{mg} / \mathrm{l}$ Glukose, Fruktose und Saccharose in $\mathrm{H}_{2} \mathrm{O}$ ) als Kontrolle gemessen. Die Berechnung der Konzentration der einzelnen Metabolite erfolgt unter Berücksichtigung der Verdünnungsfaktoren, des Testvolumens sowie der genauen Einwaage der Probe nach dem Lambert-Beerschen-Gesetz:

Gleichung 13: $\quad \mathrm{c}[\mathrm{mg} / \mathrm{ml}]=\quad \underline{\text { Testvolumen } * \mathrm{MG}}$ $(\epsilon \mathrm{NADPH} *$ Schichtdicke in $\mathrm{cm} *$ Probenvolumen in $\mathrm{ml}) * \Delta \mathrm{E}$

$\mathrm{MG}=$ Molekulargewicht des jeweiligen Zuckermetaboliten $\varepsilon(\mathrm{NADPH})=$ Extinktionskoeffizient von NADPH $=6300 \mathrm{mM}^{-1} \mathrm{~cm}^{-1}$

$\Delta \mathrm{E}=$ Extinktion - zuvor gemessene Extinktion, also für Glukose E2-E1, für Fruktose E3-E2 und für Saccharose E4-E3

\subsubsection{Aminosäurebestimmung}

Die Konzentration von Aminosäuren im Xylemsaft wurde mit Hilfe einer Hochleistungsflüssigkeitschromatographie (High-performance liquid chromatography, HPLC, Pharmacia LKB, Freiburg, Deutschland) ermittelt wie in Riens et al. (1991) und in Zhou (2000) beschrieben. Dabei wurden die Aminosäuren mit ortho-Phthaldialdehyd (OPA) und ß-Mercaptoethanol derivatisiert, wodurch diese mittels Fluoreszenz nachweisbar waren. Hierzu wurden 0,5 ml OPA-Stocklösung (16 mM OPA, 88 \% (v/v) Methanol, 0,1 M Kaliumborat (pH 10,4), 1,1 \% (v/v) ß-Mercaptoethanol) zu $1 \mathrm{ml}$ einer 1 M Kaliumboratlösung ( $\mathrm{pH} \mathrm{10,4)} \mathrm{gegeben.} 20 \mu 1$ dieser Arbeitslösung wurden mit $20 \mu 1$ 
Xylemsaft gemischt und 1 min derivatisiert. Anschließend wurden $20 \mu 1$ des Gemischs mit einem automatisch gesteuerten Probengeber (Autosampler 2157, Pharmacia LKB, Freiburg, Deutschland) bei $35^{\circ} \mathrm{C}$ auf eine C-18 Reversed Phase Säule (Superspher, 100 RP 18 endcapped, $4 \mu \mathrm{m}, 4$ x 125 mm; Merck, Darmstadt, Deutschland) aufgetragen. Um Verunreinigungen der Säule zu verhindern, wurde zusätzlich eine Vorsäule (LiChrospher 100 RP 18e, $5 \mu \mathrm{m}$, Merck, Darmstadt, Deutschland) verwendet. Als Standard wurde eine fertige Lösung (Amino Acid Standard Solution A-2161, Sigma, Steinheim, Deutschland) verwendet, der zusätzlich Glutamin, Asparagin, Tryptophan und $\gamma$-Aminobuttersäure sowie $\alpha$-Aminobuttersäure (interner Standard) in den entsprechenden Konzentrationen zugesetzt waren.

Die Aminosäurederivate wurden durch einen Gradienten aus Acetonitril und Phosphatpuffer aus der Säule eluiert (detailliertes Protokoll siehe Zhou 2000). Zur Erzeugung des Gradienten wurde ein Gradientenmischer (Low Pressure Mixer, Ternary, Pharmacia LKB, Freiburg, Deutschland) verwendet. Die Emission der Derivatisierungsprodukte wurde nach einer Anregung bei $330 \mathrm{~nm}$ bei $408 \mathrm{~nm}$ gemessen (Fluoreszenzdetektor 2144, Pharmacia LKB, Freiburg, Deutschland). Zur Auswertung der Daten wurde ein Integrationsprogramm (PeakNet Version 5.1, Chromatographie Datenstation, Dionex GmbH, Idstein, Deutschland) verwendet.

\subsubsection{Anatomische und histologische Methoden}

\subsubsection{Einbettung in Styrol-Methacrylat}

Pflanzenteile, die anatomisch untersucht werden sollten, wurden nach der Ernte in einer Mischung aus $37 \%(\mathrm{v} / \mathrm{v})$ Formaldehyd, $100 \%(\mathrm{v} / \mathrm{v})$ Eisessig und $70 \%(\mathrm{v} / \mathrm{v})$ Ethanol (FAE, 5:5:90) aufbewahrt. Für die Einbettung wurde das Material in $70 \%$ (v/v) Ethanol überführt, wobei das Hypokotyl von A. thaliana als Ganzes belassen wurde, während von den Blättern 0,5 x 0,5 cm große Fragmente von der adaxialen Seite der Blätter im Bereich der Mittelrippe verwendet wurden. Die Proben wurden dann entwässert, bevor sie mit dem Plastik infiltriert wurden. Dazu wurden sie nacheinander in den folgenden Lösungen inkubiert: $70 \%(\mathrm{v} / \mathrm{v})$ Ethanol für 2 h, $80 \%$ (v/v) Ethanol für 2 h, $90 \%$ (v/v) Ethanol für 2 h, $96 \%(v / v)$ Ethanol für 2 h, $96 \%$ (v/v) Ethanol für 12 h, $100 \%(v / v)$ Ethanol für 2 h,

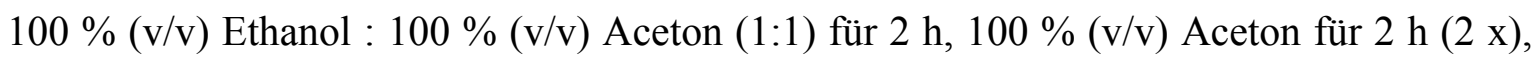
$100 \%(\mathrm{v} / \mathrm{v})$ Aceton : Plastik (1:1) für 4 h, $100 \%(\mathrm{v} / \mathrm{v})$ Aceton : Plastik (1:3) für $12 \mathrm{~h}$, 
reines Plastik für 12 h (2 x). Für die Plastik-Lösung wurden Styrol (Merck, Darmstadt, Deutschland) und Butyl-Methacrylat (Sigma, Steinheim, Deutschland) im Verhältnis 1:1 gemischt. Zusätzlich wurde $2 \%$ (w/v) Dibenzoylperoxid hinzugegeben, welches $50 \%$ Phthalat enthält (Peroxid Chemie GmbH, Pullach, Deutschland). Nach der Infiltration mit flüssigem Plastik wurden die Proben in Gelatine-Kapseln (Größe 0, Plano GmbH, Wetzlar, Deutschland) überführt, mit frischer Plastik-Lösung bedeckt und leicht gekippt in einem Trockenschrank für 1 Tag bei $60^{\circ} \mathrm{C}$ und weitere 10 Tage bei $37^{\circ} \mathrm{C}$ inkubiert, bis das Plastik polymerisiert war.

\subsubsection{Herstellung von Semidünnschnitten mit Hilfe eines Mikrotoms}

Vor dem Schneiden mit dem Mikrotom wurden die eingebetteten Proben zunächst getrimmt. Beim Trimmen wurde überflüssiges Plastik, das die Probe umgibt, entfernt. Die später mit dem Mikrotom zu schneidende Fläche sollte möglichst klein, die Probe aber noch von allen Seiten vom Einbettungsmedium umgeben sein. Hierfür wurden die Plastikblöckchen zunächst mit Hilfe einer kleinen Handsäge bearbeitet. Das feinere Trimmen erfolgte mit einer Rasierklinge und Zuhilfenahme eines Binokulars. Dabei wurde die Probe in eine pyramidenartige Form gebracht. Hierbei war darauf zu achten, dass die Seitenkanten möglichst parallel waren. Die Spitze der Pyramide wurde so weit abgetragen, bis die Probe frei lag. Das ca. 0,5 x 0,5 x $1 \mathrm{~cm}$ große Blöckchen wurde anschließend mit der Grundseite auf eine Probenhalterung aufgeklebt (Pattex Sekundenkleber Blitzkleber Gel, Henkel, Düsseldorf, Deutschland). Nach einer Trockenzeit von 1 - 2 Stunden bei $60^{\circ} \mathrm{C}$ wurden die Proben weiter bearbeitet.

Die Herstellung von Semidünnschnitten erfolgte mit Hilfe eines Mikrotoms (Autocut, Reichert-Jung, Heidelberg, Deutschland). Zum Schneiden wurden frisch gebrochene Glasmesser (Knifemaker 7800, LKB, Stockholm, Schweden) verwendet. Die fertigen Schnitte wurden mit Hilfe eines Pinsels oder einer Federstahlpinzette auf gelatinierte Objektträger auf einen Tropfen frisch abgekochtes Wasser aufgesetzt. Anschließend wurden die Schnitte 30 Sekunden mit Chloroform bedampft, wodurch sich eingerollte und gefaltete Schnitte wieder streckten. Zum Schluss wurden die Objektträger auf eine Heizplatte $\left(60^{\circ} \mathrm{C}\right)$ gelegt, bis der Wassertropfen getrocknet war. 


\subsubsection{Herstellung von Schnitten mit dem Gefriermikrotom}

Die Herstellung der Querschnitte der GUS-Reporterpflanzen erfolgte mit einem Gefriermikrotom (2800 Frigocut N, Reichert-Jung, Heidelberg, Deutschland). Damit die Zellen bei dieser Methode nicht platzen, wurden die Proben zuvor mit einem speziellen, zuckerhaltigen Einbettungsmedium (Pabisch, Bielefeld, Deutschland) infiltriert. Dazu wurden die in FAE fixierten Proben zunächst in $70 \%$ (v/v) Ethanol überführt. Danach wurden sie für 2 Stunden unter leichtem Schwenken in einem Gemisch aus $70 \%(\mathrm{v} / \mathrm{v})$ Ethanol und dem Einbettungsmedium (1:1) und anschließend für weitere 2 Stunden in 100 $\%$ Einbettungsmedium inkubiert. Die vorbereiteten Proben wurden bei $-25^{\circ} \mathrm{C}$ geschnitten. Die fertigen, $10 \mu \mathrm{m}$ dicken Schnitte wurden auf einen Objektträger mit $50 \%(\mathrm{v} / \mathrm{v})$ Glycerin gelegt, mit einem Deckgläschen bedeckt und sofort mikroskopisch untersucht.

\subsubsection{Herstellung von gelatinierten Objektträgern}

Damit die Schnitte gut auf den Objektträgern haften, wurden sie zuvor mit einer GelatineLösung überzogen. Dafür wurden die Objektträger zunächst mit Aceton von Fettschlieren befreit, indem sie 30 Minuten in einer Glaspetrischale mit Aceton inkubiert wurden. Anschließend wurden die Objektträger in ein Edelstahlgestell positioniert, mit Leitungswasser abgespült und für 2 Stunden im Ultraschallbad in einer $2 \%(\mathrm{v} / \mathrm{v})$ Extranlösung gereinigt. Danach wurden sie 2 Stunden unter fließendem Leitungswasser und weitere 5 Minuten mit demineralisiertem $\mathrm{H}_{2} \mathrm{O}$ gespült. Die gesäuberten Objektträger wurden noch im feuchten Zustand in eine 0,5 \% (w/v) Gelatine-Lösung getaucht. Die Lösung wurde zuvor frisch angesetzt, bei $50^{\circ} \mathrm{C}$ gelöst und mit Hilfe eines Faltenfilters filtriert. Um eine bessere Haltbarkeit zu gewährleisten und Kontaminationen mit Mikroorganismen zu verhindern, wurde der Gelatine-Lösung 1,77 mM Kaliumchrom-IIIsulfat zugesetzt. 2 Stunden nach dem Überziehen mit der Gelatine-Lösung waren die Objektträger getrocknet und konnten verwendet werden.

\subsubsection{Färbung mit Toluidinblau}

Toluidinblau ist ein Farbstoff, der an saure Gruppen bindet und eine Färbung von grün bis violett hervorruft, je nachdem, wie stark und an welches Molekül er gebunden ist. Lignifizierte Zellwände färben sich beispielsweise türkisblau, während Cytoplasma und unverholzte Zellwände sich violett färben. 
Für die Färbung wurden die Schnitte für 10 Minuten in einem Tropfen 0,05 \% (w/v) Toluidinblau in destilliertem Wasser bei $60^{\circ} \mathrm{C}$ inkubiert. Anschließend wurde überschüssiger Farbstoff unter fließendem Wasser entfernt, und der Schnitt wurde auf der Heizplatte bei $60^{\circ} \mathrm{C}$ getrocknet.

\subsubsection{Licht- und Fluoreszenzmikrokopie}

Gefärbte Schnitte wurden im Hellfeld eines Lichtmikroskops (Axioskop, Zeiss, Oberkochen, Deutschland) untersucht. Autofluoreszenz wurde an ungefärbten Schnitten mit der Filterkombination G365/FT395/LP420 detektiert. Digitale Bilder der Autofluoreszenz wurden mit einer Belichtungszeit von 1,5 Sekunden aufgenommen.

\subsubsection{Statistik}

Für die Auswertung wurde mit Hilfe der Software Statgraphics überprüft, ob die Ergebnisse normalverteilt waren und die Varianzhomogenität gegeben war. War dies der Fall, so wurden die Daten bei einem Vergleich von zwei Varianten mit dem Student's TTest analysiert. Bei einer Irrtumswahrscheinlichkeit von $\mathrm{p} \leq 0,05$ wurden die Ergebnisse mit einem Stern gekennzeichnet. Bei einer noch geringeren Irrtumswahrscheinlichkeit wurden die Unterschiede mit zwei $(p \leq 0,01)$ bzw. drei $(p \leq 0,001)$ Sternen markiert. Zur Ermittlung der Signifikanz von Unterschieden zwischen mehreren Varianten wurde eine einfache Varianzanalyse (ANOVA) gefolgt von einem Multiple Range Test (Fisher's LSD Test) durchgeführt. Signifikante Unterschiede $(\mathrm{p} \leq 0,05)$ werden in dieser Arbeit durch unterschiedliche Buchstaben dargestellt. Wenn die Daten nicht normalverteilt oder die Varianzen nicht homogen waren, wurde der Mann-Whitney-Test verwendet. Die Ergebnisse werden in Form von mit dem PC-Programm Origin erstellten Box-undWhisker-Plots präsentiert. 


\section{Ergebnisse}

\subsection{Analysen des Xylemsaftes von Brassica napus im Bezug auf potentielle antifungale Eigenschaften}

Um zu überprüfen, ob der Xylemsaft von Raps (B. napus var. napus) antifungale Eigenschaften aufweist und ob diese sich nach Infektion der Pflanzen mit $V$. longisporum verändern, wurde die Proliferation des Pathogens im Xylemsaft von infizierten Pflanzen und in Xylemsaft von Kontrollpflanzen in vitro untersucht. Dafür wurden Sporen von $V$. longisporum in Xylemsaft inkubiert (Gesamtvolumen $=1 \mathrm{ml}$ ). Nach 3 Tagen wurde die Pilzmenge anhand von DNA-Messungen ermittelt (Punkt 2.2.3.3).

Die Ergebnisse zeigten, dass der Pilz im Xylemsaft von infizierten Pflanzen schlechter wuchs als im Xylemsaft von Kontrollen (Abb. 3). Während die Konzentration der PilzDNA im Xylemsaft von infizierten Pflanzen um 15 pg pro $\mu$ l betrug, war sie im Xylemsaft von Kontrollpflanzen um etwa $50 \%$ reduziert.



Abb. 3: Wachstum von $V$. longisporum im Xylemsaft von infizierten (schwarze Säule) und im Xylemsaft von mock inokulierten Pflanzen (weiße Säule). Der Xylemsaft wurde zwischen 25 und 28 dpi gewonnen. Abgebildet ist die mittlere Konzentration pilzlicher DNA nach 3tägier Inkubation mit Standardabweichung ( $n=15$ für Xylemsaft aus infizierten Pflanzen, $n=13$ für Xylemsaft aus nicht infizierten Pflanzen). Signifikante Unterschiede $(p \leq 0,01)$ sind durch zwei Sterne gekennzeichnet. Die DNA-Messung wurde von der AG Karlovsky durchgeführt. Die Daten wurden bereits veröffentlicht (Floerl, Druebert et al. 2008). 
Um auszuschließen, dass der beobachtete inhibitorische Effekt von Xylemsaft aus infizierten Pflanzen auf $V$. longisporum auf Unterschiede in der Nährstoffzusammensetzung zurückzuführen war, wurde die Konzentration von Zuckern, Aminosäuren, Mineralelementen sowie der Proteine bestimmt.

Die Konzentration von Glukose, Fruktose und Saccharose im Xylemsaft von infizierten Pflanzen unterschied sich nicht von der im Xylemsaft von Kontrollpflanzen (Abb. 4).



Abb. 4: Glukose, Fruktose und Saccharose im Xylemsaft infizierter (schwarze Säulen) und nicht infizierter Pflanzen (weiße Säulen). Der Xylemsaft wurde zwischen 25 und 28 dpi gewonnen. Dargestellt ist die mittlere Konzentrationen der einzelnen Zuckermetabolite mit Standardabweichung $(n=8)$.

Auch hinsichtlich der Proteinmenge gab es keine Unterschiede zwischen den Xylemsäften der unterschiedlich behandelten Pflanzen (Abb. 5). Die Summe aller löslichen Aminosäuren war in den verschiedenen Xylemsäften ebenfalls gleich (Abb. 6). Jedoch ergab die Messung signifikante Unterschiede bei einzelnen Aminosäuren. So war die Konzentration von Glycin und Isoleucin im Xylemsaft von infizierten Pflanzen erhöht, während die Menge an Tryptophan in infizierten Pflanzen im Vergleich zu Kontrollpflanzen verringert war (Tabelle 13). 


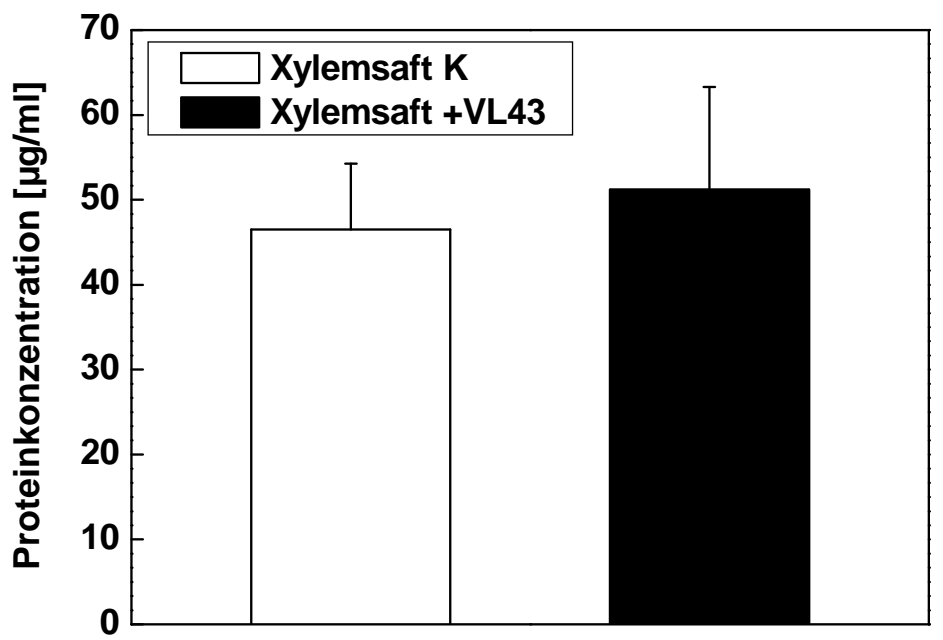

Abb. 5: Gesamt-Proteinkonzentration im Xylemsaft infizierter (schwarze Säulen) und nicht infizierter Pflanzen (weiße Säulen). Der Xylemsaft wurde zwischen 25 und 28 dpi gewonnen. Dargestellt ist die mittlere Proteinkonzentrationen mit Standardabweichung $(n=5)$.

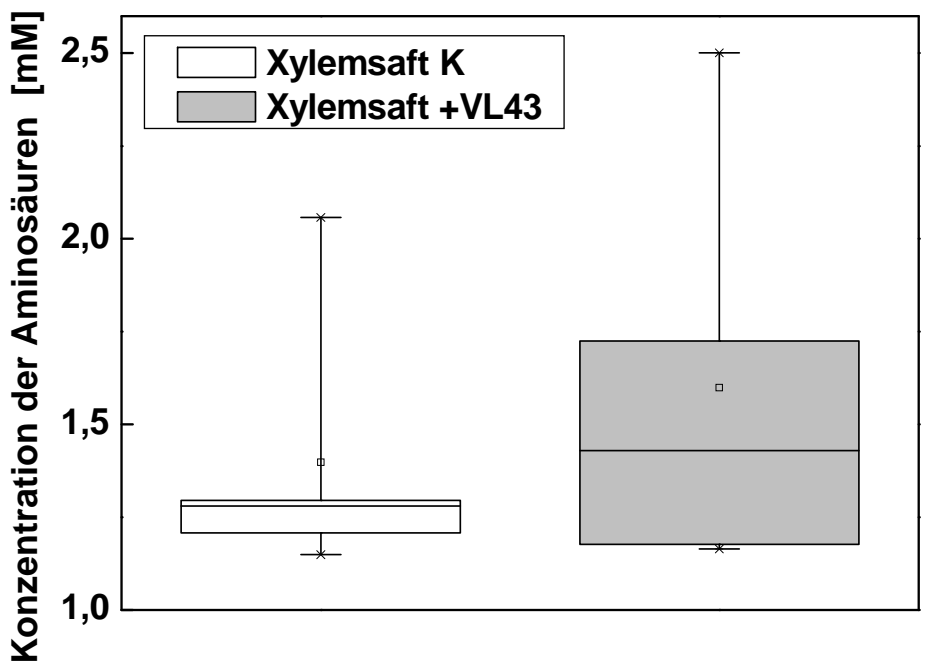

Abb. 6: Summe aller freien Aminosäuren im Xylemsaft infizierter (graue Box) und nicht infizierter Pflanzen (weiße Box). Der Xylemsaft wurde zwischen 25 und 28 dpi gewonnen. Die Daten sind dargestellt als Box-Plots $(n=5)$. Die Box beinhaltet $50 \%$ der Werte. Die Linie innerhalb der Box stellt den Median dar. Zusätzlich ist der Mittelwert als Quadrat abgebildet. 
Tabelle 13: Konzentration der verschiedenen Aminosäuren im Xylemsaft infizierter und nicht infizierter Pflanzen. Der Xylemsaft wurde zwischen 25 und 28 dpi gewonnen. Angegeben sind Mittelwerte \pm Standardabweichung $(n=5)$. Signifikante Unterschiede zwischen den Konzentrationen im Xylemsaft infizierter und nicht infizierter Pflanzen sind durch unterschiedliche Buchstaben in Klammern gekennzeichnet.

\begin{tabular}{|c|c|c|}
\hline Aminosäure & $\begin{array}{c}\text { Konzentration im } \\
\text { Xylemsaft aus nicht } \\
\text { infizierten Pflanzen }[\mu \mathrm{M}]\end{array}$ & $\begin{array}{c}\text { Konzentration im } \\
\text { Xylemsaft aus infizierten } \\
\text { Pflanzen }[\mu \mathrm{M}] \\
\end{array}$ \\
\hline Asparagin & $125,6 \pm 55,6(a)$ & $89,6 \pm 80,4$ (a) \\
\hline Glutamin & $241,4 \pm 90(a)$ & $191,6 \pm 124,1(a)$ \\
\hline Asparaginsäure & $36,8 \pm 8,2(a)$ & $49,6 \pm 19,7$ (a) \\
\hline Serin & $67,8 \pm 17,6(a)$ & $89,6 \pm 35,1$ (a) \\
\hline Histidin & $17,6 \pm 5,8(a)$ & $19,8 \pm 3,6(a)$ \\
\hline Glutaminsäure & $240,2 \pm 84,7$ (a) & $286,4 \pm 151(a)$ \\
\hline Glycin & $36,8 \pm 7,1$ (a) & $62,6 \pm 10,5(b)$ \\
\hline Threonin & $39,6 \pm 18,4$ (a) & $61,6 \pm 19,2$ (a) \\
\hline Arginin & $34,8 \pm 11,9$ (a) & $48,2 \pm 16,5$ (a) \\
\hline Alanin & $149,8 \pm 72,9$ (a) & $205,2 \pm 31,6(a)$ \\
\hline$\gamma$-Aminobuttersäure & $176,2 \pm 43(\mathrm{a})$ & $237,4 \pm 56,2$ (a) \\
\hline Tyrosin & $21,2 \pm 3,1(\mathrm{a})$ & $17,2 \pm 10,7$ (a) \\
\hline Valin & $88,2 \pm 12,2(a)$ & $105,6 \pm 32,7(a)$ \\
\hline Methionin & $5,4 \pm 0,9$ (a) & $4,4 \pm 3,7(a)$ \\
\hline Tryptophan & $11,6 \pm 2,3(b)$ & $6,6 \pm 4,6(a)$ \\
\hline Isoleucin & $32,2 \pm 3,8(a)$ & $45 \pm 12,6(b)$ \\
\hline Phenylalanin & $14,2 \pm 2(a)$ & $11,2 \pm 5,7(a)$ \\
\hline Leucin & $30,8 \pm 6,5(a)$ & $38,2 \pm 16,2(a)$ \\
\hline Lysin & $27,6 \pm 4,8$ (a) & $30 \pm 16,7(a)$ \\
\hline
\end{tabular}

Bezüglich der Mineralnährstoffe gab es geringe, jedoch signifikante Unterschiede bei einzelnen Elementen (Abb. 7). Die Konzentration von Kalium und Magnesium war im Xylemsaft von infizierten Pflanzen im Vergleich zu dem Saft aus Kontrollen erhöht, während die von Phosphor und Schwefel verringert war. Die Mengen von Calcium und Eisen waren im Xylemsaft von den unterschiedlich behandelten Pflanzen gleich. 


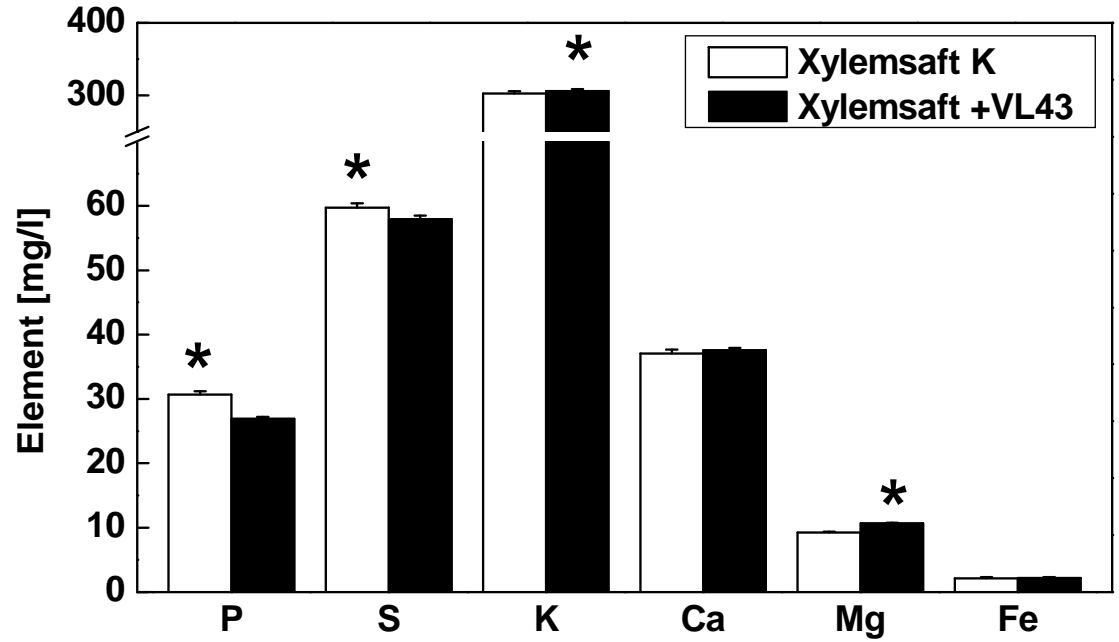

Abb. 7: Mineral-Nährelemente im Xylemsaft infizierter (schwarze Säulen) und nicht infizierter Pflanzen (weiße Säulen). Dargestellt ist die mittlere Konzentration von Phosphor (P), Schwefel (S), Kalium (K), Calcium (Ca), Magnesium (Mg) und Eisen (Fe) mit Standardabweichung $(n=5)$. Signifikante Unterschiede $(p \leq 0,05)$ zwischen den Xylemsäften der unterschiedlich behandelten Pflanzen sind mit einem Stern markiert. Der Xylemsaft wurde zwischen 25 und 28 dpi gewonnen.

Zusammenfassend ist also festzustellen, dass es nur geringfügige Unterschiede im Xylemsaft von infizierten und dem von Kontrollpflanzen hinsichtlich der Bestandteile gab, die $V$. longisporum als Nährstoffquelle benutzen kann. Der beobachtete Wachstumsunterschied des Pilzes im Xylemsaft von infizierten Pflanzen konnte also nicht durch eine geringere Nährstoffverfügbarkeit der hier untersuchten Bestandteile erklärt werden.

Als andere mögliche Substanz für den inhibierenden Effekt kam Salicylsäure in Frage. Im Xylemsaft von B. napus var. napus wurden signifikant höhere Mengen Salicylsäure (SA) sowie Salicylsäure-Glycosid (SAG) nach Infektion mit $V$. longisporum detektiert (Ratzinger et al. 2009). Daher wurde das oben beschriebene Wachstumsexperiment von $V$. longisporum in Xylemsaft unter Zugabe von $3 \mu \mathrm{M}$ Salicylsäure wiederholt. Die Konzentration von Salicylsäure richtete sich hierbei nach den Messergebnissen des Pflanzenhormons im Xylemsaft von B. napus Pflanzen nach Infektion mit V. longisporum (Ratzinger et al. 2009). Das Experiment wurde sowohl mit Xylemsaft von Kontrollpflanzen als auch mit PDB Medium durchgeführt. In keinem der beiden verschiedenen Versuchsansätze gab es Unterschiede hinsichtlich der DNA-Menge von $V$. 
longisporum (Abb. 8). Salicylsäure hatte also keinen direkten Effekt auf das Pilzwachstum und konnte daher als Auslöser für das eingeschränkte Wachstum von V. longisporum im Xylemsaft von infizierten B. napus Pflanzen ausgeschlossen werden.
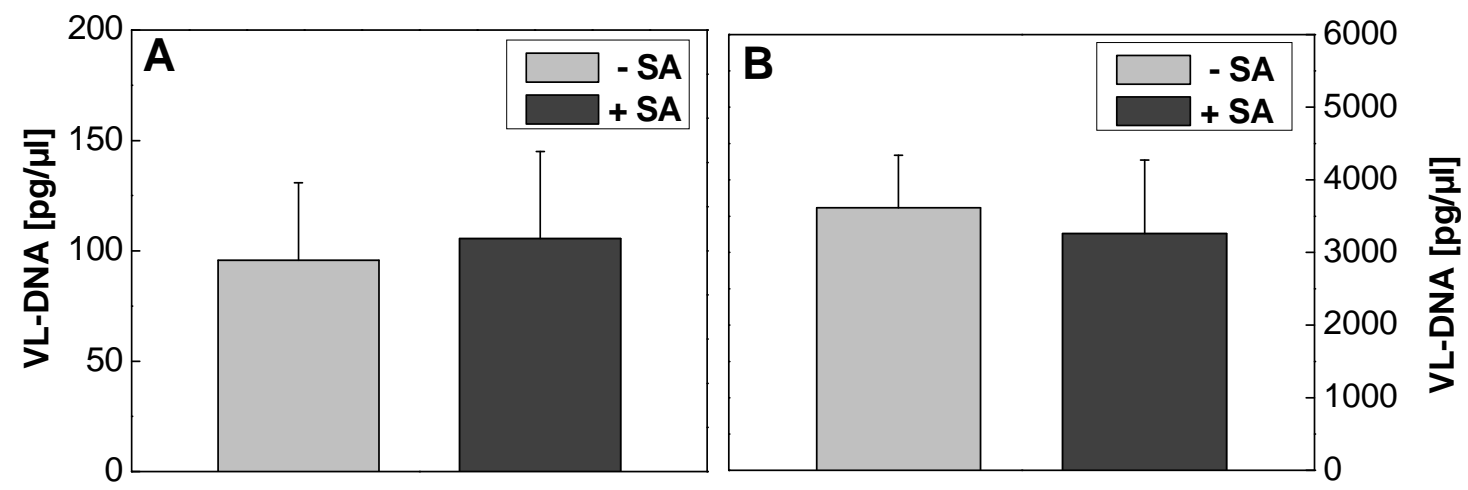

Abb. 8: Wachstum von $V$. longisporum unter dem Einfluss von Salicylsäure. Dargestellt ist die Konzentration von Verticillium-DNA im Xylemsaft von Kontrollpflanzen (A) und in PDB-Medium (B) mit (dunkelgraue Säulen) und ohne (hellgraue Säulen) Zusatz von $3 \mu$ M Salicylsäure. Präsentiert werden Mittelwerte mit Standardabweichung ( $n=6$ für Xylemsaft, $n=10$ für PDB-Medium). Der Xylemsaft wurde zwischen 25 und 28 dpi gewonnen. Die DNA-Messung wurde von der AG Karlovsky durchgeführt.

Neben dem putativen Nutzen der Proteine im Xylemsaft von Raps als Nährstoffquelle für $V$. longisporum könnten diese auch wachstumsinhibierende Eigenschaften gegen das Pathogen aufweisen. Da Floerl et al. (2008) Proteine mit putativ antifungalen Eigenschaften im Xylemsaft von Raps nachgewiesen hatten, sollte überprüft werden, ob diese Xylemsaft-Proteine das Wachstum von V. longisporum beeinflussen können und ob die nach Infektion durch $V$. longisporum neu oder vermehrt sekretierten Proteine für den beschriebenen inhibitorischen Effekt bezüglich des Wachstums des Pilzes im Xylemsaft von infizierten Pflanzen verantwortlich waren. Daher wurde der Einfluss der Proteine aus dem Xylemsaft von infizierten und nicht infizierten B. napus Pflanzen auf das Wachstum von $V$. longisporum in vitro untersucht. Dazu wurden die Wachstumsexperimente mit Xylemsaft wiederholt, aus dem Moleküle mit einem Molekulargewicht von mehr als $3 \mathrm{kDa}$ durch Filtration entfernt wurden. In einem Bradford-Test konnten in filtriertem Xylemsaft keine Proteine mehr detektiert werden. Parallel dazu wurde das Wachstum des Pilzes in PDB-Medium untersucht, welches mit $15 \mu \mathrm{g} / \mathrm{ml}$ (Endkonzentration) der aus dem Xylemsaft heraus gefilterten Proteine versetzt wurde. 
Die DNA-Menge von $V$. longisporum war nach 3tägiger Inkubation im proteinfreien Xylemsaft deutlich höher als die in ungefiltertem Xylemsaft (Abb. 9 A). Dieser Effekt war in gleichem Maße im Xylemsaft von infizierten wie in dem von Kontrollpflanzen zu beobachten. In Übereinstimmung mit diesen Ergebnissen konnte in Wachstumsexperimenten in PDB-Medium gezeigt werden, dass das Wachstum von $V$. longisporum durch Zugabe der Proteine aus dem Xylemsaft im Vergleich zu nicht supplementiertem PDB-Medium deutlich eingeschränkt wurde (Abb. 9 B). Die Proteine im Xylemsaft von B. napus hatten also eine inhibierende Wirkung auf die Proliferation von $V$. longisporum. Da die Proteine aus dem Xylemsaft von nicht infizierten Pflanzen ähnliche antifungale Eigenschaften aufwiesen wie die aus dem Xylemsaft von infizierten Pflanzen, lässt sich schlussfolgern, dass B. napus konstitutiv Proteine in den Apoplast sekretiert, die unkontrolliertes Wachstum von $V$. longisporum unterdrücken.

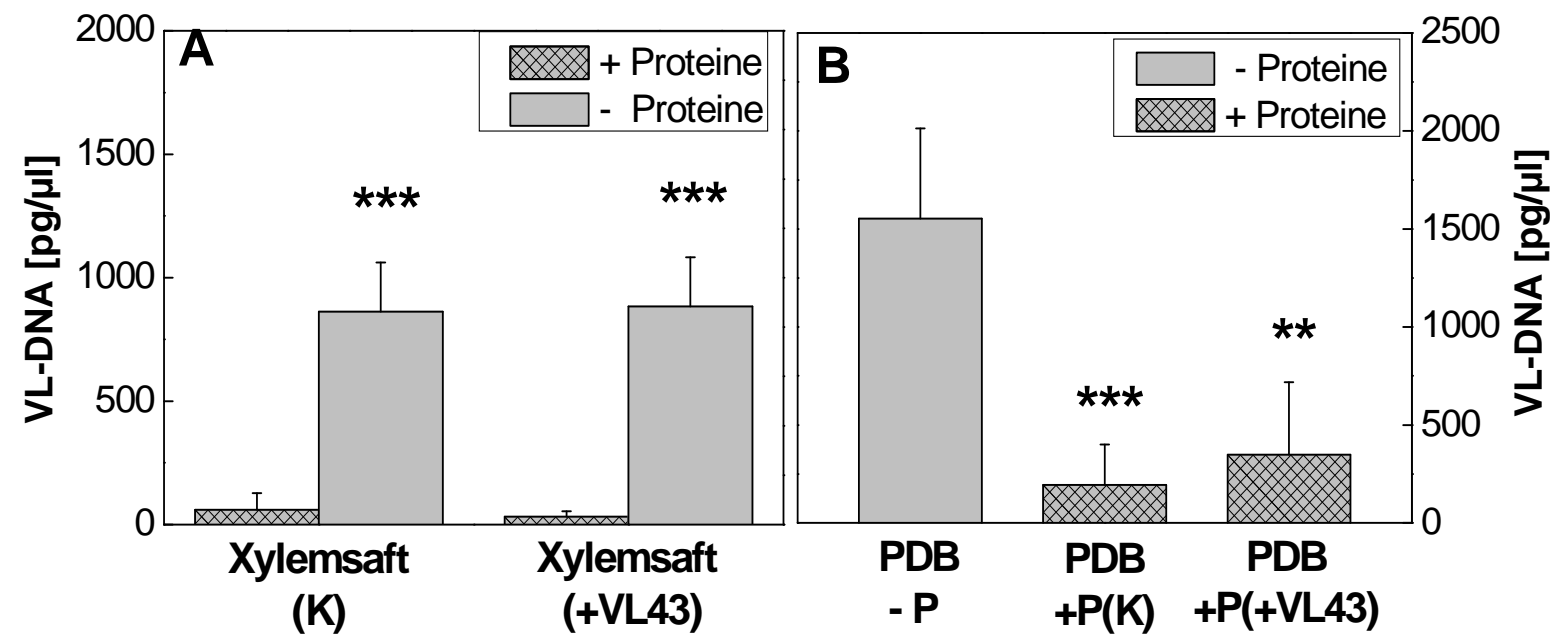

Abb. 9: Einfluss von Xylemsaft-Proteinen auf das Wachstum von V. longisporum. Abgebildet ist die Konzentration von Verticillium-DNA im Xylemsaft (A) und in PDBMedium (B) in Anwesenheit (schraffierte Säulen) oder Abwesenheit (graue, nicht schraffierte Säulen) von Xylemsaft-Proteinen. Präsentiert werden Mittelwerte mit Standardabweichung $(n=5)$. Signifikante Unterschiede zwischen den Proben mit und denen ohne Proteine sind durch zwei $(p \leq 0,01)$ oder drei $(p \leq 0,001)$ Sterne gekennzeichnet. Zwischen der Behandlung mit Proteinen aus dem Xylemsaft aus Kontrollpflanzen (Xylemsaft (K) bzw. PDB + P (K)) und denen aus infizierten Pflanzen (Xylemsaft (+VL43) bzw. PDB + P (+VL43)) gab es keine Unterschiede $(p=$ 0,4 im Xylemsaft bzw. $p=0,2$ im PDB-Medium). Der Xylemsaft wurde zwischen 25 und 28 dpi gewonnen. Die DNA-Messung wurde von der AG Karlovsky durchgeführt. 


\subsection{Charakterisierung von T-DNA-Insertionsmutanten von Arabidopsis thaliana hinsichtlich ihrer Sensitivität gegenüber Verticillium longisporum}

Für die funktionelle Charakterisierung der von V. longisporum beeinflussten Proteine wurden Pflanzen mit einer veränderten Expression des entsprechenden Gens untersucht. Hierfür wurden T-DNA-Insertionslinien verwendet. Bei diesen Linien handelt es sich um Pflanzen, bei denen eine T-DNA in ein bestimmtes Gen oder in dessen Promoterbereich integriert ist, was $\mathrm{zu}$ einer Beeinträchtigung oder zum vollständigen Verlust der Genfunktion führen kann. Für die zu analysierenden Kandidatengene waren 1 bis 3 verschiedene Linen pro Gen verfügbar. Mit Hilfe der öffentlich zugänglichen Angaben zur Sequenz der verschiedenen Gene (The Arabidopsis Information Resource; www.tair.org) wurde überprüft, in welchem Bereich des jeweiligen Gens die T-DNA inseriert ist (Abb. 10). Nur für 2 Gene (At5g05340 und At5g08370) gab es Linien, bei denen die kodierenden Bereiche des Gens von der Insertion direkt betroffen sind. Bei allen anderen Linien lag die Insertion im UTR-Bereich oder außerhalb des Gens. Die Samen wurden bestellt und vermehrt. Für alle Linien konnten mittels PCR in der folgenden Generation homozygote Pflanzen identifiziert werden. Dies ist beispielhaft für die Linie SALK_147839, die das Gen At4g12910 (Serin-Carboxypeptidase) betrifft, dargestellt (Abb. 11).

Um zu überprüfen, ob die Expression des jeweiligen Gens durch die Insertion der T-DNA beeinträchtigt war, wurden unter Kurztag-Bedingungen angezogene, homozygote Pflanzen aller Linien mittels qRT-PCR überprüft. Da für die Generierung der SALK-Linien der Ökotyp Columbia, für die FLAG-Linien dagegen der Ökotyp Wassilewskija verwendet wurde, wurden beide Ökotypen in den Versuchen mitgeführt. Die Expression der durch die Insertion betroffenen Gene der SALK-Linien wurde relativ zu der des gleichen Gens im Columbia Wildtyp (Col-0) ermittelt. Die Expression der Gene der FLAG-Linien wurde mit der im Wassilewskija Wildtyp (Ws-2) verglichen.

Bei der Linie SALK_051769, bei der die T-DNA-Insertion den Promoterbereich des Gens für die Peroxidase 34 (pod34) betrifft, war die relative Transkriptmenge von pod34 signifikant gegenüber der im Wildtyp erhöht (Abb. 12). Bezüglich der Peroxidase 37 (pod37) wurden drei SALK-Linien getestet. Eine (SALK_024708) wies eine erhöhte Expression von pod37 auf, während sich die Transkriptmenge von pod37 der weiteren Linien (SALK_022520 und SALK_089515) nicht von der des Wildtyps unterschied. 
POD34 (At3g49120)



POD37 (At4g37530)

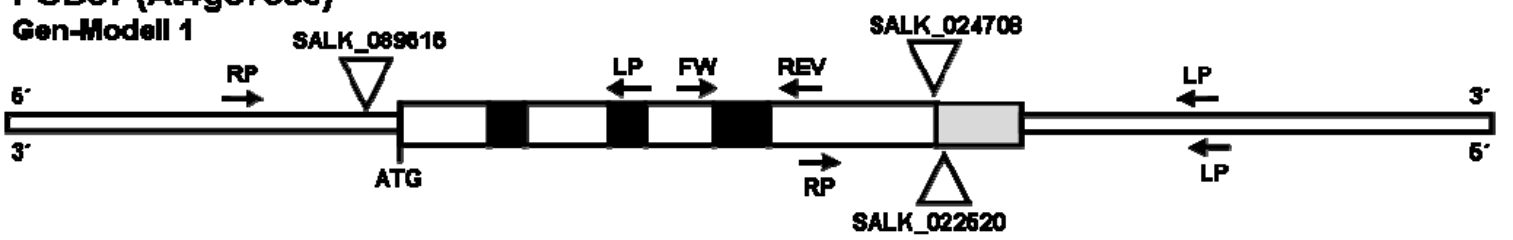

POD52 (At5g05340)
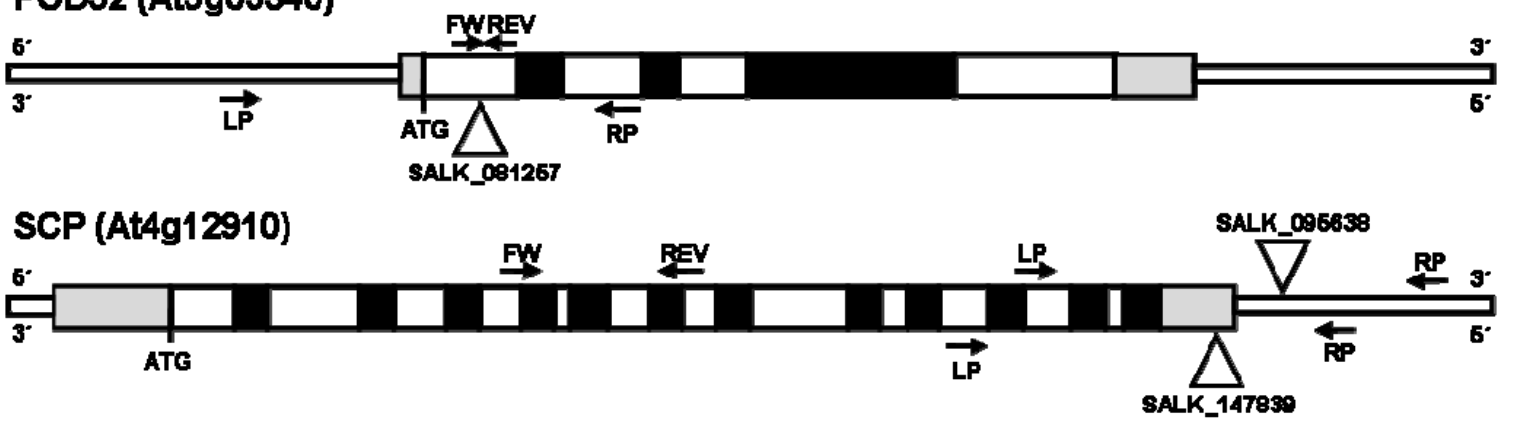

GAL (At5g08370)

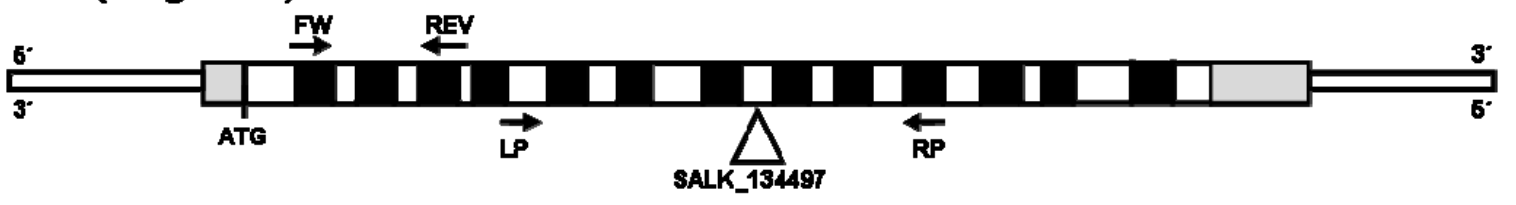

LLP (At3g16530)

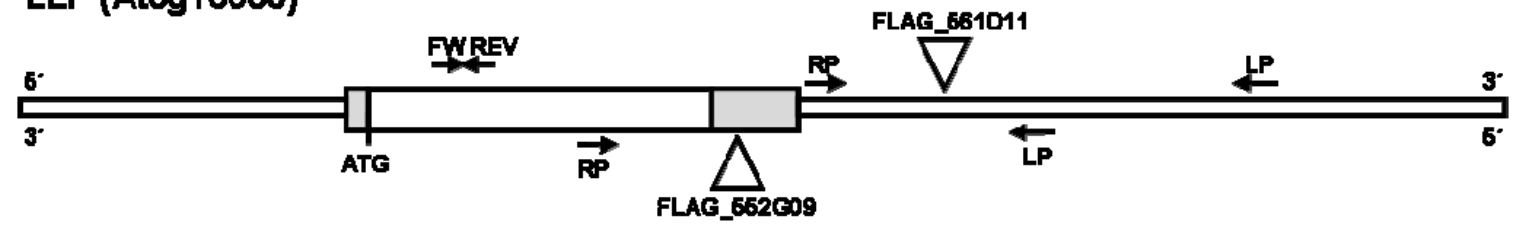

GLP3 (At5g20630)

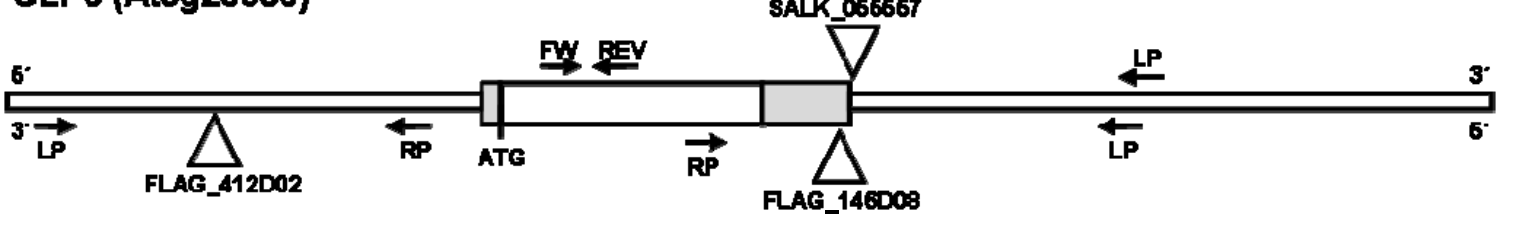

Abb. 10: Schematische Darstellung der untersuchten Zielgene. Diese codieren für folgende Proteine: Peroxidase 34 (POD34), Peroxidase 37 (POD37), Peroxidase 52 (POD52), Serin-Carboxypeptidase (SCP), a-Galactosidase (GAL), Lektin-ähnliches Protein (LLP) und Germin-ähnliches Protein 3 (GLP3). Abgebildet sind Exons (weiß), Introns (schwarz) und die UTR-Bereiche (grau) sowie die cDNA umgebende Region der DNA (dünnere Linie). Die Position der inserierten T-DNA der verschiedenen T-DNA-Insertionslinien ist mit einem Dreieck gekennzeichnet. Pfeile zeigen die Bindestellen der Primer für die qRT-PCR-Analysen (FW und REV) sowie die der Primer an, die für die PCR zur Selektion homozygoter Pflanzen verwendet wurden (RP und LP). 


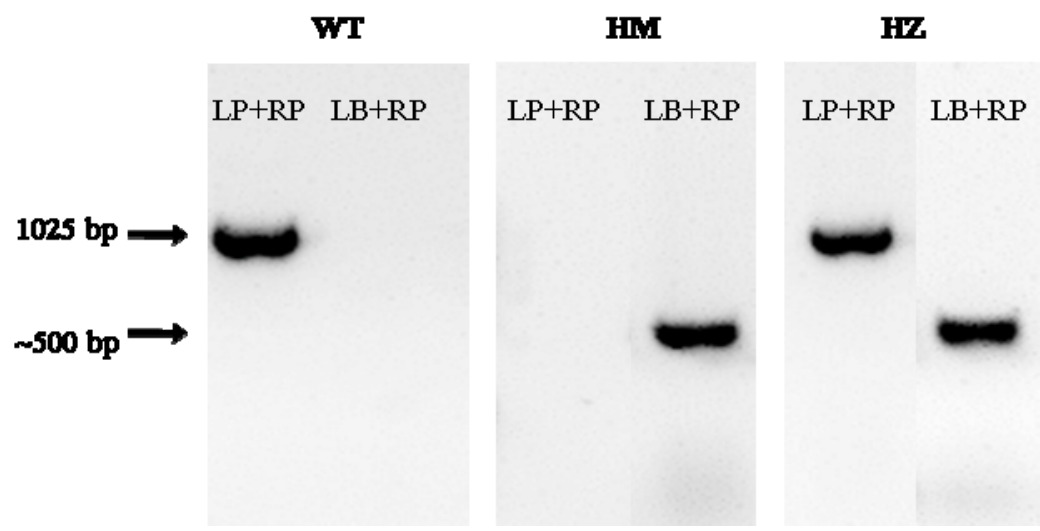

Abb. 11: 3-Primer-PCR zur genotypischen Charakterisierung einer T-DNAInsertionsmutante. Wildtyp-Proben (WT, links) zeigen eine Bande zwischen 1000 und $1500 \mathrm{bp}$, während mit der Primerkombination LB und RP keine DNA amplifiziert werden kann. Bei homozygoten Pflanzen (HM, Mitte) führt die PCR mit dem LB-Primer zu einer Bande um 500 bp, während bei der PCR mit dem LPPrimer die Bande fehlt. Können mit beiden Primerpaaren Banden detektiert werden, handelt es sich um Proben von heterozygoten Pflanzen (HZ, rechts). Abgebildet ist als Beispiel ein Agarosegel mit den Produkten der zwei PCR-Reaktionen zur Selektion homozygoter Pflanzen der T-DNA-Insertionslinie SALK_147839.

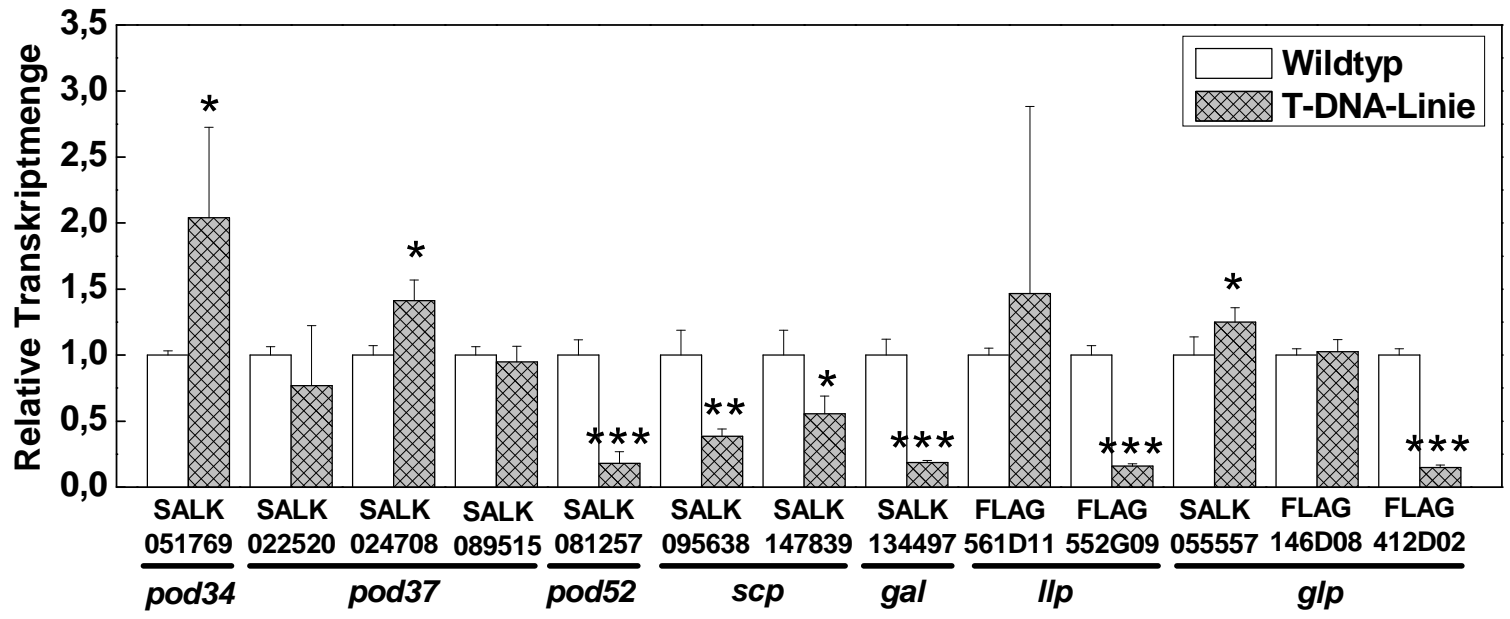

Abb. 12: Relative Expression der Zielgene in verschiedenen T-DNA-Insertionslinien. Dargestellt ist die mittlere relative Expression des durch die Insertion betroffenen Gens in den T-DNA-Insertionslinien (schraffierte Säulen) im Vergleich zum jeweiligen Wildtyp (weiße Säulen) mit Standardabweichung $(3 \leq n \leq 5)$. Signifikante Unterschiede zwischen der T-DNA-Linie und dem Wildtyp sind mit einem $(p \leq 0,05)$, zwei $(p \leq 0,01)$ oder drei Sternen $(p \leq 0,001)$ gekennzeichnet. Als Haushaltsgen diente Ubiquitin. 
Für die Peroxidase 52 (pod52) wurde eine Linie (SALK_081257) mit einer signifikant reduzierten Transkriptmenge identifiziert. Die Expression des Gens, das für die SerinCarboxypeptidase (scp) codiert, war in zwei Linien (SALK_095638 und SALK_147839) signifikant gegenüber der im Wildtyp verringert. Für die $\alpha$-Galactosidase (gal) wurde eine Linie (SALK_134497) mit einer signifikant verringerten Expression von gal gefunden. Bezüglich des Lektin-ähnlichen Proteins (llp) waren zwei Linien verfügbar. Die relative Transkriptmenge für llp war in der Linie FLAG_561D11 im Vergleich zum Wildtyp unverändert, während die T-DNA-Insertion bei der Linie FLAG_552G09 eine Reduktion der Transkriptmenge verursachte. Für das Germin-ähnliche Protein (glp3) zeigte die Linie FLAG_412D02 eine signifikant verringerte Expression, während die der zwei weiteren getesteten Linien (SALK_055557 und FLAG_146D08) im Vergleich zum Wildtyp unverändert war.

Bei den T-DNA-Insertionslinien, bei denen Peroxidasen betroffen sind, wurde ergänzend zu den Messungen der Transkriptmenge die Aktivität der Guajakolperoxidase getestet, um zu untersuchen, ob die Funktion der entsprechenden Enzyme durch die Insertion der TDNA beeinträchtigt war.

Die Ergebnisse zeigten, dass die Linien SALK_051769 (pod34) und SALK_024708 (pod37) eine signifikant erhöhte Guajakolperoxidase-Aktivität aufwiesen, während es bei den weiteren pod37 betreffenden Linien SALK_022520 und SALK_089515 keine Unterschiede zum Wildtyp gab (Abb. 13). Die erhöhte Guajakolperoxidase-Aktivität der beiden Erstgenannten stand in Übereinstimmung mit den Daten der qRT-PCR-Analysen, bei denen eine signifikante Erhöhung der Expression im Vergleich zum Wildtyp nachgewiesen wurde. Vermutlich führte die erhöhte Transkriptmenge zu der erhöhten Enzymaktivität. Die unveränderte Guajakolperoxidase-Aktivität der Linie SALK_022520 (pod37) im Vergleich zum Wildtyp war auf die unveränderte Expression des Gens zurückzuführen.

Die Linie SALK_081257 zeigte trotz signifikant verringerter Expression von pod52 keine Verminderung in der Guajakolperoxidase-Aktivität. Da eine spezifische Funktion von POD52 bislang nicht beschrieben wurde und somit auch das Substratspektrum nicht bekannt ist, ist ein möglicher Grund für die Diskrepanz der Ergebnisse der qRT-PCR und der Messungen der Guajakolperoxidase-Aktivität, dass POD52 Guajakol nicht so effizient oder gar nicht umsetzen kann. 


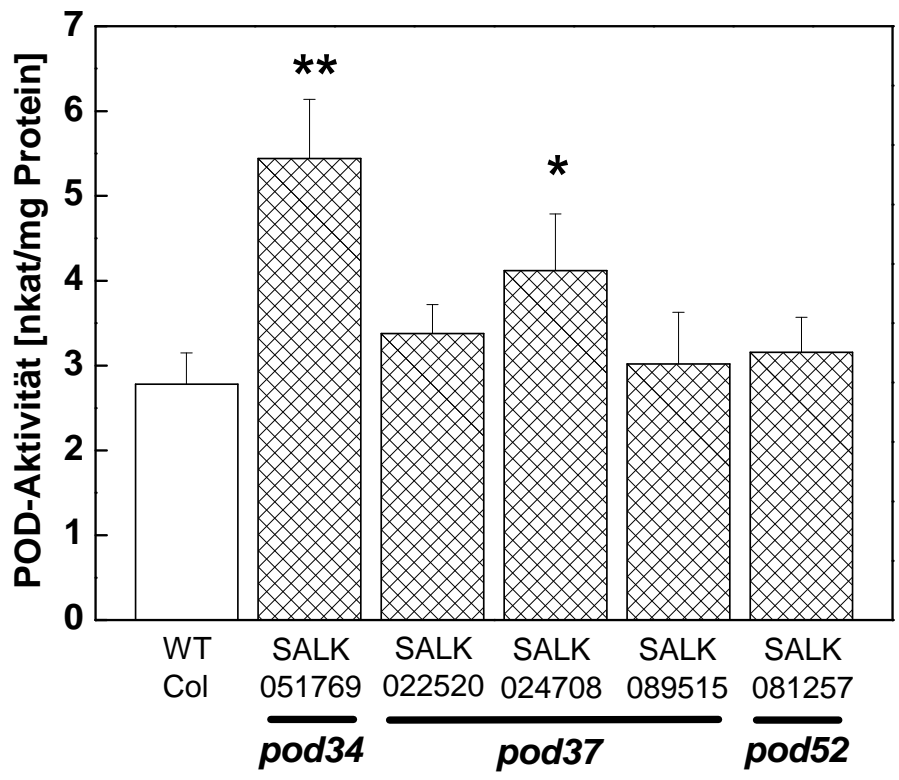

Abb. 13: Aktivität der Guajakolperoxidase in den T-DNA-Insertionslinien, in denen eine der drei Peroxidasen (pod34, pod37 oder pod52) betroffen ist, sowie im Wildtyp Col-0. Dargestellt ist mittlere Enzymaktivität mit Standardabweichungen $(3 \leq n \leq 5)$ in nanokatal bezogen auf $1 \mathrm{mg}$ der Proteine im Extrakt. Bei signifikanten Unterschieden zum Wildtyp sind die Ergebnisse mit einem $(p \leq 0,05)$ oder zwei Sternen $(p \leq 0,01)$ gekennzeichnet.

Um zu testen, ob die durch die 2-D-Gelelektrophorese entdeckten Proteine eine Funktion in der Pathogenabwehr von A. thaliana aufweisen, wurden die homozygoten T-DNAInsertionslinien, bei denen eine im Vergleich zum Wildtyp veränderte Transkriptmenge detektiert werden konnte, hinsichtlich ihrer Suszeptibilität gegenüber V. longisporum untersucht. Dazu wurden die Pflanzen in mehreren Experimenten mit dem Pathogen infiziert und unter Kurztag-Bedingungen kultiviert.

Erste Veränderungen der Pflanzen durch die Infektion mit $V$. longisporum waren in der Regel ca. 10 Tage nach Infektion zu sehen. Die Pflanzen wiesen zu diesem Zeitpunkt vergilbte Blattadern und ein verringertes Wachstum auf. Im weiteren Verlauf der Infektion traten Chlorosen auf. Zudem waren an einzelnen Pflanzen morphologische Veränderungen wie das Einrollen einzelner Blättern und ein asymmetrisches Wachstum der Blattrosette erkennbar (Abb. 1, Einleitung). Des Weiteren wurde durch Messungen der Chlorophyllfluoreszenz eine Reduktion der Quantenausbeute festgestellt (siehe Anhang A). 
Um den Pathophänotypen der Mutanten mit dem des Wildtyps vergleichen zu können und eine potentielle Veränderung der Suszeptibilität beurteilen zu können, wurde zur Quantifizierung der Stauchung die Blattfläche der einzelnen Pflanzen anhand von digitalen Bildern gemessen. Außerdem wurden die Blattrosetten 21 oder 28 Tage nach Infektion geerntet und die Biomasse ermittelt. Da es bei diesen Parametern Unterschiede zwischen den Kontrollpflanzen der verschiedenen T-DNA-Insertionslinien und den Wildtypen gab, wurde für alle Messungen die relative Veränderung zwischen infizierten und nicht infizierten Pflanzen berechnet. Zudem traten Schwankungen zwischen den verschiedenen Experimenten auf. Daher wurden die Daten aus den verschiedenen Experimenten anhand der immer mitgeführten Wildtyp-Kontrollen normalisiert.

Bei den meisten T-DNA-Insertionslinien waren keine Unterschiede zum Wildtyp hinsichtlich der Suszeptibilität gegenüber V. longisporum feststellbar. Die Blattfläche der SALK-Linien im Col-0 Hintergrund wies nach Infektion eine Reduktion zwischen 29 und $41 \%$ auf (Abb. 14).

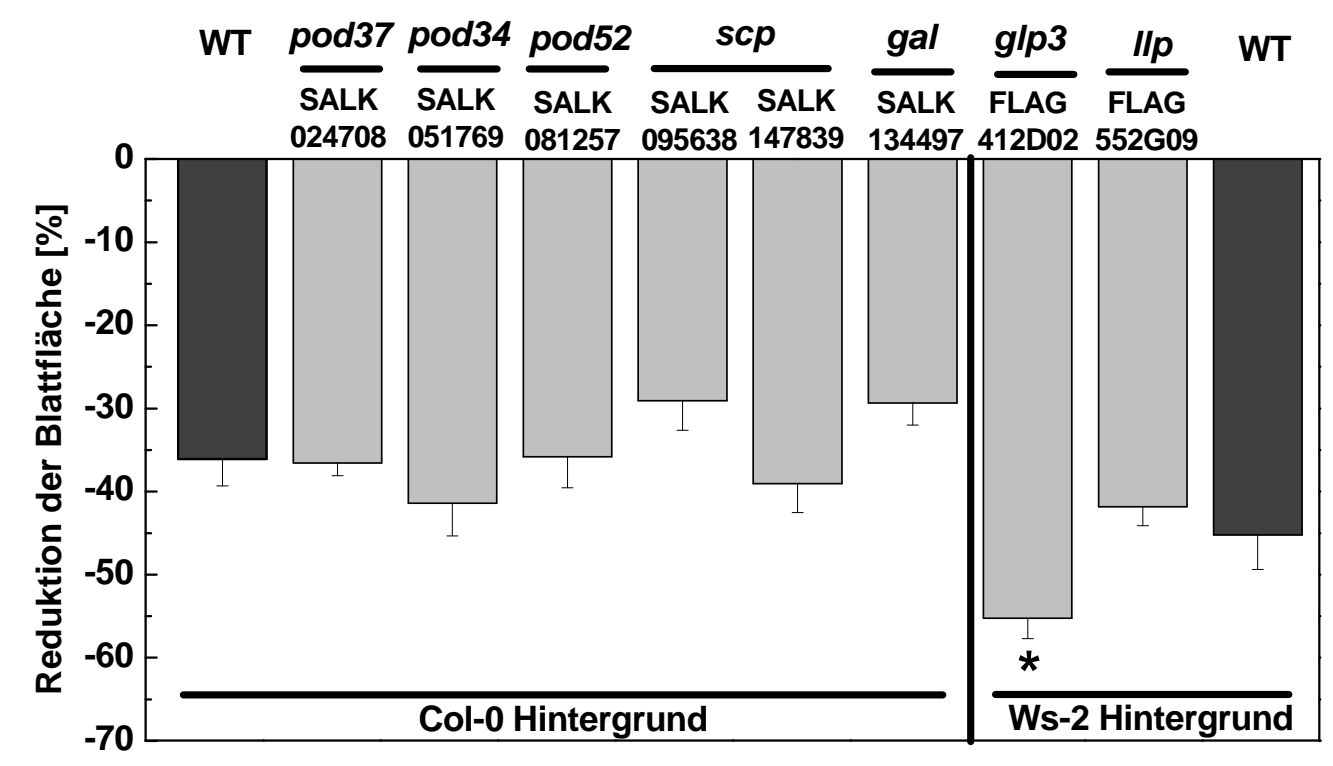

\begin{abstract}
Abb. 14: Reduktion der Blattfläche der T-DNA-Insertionslinien (hellgraue Säulen) und der Wildtypen Col-0 und Ws-2 (dunkelgraue Säulen) 21 dpi. Dargestellt ist die Reduktion der Blattfläche infizierter Pflanzen relativ zu den mock inokulierten Pflanzen in Prozent. Gezeigt werden die Mittelwerte mit Standardfehler aus unabhängigen Versuchen mit jeweils 20 Pflanzen je Behandlung und Linie $(n=1$ für pod37; $\mathrm{n}=2$ für pod52, scp und gal; $\mathrm{n}=3$ für pod34, Ilp und glp3). Signifikante Unterschiede $(p \leq 0,05)$ sind durch einen Stern gekennzeichnet.
\end{abstract}


Die Reduktion der Blattfläche des Wassilewskija Wildtyps war generell stärker ausgeprägt als die des Ökotyps Col-0. Bei der mit dem Ökotypen Wassilewskija zu vergleichenden FLAG-Linie bezüglich 1lp gab es keinen Unterschied zum Wildtyp. Bei der glp3 betreffenden FLAG-Linie war die Reduktion der Blattfläche durch V. longisporum dagegen signifikant größer als die des Wildtyps.

Die Ermittlung der frischen Biomasse ergab ähnliche Ergebnisse wie die Blattflächenmessungen. Während es bei allen SALK-Linien und bei der llp-Mutante keine signifikanten Unterschiede zum entsprechenden Wildtyp gab, war die infektionsbedingte Reduktion der Biomasse bei der glp3-Mutante deutlich stärker als die des Ws-2 Wildtyps (Abb. 15).

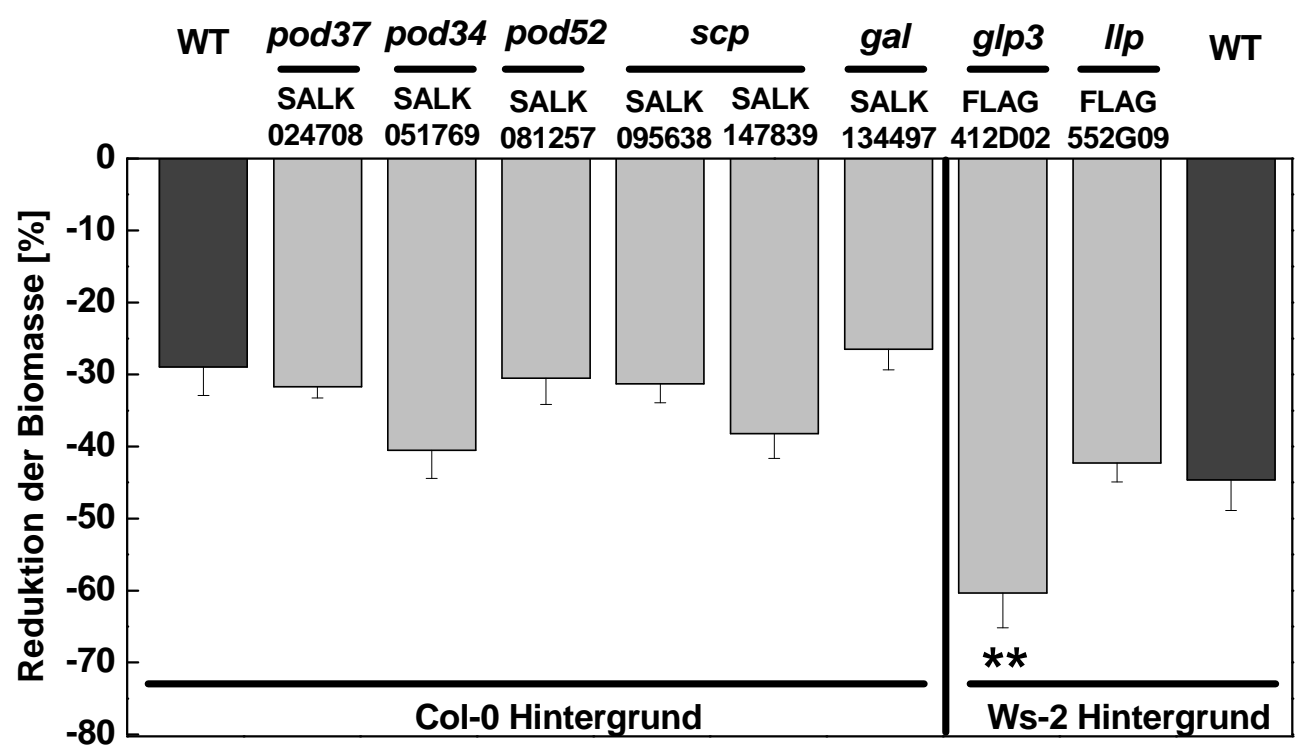

Abb. 15: Reduktion der Biomasse der T-DNA-Insertionslinien (hellgraue Säulen) und der Wildtypen Col-0 und Ws-2 (dunkelgraue Säulen) zwischen 21 und 28 dpi. Dargestellt ist die Reduktion der oberirdischen Frischmasse infizierter Pflanzen relativ zu den Kontrollen in Prozent. Abgebildet sind die Mittelwerte mit Standardfehler aus unabhängigen Versuchen mit jeweils 20 Pflanzen je Behandlung und Linie ( $n=1$ für pod37, scp, Linie SALK_147839; $n=2$ für pod34, pod52, scp, Linie SALK_095638 und gal; $n=3$ für Ilp und glp3). Signifikante Unterschiede (p $\leq$ 0,01) sind mit zwei Sternen markiert.

Bei einem Rückblick auf die bisherigen Ergebnisse bezüglich der verschiedenen getesteten T-DNA-Insertionslinien ist also festzustellen, dass die meisten Linien, die eine veränderte Expression des durch die Insertion betroffenen Gens aufwiesen, keinen Unterschied zum Wildtyp hinsichtlich der Suszeptibilität gegenüber $V$. longisporum zeigten. Nur die T- 
DNA-Insertionslinie FLAG_412D02, bei der das T-DNA-Fragment im Promoterbereich des glp3-Gens inseriert ist und für die eine verringerte Expression von glp3 im Vergleich zum Wildtyp nachgewiesen werden konnte, zeigte eine größere infektionsbedingte Reduktion der Blattfläche und der Biomasse. Die glp3-Insertionslinie ist somit suszeptibler gegenüber $V$. longisporum im Vergleich zum Wildtyp.

\subsection{Charakterisierung von Arabidopsis-Pflanzen mit konstitutiv erhöhter glp3-Expression hinsichtlich ihrer Suszeptibilität gegenüber Verticillium longisporum}

Da beobachtet wurde, dass eine Verringerung des Transkriptlevels von glp3 in A. thaliana zu einer erhöhten Suszeptibilität der Pflanzen gegenüber V. longisporum führte, sollte geprüft werden, ob eine Erhöhung der Menge von GLP3 eine erhöhte Toleranz der Pflanzen gegenüber dem Pathogen hervorrufen kann. Um diese Hypothese zu testen, wurden Arabidopsis-Pflanzen hergestellt, die glp3 konstitutiv und ektopisch in deutlich größeren Mengen exprimierten als der Wildtyp. Zur Transformation wurde der Ökotyp Wassilewskija verwendet, da die glp3-Mutante von diesem Wildtyp abstammt und die Überexpressionspflanzen mit dieser verglichen werden sollten. Die Pflanzen wurden mit einem Vektor transformiert, in den die codierende Sequenz für glp3 unter der Kontrolle eines konstitutiv aktiven 35s-Promoters eingefügt worden war. Die Pflanzen der T1Generation wurden hinsichtlich ihres glp3-Transkriptlevels überprüft. Vier von zehn getesteten heterozygoten Pflanzen zeigten eine deutlich erhöhte Menge der glp3-mRNA im Vergleich zum Wildtyp Ws-2. Diese Linien wurden weiter selektiert, bis von zwei der Linien (Linie 7 und Linie 9) homozygote Pflanzen vorhanden waren. In diesen Pflanzen der T3-Generation wurde erneut die Menge der glp3-mRNA gemessen. Bei diesen homozygoten Pflanzen war die Expression im Durchschnitt rund 800 mal höher als im Wildtyp Ws-2 (Abb. 16).

Um zu testen, ob die Überexpression von glp3 zu einer veränderten Suszeptibilität gegenüber $V$. longisporum führt, wurden die homozygoten Linien mit dem Pilz infiziert, unter Kurztag-Bedingungen kultiviert und die Entwicklung des Pathophänotypen verfolgt. Als Vergleich wurden sowohl der Wassilewskija-Wildtyp als auch die suszeptiblere glp3Insertionslinie (FLAG_412D02) im selben Experiment mitgeführt. 


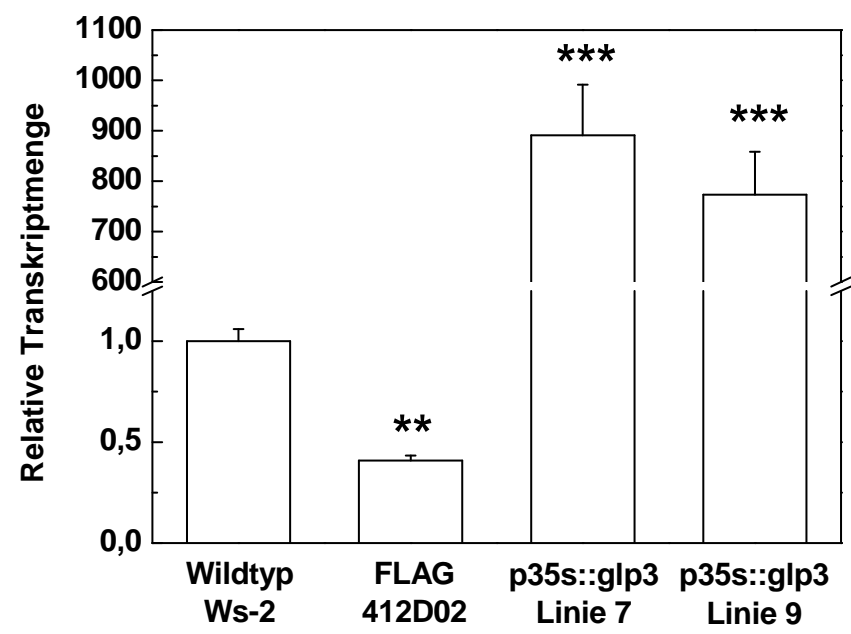

Abb. 16: qRT-PCR-Analysen der Überexpressionspflanzen zur Quantifizierung der glp3-mRNA. Dargestellt ist die relative Expression von homozygoten Pflanzen der Linien 7 und 9 (p35s::glp3) im Vergleich zum Wildtyp. Zusätzlich ist die Expression der glp3-Mutante (FLAG_412D02) abgebildet. Präsentiert werden Mittelwerte mit Standardfehler aus 3 unabhängigen Versuchen mit je 5 Replikaten. Signifikante Unterschiede im Vergleich zum Wildtyp Ws-2 sind mit zwei $(p \leq 0,01)$ oder drei Sternen $(\mathbf{p} \leq \mathbf{0 , 0 0 1 )}$ markiert.

21 dpi wiesen alle infizierten Versuchspflanzen die typischen Symptome auf (Abb. 17). Für die bereits unter Punkt 3.2 beschriebene glp3-Insertionslinie konnte der stärker ausgeprägte Pathophänotyp bestätigt werden. Bei den Überexpressionspflanzen waren dagegen die charakteristischen Symptome insgesamt deutlich schwächer ausgebildet als beim Wildtyp oder den glp3 Pflanzen.

Die Quantifizierung der Blattfläche zeigte eine stärkere Reduktion der Blattfläche der glp3-Mutante im Vergleich zum Wildtyp nach Infektion mit V. longisporum (Abb. 18). Während die Wildtyp-Pflanzen durch die Infektion eine im Mittel um $40 \%$ verringerte Blattfläche zeigten, waren die Blattflächen der glp3-Mutante infektionsbedingt $58 \%$ kleiner als die der Kontrollen. Die durch das Pathogen hervorgerufene Reduktion der Blattflächen der Überexpressionspflanzen war dagegen signifikant geringer als die des Wildtyps und betrug $29 \%$ bei der Linie 7 und $28 \%$ bei der Linie 9. 
Kontrolle

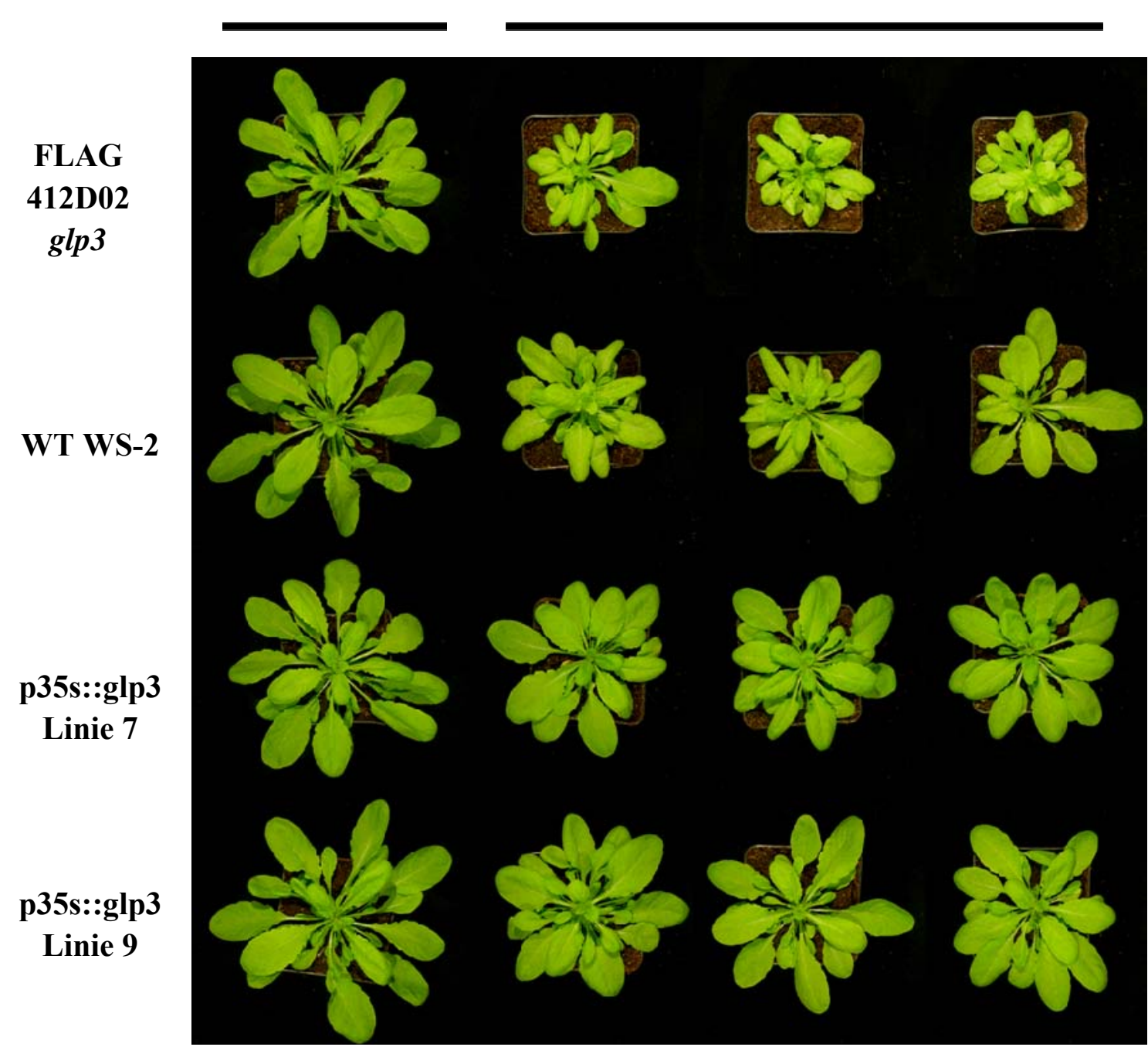

Abb. 17: Fotos von mit $V$. longisporum infizierten (+VL43) und nicht infizierten Pflanzen (Kontrolle) des Wassilewskija-Wildtyps (WT Ws-2), der glp3-Insertionslinie FLAG_412D02 sowie der Überexpressionslinien 7 und 9 (p35s::glp3) 21 dpi.

Neben der Ermittlung der Blattflächen wurde auch die Frischmasse bestimmt. Die Ergebnisse zeigten ein ähnliches Bild wie die der Blattflächen-Analysen. Bei den WildtypPflanzen resultierte die Infektion durch V. longisporum in einer Verringerung der Masse um $32 \%$ (Abb. 19). Bei der glp3-Insertionslinie war die Reduktion um 24 \% stärker. Die relative Verringerung der Frischmasse der Überexpressionslinien war tendenziell geringer als die des Wildtyps und betrug im Mittel $25 \%$ bei der Linie 7 und $18 \%$ bei der Linie 9. 


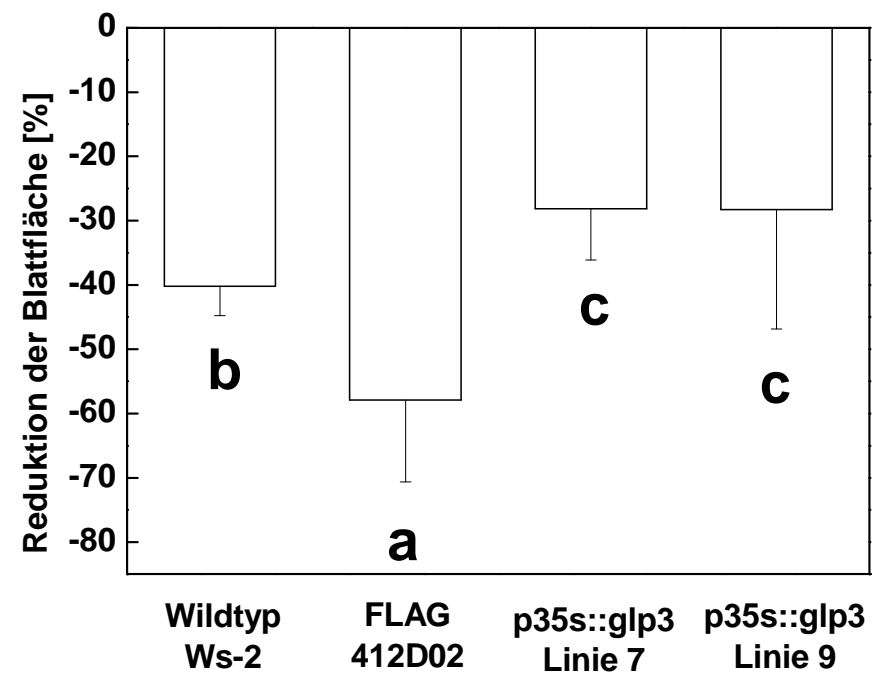

Abb. 18: Reduktion der Blattfläche des Wildtyps Ws-2, der glp3 Insertionslinie FLAG_412D02 sowie der beiden Überexpressionslinien 7 und 9 (p35s::glp3, Linie 7 und p35s::glp3, Linie 9) 21 dpi. Dargestellt ist die Reduktion der Blattfläche infizierter Pflanzen relativ zu den Kontrollen in Prozent. Gezeigt werden die Mittelwerte mit Standardabweichungen aus vier unabhängigen Versuchen, bei denen die Anzahl der biologischen Replikate jeweils 20 betrug. Signifikante Unterschiede (p $\leq \mathbf{0 , 0 5})$ sind durch unterschiedliche Buchstaben gekennzeichnet.

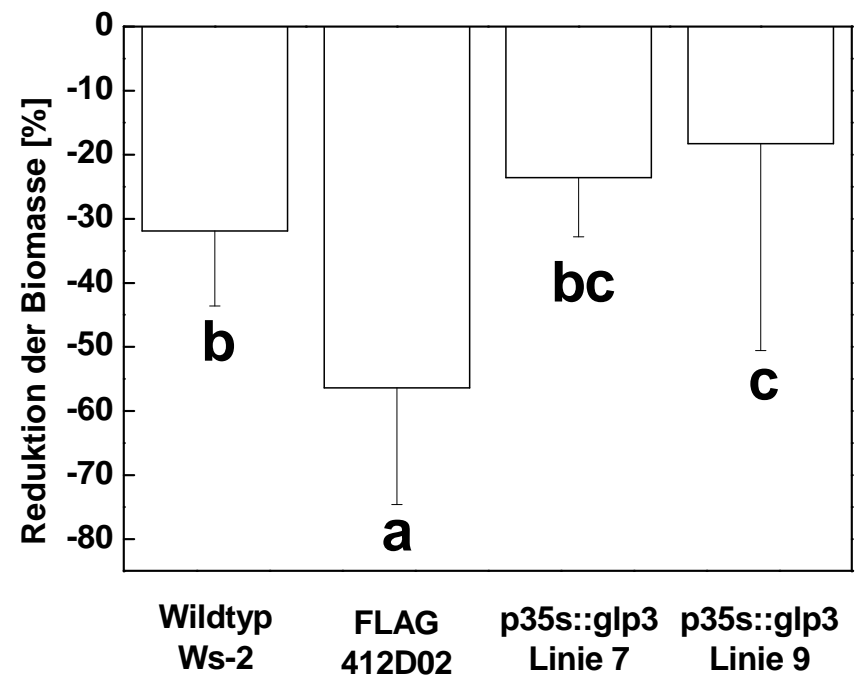

Abb. 19: Reduktion der Frischmasse des Wildtyps Ws-2, der glp3-Insertionslinie FLAG_412D02 sowie der beiden Überexpressionslinien 7 und 9 (p35s::glp3, Linie 7 und p35s::glp3, Linie 9) 21 dpi. Abgebildet ist die Reduktion der Frischmasse infizierter Pflanzen im Verhältnis zu den uninfizierten Pflanzen in Prozent. Gezeigt werden die Mittelwerte mit Standardabweichungen aus drei unabhängigen Versuchen mit je 20 biologischen Replikaten. Signifikante Unterschiede $(p \leq 0,05)$ sind durch unterschiedliche Buchstaben gekennzeichnet. 
Als weiterer Parameter zur Quantifizierung der Symptome diente der Pigmentgehalt. Dazu wurden Chlorophyll $\mathrm{a}$ und $\mathrm{b}$ sowie Carotinoide in infizierten und Kontroll-Pflanzen photometrisch gemessen. Die mittlere Konzentration der gesamten Pigmente der Kontrollen betrug 21 dpi $1015 \mu \mathrm{g}$ pro g Blattmasse (Tabelle 14). 28 dpi war der Pigmentgehalt etwas geringer und lag im Mittel bei $925 \mu \mathrm{g}$ pro g. Zu beiden Zeitpunkten war eine Reduktion durch die Infektion mit V. longisporum zu verzeichnen (Abb. 20).

Tabelle 14: Pigmentgehalt des Wildtyps Ws-2, der glp3-Insertionslinie FLAG_412D02 sowie zweier Überexpressionslinien (p35s::glp3, Linie 7 und p35s::glp3, Linie 9). Aufgeführt sind die Mittelwerte \pm Standardabweichungen der Konzentration von Chlorophyll a, Chlorophyll b und den Carotinoiden sowie das Verhältnis von Chlorophyll a zu Chlorophyll b von infizierten (VL) und nicht infizierten (K) Pflanzen der verschiedenen Linien 21 dpi (A) und 28 dpi (B) in $\mu g$ des Pigments pro $g$ Frischmasse. Die Daten der verschiedenen Zeitpunkte stammen aus unabhängigen Experimenten mit jeweils 20 Pflanzen, die für die Analyse zu 5 Pools mit je 4 Pflanzen zusammengefasst wurden. Signifikante Unterschiede in einer Spalte $(\mathbf{p} \leq \mathbf{0 , 0 5})$ sind durch unterschiedliche Buchstaben in Klammern gekennzeichnet.

A

\begin{tabular}{|c|c|c|c|c|c|}
\hline Linie & $\begin{array}{c}\text { Behand- } \\
\text { lung }\end{array}$ & $\begin{array}{c}\text { Chlorophyll a } \\
{[\boldsymbol{\mu g} / \mathbf{g}]}\end{array}$ & $\begin{array}{c}\text { Chlorophyll b } \\
{[\boldsymbol{\mu g} / \mathbf{g}]}\end{array}$ & $\begin{array}{c}\text { Carotinoide } \\
{[\boldsymbol{\mu g} / \mathbf{g}]}\end{array}$ & $\begin{array}{c}\text { Chlorophyll a/ } \\
\text { Chlorophyll b }\end{array}$ \\
\hline \multirow{2}{*}{$\begin{array}{c}\text { Wildtyp } \\
\text { Ws-2 }\end{array}$} & $\mathbf{K}$ & $601,6 \pm 14,2(\mathrm{~b})$ & $153,5 \pm 6,8(\mathrm{c})$ & $198,5 \pm 5,1(\mathrm{~b})$ & $3,93 \pm 0,09(\mathrm{~d})$ \\
\cline { 2 - 6 } & $\mathbf{V L}$ & $520,5 \pm 15,4(\mathrm{a})$ & $137,7 \pm 4,7(\mathrm{a})$ & $172,1 \pm 4,4(\mathrm{a})$ & $3,78 \pm 0,04(\mathrm{~b})$ \\
\hline \multirow{2}{*}{$\begin{array}{c}\text { FLAG } \\
\text { 412D02 }\end{array}$} & $\mathbf{K}$ & $656,5 \pm 26,1(\mathrm{~d})$ & $171,5 \pm 5,7(\mathrm{ef})$ & $217,1 \pm 8,2(\mathrm{c})$ & $3,83 \pm 0,05(\mathrm{bc})$ \\
\cline { 2 - 6 } & $\mathbf{V L}$ & $535,2 \pm 11,7(\mathrm{a})$ & $145,9 \pm 2,6(\mathrm{~b})$ & $178,6 \pm 3,8(\mathrm{a})$ & $3,67 \pm 0,09(\mathrm{a})$ \\
\hline \multirow{2}{*}{$\begin{array}{c}\text { p35s::glp3, } \\
\text { Linie 7 }\end{array}$} & $\mathbf{K}$ & $630,9 \pm 21,5(\mathrm{c})$ & $164,5 \pm 4,9(\mathrm{de})$ & $204,3 \pm 7,5(\mathrm{~b})$ & $3,83 \pm 0,03(\mathrm{bc})$ \\
\cline { 2 - 7 } & $\mathbf{V L}$ & $619,7 \pm 20,7(\mathrm{bc})$ & $164,5 \pm 5,9(\mathrm{de})$ & $200,9 \pm 5,0(\mathrm{~b})$ & $3,77 \pm 0,05(\mathrm{~b})$ \\
\hline \multirow{2}{*}{$\begin{array}{c}\text { p35s::glp3, } \\
\text { Linie 9 }\end{array}$} & $\mathbf{K}$ & $668,9 \pm 13,6(\mathrm{~d})$ & $173,0 \pm 6,3(\mathrm{f})$ & $218,8 \pm 5,6(\mathrm{c})$ & $3,87 \pm 0,07(\mathrm{~cd})$ \\
\cline { 2 - 7 } & $\mathbf{V L}$ & $615,7 \pm 19,1(\mathrm{bc})$ & $164,0 \pm 2,9(\mathrm{~d})$ & $198,6 \pm 6,1(\mathrm{~b})$ & $3,75 \pm 0,07(\mathrm{~b})$ \\
\hline
\end{tabular}

B

\begin{tabular}{|c|c|c|c|c|c|}
\hline Linie & $\begin{array}{l}\text { Behand- } \\
\text { lung }\end{array}$ & $\begin{array}{c}\text { Chlorophyll a } \\
{[\mu \mathrm{g} / \mathrm{g}]}\end{array}$ & $\begin{array}{c}\text { Chlorophyll b } \\
{[\mu \mathrm{g} / \mathrm{g}]}\end{array}$ & $\begin{array}{c}\text { Carotinoide } \\
{[\mu \mu \mathrm{g} / \mathrm{g}]}\end{array}$ & $\begin{array}{l}\text { Chlorophyll a/ } \\
\text { Chlorophyll b }\end{array}$ \\
\hline \multirow{2}{*}{$\begin{array}{c}\text { Wildtyp } \\
\text { Ws-2 }\end{array}$} & $\mathbf{K}$ & $577,6 \pm 36,3(\mathrm{~d})$ & $160,5 \pm 10,4(\mathrm{e})$ & $202,6 \pm 12,2(\mathrm{~d})$ & $3,60 \pm 0,12(\mathrm{a})$ \\
\hline & $\mathbf{V L}$ & $450,8 \pm 49,1$ (a) & $122,9 \pm 10,9(\mathrm{ab})$ & $159,1 \pm 14,9$ (a) & $3,66 \pm 0,08(\mathrm{ab})$ \\
\hline \multirow{2}{*}{$\begin{array}{c}\text { FLAG } \\
\text { 412D02 }\end{array}$} & $\mathbf{K}$ & $569,6 \pm 44,8(\mathrm{~d})$ & & $198,9 \pm 11,5(\mathrm{~cd})$ & $3,70 \pm 0,13(\mathrm{ab})$ \\
\hline & $\mathbf{V L}$ & $420,6 \pm 43,0(\mathrm{a})$ & $114,9 \pm 10,1(\mathrm{a})$ & $153,3 \pm 13,1(a)$ & $3,66 \pm 0,06(\mathrm{ab})$ \\
\hline \multirow{2}{*}{$\begin{array}{c}\text { p35s::glp3, } \\
\text { Linie } 7\end{array}$} & $\mathbf{K}$ & $582,3 \pm 27,0(\mathrm{~d})$ & $155,7 \pm 7,9(\mathrm{e})$ & $194,0 \pm 12,6(\mathrm{bcd})$ & $3,73 \pm 0,13(b)$ \\
\hline & VL & $504,8 \pm 43,4(\mathrm{~b})$ & $135,4 \pm 11,6(\mathrm{bc})$ & $176,8 \pm 17,8(\mathrm{~b})$ & $3,73 \pm 0,04(\mathrm{~b})$ \\
\hline \multirow{2}{*}{$\begin{array}{c}\text { p35s::glp3, } \\
\text { Linie } 9\end{array}$} & $\mathbf{K}$ & $560,6 \pm 41,0(\mathrm{~cd})$ & $149,7 \pm 13,4(\mathrm{de})$ & $198,3 \pm 15,5(\mathrm{~cd})$ & $3,75 \pm 0,09(\mathrm{~b})$ \\
\hline & $\mathbf{V L}$ & $514,8 \pm 35,9(\mathrm{bc})$ & $139,2 \pm 7,1(\mathrm{~cd})$ & $182,9 \pm 10,4(\mathrm{bc})$ & $3,70 \pm 0,08(\mathrm{ab})$ \\
\hline
\end{tabular}




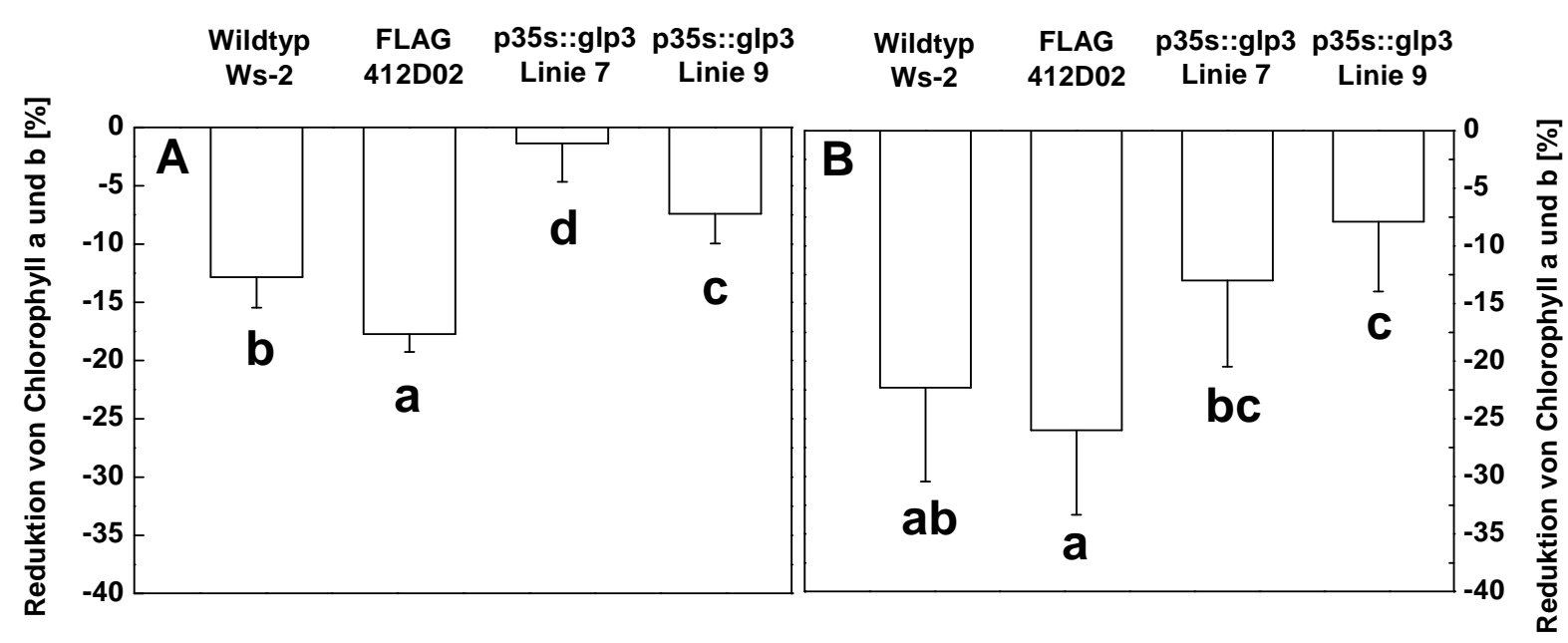

Abb. 20: Reduktion des Chlorophyllgehalts des Wildtyps Ws-2, der glp3Insertionslinie FLAG_412D02 sowie der beiden Überexpressionslinien 7 und 9 (p35s::glp3, Linie 7 und p35s::glp3, Linie 9) 21 dpi (A) und 28 dpi (B). Dargestellt ist die mittlere Reduktion der Summe von Chlorophyll a und Chlorophyl b infizierter Pflanzen relativ zu den Kontrollen in Prozent mit Standardabweichung. Die Daten der verschiedenen Zeitpunkte stammen aus unabhängigen Experimenten mit jeweils 20 Pflanzen, die für die Analyse zu 5 Pools mit je 4 Pflanzen zusammengefasst wurden. Signifikante Unterschiede $(p \leq 0,05)$ sind durch unterschiedliche Buchstaben gekennzeichnet.

21 dpi war der Pigmentgehalt des Wildtyps infektionsbedingt $13 \%$ geringer. 28 dpi war diese Reduktion noch weiter erhöht, so dass die infizierten Pflanzen $22 \%$ weniger Chlorophyll besaßen als die Kontrollen. Die glp3-Mutante zeigte zu beiden Zeitpunkten eine stärkere Reduktion der Pigmentkonzentration als der Wildtyp, die aber nur 21 dpi signifikant war. Der Pigmentgehalt der infizierten Überexpressionspflanzen dagegen war 21 dpi im Vergleich zu den Kontrollen um rund 1,5\% (Linie 7) bzw. 8 \% (Linie 9) reduziert. 28 dpi waren die Unterschiede zum Wildtyp nicht mehr so stark ausgeprägt wie 21 dpi, so dass dieser zu diesem Zeitpunkt nur bei der Linie 9 signifikant war.

Um zu untersuchen, ob die GLP3-Menge in A. thaliana neben der Symptomausprägung auch die Proliferation des Pilzes in der Pflanze beeinflusst, wurde die DNA des Pilzes in den Blattrosetten mittels qRT-PCR gemessen. In Wildtyp-Pflanzen ließen sich im Mittel Mengen von ca. 10500 pg Verticillium-DNA je g Frischmasse nachweisen (Abb. 21). In der glp3-Insertionslinie konnten doppelt so hohe Konzentrationen detektiert werden, während in den Pflanzen, die glp3 konstitutiv überexprimieren, die VL-DNAKonzentrationen mehr als $60 \%$ geringer waren und signifikant vom Wildtyp zu unterscheiden waren. 


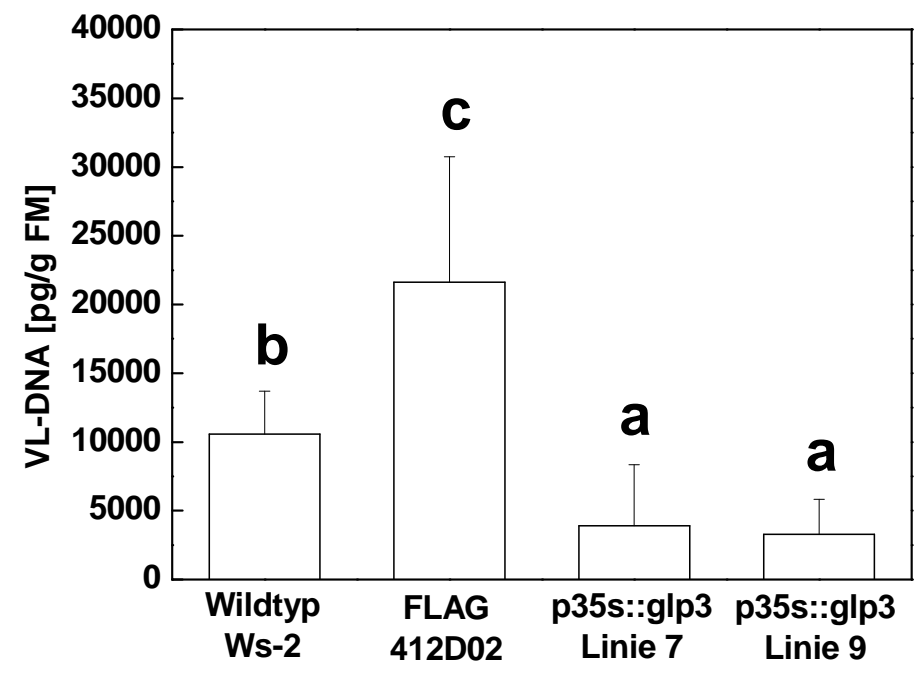

Abb. 21: VL-DNA in infizierten Pflanzen des Wildtyps Ws-2 (WT), der glp3Insertionslinie FLAG_412D02 sowie der beiden Überexpressionslinien 7 und 9 (p35s::glp3, Linie 7 und p35s::glp3, Linie 9) 21 bis 28 dpi. Dargestellt sind die Mittelwerte mit Standardabweichungen aus 3 unabhängigen Versuchen mit je 20 Pflanzen pro Linie und Behandlung. Für die Messung wurden jeweils 5 Pools aus je 4 Pflanzen gebildet. Signifikante Unterschiede $(p \leq 0,05)$ sind durch unterschiedliche Buchstaben gekennzeichnet. Die Daten wurden für die statistischen Analysen Logtransformiert. Die DNA-Messung wurde von der AG Karlovsky durchgeführt.

Zusammenfassend lässt sich also feststellen, dass die infektionsbedingte Wachstumsdepression und die Reduktion des Pigmentgehalts in den Überexpressionspflanzen im Vergleich zum Wildtyp verringert war, während die erhöhte Suszeptibilität der glp3-Mutante bestätigt werden konnte. Zusätzlich zu der veränderten Symptomatik war die Pilzmenge innerhalb der Pflanze bei der glp3-Mutante signifikant erhöht, während sie bei den Überexpressionspflanzen signifikant niedriger war als die des Wildtyps. Die Pilzproliferation scheint also mit der Menge GLP3 in der Pflanze in Zusammenhang zu stehen. Die Überexpressionspflanzen können somit bei einem Vergleich mit dem Wildtyp Ws-2 als toleranter gegenüber $V$. longisporum bezeichnet werden. 


\subsection{Komplementierung der glp3-Mutante}

Bei einer Transformation von Pflanzen mittels Insertion einer T-DNA kann es vorkommen, dass die T-DNA mehrere Male in das Genom integriert wird. So ist es möglich, dass neben dem Zielgen auch andere Gene betroffen sind, die ebenfalls eine verminderte Expression aufweisen. Um zu verifizieren, dass der gegenüber dem Wildtyp veränderte Pathophänotyp der T-DNA-Insertionslinie FLAG_412D02 auf die verminderte Expression von glp3 und nicht die anderer Gene zurückzuführen ist, wurde die entsprechende Linie komplementiert. Dazu wurde ein Vektorkonstrukt mit glp3 unter der Kontrolle eines 35s-Promoters in die glp3-Mutante transferiert. Die mittels qRT-PCR analysierte Expression von glp3 in den transgenen Pflanzen war 21-fach (Linie 1) bzw. 27-fach (Linie 5) gegenüber der des Wildtyps erhöht (Abb. 22).



Abb. 22: Relative Expression von glp3 in der komplementierten T-DNAInsertionsmutante FLAG_412D02. Dargestellt ist die relative Expression von zwei Linien (1 und 5) der komplementierten Pflanzen sowie der Mutante im Vergleich zum Wildtyp Ws-2. Präsentiert werden Mittelwerte mit Standardabweichungen ( $n=5$ für Ws-2 und FLAG_412D02, $n=15$ für Kompl. Linie 1 und $n=20$ für Kompl. Linie 5). Signifikante Unterschiede im Vergleich zum Wildtyp Ws-2 $(p \leq 0,001)$ sind mit drei Sternen markiert.

Die zwei Linien (1 und 5) der komplementierten Insertionsmutante wurden in zwei unabhängigen Experimenten hinsichtlich der Suszeptibilität gegenüber V. longisporum getestet wie im vorherigen Kapitel beschrieben. Die infizierten Pflanzen aller Linien 
wiesen die typischen Symptome wie Stauchung und Chlorosen auf. 21 dpi waren bei allen Linien signifikante Unterschiede zwischen infizierten Pflanzen und Kontrollen hinsichtlich Blattfläche und Frischgewicht (Abb. 23) zu beobachten. Bei einem Vergleich der uninfizierten Kontrollen der verschiedenen Linien fiel zudem auf, dass die Pflanzen der komplementierten Mutante signifikant kleiner waren als die Mutante selbst (Abb. 23).

Die durch $V$. longisporum hervorgerufene Reduktion der Wuchsparameter betrug in diesen Versuchen für den Wildtyp Ws-2 im Mittel $37 \%$ für die Blattfläche bzw. 26 \% für die Frischmasse, während die Reduktion der Insertionsmutante wie in vorausgegangenen Versuchen signifikant größer war (Abb. 24). Bei den Linien der komplementierten glp3Mutante war die Reduktion der Blattfläche und der Frischmasse nicht so ausgeprägt wie die der Insertionsmutante, jedoch war die Reduktion nicht geringer als die des Wildtyps. Tendenziell wurde also durch das Einbringen des glp3-Konstruktes die erhöhte Suszeptibilität der Mutante aufgehoben, jedoch war dieser Effekt nur bei einer der beiden gestesteten Linien signifikant.
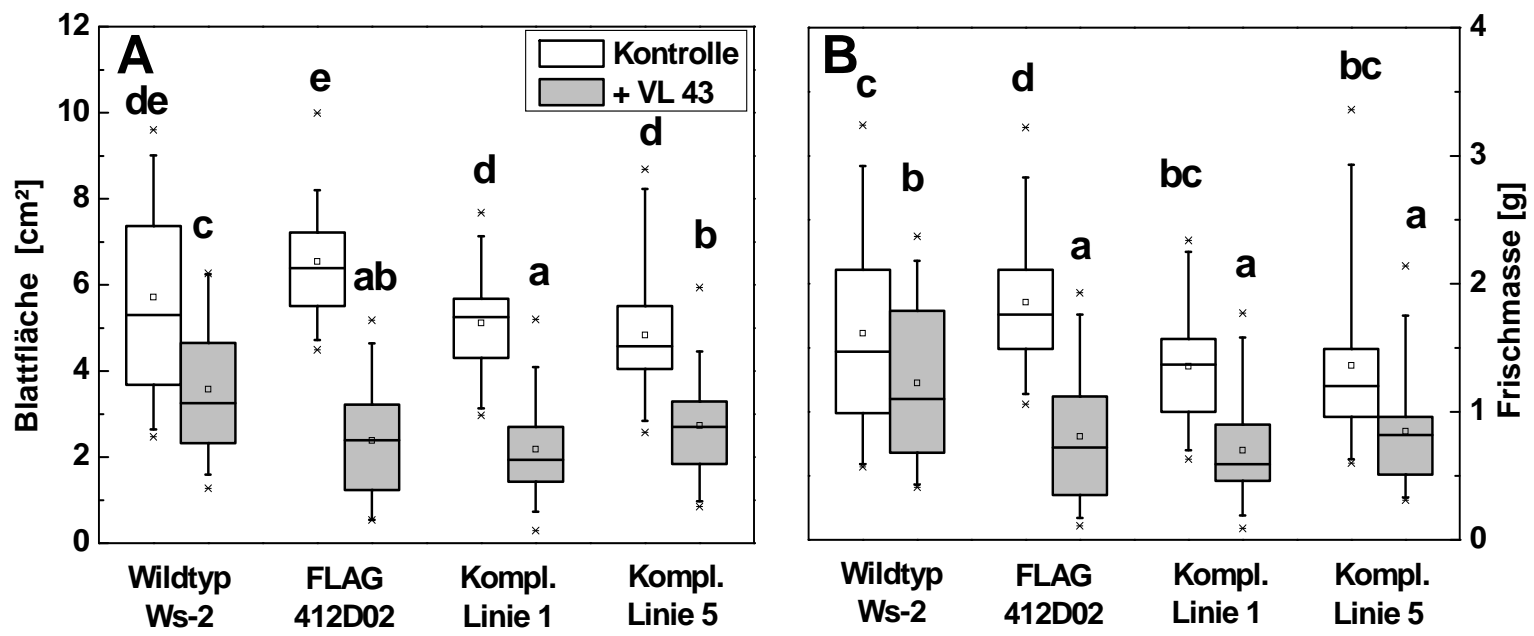

Abb. 23: Blattfläche (A) und Frischmasse (B) des Wildtyps Ws-2, der glp3-Mutante (FLAG_412D02) sowie der Linien 1 und 5 der komplementierten Mutante (Kompl., Linie 1 und Kompl., Linie 5) 21 dpi. Dargestellt sind die Daten infizierter (+ VL 43, graue Boxen) und nicht infizierter Pflanzen (Kontrollen, weiße Boxen) aus zwei unabhängigen Versuchen mit jeweils 17 bis 24 Pflanzen als Box-und-Whisker-Plot. Signifikante Unterschiede $(p \leq 0,05)$ sind durch unterschiedliche Buchstaben gekennzeichnet. Die Linie innerhalb der Box stellt den Median dar. Zusätzlich ist der Mittelwert als Quadrat abgebildet. Die Kreuze zeigen Ausreißer an. 


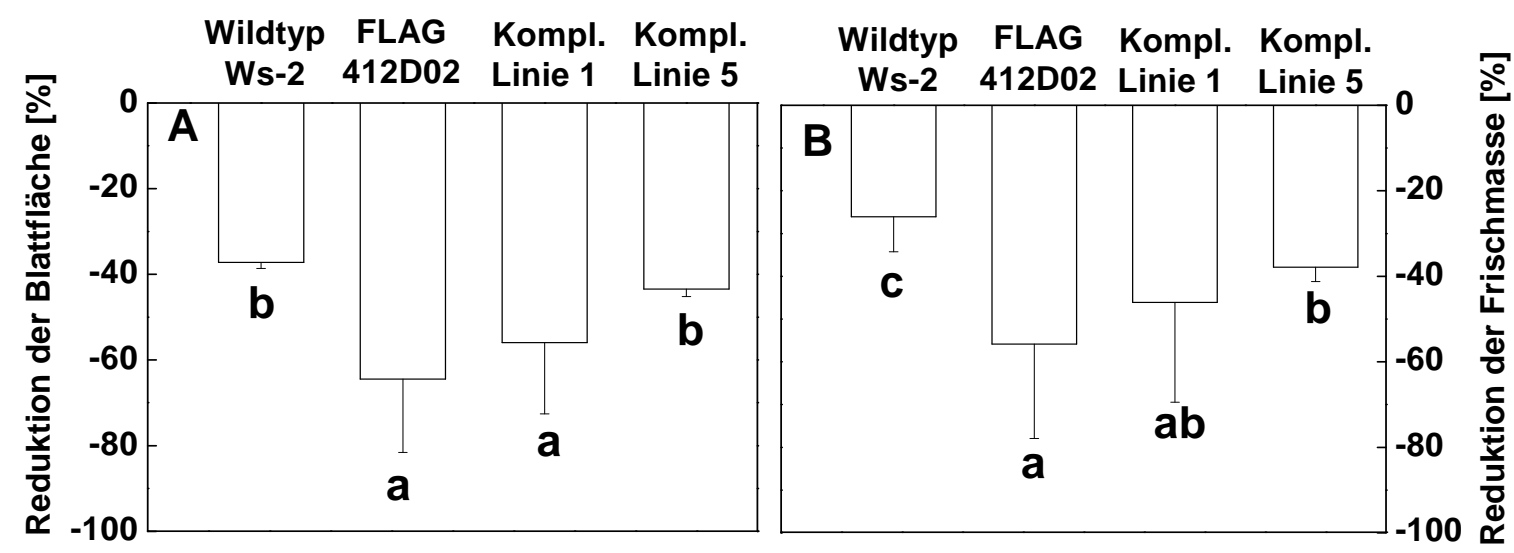

Abb. 24: Reduktion der Blattfläche (A) sowie der Frischmasse (B) des Wildtyps Ws-2, der glp3-Mutante (FLAG_412D02) sowie der Linien 1 und 5 der komplementierten Mutante (Kompl., Linie 1 und Kompl., Linie 5) 21 dpi. Abgebildet ist die Reduktion der Blattfläche bzw. der Biomasse infizierter Pflanzen relativ zu den Kontrollen in Prozent. Gezeigt werden die Mittelwerte mit Standardabweichungen aus zwei unabhängigen Versuchen mit jeweils 17 bis 24 Pflanzen. Signifikante Unterschiede (p $\leq 0,05)$ sind durch unterschiedliche Buchstaben gekennzeichnet.

\subsection{Charakterisierung von amiRNA-Pflanzen bezüglich der Sensitivität gegenüber Verticillium longisporum}

Nur eine der verfügbaren T-DNA-Insertionsmutanten wies eine signifikant reduzierte Transkriptmenge auf. Hierbei handelte es sich außerdem um eine FLAG-Linie, die mit Hilfe des Ökotyps Wassilewskija generiert worden war, während die meisten vorherigen Ergebnisse sich auf den Ökotyp Columbia beziehen. Aus diesen Gründen wurden als weiterer „Loss of function“ - Ansatz ausgehend vom Columbia-Wildtyp transgene Pflanzen generiert, in die ein artifizielles microRNA (amiRNA) Konstrukt eingebracht wurde. Hergestellt wurden 2 verschiedene Konstrukte (A und B) mit unterschiedlichen Sequenzen, die aber beide komplementär zur glp3-mRNA waren. Die transgenen Pflanzen der T1-Generation wurden mittels qRT-PCR hinsichtlich ihres glp3-Transkriptlevels analysiert. Die Linien beider Konstrukte, welche die geringsten Transkriptmengen im Vergleich zum Wildtyp aufwiesen, wurden bis zur T3-Generation weiter vermehrt und selektiert, bis homozygote Linien detektiert werden konnten. Diese wurden erneut mittels qRT-PCR getestet. Die Ergebnisse bestätigten, dass die Mengen des glp3-Transkriptes in den amiRNA-Linien im Vergleich zum Wildtyp Columbia 20-fach reduziert waren (Abb. 25). 


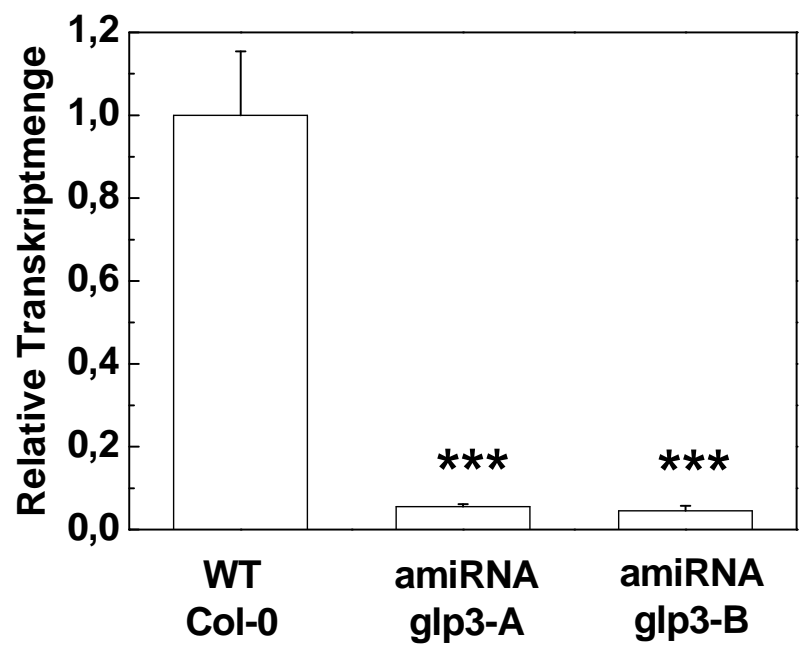

Abb. 25: Relative Genexpression von glp3 in den amiRNA-Linien. Präsentiert werden Mittelwerte der n-fachen Expression der Linien A und B (p35s::amiRNA-glp3-A und p35s::amiRNA-glp3-B) im Vergleich zum Wildtyp Col-0 mit Standardabweichungen $(n=5)$. Signifikante Unterschiede im Vergleich zum Wildtyp $(p \leq 0,001)$ sind mit Sternen markiert.

Die Pflanzen reagierten ebenso wie der Wildtyp mit gedrungenem Wuchs und chlorotischen Blättern auf $V$. longisporum. 28 dpi waren bei allen Linien signifikante Unterschiede zwischen infizierten Pflanzen und Kontrollen hinsichtlich Blattfläche und Frischgewicht zu beobachten (Abb. 26 und 27). Diese Reduktion der Wuchsparameter war bei den amiRNA-Linien ausgeprägter als beim Wildtyp. Während die Verticilliuminduzierte Reduktion der Blattfläche beim Wildtyp $47 \%$ betrug, verursachte der Pilz bei den amiRNA-Linien eine Reduktion der Blattfläche um $65 \%$ (Linie amiRNA-glp3-A) bzw. $58 \%$ (Linie amiRNA-glp3-B). Die Ergebnisse der Frischmassen-Bestimmung der 28 dpi geernteten Pflanzen waren ähnlich. Bei der Linie amiRNA-glp3-B war die Frischmasse infektionsbedingt um 57 \% verringert. Die Frischmasse der Linie amiRNA-glp3-A war sogar um 61 \% reduziert, während für den Wildtyp eine Reduktion um $44 \%$ zu verzeichnen war. Diese erhöhte Suszeptibilität war jedoch nur bei der Linie amiRNA-glp3A signifikant $(\mathrm{p} \leq 0,05)$. 


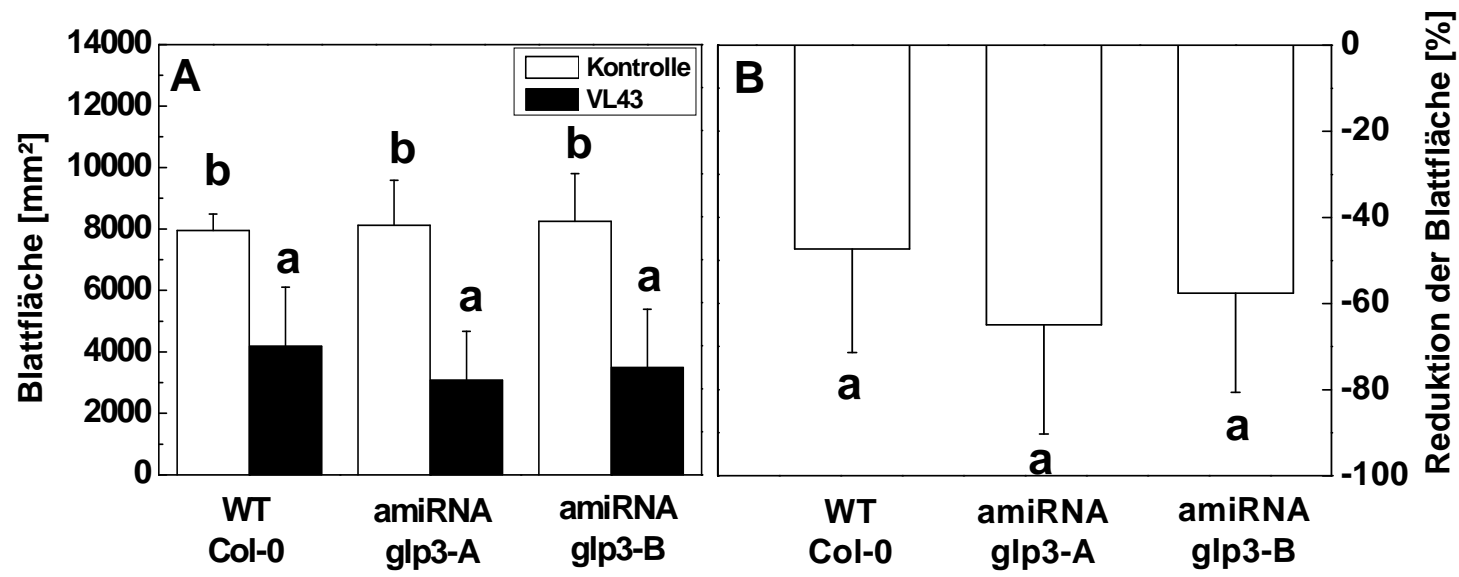

Abb. 26: Blattfläche des Wildtyps Col-0 (WT) sowie der beiden amiRNA-Linien (p35s::amiRNA-glp3-A und p35s::amiRNA-glp3-B) 28 dpi. Dargestellt ist die Blattfläche infizierter (schwarzer Balken) und nicht infizierter (weißer Balken) Pflanzen (A) sowie die prozentuale Reduktion der Blattfläche infizierter Pflanzen im Vergleich zu den Kontrollen (B). Gezeigt werden Mittelwerte mit Standardabweichungen. Die Anzahl der Pflanzen im Experiment betrug $10 \leq n \leq 20$ für die Kontrollen und $12 \leq n \leq 22$ für die infizierten Pflanzen. Signifikante Unterschiede $(p \leq 0,05)$ sind durch unterschiedliche Buchstaben gekennzeichnet.
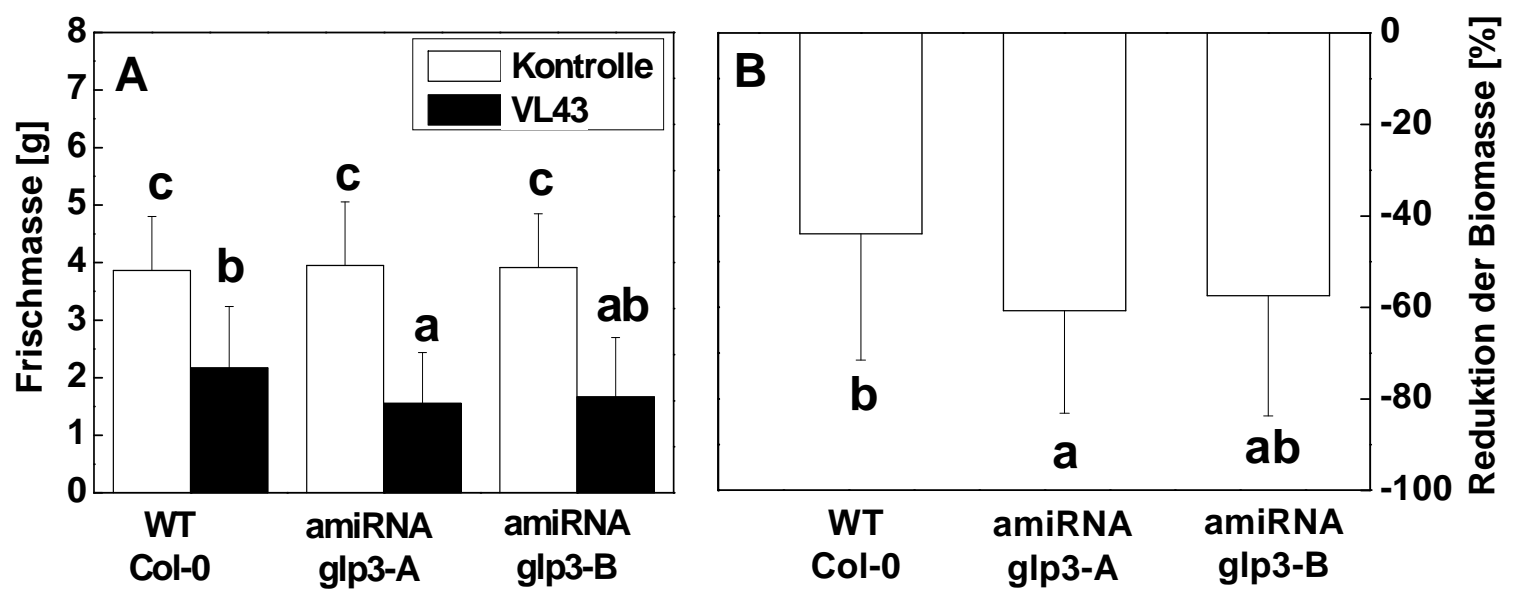

Abb. 27: Frischmasse des Wildtyps Col-0 (WT) sowie der beiden amiRNA-Linien (p35s::amiRNA-glp3-A und p35s::amiRNA-glp3-B) 28 dpi. Dargestellt ist die Frischmasse infizierter (schwarzer Balken) und nicht infizierter (weißer Balken) Pflanzen (A) sowie die prozentuale Reduktion der Frischmasse infizierter Pflanzen im Vergleich zu den Kontrollen (B). Gezeigt werden Mittelwerte mit Standardabweichungen. Die Anzahl der Pflanzen im Experiment betrug $10 \leq n \leq 20$ für die Kontrollen und $12 \leq n \leq 22$ für die infizierten Pflanzen. Signifikante Unterschiede $(p \leq 0,05)$ sind durch unterschiedliche Buchstaben gekennzeichnet. 


\subsection{Anatomische Untersuchungen von Arabidopsis-Wildtyp-Pflanzen sowie der glp3-Mutante hinsichlich Verticillium-induzierter Veränderungen}

Einigen der von einer Verticillium-Infektion beeinflussten Gene wird eine putative Funktion in der Modifikation der Zellwand zugeschrieben (siehe Einleitung). Zudem wurde eine Erhöhung des Lignin- und Zellwandanteils in infizierten Pflanzen im Vergleich zu mock inokulierten Pflanzen nachgewiesen (Flörl 2007).

Um zu untersuchen, ob diese Effekte auf einen Anstieg des Ligninanteils pro Zelle durch Verstärkung der Zellwand oder auf vermehrte Bildung von Zellen mit lignifizierten Wänden (z. B. Gefäße oder Fasern) zurückzuführen sind, wurden Hypokotyl- und Blattproben von infizierten Pflanzen anatomisch untersucht und mit mock inokulierten Pflanzen verglichen. Da für die glp3-Mutante eine erhöhte Suszeptibilität gegenüber $V$. longisporum nachgewiesen werden konnte, wurden neben dem Wildtyp Col-0 auch die glp3-Mutante sowie der zugehörige Wildtyp Ws-2 hinsichtlich anatomischer Veränderungen untersucht. Von eingebetteten Proben wurden Querschnitte hergestellt. Diese wurden mit Toluidinblau angefärbt. Dadurch färben sich lignifizierte Zellwände türkisblau, Cytplasma und unverholzte Primärwände dagegen violett. Zudem wurde die Autofluoreszenz detektiert, durch die phenolische Substanzen wie Lignin sichtbar werden.

Die Hypokotylproben des Wildtyps Col-0 ließen bereits in der Übersicht einen deutlichen Unterschied zwischen infizierten Pflanzen und den uninfizierten Kontrollen erkennen (Abb. 28, A und B). Während das Xylem bei den Kontrollen ungefähr ein Drittel der Fläche des Gesamt-Querschnitts einnahm, war es bei den infizierten Pflanzen deutlich größer. Detaillierte Aufnahmen des Xylems zeigen, dass die durch die türkisblauen Zellwände gut erkennbaren Gefäße in Kontrollpflanzen relativ groß und von einer Vielzahl lebenden Zellen (Parenchym und Collenchym) umgeben waren (Abb. 28, C). Infizierte Pflanzen dagegen verfügten über eine größere Anzahl Gefäße, die jedoch einen geringeren Durchmesser als die der Kontrollen aufwiesen (Abb. 28, D). Hinsichtlich der Zellwanddicke der Gefäße gab es jedoch keinen Unterschied zwischen infizierten und nicht infizierten Pflanzen. Neben den Gefäßen waren auch in infizierten Pflanzen parenchymatische Zellen zu finden. Diese bildeten jedoch nicht wie bei den mock inokulierten Pflanzen Reihen in radialer Richtung, sondern kamen nur vereinzelt und in geringerer Anzahl vor. 




Abb. 28: Querschnitte des Hypokotyls uninfizierter (A und $C$ ) und infizierter (B und D) Pflanzen des Wildtyps Col-0 21 dpi. C: Cortex, Ph: Phloem, K: Kambiumzone, Xy: Xylem, P: parenchymatische Zellen, G: Gefäße. Die $1 \mu \mathrm{m}$ dicken Schnitte wurden mit Toluidinblau angefärbt. Lignifizierte Zellwände sind daher türkisblau, Cytoplasma und Primärwände dagegen violett. Die Längenstandards entsprechen $100 \mu \mathrm{m}(\mathrm{A}, \mathrm{B})$ bzw. $50 \mu \mathrm{m}(\mathrm{C}, \mathrm{D})$.

Die durch V. longisporum bedingte vermehrte Produktion von Gefäßen war auch in den Blättern des Wildtyps Col-0 wieder zu finden (Abb. 29). Während bei den KontrollPflanzen in der Regel nicht mehr als 5 Gefäße in adaxiale Richtung vom Kambium abgegeben wurden, war diese Zahl bei den infizierten Pflanzen deutlich erhöht. Wie beim Hypokotyl waren die ausdifferenzierten Zellen jedoch kleiner als die der Kontrollen. Die Blattquerschnitte der glp3-T-DNA-Insertionsmutante und des Ws-2 Wildtyps zeigten ebenfalls eine vermehrte Produktion von Gefäßen nach einer Verticillium-Infektion (Abb. 30). 

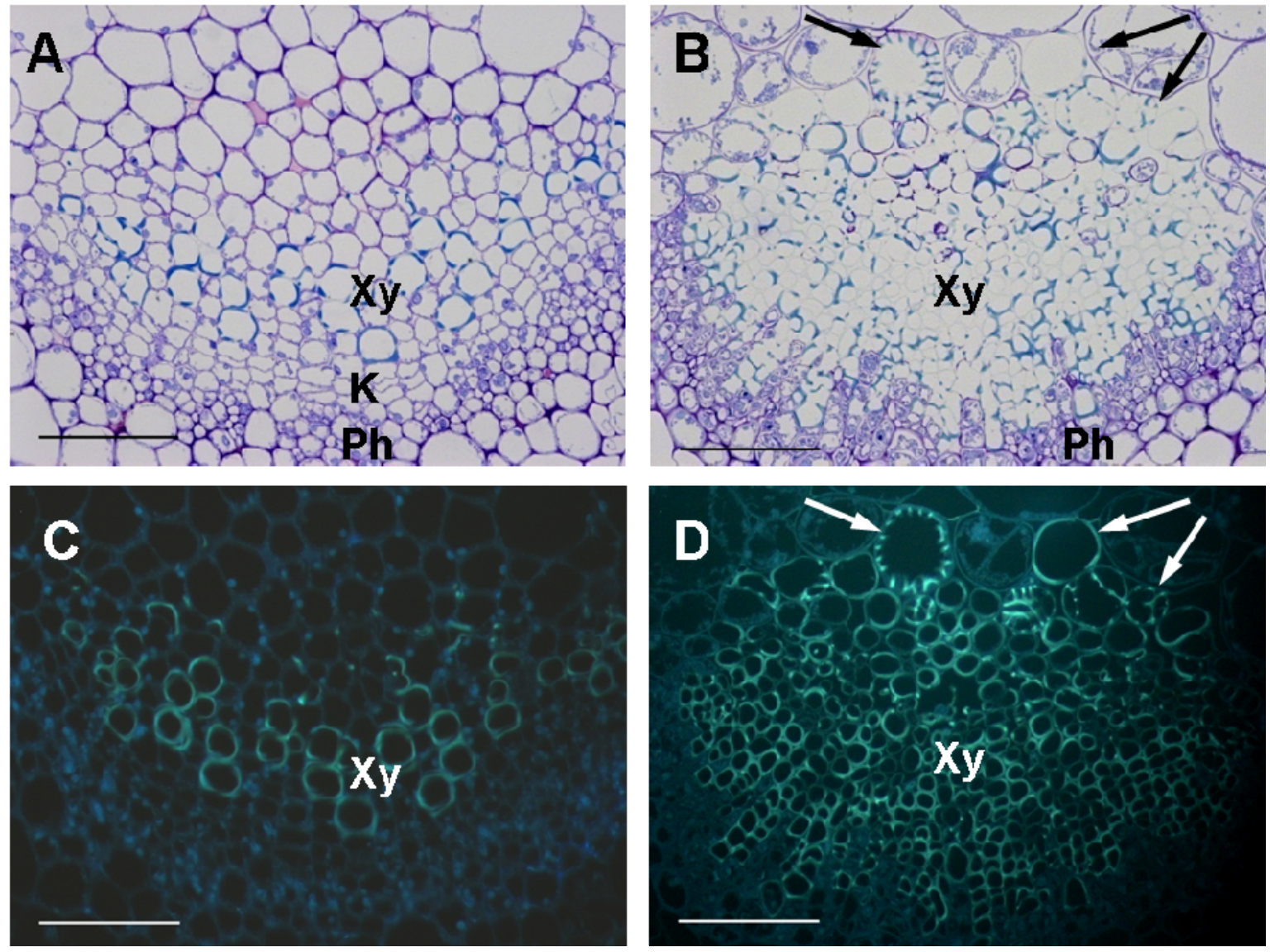

Abb. 29: Leitgewebe von Blättern uninfizierter (A und $C$ ) und infizierter (B und $D)$ Pflanzen des Wildtyps Col-0 21 dpi im Querschnitt. A und B: Mit Toluidinblau angefärbte, $1 \mu \mathrm{m}$ dicke Schnitte. Lignifizierte Zellwände sind türkisblau, Cytoplasma und Primärwände violett. C und D: Autofluoreszenz von $5 \mu \mathrm{m}$ dicken Schnitten. Xy: Xylem, Ph: Phloem, K: Kambium. Die infizierten Pflanzen weisen im adaxialen Bereich des Xylems sehr große Zellen mit lignifizierten Wänden auf (Pfeile). Die Längenstandards entsprechen $50 \mu \mathrm{m}$.

Des Weiteren offenbarten die Querschnitte der Blätter beider Ökotypen sowie der glp3Mutante im Bereich des Leitgewebes noch weitere Unterschiede zwischen infizierten und nicht infizierten Pflanzen, die im Hypokotyl nicht zu finden waren. So traten bei den infizierten Pflanzen im adaxialen Randbereich des Leitgewebes Zellen auf, die in ihrer Größe den das Leitgewebe umgebenden parenchymatischen Zellen entsprachen (Abb. 29, B und D sowie Abb. 30, B und D; Beispiele der beschriebenen Zellen sind mit Pfeilen markiert). Auch die Position ließe auf diesen Zelltyp schließen. Allerdings waren die Wände der betroffenen Zellen lignifiziert, was sowohl aufgrund der türkisblauen, durch Toluidinblau hervorgerufenen Farbe (Abb. 29 B sowie Abb. 30 B und D) als auch bei der 
Abbildung der Autofluoreszenz (Abb. 29 D) sichtbar wurde. Bei einigen dieser Zellen war die lignifizierte Verstärkung wie bei Xylem-Gefäßen im Querschnitt als vollständiger Ring zu sehen, in anderen Zellen war sie in regelmäßigen Abständen unterbrochen (Abb. 29 und 30). Außerdem wurde in einigen dieser Zellen eine netzartige, sich durch den gesamten Zellquerschnitt ausbreitende lignifizierte Struktur beobachtet (Abb. 31).
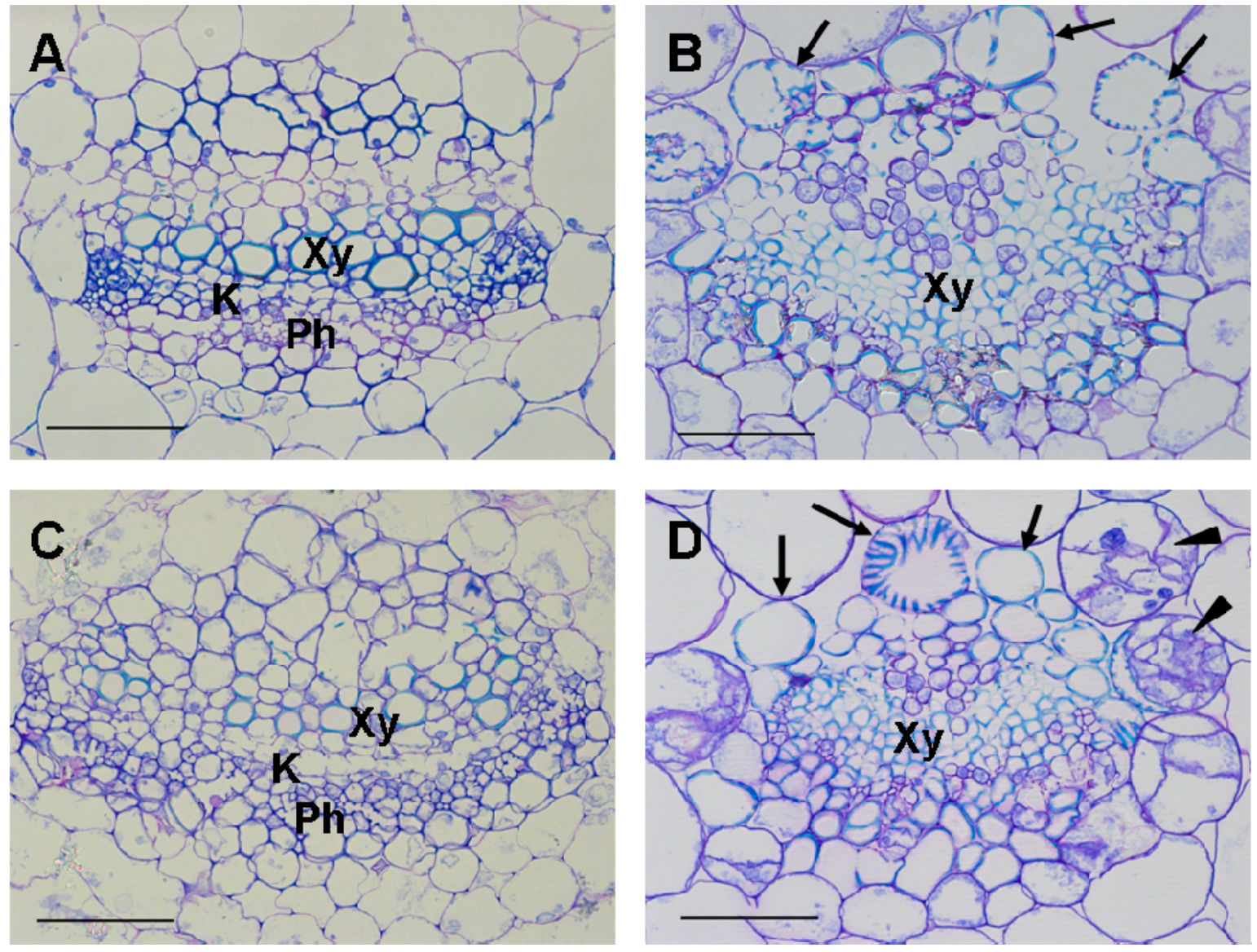

Abb. 30: Leitgewebe von Blättern nicht infizierter ( $A$ und $C$ ) und infizierter ( $B$ und D) Pflanzen des Wildtyps Ws-2 (A und B) sowie der glp3-T-DNA-Insertionsmutante (C und D) 21 dpi im Querschnitt. Xy: Xylem, Ph: Phloem, K: Kambium. Die $1 \mu \mathrm{m}$ dicken Schnitte wurden mit Toluidinblau angefärbt. Lignifizierte Zellwände sind daher türkisblau, Cytoplasma und Primärwände dagegen violett. Bei den Bildern der infizierten Pflanzen sind im Übergangsbereich vom Xylem zum umgebenden Mesophyll sehr große Zellen ohne Cytoplasma mit lignifizierten Wänden zu sehen (Pfeile). Außerdem sind Zellen zu sehen, die Cytoplasma enthalten und partiell lignifizierte Wände aufweisen (Pfeilspitzen). Die Längenstandards entsprechen 50 $\mu \mathrm{m}$. 

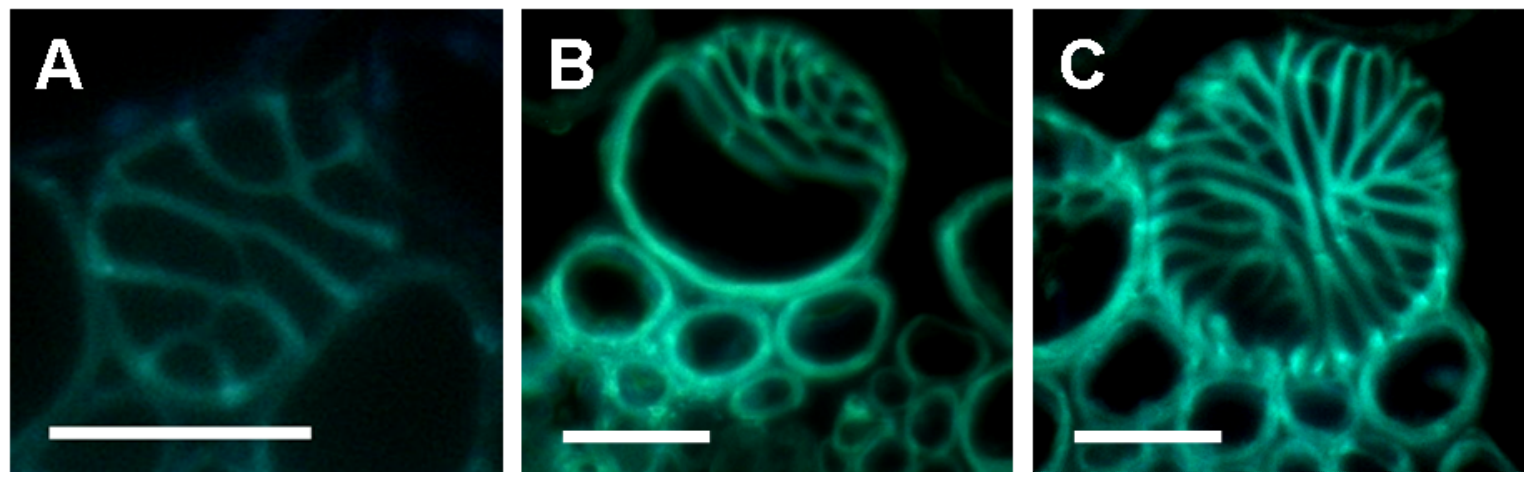

Abb. 31: Netzartige Zellwandverstärkungen in infizierten Pflanzen. Diese konnten im Blattquerschnitt sowohl in den Wildtypen Col-0 (A) und Ws-2 (B) als auch in der glp3-Mutante (C) 21 dpi in einzelnen Zellen im Randbereich des Xylems im Übergang zum adaxialen Parenchym anhand der Autofluoreszenz nachgewiesen werden. Der Längenstandard entspricht $20 \mu \mathrm{m}$.

Um dieses Phänomen besser beurteilen zu können, wurden Serienschnitte angefertigt und mikroskopisch untersucht. Diese zeigten eine Veränderung der beobachteten Struktur von einem Schnitt zum nächsten und eine Verschiebung vom Rand zur Mitte der Zelle hin (Abb. 32). Die Beobachtung weist auf eine runde Form der Zelle und somit auf einen parenchymatischen Ursprung hin.

Zusammenfassend lässt sich feststellen, dass eine Infektion mit $V$. longisporum sowohl in den beiden untersuchten Ökotypen Col-0 und Ws-2 als auch in der GLP3 betreffenden TDNA-Insertionslinie FLAG_412D02 zu einer vermehrter Produktion von Gefäßen durch das Kambium führte. In den Blättern waren am Rand des Xylems im Übergang zum adaxialen parenchymatischen Gewebe zusätzlich sehr große Zellen mit lignifizierten Zellwänden zu finden. Dies weist auf eine nachträgliche Differenzierung von parenchymatischen Zellen zu Gefäß-ähnlichen Elementen hin. 

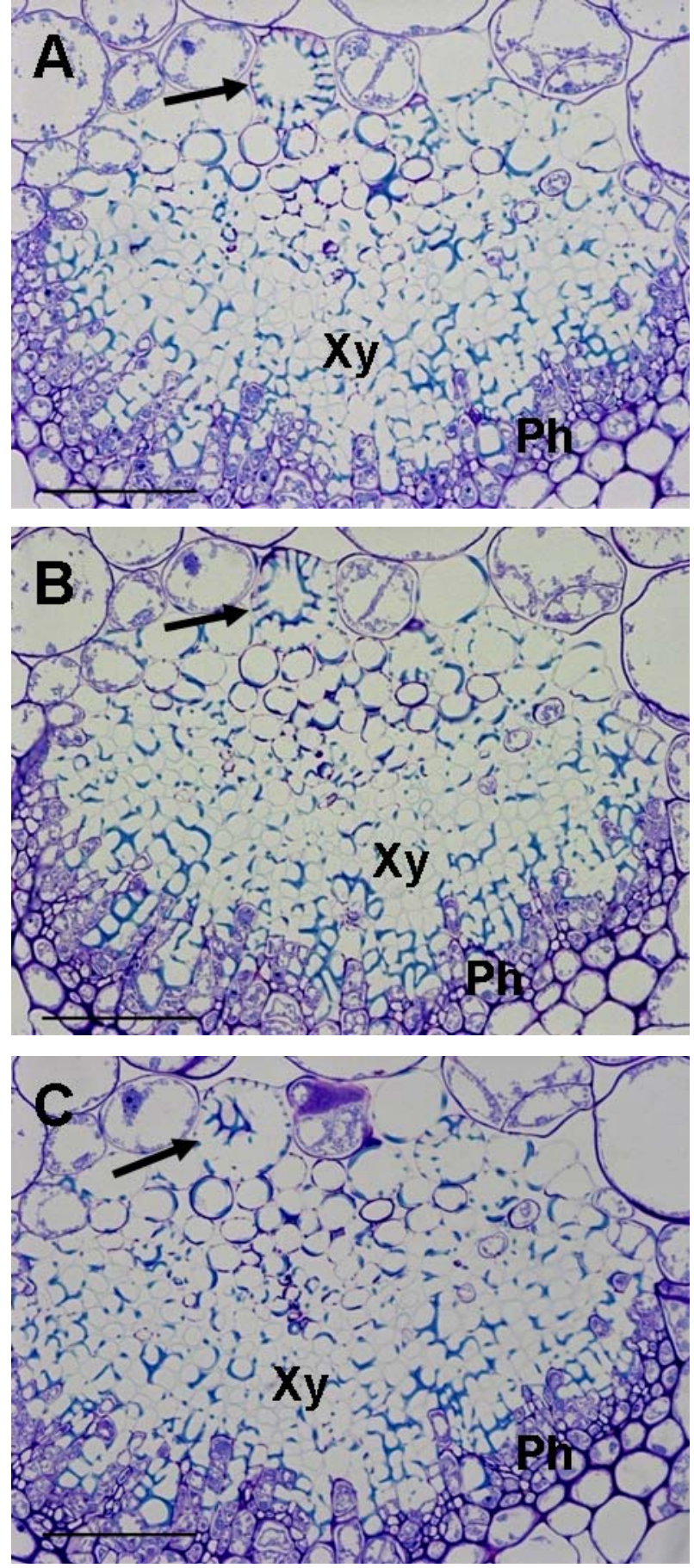

Abb. 32: Serienaufnahme derselben Blattprobe einer infizierten Pflanze des Wildtyps Col-0 21 dpi. Die lignifizierte, türkisfarbene Struktur innerhalb der markierten Zelle (Pfeil) ist zuerst nur am Rand zu sehen (A), im nächsten Schnitt reicht diese weiter in die Zelle hinein (B), im letzten Schnitt ist die Struktur in der Mitte der Zellen zu finden (C). Die Beobachtung weist auf eine runde Form der Zellen hin. Xy: Xylem, Ph: Phloem. Längenstandard $=50 \mu \mathrm{m}$. 


\subsection{Analyse von Promoter $_{\text {glp } 3}$-GUS-Reporterpflanzen Lokalisierung der glp3-Expression in Arabidopsis thaliana}

zur

Um weitere Hinweise auf die Funktion von GLP3 in A. thaliana zu bekommen, sollte untersucht werden, in welchen Pflanzenorganen und -geweben und zu welchem Zeitpunkt während des Lebenszyklus glp3 exprimiert wird. Zudem sollte getestet werden, ob sich nach Infektion mit $V$. longisporum das Transkriptlevel in bestimmten Geweben ändert oder glp3 in anderen Pflanzenteilen exprimiert wird als in den Kontrollen. Dazu wurden GUSReporter-Pflanzen hergestellt, indem Pflanzen des Ökotyps Col-0 mit einem Konstrukt transformiert wurden, in welchem der Promoter von glp3 vor das uidA-Gen aus E. coli kloniert wurde. Wenn der glp3-Promoter in der Pflanze aktiviert wird, wird die BGlucuronidase produziert, deren Aktivität anhand einer Farbreaktion im Pflanzengewebe nachgewiesen werden kann. Um auszuschließen, dass die Expression des uidA-Gens durch 35s-Promotoren, die vor anderen Genen innerhalb des Vektors liegen, induziert wird, wurden zusätzlich Pflanzen mit dem unveränderten Vektor (ohne glp3-Promoter) transformiert, die als Kontrolle in den Experimenten mitgeführt wurden.

Aus der Transformation gingen fünf Pflanzen hervor, die in der T1-Generation hinsichtlich der Funktionalität des Konstruktes überprüft wurden, indem einzelne Pflanzenteile in GUS-Färbelösung inkubiert wurden. Bei zwei der fünf Pflanzen war die Farbreaktion erfolgreich. Diese Pflanzen wurden weiter vermehrt und selektiert, bis Homozygote vorhanden waren, die für Experimente verwendet wurden. Mit den mit dem leeren Vektor transformierten Pflanzen wurde ebenso verfahren. Bei diesen konnte sowohl in den Pflanzen der T1-Generation als auch in den homozygoten Pflanzen keine Blaufärbung detektiert werden. Daher war die in den GUS-Reporterlinien auftretende ß-GlucuronidaseAktivität ausschließlich auf die Induktion des glp3-Promoters und nicht auf durch den verwendeten Vektor bedingte Faktoren zurückzuführen (Abb. 33).

Die Reporterlinien 2 und 3 sowie eine Leervektor-Kontroll-Linie wurden unter KurztagBedingungen angezogen, mit $V$. longisporum infiziert und regelmäßig auf die GUSExpression hin untersucht. Um zu prüfen, ob die GUS-Linien genauso auf $V$. longisporum reagieren wie der Wildtyp, wurden als Kontrolle zusätzlich infizierte und nicht infizierte Wildtyp-Pflanzen des Ökotyps Col-0 im Experiment mitgeführt. Bei einem Vergleich der uninfizierten Pflanzen war ein Unterschied zwischen der GUS-Reporterlinie 3 und den anderen Linien erkennbar (Abb. 34). 

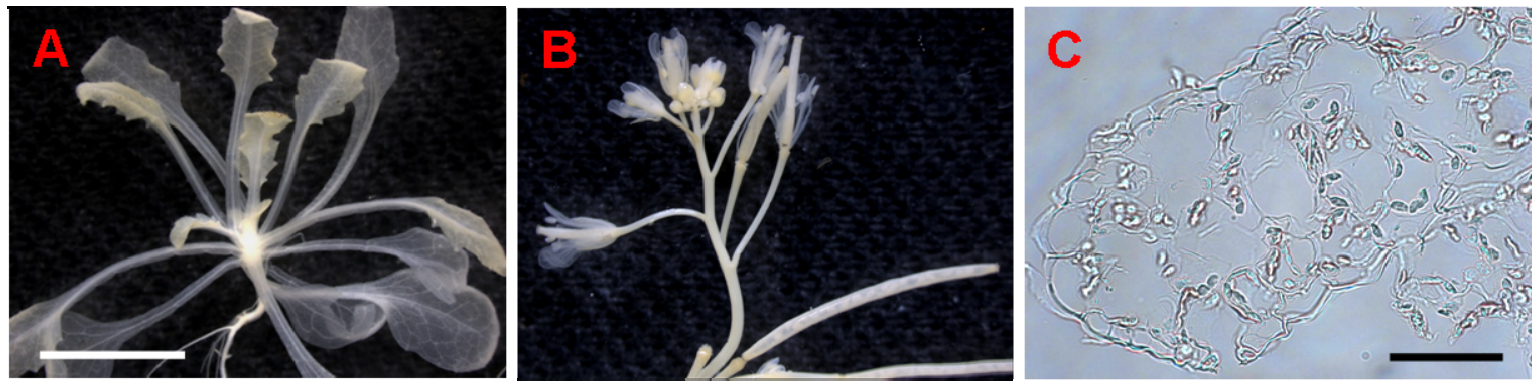

Abb. 33: Leervektor-Kontrollpflanzen zeigen keine unspezifischen Färbungen. Fotos von mit dem leeren Vektor transformierten Kontrollen nach Inkubation mit der GUS-Färbelösung. Sowohl in vegetativen Pflanzenteilen (A) als auch in Blüten (B) konnte keine B-Glucuronidase-Aktivität nachgewiesen werden. Auch bei Blattquerschnitten (C) konnte keine Blaufärbung detektiert werden. Der Längenstandard entspricht $0,5 \mathrm{~cm}$ für die makroskopischen Bilder und $50 \mu \mathrm{m}$ für die mikroskopische Aufnahme.
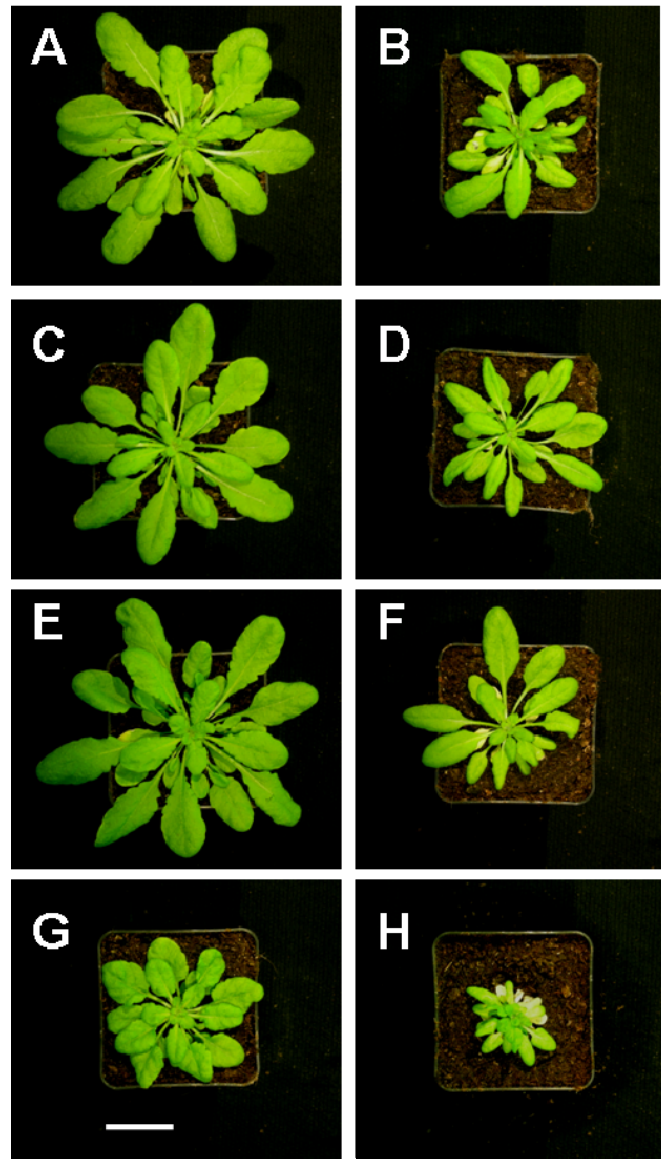

Abb. 34: Beispielbilder der für die GUS-Färbung verwendeten Pflanzen. Mock inokulierte (A, C, E, und G) und infizierte (B, D, F und H) Pflanzen des Wildtyps Col0 (A und B), der Leervektor-Kontrolle (C und D) und der GUS-Reporterlinien 2 (E und F) und 3 (G und $H$ ) 21 dpi. Der Längenstandard entspricht $3 \mathrm{~cm}$. 
Während die Blattflächen der GUS-Reporterlinie 2 sowie die mit dem leeren Vektor transformierten Pflanzen ungefähr die gleiche Größe erreichten wie die des Wildtyp, waren die der GUS-Reporterlinie 3 um mehr als die Hälfte kleiner (Abb. 34 und 35 A). Die typische Reduktion der Blattfläche nach der Infektion mit $V$. longisporum trat jedoch bei allen Linien in ähnlicher Form auf (Abb. 35 B).
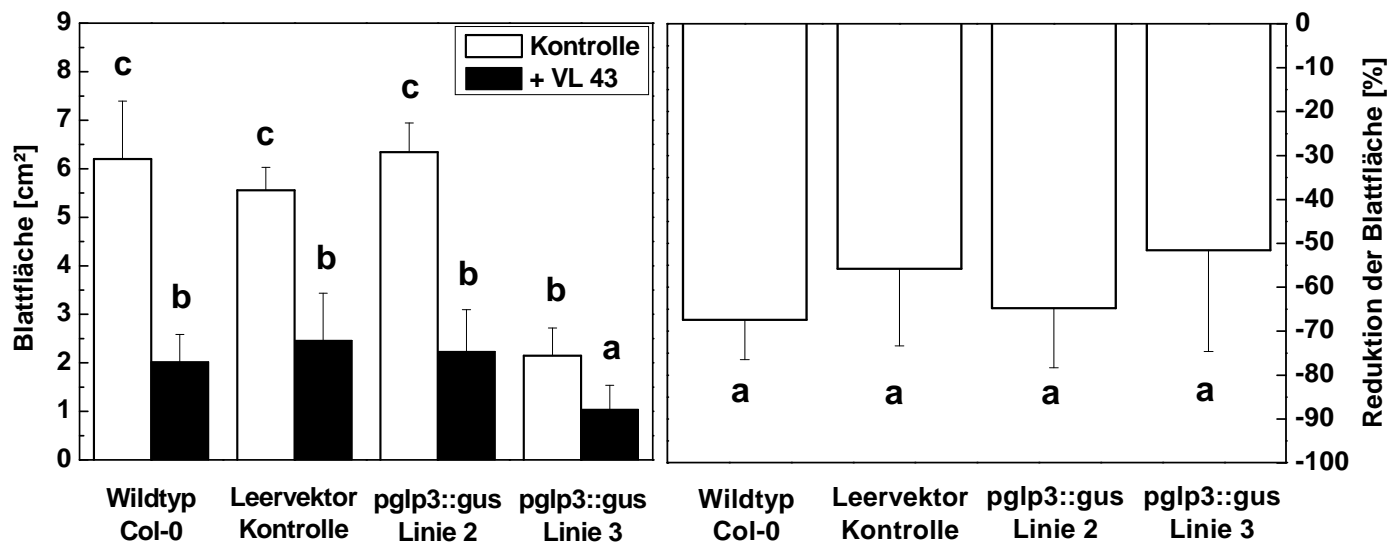

Abb. 35: Blattfläche der Pflanzen der GUS-Reporterlinien (Pglp3::GUS, Linie 2 bzw. Pglp3::GUS, Linie 3) und der Leervektor-Kontrolle im Vergleich zu der des Wildtyps Col-0 21 dpi. Dargestellt werden die Blattflächen mock inokulierter (weiße Säulen) und infizierter (schwarze Säulen) (A) sowie die Reduktion der Blattfläche infizierter Pflanzen relativ zu den Kontrollen in Prozent (B). Abgebildet sind Mittelwerte mit Standardabweichungen $(n=5)$. Signifikante Unterschiede $(p \leq 0,05)$ sind durch verschiedene Buchstaben gekennzeichnet.

Die B-Glucuronidase-Aktivität konnte in Blättern der GUS-Reporterpflanzen sowie in Petiolen anhand der Blaufärbung des Gewebes nachgewiesen werden, wobei es einen Gradient von den neu gebildeten, intensiv gefärbten hin zu den älteren Blättern gab, bei denen die Färbung nur noch lokal beschränkt und von geringer Intensität war (Abb. 36 und Abb. 37). Die ältesten Blätter waren nicht gefärbt. Ebenso nahm die Färbung mit dem Alter der Pflanzen ab (vgl. Abb. 36 und Abb. 37). Auffällig war auch, dass die Mittelrippe in der Regel ungefärbt war. Innerhalb der Blätter war sowohl in den Mesophyllzellen als auch in der Epidermis die ß-Glucuronidase-Aktivität detektierbar (Abb. 38).

Bei einem Vergleich der infizierten Pflanzen mit den Kontrollen gab es keine Unterschiede hinsichtlich der Lokalisierung der GUS-Aktivität. Allerdings waren teilweise Abweichungen bezüglich der Intensität der Färbung zu sehen. Die Blaufärbung in den 

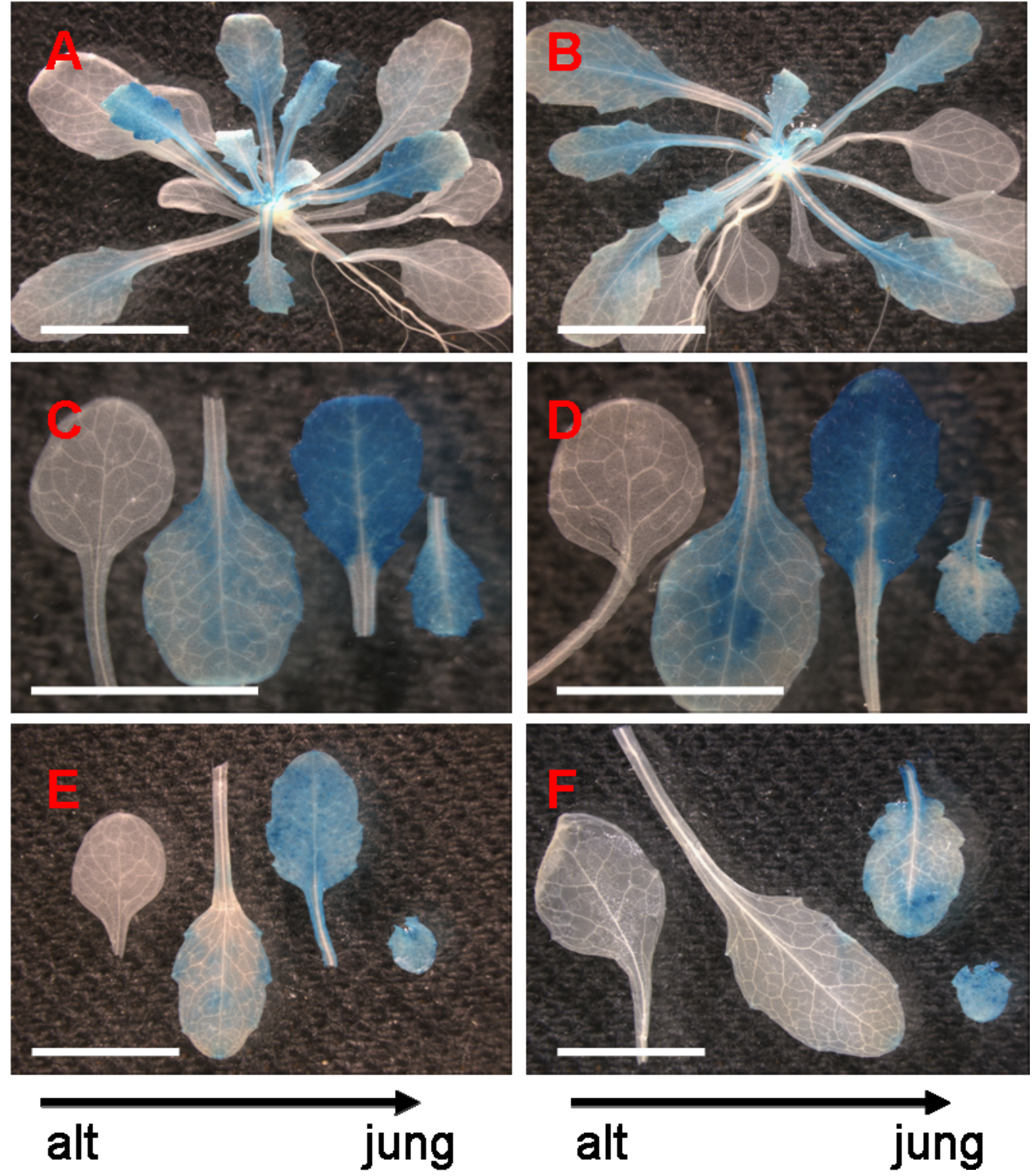

Abb. 36: GUS-Expression in vegetativen Pflanzenteilen. Nachweis der BGlucuronidase-Aktivität in vegetativen Pflanzenteilen zur Analyse der Expression von glp3 in GUS-Reporterpflanzen in mock inokulierten Kontrollen der Linie 2 (A, C und $E$ ) und nach Infektion mit $V$. longisporum (B, D und F). Abgebildet sind digitale Aufnahmen repräsentativer junger Pflanzen 1 dpi (A und B) und detaillierte Aufnahmen von Blättern verschiedener Entwicklungsstadien 3 dpi (C und D; links: jeweils eines der ältesten Blätter, rechts: jüngstes Blatt) und 7 dpi ( $E$ und $F$ ) nach 3stündiger Inkubation in der Färbelösung. Der Längenstandard entspricht $0,5 \mathrm{~cm}$. Die Linie 3 zeigte ein ähnliches Färbemuster. Entprechende Bilder der Linie 3 sind in Anhang B zu finden.

Blättern infizierter Pflanzen war 7 dpi weniger stark ausgeprägt als in denen der Kontrollen (Abb. 36). Die Expression von glp3 war also in den Blättern zu diesem Zeitpunkt nach der Infektion mit $V$. longisporum geringer als in den Kontrollen. 


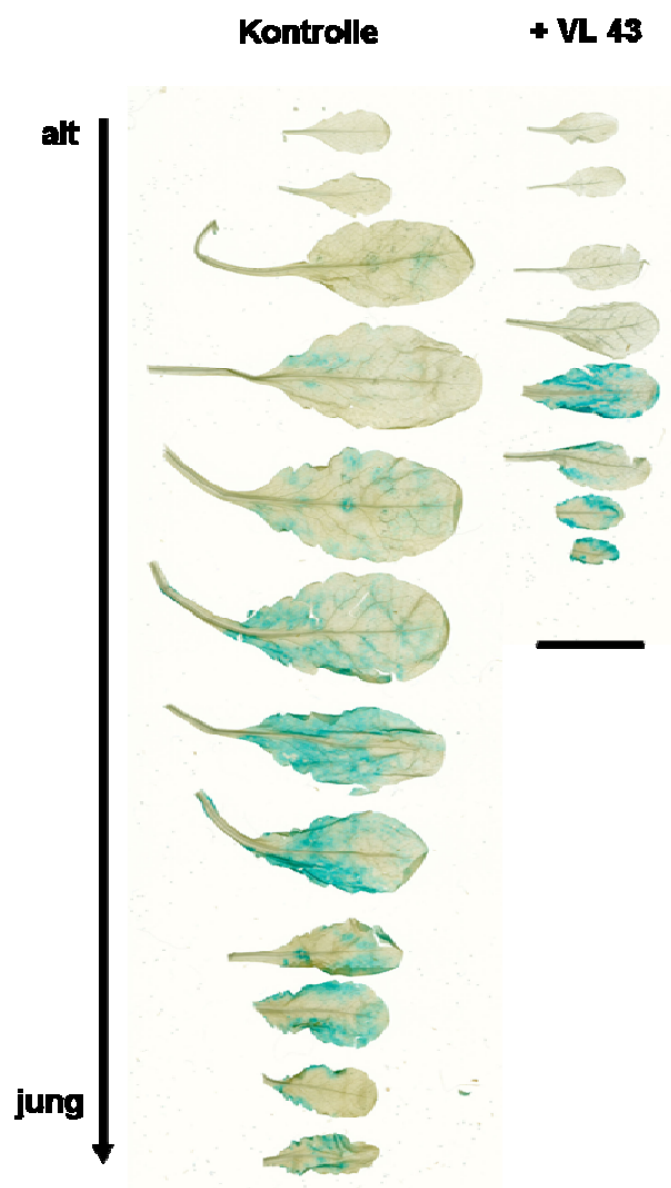

Abb. 37: Nachweis der B-Glucuronidase-Aktivität 21 dpi. Abgebildet sind Blätter repräsentativer Pflanzen der Linie 2 in mock inokulierten Kontrollen (links) und in infizierten Pflanzen (rechts) nach 3stündiger Inkubation in der Färbelösung. Der Längenstandard entspricht $2 \mathrm{~cm}$. Bilder der Linie 3 sind im Anhang zu finden.


Abb. 38: Nachweis der B-Glucuronidase-Aktivität innerhalb der Blätter 21 dpi. Abgebildet sind $10 \mu \mathrm{m}$ dicke Querschnitte von mock inokulierten (A) und infizierten Pflanzen der Linie 2 (B) nach 3stündiger Inkubation in der Färbelösung. Der Längenstandard entspricht $50 \mu \mathrm{m}$. 
In den Wurzeln konnte weder in infizierten noch in uninfizierten Pflanzen eine $\beta$ Glucuronidase-Aktivität festgestellt werden (Abb. 36).

Bei blühenden Pflanzen war der Blütenstiel (Pedicellus) intensiv blau gefärbt. Außerdem konnte in den meisten Teilen der Blüte eine GUS-Expression detektiert werden (Abb. 39).

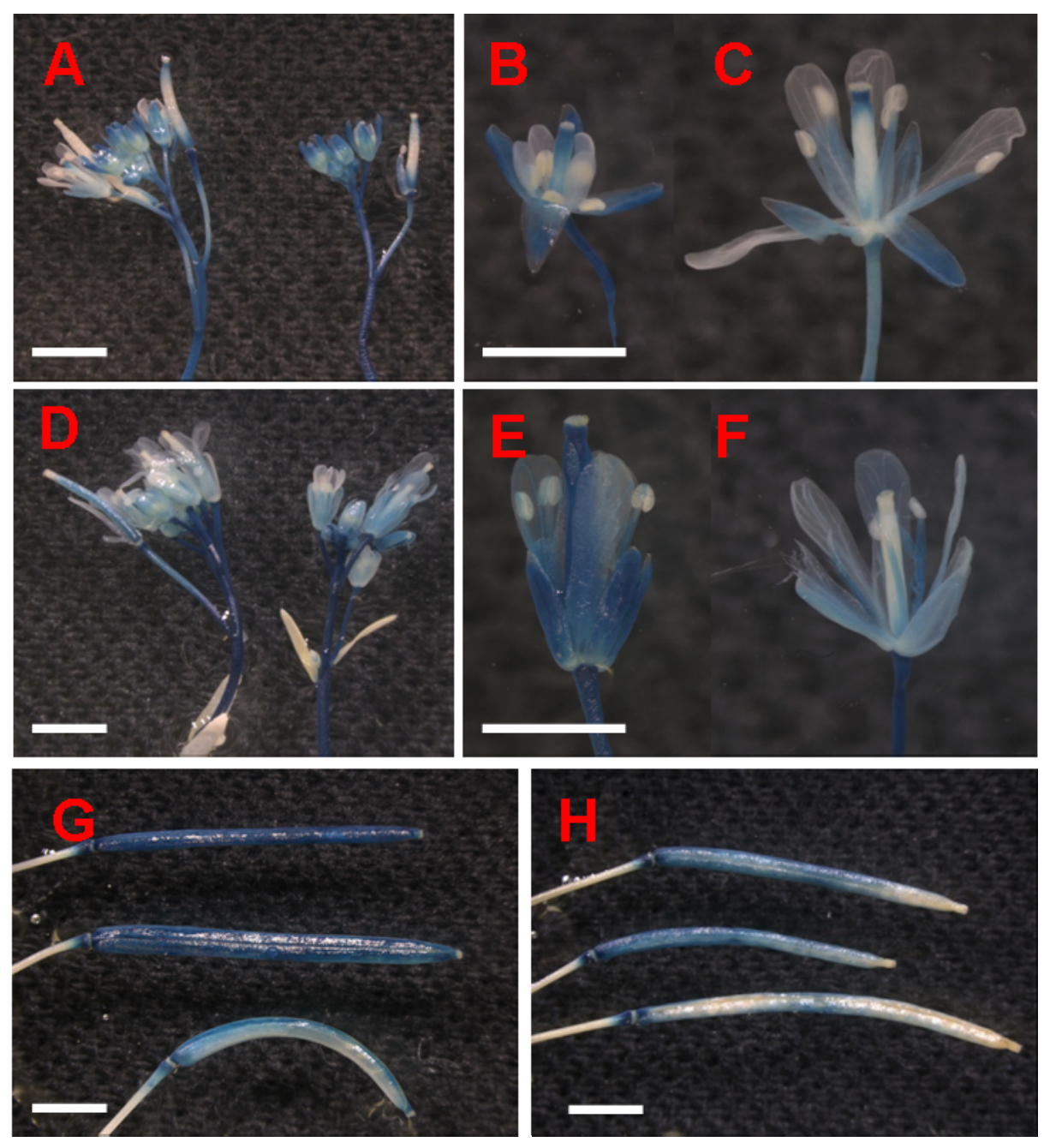

Abb. 39: GUS-Expression in Blüten. Nachweis der B-Glucuronidase-Aktivität in GUS-Reporterpflanzen in uninfizierten ( $A$ - C und $G)$ und infizierten Pflanzen (D - F und $\mathrm{H}$ ). Zu sehen sind Bilder der Blütenstände repräsentativer Pflanzen der Linie 2 (A und D) sowie detaillierte Aufnahmen junger ( $B$ und $E$ ) und älterer ( $C$ und $F$ ) Blüten und Schoten ( $G$ und $H$ ) 56 dpi nach 18stündiger Inkubation in der Färbelösung. Der Längenstandard entspricht $0,2 \mathrm{~cm}$. 
So zeigten die Kelchblätter, Teile des Fruchtblattes sowie der Staubfaden eine Blaufärbung. In einigen Blüten war zusätzlich der mittlere Teil des Staubbeutels, das Konnektiv, welches die beiden Pollensackgruppen miteinander verbindet, gefärbt. Auch in den Schoten konnte die B-Glucuronidase-Aktivität detektiert werden. Die Intensität und die Ausbreitung der Färbung war in den Blütenteilen jedoch abhängig von deren Entwicklungsstadium. Während die Blaufärbung in Knospen und jungen Blüten sehr intensiv war und meist überall auftrat, war sie in den Blüten, in denen sich bereits die Samenschote entwickelte, meist schwächer und lokal begrenzt (vgl. Abb. 39 B und E mit C und F). Zwischen infizierten und nicht infizierten Pflanzen gab es keine Unterschiede hinsichtlich der Intensität der Färbung der Blütenteile.

Anhand der GUS-Reporterpflanzen ließ sich zeigen, dass glp3 in Blättern und in allen Blütenteilen, nicht aber in der Wurzel exprimiert wird. Zudem wurde festgestellt, dass diejenigen Gewebe, die sich noch in der Entwicklung befinden und sich noch strecken, stärker gefärbt waren als bereits ausgewachsene Pflanzenteile. Zwischen infizierten und mock inokulierten Pflanzen gab es $\mathrm{zu}$ den meisten Zeitpunkten keine Unterschiede hinsichtlich der GUS-Aktivität. Lediglich 7 dpi war die Blaufärbung in Blättern infizierter Pflanzen weniger ausgeprägt als in den Kontrollen. Die Ergebnisse lassen insgesamt darauf schließen, dass die glp3-Expression mit dem Streckungswachstum korreliert.

\subsection{Untersuchung des Einflusses von heterolog produziertem GLP3 auf das Wachstum von Verticillium longisporum}

Um zu prüfen, ob GLP3 das Wachstum von V. longisporum direkt beinflusst, wurden Experimente durchgeführt, bei denen das Pathogen mit GLP3 produzierender Hefe konfrontiert wurde. $\mathrm{Zu}$ diesem Zweck wurde GLP3 in S. cerevisiae transferiert und mit einem Polyhistidin-Tag exprimiert. Mittels Western Blot Analyse konnte die Produktion des GLP3-Fusionsproteins in den mit dem entsprechenden Konstrukt transformierten Hefezellen nachgewiesen werden, während in Zelllysaten von Hefezellen, die mit dem Leervektor transformiert worden waren, kein Protein detektiert werden konnte (siehe Abb. $40)$. 


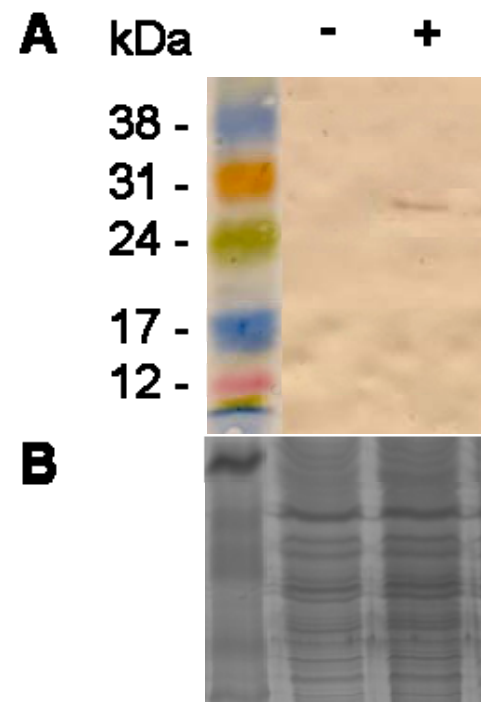

Abb. 40: Western Blot Analyse (A) und SDS-PAGE (B) von lysierten Hefezellen. GLP3-His-Fusionsproteine mit einem Molekulargewicht von 26,8 kDa konnten in Hefezellen, die mit dem GLP3-His-Konstrukt transformiert wurden, nachgewiesen werden $(+)$. Purpurfarbene Banden zeigen Bindestellen des Antikörpers. Bei Proben von Hefezellen, die mit dem Leervektor transformiert wurden (-), konnte kein Protein detektiert werden. Für den Blot wurden Hefezellen aus einer Expressionskultur mit einer $\mathrm{OD}_{600}$ von 1,5 lysiert, $20 \mu \mathrm{g}$ Protein über SDS-PAGE aufgetrennt und auf eine Nitrocellulosemembran übertragen. Die Immunodetektion erfolgte über einen anti-His-Antikörper, der an eine alkalische Phosphatase gekoppelt war. Diese katalysiert die Umsetzung von BCIP und NBT zu einem violetten Farbstoff.

Für die Wachstumsversuche wurde V. longisporum mit der GLP3 produzierenden Hefe koinkubiert. Dazu wurde eine Myzelscheibe des Pathogens mit einem Durchmesser von 2 cm von PDB-Medium auf festes, selektives Medium überführt. Die Hefezellen wurden mit einem Abstand von $2 \mathrm{~cm} \mathrm{zu} \mathrm{V.} \mathrm{longisporum} \mathrm{als} \mathrm{1,5} \mathrm{cm}$ breiter Ring auf die Agarplatten aufgebracht (Abb. 41, A und B). Das Medium enthielt zur Induktion der glp3-Expression in der Hefe Galaktose. Um unterscheiden zu können, ob auftretende Unterschiede im Wachstum von $V$. longisporum auf die Hefe oder auf GLP3 zurückzuführen sind, wurde neben den GLP3 produzierenden Hefezellen in parallelen Ansätzen auch die mit dem Leervektor transformierte Hefe für die Experimente verwendet. Als weitere Kontrolle wurden Agarplatten mit $V$. longisporum ohne Hefe mitgeführt (Abb. 41, C). Zur Quantifizierung des Wachstums von V. longisporum wurden die Agarplatten regelmäßig dokumentiert und die Fläche des Myzels anhand digitaler Bilder ausgewertet. 
V. longisporum bildete unter den Versuchsbedingungen neue, helle Hyphen aus, die sich bei allen Varianten von den dunklen Myzelscheiben in radialer Richtung ausbreiteten (Abb. 41). Bei allen Varianten war der Zuwachs in den ersten Tagen am stärksten, danach nahm die Gesamtfläche des Myzels nur noch marginal zu. Bei einzelnen Platten stagnierte das Wachstum gänzlich (Abb. 42).
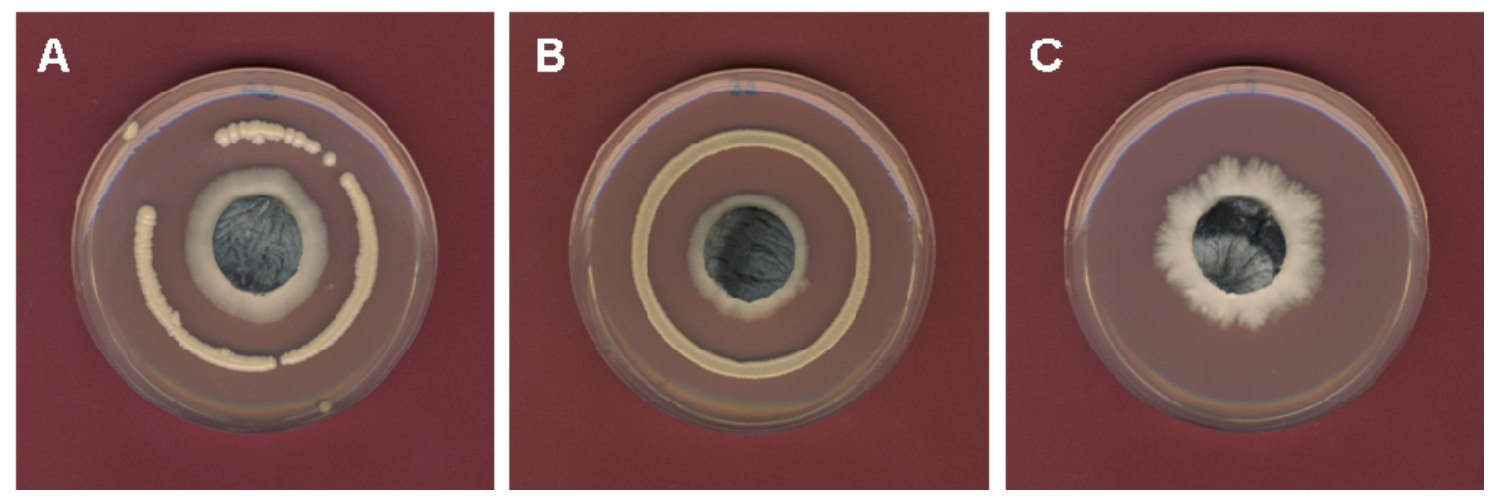

Abb. 41: In vitro Assay zur Untersuchung der wachstumsinhibierenden Wirkung von GLP3 auf $V$. longisporum. Abgebildet sind repräsentative Agarplatten des Experiments, bei dem V. longisporum mit Hefe, die mit einer Leervektor-Kontrolle transformiert wurde (A), mit GLP3 produzierender Hefe (B) sowie ohne Hefe (C) inkubiert wurde.

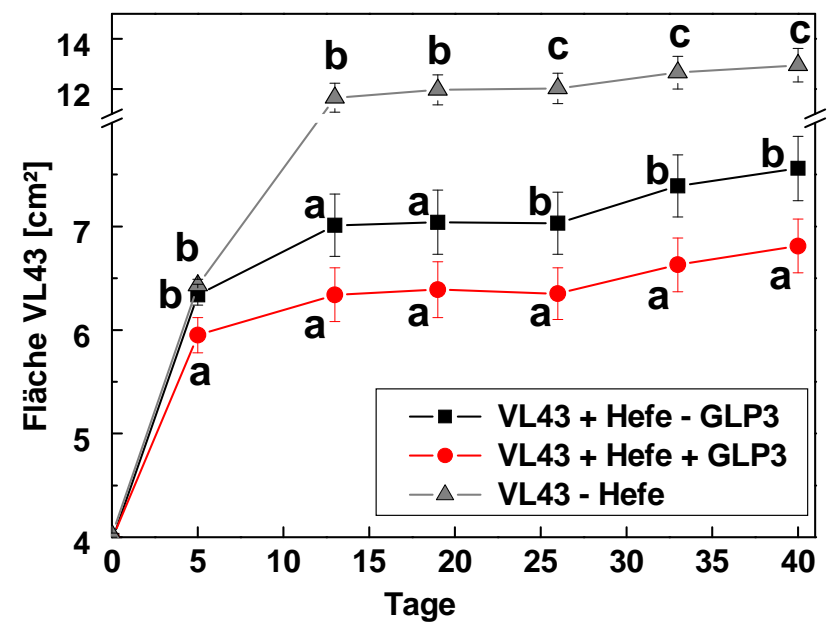

Abb. 42: Wachstum von V. longisporum unter dem Einfluss von GLP3. Dargestellt ist die mittlere Fläche des Myzels des Pathogens in $\mathbf{c m}^{2}$ mit Standardfehler $(\mathbf{n}=15)$. Untersucht wurde die Proliferation von V. longisporum unter dem Einfluss von GLP3 produzierender Hefe (rote Symbole) sowie unter dem Einfluss von Hefezellen, die kein GLP3 herstellen (Leervektor-Kontrolle, schwarze Symbole). Als weitere Kontrolle wurde das Wachstum des Pilzes ohne Hefe dokumentiert (graue Symbole). Signifikante Unterschiede zwischen den verschiedenen Varianten sind durch unterschiedliche Buchstaben gekennzeichnet. Die Daten wurden für die statistische Analyse logarithmiert. 
Bei einem Vergleich der unterschiedlichen Varianten fiel zunächst auf, dass es eine deutliche Unterdrückung der Proliferation von V. longisporum in Anwesenheit von Hefe gab. Die Ergebnisse offenbarten zusätzlich eine signifikante Reduktion des Wachstums von $V$. longisporum unter dem Einfluss von GLP3 produzierender Hefe im Vergleich zur Leervektor-Kontrolle. GLP3 produzierende Hefe verminderte das Wachstum von $V$. longisporum um rund $20 \%$.

Das GLP3-Fusionsprotein beeinträchtigte also das Wachstum von V. longisporum in vitro. Die erhöhte Toleranz von $A$. thaliana gegenüber $V$. longisporum durch konstitutive Expression von glp3 kann daher durch eine direkte antifungale Wirkung des Proteins erklärt werden. 


\section{Diskussion}

\subsection{Proteine aus dem Xylemsaft von Brassica napus weisen antifungale Eigenschaften auf}

$V$. longisporum befindet sich als vaskuläres Pathogen die meiste Zeit seines Lebenszyklus innerhalb der Pflanze in deren Xylem. Daher werden Abwehrreaktionen seitens der Pflanze vor allem hier erwartet. Um zu überprüfen, ob in $B$. napus nach Infektion mit $V$. longisporum Abwehrsubstanzen produziert und in den Xylemsaft abgegeben werden, die der Kolonisierung des Pilzes in der Pflanze entgegen wirken, sollte das Pilzwachstum in purem Xylemsaft analysiert werden. Die in vitro Bioassays haben gezeigt, dass $V$. longisporum im Xylemsaft von infizierten Pflanzen schlechter wuchs als im Xylemsaft von Kontrollpflanzen.

Über die Veränderung der antimikrobiellen Wirkung von Xylemsaft infolge eines Pathogenbefalls ist nicht viel bekannt. Lediglich der Xylemsaft von Sojabohne wurde dahingehend überprüft. Der Pilz Neurospora crassa wächst schlechter im Xylemsaft der Sojabohne, wenn die Pflanzen zuvor mit einem Elicitor aus dem Pathogen Phytophthora sojae behandelt wurden (Subramanian et al. 2009). Da es sich in der genannten Studie bei dem Auslöser der Immunantwort und dem anschließend getesteten Pilz um unterschiedliche Organismen handelt, ist zu vermuten, dass diese Immunantwort nicht spezifisch gegen ein bestimmtes Pathogen gerichtet ist. Ob die Einschränkung des Wachstums im Xylemsaft von infizierten Rapspflanzen gegenüber dem von uninfizierten Rapspflanzen nur für $V$. longisporum gilt oder ob andere Organismen sich ähnlich verhalten, wird zur Zeit von einer anderen Arbeitsgruppe (AG Karlovsky) innerhalb der Forschergruppe 546 analysiert. Erste Ergebnisse wiesen darauf hin, dass auch Agrobakterien im Xylemsaft von infizierten Pflanzen in ihrem Wachstum gegenüber dem im Xylemsaft von uninfizierten Pflanzen beeinträchtigt sind (Persönliche Mitteilung, Prof. Karlovsky). Somit wäre auch hier der wachstumsinhibierende Effekt nicht spezifisch. Weitere Experimente werden diese Hypothese klären. 
Obwohl die Nährstoffversorgung von B. napus insgesamt infolge einer Infektion durch $V$. longisporum nicht negativ beeinflusst wird (Floerl et al. 2008), könnte die Anwesenheit des Pilzes dennoch lokal im Xylem bzw. im Xylemsaft zu Unterschieden hinsichtlich der Nährstoffzusammensetzung führen. Um auszuschließen, dass ein Mangel an Nährstoffen das geringere Wachstum des Pilzes im Xylemsaft von infizierten Pflanzen verursachte, wurde der Xylemsaft hinsichtlich der Konzentration der löslichen Zucker, der Proteine, der Aminosäuren sowie der Mineralelemente überprüft.

Sowohl bezüglich der Zucker als auch der Proteine gab es keine Unterschiede zwischen dem Xylemsaft von infizierten und dem von nicht infizierten Pflanzen. Zudem sind die Messergebnisse mit denen aus anderen Studien vergleichbar, denn in anderen Studien wurden im Xylemsaft Protein-Konzentrationen von $13 \mu \mathrm{g} / \mathrm{ml}$ in Raps (Nakamura et al. 2008), $12 \mu \mathrm{g} / \mathrm{ml}$ in Mais (Alvarez et al. 2005), 7,8 $\mu \mathrm{g} / \mathrm{ml}$ in Sojabohne (Subramanian et al. 2009), 20 bis $70 \mu \mathrm{g} / \mathrm{ml}$ in Tomate (Rep et al. 2002) sowie zwischen 50 und $100 \mu \mathrm{g} / \mathrm{ml}$ in verschiedenen anderen Arten, darunter auch Raps (Buhtz et al. 2004), ermittelt. Diese Werte liegen in einem ähnlichen Bereich wie die hier gefundene Proteinkonzentration (um $50 \mu \mathrm{g} / \mathrm{ml}$ ). Zwischen der Proteinkonzentration im Xylemsaft von Verticillium-infizierten Pflanzen und mock-inokulierten Pflanzen gab es keinen Unterschied, während diese in der Sojabohne nach Behandlung der Pflanzen mit einem Elicitor von 7,8 auf $11 \mu \mathrm{g} / \mathrm{ml}$ anstieg (Subramanian et al. 2009).

Die in dieser Arbeit gemessene Glukose-Konzentration von $0,18 \mathrm{mM}$ ist etwas geringer als die in der Literatur für Raps angegebenen Werte von 0,3 mM (Nakamura et al. 2008) und 1,3 mM (Ratzinger et al. 2009). Bei der letztgenannten Studie wurde außerdem die Saccharose-Konzentration ermittelt und lag zwischen 0,7 und 1,7 mM. Zhou (2000) fand im Xylemsaft von Rapspflanzen mit unterschiedlicher Stickstoffversorgung zwischen 0,06 $\mathrm{mM}$ und 0,25 mM Saccharose. Die im Rahmen dieser Arbeit gemessene Konzentration liegt mit 0,44 mM dazwischen. Die Menge an Fruktose war sowohl in unseren (0,04 mM) als auch in anderen Untersuchungen (0,09 $\mathrm{mM}$ bei Nakamura et al. 2008) geringer als die von Glukose und Saccharose. Zwischen Verticillium-infizierten und nicht infizierten Pflanzen traten keine Unterschiede hinsichtlich der Zuckerkonzentration auf. Dies wird durch die Ergebnisse anderer Studien bestätigt (Ratzinger et al. 2009).

Bei den Elementanalysen konnten Eisen und Magnesium nur in geringen Mengen $(2 \mathrm{mg} / \mathrm{l}$ bzw. 9 mg/l) detektiert werden. Die Konzentrationen von Kalzium und Phosphor lagen im 
Bereich zwischen 25 und $37 \mathrm{mg} / 1$. Schwefel kam in etwas größeren Menge um $60 \mathrm{mg} / 1$ vor. Der Anteil an Kalium war mit Abstand am größten und betrug um 300 mg/l. Nakamura und Mitarbeiter fanden im Xylemsaft von Raps Konzentrationen von 10,4 $\mu \mathrm{M}$ (=0,58 mg/l) für Eisen, 3,5 mM (= $84 \mathrm{mg} / \mathrm{l})$ für Magnesium, 7,6 mM (= $304 \mathrm{mg} / \mathrm{l})$ für Kalzium sowie 6,4 mM (=250 mg/1) für Kalium (Nakamura et al. 2008). Die Unterschiede $\mathrm{zu}$ den in dieser Arbeit gemessenen Werten kann durch die verschiedenen Wachstumsbedingungen bedingt sein. Insgesamt liegen die Messergebnisse aber in einer ähnlichen Größenordnung.

Für Phosphor und Schwefel sind die Werte in infizierten Pflanzen etwas niedriger als in nicht infizierten Pflanzen. Diese Unterschiede sind jedoch so gering, dass sie nicht der Grund für das verringerte Wachstum von V. longisporum im Xylemsaft von infizierten Pflanzen sein können.

Hinsichtlich der Aminosäuren gab es in der Summe keine Unterschiede zwischen dem Xylemsaft von infizierten und dem von nicht infizierten Pflanzen. In anderen Studien wurden im Xylemsaft von Raps Aminosäure-Konzentrationen von 0,5 mM (Singh et al. 2010), 8,3 mM (Nakamura et al. 2008) sowie in Abhängigkeit vor der Stickstoffversorgung zwischen 2,5 und 4,8 mM (Zhou 2000) ermittelt. Auch in anderen Pflanzen ist die Summe aller Aminosäuren im Xylemsaft ähnlich. So wurde beispielsweise in Zuckerrübe eine Konzentration von 1,8 mM detektiert (López-Milán et al. 2000). Die Summe der in dieser Arbeit gemessenen Aminosäuren von 1,5 $\mathrm{mM}$ ist mit den Literaturangaben vergleichbar.

Während die Summe aller Aminosäuren im Xylemsaft von Tomatenpflanzen nach Infektion mit V. albo-atrum steigt (Dixon \& Pegg 1972), änderte diese sich im Xylemsaft von Raps durch die Infektion mit $V$. longisporum nicht. Allerdings führte die Infektion zur einem veränderten Vorkommen einzelner Aminosäuren. So war die Konzentration von Glycin und Isoleucin in infizierten Pflanzen erhöht, während die von Tryptophan im Vergleich zu den Kontrollen geringer war. Da aus der Literatur keine Eigenschaften von Tryptophan, Isoleucin und Glycin bekannt sind, durch die eine Beeinflussung des Wachstums von $V$. longisporum erklärt werden könnte, ist es sehr unwahrscheinlich, dass die Änderung der Konzentrationen dieser drei Aminosäuren das verringerte Wachstum des Pilzes verursacht haben könnten. Im Xylemsaft von Pflanzen stellt Nitrat die Haupttransportform von Stickstoff dar (Siebrecht 2000, Zhou 2000). Erste Ergebnisse von 
Messungen der Nitratkonzentration im Xylemsaft von Raps deuten an, dass diese im Xylemsaft von infizierten Pflanzen gegenüber nicht infizierten Pflanzen erhöht ist (Persönliche Mitteilung, Prof. Gatz).

Daher ist das eingeschränkte Wachstum von V. longisporum im Xylemsaft von infizierten Pflanzen höchstwahrscheinlich nicht durch eine schlechtere Nährstoffversorgung erklärbar. Bislang kann aber nicht ausgeschlossen werden, dass die Nährstoffverteilung unbeeinträchtigt bleibt. Dies muss in weiteren Analysen noch geprüft werden.

Ein anderer Grund für die Inhibierung des Wachstums von V. longisporum im Xylemsaft können de novo synthetisierte oder vermehrt produzierte und sekretierte Abwehrsubstanzen sein. Da auch Proteine zu diesen Komponenten zählen und im extrazellulären Proteom von B. napus infolge einer Infektion durch V. longisporum Veränderungen auftreten (Floerl et al. 2008), wurde die Wirkung der Xylemsaft-Proteine auf das Pilzwachstum untersucht. Es konnte gezeigt werden, dass Proteine das Wachstum des Pilzes massiv inhibieren. Interessanterweise war der Effekt auch bei Verwendung der Proteine aus den uninfizierten Pflanzen zu beobachten.

Dass Xylemsaft-Proteine generell das Wachstum von Mikroorganismen beeinflussen können, wird durch andere Studien bestätigt. So konnte für Proteine aus dem Xylemsaft von Mais eine antifungale Eigenschaft gegen Neurospora crassa nachgewiesen werden (Alvarez et al. 2005). Auch die bereits erwähnten antifungalen Effekte des Xylemsaftes von Sojabohne konnten auf die darin enthaltenen Proteine zurückgeführt werden (Subramanian et al. 2009).

Im Xylemsaft von Raps treten nach Infektion mit $V$. longisporum eine basische 1,3-ßGlucanase, eine Endochitinase sowie ein PR4-Protein in größeren Mengen als in Kontrollpflanzen auf (Floerl et al. 2008). Aber auch in unbehandelten Rapspflanzen sind bereits Proteine mit putativen Abwehrfunktionen $\mathrm{zu}$ finden, wie z.B. Peroxidasen, Chitinasen, Germin-ähnliche Proteine, Thaumatin-ähnliche Proteine und andere PRProteine (Kehr et al. 2005, Floerl et al. 2008). Ein ähnliche Situation stellt sich auch in anderen Pflanzen wie Mais, Brokkoli, Kürbis und Gurke dar (Buhtz et al. 2004, Alvarez et al. 2005).

Die antimikrobielle Wirkung von Proteinen, die im Xylemsaft vorkommen, wurde für verschiedene Proteine nachgewiesen (van Loon et al. 2006). So wirkte sich beispielsweise ein PR10-Protein negativ auf das Wachstum von Fusarium oxysporum aus (Gómez-Gómez 
et al. 2011). Aus der apoplastischen Waschflüssigkeit von Kichererbse wurde ein Thaumatin-ähnliches Protein mit antifungaler Aktivität isoliert (Hanselle et al. 2001). Ein anderes Thaumatin-ähnliches Protein aus Cynanchum komarovii konnte das Wachstum verschiedener pathogener Pilze wie Fusarium oxysporum, Botrytis cinerea, Rhizoctonia solani, Valsa mali und auch V. dahliae einschränken (Wang et al. 2011). Peroxidasen können sich indirekt durch die Produktion von ROS auf das Wachstum auswirken (Almagro et al. 2009, Wong et al. 2010). Chitinasen katalysieren die Hydrolyse von Chitin, dem Hauptbestandteil der Zellwand von Pilzen, und können so das Pilzwachstum unterdrücken (Collinge et al. 1993, Wong et al. 2010). So konnte einer Chitinase aus Urginea indica beispielsweise eine antifungale Wirkung gegen Fusarium oxysporum und Rhizoctonia solani nachgewiesen werden (Shenoy et al. 2006). Chitinasen aus Tabak können das Wachstum von Pilzen inhibieren, indem sie die Spitzen der Hyphen lysieren (Sela-Buurlage et al. 1993, Mauch et al. 1998). Auch in transgenen Pflanzen mit konstitutiv erhöhter Chitinase-Expression ist das Pilzwachstum gehemmt (Broglie et al. 1991, Jach et al. 1995). Das Auftreten einer Chitinase und einer B-1,3,-Glucanase in der apoplastischen Waschflüssigkeit von Weizen werden mit einer Resistenz gegen Septoria tritici assoziiert (Shetty et al. 2009). Ebenfalls in der apoplastischen Waschflüssigkeit von Weizen wuden in einer anderen Studie eine Chitinase, ein Thaumatin-ähnliches Protein und eine 1,3,-ß-Glucanase detektiert. Die apoplastische Waschflüssigkeit hatte eine inhibitorische Wirkung gegen Fusarium graminearum und Gaeumannomyces graminis var. tritici (Anand et al. 2004).

Die hier aufgezeigten Befunde zeigen, dass die Xylemsaft-Proteine in B. napus aufgrund ihrer wachstumsinhibierenden Eigenschaft eine wichtigen Beitrag zur Abwehr gegen $V$. longisporum liefern. Da auch die Proteine im Xylemsaft von unbehandelten Pflanzen das Wachstum des Pilzes beeinträchtigen, scheinen die Pflanzen stetig eine Vielzahl von Proteinen in das Xylem zu sekretieren, die für eine gewisse Basis-Resistenz sorgen. Das Xylem spielt also eine große Rolle bezüglich der Immunantwort von B. napus gegen $V$. longisporum.

$\mathrm{Ob}$ solche Proteine die Kolonisierung des Leitgewebes durch $V$. longisporum auch in planta minimieren, und ob sie generell das Wachstum vaskulärer Pathogene unterdrücken, müssen weitere Experimente klären. 


\subsection{Eine Infektion mit Verticillium longisporum führt in Arabidopsis thaliana zur Produktion von hyperplastischem Xylem und zu einer Transdifferenzierung von Mesophyllzellen zu Gefäß- ähnlichen Elementen}

$V$. longisporum ist wie die anderen phytopathogenen Vertreter der Gattung Verticillium ein vaskuläres Pathogen, das den größten Teil seines Lebenszyklus in der Pflanze in deren Xylem lokalisiert ist (Karapapa et al. 1997, Eynck et al. 2007). Infektionen durch Pathogene gehen oft mit anatomischen Veränderungen innerhalb der Pflanze einher (siehe Einleitung). Da in A. thaliana nach Infektion mit $V$. longisporum der Ligningehalt erhöht ist und zudem Proteine im Apoplast zu finden sind, die mit Zellwandmodifikationen assoziiert werden (Flörl 2007), wurden infizierte Pflanzen auf anatomische Veränderungen hin analysiert.

Dabei wurde festgestellt, dass eine Infektion mit $V$. longisporum im Hypokotyl sowie im Xylem-Bereich des Blattes zu einer vermehrten Produktion von Gefäßen führte. Aufgrund der Anordnung dieser zusätzlichen Gefäße in Reihen kann geschlossen werden, dass sie durch vermehrte Zellteilung aufgrund einer erhöhten Aktivität des Kambiums entstanden sein müssen. Ähnliche Muster wurden auch in anderen Pflanzen durch abiotischen und biotischen Stress ausgelöst. Bei Pappeln wurde beispielsweise eine Zunahme der Gesamtzahl der Gefäße infolge von Salz- und Trockenstress nachgewiesen (EscalantePérez et al. 2009, Beniwal et al. 2010). Ein ähnliches Phänomen wurde auch nach Infektion durch V. albo-atrum im Stamm von Hopfen dokumentiert (Talboys 1958). Trotz unterschiedlicher Ursachen geht die Erhöhung der Gesamtzellzahl in allen genannten Studien mit einer Verringerung der Zelllumina einher. Dies wurde auch in A. thaliana infolge der Infektion durch $V$. longisporum beobachtet. Eine vermehrte Produktion neuer Zellen durch eine gesteigerte Kambiumaktivität wird als Hyperplasie bezeichnet (Talboys 1958, Baayen 1986). Talboys assoziierte das Auftreten dieser Hyperplasie nach Infektion durch Pathogene mit Resistenz, da sie in Hopfen-Kultivaren, die tolerant gegen V. alboatrum sind, häufiger zu finden ist als in sensitiven Pflanzen (Talboys 1958).

In den Blättern von $A$. thaliana traten nach einer Infektion durch $V$. longisporum zusätzlich Zellen am Rand des Xylems im Übergang zum adaxialen parenchymatischen Gewebe auf, die sowohl einige Merkmale der Mesophyllzellen, jedoch auch bestimmte Merkmale von Xylem-Elementen aufwiesen. Bezüglich der Größe und der Lage entsprachen die Zellen den Mesophyllzellen, die das Leitgewebe umgeben. Doch während normale 
Mesophyllzellen durch sehr große zentrale Vakuolen, dem Vorhandensein von Cytoplasma mit Chloroplasten und primären, nicht lignifizierten Zellwänden charakterisiert sind, war bei den neuen Zellen kein Zellinhalt auszumachen. Außerdem besaßen sie lignifizierte Sekundärwände und ähnelten daher den Gefäßen. Von jenen unterschieden sie sich jedoch hinsichtlich ihrer Größe sowie ihrer Lage und Anordnung. Während durch kambiale Aktivitäten entstandenen Xylem-Elemente in Reihen angeordnet sind und in adaxiale Richtung vom Kambium abgegeben werden, traten die neuen, Gefäß-ähnlichen Zellen meist am Rand des Leitgewebes auf. Außerdem kamen sie nicht nur auf der adaxialen Seite, sondern rings um das Leitgewebe herum vor. Vereinzelt waren auch im Bereich des Phloems diese Gefäß-ähnlichen Zellen zu sehen.

Da die neuen, Gefäß-ähnlichen Zellen sowohl Ähnlichkeiten mit den Mesophyllzellen als auch mit Gefäßen besaßen, wurde vermutet, dass sich die neuen Gefäße ohne Zellteilung aus bereits bestehenden Mesophyllzellen entwickelt haben. Dazu müsste sich eine bereits ausdifferenzierte Zelle zunächst dedifferenzieren, d.h. die Charakteristika des bisherigen Zelltyps verlieren, und anschließend redifferenzieren. Ein solcher Prozess wird als Transdifferenzierung bezeichnet (Fukuda 2004, Turner et al. 2007).

Dass eine Transdifferenzierung von Zellen generell möglich ist, haben Studien mit Zellkulturen von Zinnia elegans und A. thaliana gezeigt. Zum Beispiel können Mesophyllzellen, die aus Blättern von Z. elegans isoliert werden, durch Zugabe von Cytokinin und Auxin zu Tracheen-ähnlichen Zellen transdifferenzieren (Fukuda \& Komamine 1980). A. thaliana Zellen differenzieren sich in Anwesenheit von Brassinoliden und Borsäure zu Gefäßen (Kubo et al. 2005).

In planta treten Xylem-Elemente in Bereichen außerhalb des Xylems vor allem nach Verwundungen auf, bei denen das Leitgewebe unterbrochen wurde (Aloni 2001). Bei Nelken führt eine Infektion mit Fusarium oxysporum f. sp. dianthi im Bereich der Infektionsstelle zur Bildung neuer Gefäße, wobei der Entstehung neuer Xylem-Elemente in diesem Fall jedoch Zellteilungen vorgeschaltet waren (Harling et al. 1984, Baayen 1986).

Des Weiteren wurde das Auftreten von Xylem-Elementen in Bereichen außerhalb des Leitgewebes in transgenen Pflanzen beschrieben. So führt die Überexpression von ASL (Asymmetric leaves-like) 19 oder ASL20 in A. thaliana zu einer Differenzierung von Mesophyllzellen in Gefäß-ähnliche Zellen (Soyano et al. 2008). Auch die verschiedenen Mitglieder der Familie der VND (Vascular-related NAC-domain) Transkriptionsfaktoren 
werden mit Differenzierungs- und Transdifferenzierungsprozessen assoziiert. Eine Überexpression von VND6 oder VND7 induziert die Differenzierung verschiedener Zelltypen in Xylem-Gefäße (Kubo et al. 2005).

Die Rolle dieser Transkriptionsfaktoren für die Verticillium-induzierte Transdifferenzierung von Mesophyllzellen in Gefäß-ähnliche Elemente in A. thaliana wurde im Rahmen der Forschergruppe 546 von der AG Teichmann analysiert. Durch Expressionsanalysen und die Untersuchung von induzierbaren Mutanten, bei denen die Zielgene der VND-Transkriptionsfaktoren infolge einer Verticillium-Infektion in verringerten Mengen exprimiert werden (pPer21::VND7-SRDX), konnte gezeigt werden, dass VND6 und VND7 eine essentielle Rolle bei der Verticillium-induzierten Transdifferenzierung spielen (M. Reusche, unpublizierte Daten). Im Rahmen der anatomischen Untersuchungen der vorliegenden Arbeit konnte gezeigt werden, dass die genannten VND-Repressorlinien nach Infektion keine transdifferenzierten Zellen bilden (siehe Anhang C).

Neben den putativ transdifferenzierten Zellen, die keinen Zellinhalt mehr besitzen und außerdem eine lignifizierte Zellwand aufweisen, wurden in der vorliegenden Arbeit in $A$. thaliana nach Verticillium-Infektion auch Zellen gefunden, die eine partiell lignifizierte Wand aufwiesen, obwohl das Cytoplasma noch deutlich erkennbar war. Hierbei handelt es sich vermutlich um Zwischenstufen in der Entwicklung zu Xylem-Gefäßen. Während der Differenzierung einer Zelle zu einem vollständig funktionsfähigen Gefäß entsteht zunächst die lignifizierte, sekundäre Zellwand. Hierfür sind strukturelle Veränderungen des Cytoskeletts essentiell. Anschließend wird die Autolyse eingeleitet, indem Enzyme aktiviert werden, welche die subzellulären Bestandteile und teilweise auch die Primärwand degenerieren (Turner et al. 2007, Endo et al. 2009). Wahrscheinlich haben die oben beschriebenen Zellen zwar bereits eine Sekundärwand gebildet, die Autolyse steht jedoch noch bevor.

Ein weiterer Hinweis, der die Hypothese der Transdifferenzierung aus früheren Mesophyllzellen unterstützt, war die Beobachtung von netzartigen Strukturen, die teilweise in den putativ transdifferenzierten Zellen $\mathrm{zu}$ sehen waren. Hierbei handelt es sich wahrscheinlich um die Rückwand der Zellen, auf der sich das Material der Sekundärwand abgelagert hat. Dies bedeckt die Primärwand nie vollständig. Statt dessen werden bestimmte Bereiche bei der Ablagerung des Sekundärwandmaterials ausgespart, so dass 
sich netzartige Strukturen ausbilden. Bei der normalen Differenzierung von Gefäßen aus kambialen Zellen geht der Bildung der Sekundärwand eine Elongation der Zellen voraus. Danach werden Teile der Wände während der Autolyse perforiert, so dass sich eine Röhre aus aneinander gereihten Xylem-Elementen bildet (Turner et al. 2007, Endo et al. 2009). Die Elongation und die Perforation der Zellwand scheint bei den in dieser Arbeit aufgezeigten putativ transdifferenzierten Zellen nicht stattgefunden zu haben. Daher ist die Wahrscheinlichkeit hoch, dass zufällig in den Präparaten auch Rückwände der transdifferenzierten Zellen zu sehen sind.

Nach der Beobachtung der Hyperplasie und der putativen Transdifferenzierung von Mesophyllzellen in Gefäß-ähnliche Elemente stellte sich die Frage nach der biologischen Relevanz dieser vermehrten Gefäßbildung. Die Bildung von Wasserleit-Elementen kann der Pflanze oder dem Pathogen einen Vorteil verschaffen.

Es wäre beispielsweise möglich, dass putativ mit Pilzmyzel verstopfte Gefäße ersetzt werden und so die Wasserversorgung der Pflanze gewährleistet bleibt. Dass die neu gebildeten Gefäße funktionsfähig und mit dem restlichen Xylem-Elementen verbunden sind, haben Experimente gezeigt, bei denen der Transpirationsstrom mit Hilfe einer Safranin-O-Färbung sichtbar gemacht wurde (M. Reusche, unpublizierte Daten). Ob die Transdifferenzierung der Welke, die nach Infektion durch andere Verticillium-Arten auftritt, entgegen wirkt, ist noch unklar. Die Transdifferenzierung konnte auch in Pflanzen beobachtet werden, die Welkeerscheinungen zeigen (M. Reusche, unpublizierte Daten). Außerdem zeigten die VND-Repressorlinien keine Welkesymptome, obwohl in diesen nach Infektion keine Transdifferenzierung statt fand (M. Reusche, unpublizierte Daten).

Eine andere Möglichkeit ist, dass der Pilz durch Induktion der Gefäßbildung sein Habitat in der Pflanze erweitert oder die Nährstoffverteilung zu seinen Gunsten ändert.

Diese Hypothesen werden derzeit durch weitere Experimente innerhalb der Forschergruppe 546 von der AG Teichmann untersucht.

\subsection{GLP3 vermittelt in Arabidopsis thaliana Resistenz gegenüber Verticillium longisporum durch Einschränkung des Pilzwachstums}

Proteomanalysen der apoplastischen Waschflüssigkeit von A. thaliana haben gezeigt, dass drei verschiedene Peroxidasen, eine Serin-Carboxypeptidase, eine $\alpha$-Galactosidase und ein Germin-ähnliches Protein (GLP3) infolge einer Infektion durch V. longisporum in 
größeren Mengen auftreten, während ein Lektin-ähnliches Protein in geringeren Mengen vorkommt als in den mock-inokulierten Pflanzen. Auch auf Transkriptebene sind diese Unterschiede vorhanden (Flörl 2007). Im Rahmen dieser Arbeit wurde die Rolle dieser Proteine im Hinblick auf die Abwehrfunktion gegen $V$. longisporum untersucht. Apoplastische Proteine sind ein wichtiger Teil der Immunantwort gegen Pathogene und können deren Wachstum direkt beeinflussen (siehe Kapitel 4.1). Eine Verringerung der Mengen der für die Abwehr wichtigen Proteine im Apoplast kann die Suszeptibilität einer Pflanze gegenüber einem Pathogen erhöhen, während eine konstitutive Überexpression zu einer Resistenz führen kann (van Loon et al. 2006). Es ist aber auch möglich, dass ein Pathogen mit der Immunantwort interferiert und die beobachteten Veränderungen herbeiführt (Boller \& He 2009). In einem solchen Fall wären Pflanzen mit einer verringerten Menge des entsprechenden Proteins resistenter.

Zur Überprüfung der Bedeutung der V. longisporum-responsiven Proteine wurden transgene Pflanzen hinsichtlich ihrer Suszeptibilität gegenüber $V$. longisporum untersucht. Für 5 der 7 Kandidaten, nämlich für die Peroxidase 52, Serin-Carboxypeptidase, $\alpha$ Galactosidase, LLP und GLP3, konnten T-DNA-Insertionslinien mit einer verringerter Transkriptmenge identifiziert werden. Von diesen Linien reagierte nur die GLP3 betreffende Mutante mit einer erhöhten Suszeptibilität auf eine Infektion mit $V$. longisporum, während die anderen Linien in ihrem Pathophänotyp dem Wildtyp glichen. Trotz der unveränderten Suszeptibilität der transgenen Linien bezüglich der SerinCarboxypeptidase, der $\alpha$-Galactosidase, des Lektin-ähnlichen Proteins und der Peroxidasen kann ihre Rolle in Abwehrfunktionen nicht ausgeschlossen werden, da homologe Proteine die Funktion der reprimierten Gene teilweise oder vollständig übernehmen könnten. Eine solche Redundanz ist vor allem bei den Peroxidasen wahrscheinlich, da die einzelnen Familienmitglieder sich in diesem Fall besonders stark ähneln (Cosio \& Dunand 2009). Die Rolle der Peroxidasen konnte nicht vollständig untersucht werden, weil keine T-DNAInsertionslinie für POD34 und POD37 mit einer verringerten Expression, sondern lediglich solche mit einer leicht erhöhten Transkriptmenge identifiziert werden konnten. Auch amiRNA-Linien, in denen speziell POD34, POD37 und POD52 betroffen sind, konnten nicht hergestellt werden. Obwohl Peroxidasen im Allgemeinen mit Abwehrfunktionen wie Zellwandverstärkungen und der Bildung von ROS assoziiert werden, bleibt die spezifische 
Funktion von POD34, POD37 und POD52 im Hinblick auf Abwehrfunktionen gegen $V$. longisporum noch unklar.

Für GLP3 konnte in dieser Arbeit eine Rolle für die Abwehr gegen $V$. longisporum nachgewiesen werden. Die glp3-Mutante zeigte eine verstärkte Suszeptibilität gegenüber V. longisporum. Die Komplementierung der glp3-Mutante konnte deren verstärkte Suszeptibilität zwar nicht vollständig revertieren, die komplementierten Pflanzen waren aber dennoch tendenziell toleranter als die glp3-Mutante. Dass der Effekt relativ gering war, kann daran liegen, dass die komplementierten Pflanzen generell kleiner waren als die nicht komplementierte glp3-Mutante. AmiRNA-Pflanzen mit einer deutlich verringerten glp3-Transkriptmenge zeigten eine stärkere Verticillium-bedingte Wuchsdepression als der Wildtyp und konnten so die mit der glp3-Mutante gewonnenen Ergebnisse bestätigen. Des Weiteren waren Pflanzen mit einer konstitutiv erhöhten glp3-Expression toleranter gegenüber $V$. longisporum. Bei diesen Überexpressionspflanzen war die Reduktion der Wuchsparameter nicht so stark ausgeprägt wie bei Wildtyp-Pflanzen oder der glp3Mutante, zudem enthielten sie auch deutlich geringe Mengen pilzlicher DNA.

Insgesamt betrachtet scheint also die Toleranz von A. thaliana gegenüber $V$. longisporum mit der glp3-Expression zu korrelieren. Hinweise darauf, dass GLP3 aus A. thaliana (AtGLP3) eine Rolle bei der Immunantwort spielt, liefern auch Experimente, bei welchen die Induktion von glp3 durch das fungale Pathogen Colletotrichum higginsianum dokumentiert wurde (Narusaka et al. 2004). Des Weiteren können auch andere Mitglieder der Superfamilie der Germine und Germin-ähnlichen Proteine in diversen Pflanzen Resistenz gegenüber den verschiedensten Pathogenen vermitteln. So ist Weizen resistenter gegenüber Mehltau, wenn bestimmte GLPs in der Pflanze überexprimiert werden (Schweizer et al. 1999, Christensen et al. 2004). Auch in Gerste führt eine Überexpression von einigen GLPs zu einer erhöhten Resistenz gegen Mehltau, während Pflanzen mit einer verringerten Expression suszeptibler sind (Zimmermann et al. 2006). Eine Reduktion der Transkriptmengen verschiedener GLPs in Reis verursacht ebenfalls eine erhöhte Suszeptibilität gegen pilzliche Pathogene (Manosalva et al. 2009). An Tabakpflanzen sind die Schäden durch Herbivorie bei einer verringerten Menge eines Germin-ähnlichen Proteins größer (Lou \& Baldwin 2006). Kürzlich konnte gezeigt werden, dass das aus Zuckerrübe isolierte BvGLP-1-Gen bei Expression in A. thaliana eine Resistenz gegenüber V. longisporum und Rhizoctonia solani verursacht (Knecht et al. 2010). In weiteren 
Pflanzen werden Germin-ähnliche Proteine infolge einer Infektion durch verschiedene Pathogene induziert, wie z. B. VvGLP3 in Wein durch Mehltau (Godfrey et al. 2007), verschiedene GLPs in Kiefer durch das pilzliche Pathogen Ceratobasidium bicorne (Jøhnk et al. 2005) und ein Germin-ähnliches Protein in Mais nach einer Virusinfektion (Uzarowska et al. 2009).

Durch diese Arbeit konnte gezeigt werden, dass auch AtGLP3 eine große Bedeutung hinsichtlich der Immunantwort aufweist, da es in A. thaliana Resistenz gegenüber $V$. longisporum vermitteln konnte. In diesem Zusammenang entstand die Frage, durch welche Mechanismen das Protein in der Pflanze gegen das Pathogen wirkt.

Einige der Mitglieder der GLP-Familie besitzen enzymatische Aktivitäten. Ein Germinähnliches-Protein aus Gerste (HvGER2) weist beispielsweise eine ADP-Glukose pyrophosphatase/phosphodiesterase (AGPPase) Aktivität auf (Bernier and Berna 2001, Rodríguez-López et al. 2001, Breen \& Bellgard 2010). Häufiger sind bei GLPs Manganabhängige Enzymaktivitäten, bei denen $\mathrm{H}_{2} \mathrm{O}_{2}$ freigesetzt wird, $\mathrm{zu}$ beobachten (Woo et al. 2000, Dunwell et al. 2004). Dabei fungieren einige GLPs als Superoxid-Dismutasen und degradieren Sauerstoff-Radikale (Woo et al. 2000, Breen \& Bellard 2010), andere dagegen als Oxalat-Oxidasen, welche die Degradation von Oxalsäure katalysieren (Woo et al. 2000). Oxalsäure wird von einigen Pathogenen produziert und stellt einen Virulenzfaktor dar (Godoy et al. 1990). Eine Oxalat-Oxidase verhindert also einerseits die Schädigung durch die Oxalsäure, des weiteren entsteht bei der Reaktion neben $\mathrm{CO}_{2}$ auch $\mathrm{H}_{2} \mathrm{O}_{2}$, wodurch weitere Abwehrreaktionen aktiviert werden (Dunwell et al. 2004, Breen \& Bellard 2010). AtGLP3 produziert in vitro jedoch kein $\mathrm{H}_{2} \mathrm{O}_{2}$, wenn Oxalat als Substrat angeboten wird (Membre et al. 2000).

Weitere Informationen über AtGLP3, die auf die Funktion im Hinblick auf Abwehrreaktionen schließen lassen, gibt es nur wenige. Bisher wurde vor allem die Expression sehr gut analysiert. Für diese konnte ein tageszeiten-abhängiger Rhythmus, verursacht durch den Wechsel zwischen Licht und Dunkelheit, nachgewiesen werden, wobei die Transkriptmenge zu Beginn der Nacht am stärksten ist (Staiger et. al. 1999). Lokalisiert werden konnte die glp3-Expression im Rahmen dieser Arbeit anhand von GUSReporterpflanzen in Blättern, den verschiedenen Teilen der Blüte und in den Schoten, während sie in den Wurzeln zu keinem Zeitpunkt detektiert werden konnte. Dieses Expressionsmuster wurde auch in Untersuchungen von GUS-Reporterpflanzen mit einem 
verkürzten Promoter beobachtet (Staiger et al. 1999). Ebenso konnte mittels Northern Blot Analysen kein glp3-Transkript in Wurzeln detektiert werden (Membre et al. 1997). Auf Proteinebene konnte GLP3 dagegen in den Wurzeln detektiert werden, wenn auch in sehr geringen Mengen (Schlesier et al. 2004).

Innerhalb der Blätter konnte in dieser Arbeit in den GUS-Reporterpflanzen eine deutliche ß-Glucuronidase-Aktivität vor allem in den Mesophyllzellen und der Epidermis nachgewiesen werden, während diese im Leitgewebe nur sehr gering war. Zudem konnte für die Blätter eine Korrelation zwischen der glp3-Expression und dem physiologischen Alter festgestellt werden. Eine altersabhängige Expression von Atglp3 wurde auch im Infloreszenzstängel von $A$. thaliana beobachtet. Mittels Transkriptomanalysen wurde gezeigt, dass die Expression in älteren, basipetalen Abschnitten geringer ist als in weiter oben liegenden, jüngeren Bereichen (Ehlting et al. 2005, Minic et al. 2009). Auch das zu AtGLP3 homologe GhGLP1 aus Baumwoll-Fasern tritt vermehrt in Zellen auf, welche sich im Streckungswachstum befinden. Für dieses Protein wurde daher eine Funktion beim Streckungswachstum postuliert (Kim et al. 2004, Kim \& Triplett 2004).

GLPs könnten eine Rolle bei Umgestaltungen und Modifizierungen der Zellwand spielen (Schweizer et al. 1999, Bernier \& Berna 2001). Diese Funktion wurde allerdings hauptsächlich im Zusammenhang mit der $\mathrm{H}_{2} \mathrm{O}_{2}$-Produktion durch Oxalat-Oxidase- oder Superoxid-Dismutase-Aktivitäten postuliert (Bernier \& Berna 2001). Die in dieser Arbeit untersuchte glp3-Muante mit einer verringerten glp3-Transkriptmenge zeigte in Querschnitten keinen Unterschied zum Wildtyp. Auch die Verticillium-induzierte Entstehung von hyperplastischem Xylem und die putative Transdifferenzierung konnte in der Mutante in ähnlicher Form beobachtet werden wie im Wildtyp.

Neben den putativen entwicklungsphysiologischen Funktionen von AtGLP3 zeigten die vorliegenden Untersuchungen, dass AtGLP3 relevant für die Toleranz von A. thaliana gegenüber V. longisporum war und die Menge des Pilzes in der Pflanze bei erhöhter glp3Expression in planta abnahm. AtGLP3 kommt extrazellulär vor (Boudart et al. 2005, Charmont et al. 2005, Flörl 2007, Millar et al. 2009) und könnte deshalb das Pilzwachstum direkt beeinflussen. Um diese Hypothese zu prüfen, wurde GLP3 heterolog in Hefe exprimiert. Durch anschließende Wachstumsversuche konnte gezeigt werden, dass $V$. longisporum schlechter wuchs, wenn der Pilz mit GLP3 produzierender Hefe koinkubiert wurde. 
Daher ist es wahrscheinlich, dass AtGLP3 in A. thaliana das Pilzwachstum direkt minimiert und Resistenz gegen $V$. longisporum vermittelt, indem es einer massiven Kolonisierung des Pathogens innerhalb der Pflanze entgegenwirkt.

In Kapitel 4.1 wurde bereits diskutiert, dass eine Vielzahl an Proteinen, besonders PRProteine, antimikrobielle Eigenschaften aufweisen (van Loon et al. 2006). Interessanterweise sind auch im Xylemsaft von Raps Germin-ähnliche Proteine enthalten (Kehr et al. 2005). In der apoplastischen Waschflüssigkeit von Raps wurde ebenfalls ein GLP identifiziert, welches die größte Übereinstimmung mit dem GLP3 aus A. thaliana aufweist (Floerl et al. 2008). Daher ist es möglich, dass ein oder mehrere Mitglieder der GLPs in Raps auch bei den Xylemsaft-Versuchen (Kapitel 4.1) an dem inhibitorischen Effekt beteiligt waren. Obwohl diverse Germin-ähnliche Proteine Resistenz gegen verschiedene Pathogene vermitteln können, wurde bisher für kein Mitglied dieser Multigenfamilie eine direkte wachstumshemmende Wirkung gegen Pathogene nachgewiesen. Dies wurde in der vorliegenden Arbeit erstmals gezeigt. Wichtig wäre nun in folgenden Untersuchungen den Mechanismus aufzuklären, durch welchen das Wachstum von $V$. longisporum inhibiert wird. 


\section{$5 \quad$ Zusammenfassung}

Verticillium longisporum ist ein bodenbürtiger, pathogener Pilz, der auf die Pflanzenfamilie der Brassicaceae spezialisiert ist. Da V. longisporum ein vaskuläres Pathogen ist, welches die meiste Zeit seines Lebenszyklus in der Pflanze im Xylem lokalisiert ist, werden Abwehrreaktionen der Pflanze im extrazellulären Raum erwartet.

In einer vorangegangenen Arbeit wurde das extrazelluläre Proteom von Brassica napus und Arabidopsis thaliana im Hinblick auf Veränderungen infolge der Infektion der Pflanzen durch $V$. longisporum untersucht. Es zeigte sich, dass in B. napus eine Glucanase, eine Peroxidase, eine Chitinase sowie ein PR-4-Protein und in A. thaliana drei verschiedene Peroxidasen, eine SerinCarboxypeptidase, eine $\alpha$-Galactosidase und ein Germin-ähnliches Protein (GLP3) nach Infektion mit dem Pathogen vermehrt produziert wurden, während ein Lectin-ähnliches Protein in A. thaliana in geringeren Mengen auftrat. Ziel der vorliegenden Arbeit war die funktionelle Charakterisierung dieser differenziell auftretenden extrazellulären Proteine in B. napus und A. thaliana nach einer Infektion durch $V$. longisporum in Relation $\mathrm{zu}$ physiologischen und anatomischen Veränderungen.

Der Xylemsaft von B. napus wurde auf putative Abwehrsubstanzen hin überprüft, die sich auf das Wachstum von V. longisporum auswirken könnten. Zu diesem Zweck wurde das Wachstum des Pilzes in Xylemsaft aus infizierten und uninfizierten Pflanzen verglichen. Es zeigte sich eine deutliche Beeinträchtigung des Wachstums von $V$. longisporum im Xylemsaft von infizierten Pflanzen. Diese Inhibierung konnte nicht auf eine mangelnde Nährstoffverfügbarkeit im Xylemsaft zurückgeführt werden. Auch Salizylsäure, welche im Xylemsaft von B. napus infolge einer Infektion in erhöhten Mengen vorkommt, hatte keinen direkten Einfluss auf das Pilzwachstum. Mit Hilfe weiterer Wachstumsversuche im Xylemsaft und einem Vollnährmedium konnte nachgewiesen werden, dass die im Xylemsaft enthaltenen Proteine die Proliferation von $V$. longisporum massiv inhibieren. Diese antifungale Eigenschaft konnte sowohl für die Proteine aus dem Xylemsaft von infizierten Pflanzen als auch für die aus dem Xylemsaft aus nicht infizierten Pflanzen gezeigt werden. Die Pflanze sekretiert also konstitutiv 
Proteine mit einer antifungalen Wirkungsweise in den Apoplast, wodurch sie einer unkontrollierten Ausbreitung von Mikroorganismen entgegenwirken kann.

Da einige der in A. thaliana nach einer Verticillium-Infektion differentiell auftretenden Proteine mit Funktionen bei der Modifizierung und Umgestaltung der Zellwand assoziiert werden, wurden infizierte und nicht infizierte Pflanzen anatomisch untersucht und auf Unterschiede überprüft. Es konnte gezeigt werden, dass eine Infektion mit $V$. longisporum in A. thaliana im Hypokotyl sowie in den Blättern zur Bildung von hyperplastischem Xylem und in den Blättern zusätzlich zu einer Transdifferenzierung von Mesophyllzellen zu Gefäßen führt. Die biologische Rolle dieser vermehrten Bildung neuer wasserleitender Elemente muss noch weiter untersucht werden.

Um zu überprüfen, welche Proteine in A. thaliana an der Immunantwort gegen $V$. longisporum beteiligt sind, wurden funktionelle Analysen durchgeführt. Dazu wurden homozygote Pflanze von T-DNA-Insertionslinien isoliert und hinsichtlich einer veränderten Suszeptibilität gegenüber V. longisporum untersucht. Die meisten Linien besaßen einen ähnlichen Pathophänotyp wie der Wildtyp. Eine Linie mit einer reduzierten glp3-Expression reagierte jedoch mit einer erhöhten Suszeptibilität. Weitere Analysen mit amiRNA-Linien bestätigten diese Beobachtung. Pflanzen mit einer konstitutiv erhöhten glp3-Expression waren dagegen resistenter gegenüber $V$. longisporum. Zudem war die Pilzmenge in infizierten Überexpressionspflanzen deutlich geringer als in infizierten Wildtyp-Pflanzen. Um die spezifische Funktion von GLP3 innerhalb der Pflanze-Pathogen-Interaktion weiter $\mathrm{zu}$ charakterisieren, wurde überprüft, ob GLP3 V. longisporum direkt beeinflusst. Heterolog in Hefe produziertes GLP3 konnte das Wachstum von $V$. longisporum einschränken. GLP3 vermittelt in $A$. thaliana Resistenz gegenüber $V$. longisporum, indem es offenbar die Kolonisierung durch das Pathogen direkt minimiert. Der genaue molekulare Mechanismus ist bislang unklar und sollte in weiteren Experimenten untersucht werden. 


\section{Summary}

Verticillium longisporum is a soil-borne pathogenic fungus which is restricted to the family of Brassicaceae. V. longisporum is a vascular pathogen which colonizes the xylem of its host plants. Therefore, main defence reactions are expected in the extracellular matrix.

Previously, the extracellular proteome of infected and mock inoculated Brassica napus and Arabidopsis thaliana plants was analysed and compared. In B. napus a glucanase, a peroxidase, a chitinase and a PR-4 protein were induced following infection. In A. thaliana three different peroxidases, a serine-carboxypeptidase, an $\alpha$-galactosidase and a germin-like protein (GLP3) were more abundant after infection. In contrast, a lectin-like protein was downregulated. The aim of this study was to functionally characterize those differentially expressed extracellular proteins in B. napus and A. thaliana in relation to physiological and anatomical alterations.

To test the hypothesis that defence related proteins in the xylem sap of B. napus could influence $V$. longisporum fungal proliferation was investigated in xylem sap of infected and mock inoculated plants. The growth of the fungus was restricted in xylem sap of infected plants compared to controls. This growth behaviour cannot be attributed to nutrient deficiencies in xylem sap of infected plants. Furthermore, the effect of salicylic acid on the growth of the fungus was studied. Salicylic acid was reported to increase after $V$. longisporum infection in the xylem sap of B. napus. But there was no effect on the proliferation of $V$. longisporum. In additional experiments the influence of xylem sap proteins on fungal growth was tested. Proliferation of $V$. longisporum was strongly enhanced in protein-free xylem sap regardless whether the sap was from infected or non-infected oil seed rape plants. These results show that the constitutive presence of defence proteins in xylem sap suppresses uncontrolled proliferation of $V$. longisporum.

Since some of the differentially expressed candidate proteins in A. thaliana are suggested to play a role in cell wall remodelling and modifications infected and mock inoculated plants were investigated anatomically. Infection with $V$. longisporum led to the production of hyperplastic xylem in the hypocotyl as well as in leaves. Moreover, transdifferentiation of mesophyll cells 
into xylem vessels was observed in the leaves. The biological role of this observations remains unclear and needs to be investigated in future studies.

To investigate which proteins are responsible for the immune response against $V$. longisporum in A. thaliana, functional analysis were performed. For this purpose, homozygous plants of T-DNA insertion lines were isolated and challenged with $V$. longisporum. Most of them displayed a similar pathophenotype like the wildtype. However, one line with a reduced expression of the germin-like protein 3 (GLP3) showed enhanced susceptibility to the fungus. Further experiments with amiRNA lines supported these results. Moreover, glp3-overexpressing plants with a constitutively higher glp3 transcript level were more resistant to $V$. longisporum. Also the amount of fungal DNA within the plants was significantly reduced in infected overexpressing plants compared to wildtype plants. The next step then was to characterize the function of GLP3 for the plant-pathogen interaction. Growth experiments with heterologous expressed GLP3 showed that the protein was able to attenuate proliferation of $V$. longisporum in vitro. The results indicate that GLP3 mediates resistance in A. thaliana by restricting the growth of the fungus directly. The molecular mechanisms of glp3 action is unclear and should be investigated in further experiments. 


\section{$6 \quad$ Literaturverzeichnis}

Aitchitt M., Ainsworth C.C., Thangavelu M. (1993): A rapid and efficient method for the extraction of total DNA from mature leaves of the date palm (Phoenix dactylifera L.). Plant Molecular Biology Reporter 11: 317-319.

Aloni R. (2001): Foliar and axial aspects of vascular differentiation: Hypotheses and evidence. Journal of Plant Growth Regulation 30: 22-34.

Almagro L., Gómez Ros L.V., Belchi-Navarro S., Bru R., Ros Barcelo A., Pedreño M.A. (2009): Class III peroxidases in plant defense reactions. Journal of Experimental Botany 60: 377-390.

Alvarez S., Goodger J.Q.D., Marsh E.L., Chen S., Asirvatham V.S., Schachtman D.P. (2005): Characterization of the maize xylem sap proteome. Journal of Proteome Research 5: 963-972.

Anand A., Lei Z., Sumner L.W., Mysore K.S., Arakane Y., Bockus W.W., Muthukrishnan S. (2004): Apoplastic extracts from a transgenic wheat line exhibiting lesion-mimic phenotype have multiple pathogenesis-related proteins that are antifungal. Molecular Plant-Microbe Interactions 17: 1306-1317.

Apel K. \& Hirt H. (2004): Reactive oxygen species: metabolism, oxidative stress, and signal tranduction. Annual Review of Plant Biology 55: 373-399.

Baayen (1986): Regeneration of vascular tissuesin relation to Fusarium wilt resistance of carnation. Netherland Journal of Plant Pathology 92: 273-285.

Barbara D.J. \& Clewes E. (2003): Plant pathogenic Verticillium species: how many of them are there? Molecular Plant Pathology 4: 287-305.

Barbara D.J., Morton A., Miller N.J. (2005): Isolation of microsatellite markers from an interspecific hybrid isolate of the fungal plant pathogen Verticillium dahliae. Molecular Ecology Notes 5: 854-856.

Bari R. \& Jones J.D.G. (2009): Role of plant hormones in plant defence responses. Plant Molecular Biology 69: 473-488. 
Bartel D.P. (2004): MicroRNAs: genomics, biogenesis, mechanism, and function. Cell 116: 281 297.

Beckman C.H. (1987): The nature of wilt diseases of plants. The American Phytopathological Society, St. Paul, MN, USA.

Bednarek P. \& Osbourn A. (2009): Plant-microbe interactions: chemical diversity in plant defense. Science 324: 746-748.

Beliën T., Van Campenhout S., Robben J., Volckaert G. (2006): Microbial endoxylanases: effective weapons to breach the plant cell-wall barrier or, rather, triggers of plant defense systems? Molecular Plant-Microbe Interactions 19: 1072-1081.

Beligni M.V. \& Lamattina L. (2001): Nitric oxide in plants: the history is just beginning. Plant, Cell and Environment 24: 267-278.

Benhamou N. (1995): Immunocytochemistry of plant defense mechanisms induced upon microbial attack. Microscopy Research and Technique 31: 63-78.

Beniwal R.S., Langenfeld-Heyser R., Polle A. (2010): Ectomycorrhiza and hydrogen protect hybrid poplar from water deficit and unravel plastic responses of xylem anatomy. Environmental and Experimental Botany 69: 189-197.

Bent A.F. (2000): Arabidopsis in planta transformation. Uses, mechanisms, and prospects for transformation of other species. Plant Physiology 124: 1540-1547.

Berger S., Papadopoulos M., Schreiber U., Kaiser W., Roitsch T. (2004): Complex regulation of gene expression, photosynthesis and sugar levels by pathogen infection in tomato. Physiologia Plantarum 122: 419-428.

Berger S., Benediktyová Z., Matouš K., Bonfig K., Mueller M.J., Nedbal L., Roitsch T. (2007): Visualization of dynamics of plant-pathogen interaction by novel combination of chlorophyll fluorescence imaging and statistical analysis: differential effects of virulent and avirulent strains of P. syringae and of oxylipins on A. thaliana. Journal of Experimental Botany 58: 797-806.

Berlanger I. \& Powelson M. L. (2000): Verticillium wilt. The Plant Health Instructor. American Phytopathological Society. Plant Disease Lesson.

http://www.apsnet.org/education/lessonsplantpath/Verticillium/default.htm 
Bernier F. \& Berna A. (2001): Germins and germin-like proteins: Plant do-all proteins. But what do they do exactly? Plant Physiology and Biochemistry 39: 545-554.

Beutler H.O. (1978): Enzymatic determination of starch in food by hexokinase method. Starch 30: 309-312.

Bindschedler L.V., Dewdney J., Blee K.A., Stone J.M., Asai T., Plotnikov J., Denoux C., Hayes T., Gerrish C., Davies D.R., Ausubel F.M., Bolwell G.P. (2006): Peroxidase-dependent apoplastic oxidative burst in Arabidopsis required for pathogen resistance. The Plant Journal 47: 851-863.

Bishop C.D. \& Cooper R.M. (1984): Ultrastructure of vascular colonization by fungal wilt pathogens. II. Invasion of resistant cultivars. Physiological Plant Pathology 24: 277-289.

Blume B., Nürnberger T., Nass N., Scheel D. (2000): Receptor-mediated increase in cytoplasmatic free calcium required for activation of pathogen defence in barley. The Plant Cell 12: $1425-1440$.

Boller T. \& He S.Y. (2009): Innate Immunity in Plants: An arms race between Pattern Recognition Receptors in plants and Effectors in microbial pathogens. Science 324: 742-744.

Bolton E.T. \& McCarthy B.J. (1962): A general method for isolation of RNA complementary to DNA. Proceedings of the National Academy of Sciences of the United States of America 48: 1390-1397.

Bolwell G.P., Bindschedler L.V., Blee K.A., Butt V.S., Davies D.R., Gardner S.L., Gerrish C., Minibayeva F. (2002): The apoplastic oxidative burst in response to biotic stress in plants: a three component system. Journal of Experimental Botany 53: 1367-1376.

Boudart G., Jamet E., Rossignol M., Lafitte C., Borderies G., Jauneau A., Esquerre-Tugaye M.T., Pont-Lezica R. (2005): Cell wall proteins in apoplastic fluids of Arabidopsis thaliana rosettes: Identification by mass spectrometry and bioinformatics. Proteomics 5: 212-221.

Boudsocq M., Willmann M.R., McCormack M., Lee H., Shan L., He P., Bush J, Cheng S.-H., Sheen J. (2010): Differential innate immune signalling via $\mathrm{Ca}^{2+}$ sensor protein kinases. Nature 464: 418-422. 
Bowling S.A., Clarke J.D., Liu Y., Klessig D.F., Dong X. (1997): The cpr5 mutant of Arabidopsis expresses both Npr1-dependent and npR1-independent resistance. The Plant Cell 9: 1573-1584.

Breen J. \& Bellgard M. (2010): Germin-like proteins (GLPs) in cereal genomes: gene clustering and dynamic roles in plant defence. Functional \& Integrative Genomics 4: 463-476.

Brininstool G., Kasili R., Simmons L.A., Kirik V., Hülskamp M., Larkin J.C. (2008): Constitutive expressor of pathogenesis-related genes5 affects cell wall biogenesis and trichome development. BMC Plant Biology 8: 58.

Broglie K., Chet I., Holliday M., Cressman R., Biddle P., Knowlton S., Mauvais C. J., Broglie R. (1991): Transgenic plants with enhanced resistance to the fungal pathogen Rhizoctonia solani. Science 254: 1194-1197.

Buhtz A., Kolasa A., Arlt K., Walz C., Kehr, J. (2004): Xylem sap protein composition is conserved among different plant species. Planta 219: 610-618.

Charmont S., Jamet E., Pont-Lezica R., Canut H. (2005): Proteomic analysis of secreted proteins from Arabidopsis thaliana seedlings: improved recovery following removal of phenolic compounds. Phytochemistry 66: 453-461.

Chen X. (2005): MicroRNA biogenesis and function in plants. FEBS Letters 579: 5923-5931.

Chinchilla D., Bauer Z., Regenass M., Boller T., Felix G. (2006): The Arabidopsis receptor kinase FLS2 binds flg22 and determines the specifity of flagellin perception. The Plant Cell 18: 465-476.

Chinchilla D., Zipfel C., Robatzek S., Kemmerling B., Nürnberger T., Jones J.D.G., Felix G., Boller T. (2007): A flagellin-induced complex of the receptor FLS2 and BAK1 initiates plant defence. Nature 448: 497-501.

Chomczynski P. \& Sacchi N. (1987): Single-step method of RNA isolation by acid guanidinium thiocyanate-phenol-chloroform extraction. Analytical Biochemistry 162: 156-159.

Chomczynski P. (1993): A reagent for the single-step simultaneous isolation of RNA, DNA and proteins from cell and tissue samples. Biotechniques 15: 532-537. 
Christensen A.B., Thordal-Christensen H., Zimmermann G., Gjetting T., Lyngkjaer M.J., Dudler R., Schweizer P. (2004): The germin-like protein GLP4 exhibits superoxide dismutase activity and is an important component of quantitative resistance in wheat and barley. Molecular PlantMicrobe Interactions 17: 109-117.

Chrost B. \& Krupinska K. (2000): Genes with homologies to known $\alpha$-galactosidases are expressed during senescence of barley leaves. Physiologia Plantarum 110: 111-119.

Chrost B., Kolukisaoglu U., Schulz B., Krupinska K. (2007): An $\alpha$-galactosidase with an essential function during leaf development. Planta 225: 311-320.

Clough S.J. \& Bent A.F. (1998): Floral dip: a simplified method for Agrobacterium mediated transformation of Arabidopsis thaliana. The Plant Journal 16: 735-743.

Collard B.C.Y. \& Mackill D.J. (2008): Marker-assisted selection: an approach for precision plant breeding in the twenty-first century. Philosophical Transactions of the Royal Society of London. Series B. Biological Sciences 363: 557-572.

Collinge D.B., Kragh K.M., Mikkelsen J.D., Nielsen K.K., Rasmussen U., Vad K. (1993): Plant chitinases. The Plant Journal 3: 31-40.

Collins A., Okoli C.A.N., Morton A., Parry D., Edwards S.G., Barbara D.J. (2003): Isolates of Verticillium dahliae pathogenic to Crucifers are of at least three distinct molecular types. Phytopathology 93: 364-76.

Cooper R.M., Resende M.L.V., Flood J., Rowan M.G., Beale M.H., Potter U. (1996): Detection and cellular localization of elemental sulphur in disease resistant genotypes of Theobroma cacao. Nature 246: 309-311.

Cosio C. \& Dumand C. (2009): Specific functions of individual class III peroxidase genes. Journal of Experimental Botany 60: 391-408.

Czechowski T., Stitt M., Altmann T., Udvardi M.K., Scheible W.R. (2005): Genomewide identification and testing of superior reference genes for transcript normalization in Arabidopsis. Plant Physiology 139: 5-17.

Daayf F., Nicole M., Boher B., Pando A., Geiger J.A. (1997): Early vascular defense reactions of cotton roots infected with a defoliating mutant strain of Verticillium dahliae. European Journal of Plant Pathology 103: 125-136. 
Daebeler F., Amelung D., Zeise K. (1988): Verticillium-Welke an Winterraps - Auftreten und Bedeutung. Nachrichtenblatt Pflanzenschutzdienst DDR 42: 71-73.

Demond-Caulet N., Lapierre C., Jouanin L., Baumberger S., Méchin V. (2010) : Arabidopsis peroxidase-catalyzed copolymerization of coniferyl and sinapyl alcohols: Kinetics of an endwise process. Phytochemistry 71: 1673-1683.

Ding X., Cao Y., Huang L., Zhao J., Xu C., Li X., Wang S. (2008): Activation of the indole-3acetic acid-amido synthetase Gh3-8 suppresses expansin expression and promotes salicylate- and jasmonate-independent basal immunity in rice. The Plant Cell 20: 228-240.

Dixelius C., Happstadius I., Berg G. (2005): Verticillium wilt on Brassica oil crops - a swedish perspective. Journal of the Swedish Seed Association 115: 36-48.

Dixon G.R. \& Pegg G.F. (1972): Changes in amino acid content of tomato xylem sap following infection with strains of Verticillium albo-atrum. Annals of Botany 36:147-154.

Do C.-T., Pollet B., Thévenin J., Sibout R., Denoue D., Barrière Y., Lapierre C., Jouanin L. (2007): Both caffeoyl coenzyme A 3-O-methyltransferase 1 and caffeic acid O-methyltransferase 1 are involved in redundant functions for lignin, flavonoids and sinapoyl malate biosynthesis in Arabidopsis. Planta 226: 1117-1129.

Dubery I.A. \& Slater V. (1997): Induced defence responses in cotton leaf disks by elicitors from Verticillium dahliae. Phytochemistry 44: 1429-1434.

Dunker S. \& von Tiedemann A. (2005): Zur Ertragswirkung von Pilzkrankheiten im Raps. Raps 23: 6-19.

Dunker S., Keunecke H., Steinbach P., von Tiedemann A. (2008): Impact of Verticillium longisporum on yield and morphology of winter oilseed rape (Brassica napus) in relation to systemic spread in the plant. Journal of Phytopathology 156: 698-707.

Dunwell J.M., Purvis A., Khuri S. (2004): Cupins: the most functionally diverse protein superfamily? Phytochemistry 65: 7-17.

Ebbole D.J. (2007): Magnaporthe as a model for understanding host-pathogen interactions. Annual Review of Phytopathology 45: 437-456. 
Ehlting J., Mattheus N., Aeschliman D.S., Li E., Hamberger B., Cullis I.F., Zhuang J., Kaneda M., Mansfield S.D., Samuels L., Ritland K., Ellis B.E., Bohlmann J., Douglas C.J. (2005): Global transcript profiling of primary stems from Arabidopsis thaliana identifies candidate genes for missing links in lignin biosynthesis and transcriptional regulators of fiber differentiation. The Plant Journal 42: 618-640.

El-Bebany A.F., Rampitsch C., Daayf F. (2010): Proteomic analysis of the phytopathogenic soilborne fungus Verticillium dahliae reveals differential protein expression in isolates that differ in aggressiveness. Proteomics 10: 289-303.

Endo S., Pesquet E., Yamaguchi M., Tashiro G., Sato M., Toyooka K., Nishikubo N., UdagawaMotose M., Kubo M., Fukuda H., Demura T. (2009): Identifying new components participating in the secondary cell wall formation of vessel elements in Zinnia and Arabidopsis. The Plant Cell 21: $1155-1165$.

Escalante-Pérez M., Lautner S., Nehls U., Selle A., Teubner M., Schnitzler J.-P., Teichmann T., Fayyaz P., Hartung W., Polle A., Fromm J., Hedrich R., Ache P. (2009): Salt stress affects xylem differentiation of grey poplar (Populus x canescens). Planta 229: 299-309.

Eynck C., Koopmann B., Grunewaldt-Stoecker G., Karlovsky P., von Tiedemann A. (2007): Differential interactions of Verticillium longisporum and V. dahliae with Brassica napus detected with molecular and histological techniques. European Journal of Plant Pathology 118: 259-274.

Eynck C., Koopmann B., Karlovsky P., von Tiedemann A. (2009): Internal resistance in winter oilseed rape inhibits systemic spread of the vascular pathogen Verticillium longisporum. Phytopathology 99: 802-811.

Fahleson J., Lagercrantz U., Hu Q., Steventon L.A., Dixelius C. (2003): Estimation of genetic variation among Verticillium isolates using AFLP analysis. European Journal of Plant Pathology 109: 361-371.

Felle H.H., Herrmann A., Hückelhoven R., Kogel K.-H. (2005): Root-to-shoot signalling: apoplastic alkalinization, a general stress response and defence factor in barley (Hordeum vulgare). Protoplasma 227: 17-24. 
Ferrari S., Vairo D., Ausubel F.M., Cervone F., de Lorenzo G. (2003): Tandemly duplicated Arabidopsis genes that encode polygalacturonase-inhibiting proteins are regulated coordinately by different signal transduction pathways in response to fungal infection. The Plant Cell 15: 93106.

Filipowicz W. (2005): RNAi: the nuts and bolts of the RISC machine. Cell 122: 17-20.

Flick J.S. \& Johnston M. (1990): Two systems of glucose repression of the GAL1 promoter in Saccharomyces cerevisiae. Molecular and Cellular Biology 10: 4757-4769.

Flörl (2007): Identifizierung und Charakterisierung extrazellulärer Proteine unter dem Einfluss von Verticillium longisporum in Arabidopsis thaliana und Raps (Brassica napus). Dissertation, Georg-August-Universität Göttingen.

Floerl S., Druebert C., Majcherczyk A., Karlosky P., Kües U., Polle A. (2008): Defence reactions in the apoplastic proteome of oilseed rape (Brassica napus var. napus) attenuate Verticillium longisporum growth but not disease symptoms. BMC Plant Biology 8: 129.

Floerl S., Druebert C., Aroud H.I, Karlovsky P., Polle A. (2010): Disease symptoms and mineral nutrition in Arabidopsis thaliana in response to Verticillium longisporum VL43 infection. Journal of Plant Pathology 92: 695-702.

Fradin E.F. \& Thomma B.P.H.J. (2006): Physiology and molecular aspects of Verticillium wilt diseases caused by V. dahliae and V. albo-atrum. Molecular Plant Pathology 7: 71-86.

Fraser C.M., Rider L.W., Chapple C. (2005): An expression and bioinformatics analysis of the Arabidopsis serine carboxypeptidase-like gene family. Plant Physiology 138: 1136-1148.

Fukuda H. \& Komamine A. (1980): Establishment of an experimental system for the tracheary element differentiation from single cells isolated from the mesophyll cells of Zinnia elegans. Plant Physiology 65: 57-60.

Fukuda H. (2004): Signals that control plant vascular cell differentiation. Nature Reviews. Molecular Cell Biology 5: 379-391.

Galanopoulus W. \& Triebe M.T. (1974): Conidial survival of V. dahliae. Transactions of the British Mycological Society 63: 85-91. 
Gancedo J.M. (1998): Yeast carbon catabolite expression. Microbiology and Molecular Biology Reviews 62: 334-361.

Gao X., Wheeler T., Li Z., Kenerley C.M., He P., Shan L. (2011): Silencing GhNDR1 and GhMKK2 compromises cotton resistance to Verticillium wilt. The Plant Journal, OnlineErstausgabe, doi: 10.1111/j.1365-313X.2011.04491.x.

Gayoso C., Pomar F., Novo-Uzal E., Merino F., Martínez de Ilárduya Ó. (2010): The Vemediated resistance response of the tomato to Verticillium dahliae involves $\mathrm{H}_{2} \mathrm{O}_{2}$, peroxidase and lignins and drives PAL gene expression. BMC Plant Biology 10: 232.

Giniger E., Varnum S.M., Ptashne M. (1985): Specific DNA-binding of GAL4, a positive regulatory protein of yeast. Cell 40: 767-774.

Godfrey D., Able A.J., Dry I.B. (2007): Induction of a grapevine germin-like protein (VvGLP3) gene is closely linked to the site of Erysiphe necator infection: A possible role in defense? Molecular Plant-Microbe Interactions 20: 1112-1125.

Godoy G., Steadman J.R., Dickman M.B., Dam R. (1990): Use of mutants to demonstrate the role of oxalic acid in pathogenicity of Sclerotinia sclerotiorum on Phaseolus vulgaris. Physiological and Molecular Plant Pathology 37: 179-191.

Gold J. \& Robb J. (1995): The role of the coating response in Craigella tomatoes infected with Verticillium dahliae, races 1 and 2. Physiological and Molecular Plant Pathology 47: 141-157.

Gold J., Lee B., Robb J. (1996): Colonization of tomatoes by Verticillium dahliae: determinative phase II. Canadian Journal of Botany 74: 1279-1288.

Gomez-Gomez L. \& Boller T. (2002): Flagellin perception: a paradigm for innate immunity. Trends in Plant Science 7: 251-256.

Gómez-Gómez L., Rubio-Moraga A., Ahrazem O. (2011): Molecular cloning and characterisation of a pathogenesis-related protein CsPR10 from Crocus sativus. Plant Biology 13: 297-303.

Gordee R.S. \& Porter C.L. (1985): Structure, germination, and physiology of microsclerotia of Verticillium albo-atrum. Physiological Plant Pathology 27: 109-118. 
Gordon T.R., Kirkpatrick S.C., Hansen J., Shaw D.V. (2006): Response of strawberry genotypes to inoculation with isolates of Verticillium dahliae differing in host origin. Plant Pathology 55: 766-769.

Gresshoff P.M. \& Doy C.H. (1974): Derivation of haploid cell line from Vitis vinifera and the importance of the stage of meiotic development of anthers for haploid culture of this and other genera. Zeitschrift für Pflanzenphysiologie 37: 132-141.

Guénin S., Mauriad M., Pelloux J., Van Wuytswinkel O., Bellini C., Gutierrez L. (2008): Normalization of qRT-PCR data: the necessity of adopting a systemic, experimental conditionsspecific, validation of references. Journal of Experimental Botany 60: 487-493.

Günzelmann H. \& Paul V.H. (1990): Zum Auftreten und zur Bedeutung der Verticillium-Welke an Raps in der Bundesrepublik Deutschland in 1989. Raps 8: 23-25.

Häffner E., Karlovsky P., Diederichsen E. (2010): Genetic and environmental control of the Verticillium syndrome in Arabidopsis thaliana. BMC Plant Biology 10: 235.

Hanselle T., Ichinoseb Y., Barz W. (2001): Biochemical and molecular biological studies on infection (Ascochyta rabiei)-induced thaumatin-like proteins from chickpea plants (Cicer arietinum L.). Zeitschrift für Naturforschung C 56: 1095-1107.

Happstadius I., Ljungberg A., Kristiansson B., Dixelius C. (2003): Identification of Brassica oleracea germplasm with improved resistance to Verticillium wilt. Plant Breeding 122: 30-34.

Harling R., Taylor G.S, Charlton W.A. (1984): Xylem vessel regeneration in carnation in response to infection bx Fusarium oxysporum $f$. sp. dianthi. Netherland Journal of Plant pathology 90: 173-176.

Hartley J.L., Temple G.F., Brasch M.A. (2000): DNA cloning using in vitro site-specific recombination. Genome Research 10: 1788-1795.

Heale J.B. (2000): Diversification and speciation in Verticillium - An overview. In: Advances in Verticillium research and disease management. Tjamos E.C., Rowe R.C., Heale J.B., Fravel D.R. (eds.), St. Paul, Minnesota, APS Press: 175-177.

Heale J. \& Karapapa V.K. (1999): The Verticillium threat to Canada's major oilseed crop: Canola. Canadian Journal of Plant Pathology 21: 1-7. 
Heinz R., Lee S.W., Saparno A., Nazar R.N., Robb J. (1998): Cyclical systemic colonization in Verticillium-infected tomato. Physiological and Molecular Plant Pathology 52: 385-396.

Herrera-Estrella L., Depicker A., Van Montagu M., Schell J. (1992): Expression of chimaeric genes transferred into plant cells using a Ti-plasmid-derived vector. Biotechnology 24: 377-381.

Hibbett D.S., Binder M., Bischoff J.F., Blackwell M., Cannon P.F., Eriksson O.E., Huhndorf S., James T., Kirk P.M., Lücking R., Lumbsch H., Lutzoni F., Matheny P.B., McLaughlin D.J., Powell M.J., Redhead S., Schoch C.L., Spatafora J.W., Stalpers J.A., Vilgalys R., Aime M.C., Aptroot A., Bauer R., Begerow D., Benny G.L., Castlebury L.A., Crous P.W., Dai Y.C., Gams W., Geiser D.M., Griffith G.W., Gueidan C., Hawksworth D.L., Hestmark G., Hosaka K., Humber R.A., Hyde K.D., Ironside J.E., Kõljalg U., Kurtzman C.P., Larsson K.H., Lichtwardt R., Longcore J., Miadlikowska J., Miller A., Moncalvo J.M., Mozley-Standridge S., Oberwinkler F., Parmasto E., Reeb V., Rogers J.D., Roux C., Ryvarden L., Sampaio J.P., Schüssler A., Sugiyama J., Thorn R.G., Tibell L., Untereiner W.A., Walker C., Wang Z., Weir A., Weiss M., White M.M., Winka K., Yao Y.J., Zhang N. (2007): A higher-level phylogenetic classification of the Fungi. Mycological Research 111: 509-547.

Hilaire E., Young S.A., Willard L.H., McGee J.D., Sweat T., Chittoor J.M., Guikema J.A., Leach J.E. (2001): Vascular defense responses in rice: Peroxidase accumulation in xylem parenchyma cells and xylem cell wall thickening. Molecular Plant-Microbe Interactions 14: 1411-1419.

Huisman O.C. (1982): Interrelations of root growth dynamics to epidemiology of rootinvading fungi. Annual Review of Phytopathology 20: 303-327.

Irshad M., Canut H., Borderies G., Pont-Lezica R., Jamet E. (2008): A new picture of cell wall protein dynamics in elongating cells of Arabidopsis thaliana: Confirmed actors and newcomers. BMC Plant Biology 8: 94.

Isaac I. (1957): Verticillium wilt of Brussels sprout. Annals of Applied Biology 45: 276-283.

Iven (2009): Transkriptomanalyse der Arabidopsis-Wurzel nach Infektion mit dem pilzlichen Pathogen Verticillium longisporum und Identifizierung von transkriptionellen Regulatoren der Pathogenantwort. Dissertation, Georg-August-Universität Göttingen.

Jach G., Gornhardt B., Mundy J., Logemann J., Pinsdorf P., Leah R., Schell J., Maas C. (1995): Enhanced quantitative resistance against fungal disease by combinatorial expression of different barley antifungal proteins in transgenic tobacco. The Plant Journal 8: 97-109. 
Jefferson R.A., Kavanagh T.A., Bevan M.W. (1987): GUS fusions: B-glucuronidase as a sensitive and versatile gene fusion marker in higher plants. EMBO Journal 6: 3901-3907.

Johansson A., Goud J.-K., Dixelius C. (2006a): Plant host range of Verticillium longisporum and microsclerotia density in Swedish soils. European Journal of Plant Pathology 114: 139-149.

Johansson A., Staal J., Dixelius C. (2006b): Early responses in the Arabidopsis-Verticillium longisporum pathosystem are dependent on NDR1, JA- and ET-associated signals via cytosolic NPR1 and RFO1. Molecular Plant-Microbe Interactions 19: 958-969.

Jøhnk N., Hietala A.M., Fossdal C.G., Collinge D.B., Newman M.-A. (2005): Defense-related genes expressed in Norway spruce roots after infection with the root rot pathogen Ceratobasidium bicorne (anamorph: Rhizoctonia sp.). Tree Physiology 25: 1533-1543.

Jones J.D.G. \& Dangl J.L. (2006): The plant immune system. Nature 444: 323-329.

Jones-Rhoades M.W., Bartel D.P, Bartel B. (2006): MicroRNAS and their regulatory roles in plants. Annual Review of Plant Biology 57: 19-53.

Joosten M.H.A.J. \& De Wit P.J.G.M. (1989): Identification of several pathogenesis-related proteins in tomato leaves inoculated with Cladosporium fulvum (syn. Fulvia fulva) as 1,3- $\beta$ glucanases and chitinases. Plant Physiology 89: 945-951.

Karapapa V.K., Bainbridge B.W., Heale J.B. (1997): Morphological and molecular characterization of Verticillium longisporum comb. nov., pathogenic to oilseed rape. Mycological Research 101: 1281-1294.

Karapapa V.K. \& Typas M.A. (2001): Molecular characterization of the host-adapted pathogen Verticillium longisporum on the basis of a group-I intron found in the nuclear SSU-rRNA gene. Current Microbiology 42: 217-224.

Kehr J., Buhtz A., Giavalisco P. (2005): Analysis of xylem sap proteins from Brassica napus. BMC Plant Biology 5: 11.

Kim H.J. \& Triplett B.A. (2004): Cotton fiber germin-like protein. I. Molecular cloning and gene expression. Planta 218: 516-524. 
Kim H.J., Pesacreta T.C., Triplett B.A. (2004): Cotton-fiber germin-like protein. II: Immunolocalization, purification, and functional analysis. Planta 218: 525-535.

Kitajima M. \& Butler W.L. (1975): Quenching of chlorophyll fluorescence and primary photochemistry in chloroplasts by dibromothymoquinone. Biochemica et Biophysica Acta 376: 201-204.

Klimes A. \& Dobinson K.F. (2006): A hydrophobin gene, VDH1, is involved in microsclerotial development and spore viability in the plant pathogen Verticillium dahliae. Fungal Genetics and Biology 43: 283-94.

Knecht K., Seyffarth M., Desel C., Thurau T., Sherameti I., Lou B., Oelmüller R., Cai D. (2010): Expression of BvGLP-1 encoding a germin-like protein from sugar beet in Arabidopsis thaliana leads to resistance against phytopathogenic fungi. Molecular Plant-Microbe Interactions 23: 446457.

Koncz C. \& Schell J. (1986): The promoter of TL-DNA gene 5 controls the tissue specific expression chimeric genes carried by a novel type of Agrobacterium binary vector. Molecular \& General Genetics 204: 383-396.

Krüger W. (1989): Untersuchungen zur Verbreitung von Verticillium dahliae Kleb. und anderen Krankheits- und Schaderregern bei Raps in der Bundesrepublik Deutschland. Nachrichtenblatt Deutscher Pflanzenschutzdienst 41: 49-56.

Kruse J., Hetzger I., Mai C., Polle A., Rennenberg H. (2003): Elevated $\mathrm{pCO}_{2}$ affects N metabolism of young poplar plants (Populus tremula $\times$ P. alba) differently at deficient and sufficient N supply. New Phytologist 157: 65-81.

Kubo M., Udagawa M., Nishikubo N., Horiguchi G., Yamaguchi M., Ito J., Mimura T., Fukuda H., Demura T. (2005): Transcription switches for protoxylem and metaxylem vessel formation. Genes Development 19: 1855-1860.

Lamb C. \& Dixon R.A. (1997): The oxidative burst in plant disease resistance. Annual Review of Plant Physiology and Plant Molecular Biology 48: 251-275.

Lamanda A., Zahn A., Röder D., Langen H. (2004): Improved ruthenium (II) tris (bathophenantroline disulfonate) staining and destaining protocol for a better signal-tobackground ratio and improved baseline resulution. Proteomics 4: 599-608. 
Laemmli U.K. (1970): Cleavage of structural proteins during the assembly of the head of bacteriophage T4. Nature 227: 680-685.

Le Gouill C., Parent J.-L., Rola-Pleszczynski M., Stankova J. (1994): Analysis of recombinant plasmids by a modified alkaline lysis method. Analytical Biochemistry 219: 164.

Lee R.-H., Hsu J.-H., Huang H.-J., Lo S.-F., Chen S.-C. G. (2009): Alkaline $\alpha$-galactosidase degrades thylakoid membranes in the chloroplast during leaf senescence in rice. New Phytologist 184: 596-606.

Lee S.W., Nazar R.N., Powell D.A., Robb J. (1992): Reduced PAL gene suppression in Verticillium-infected resistant tomatoes. Plant Molecular Biology 18: 345-352.

Lichtenthaler H.K. \& Wellburn A.R. (1983): Determination of total carotenoids and chlorophyll $a$ and $b$ of leaf extracts in different solvents. Biochemical Society Transactions 603: 591-592.

Lipka V., Dittgen J., Bednarek P., Bhat R., Wiermer M., Stein M., Landtag J., Brandt W., Rosahl S., Scheel D., Llorente F., Molina A., Parker J., Somerville S., Schulze-Lefert P. (2005): Preand postinvasion defenses both contribute to nonhost resistance in Arabidopsis. Science 310: $1180-1183$.

Little D., Gouhier-Darimont C., Bruessow F., Reymond P. (2007): Oviposition by Pierid butterflies triggers defense responses in Arabidopsis. Plant Physiology 143: 784-800.

López-Milán A.F., Morales F., Abadía A., Abadía J. (2000): Effects of iron deficiency on the composition of the leaf apoplastic fluid and xylem sap in sugar beet. Implications for iron and carbon transport. Plant Physiology 124: 873-884.

Lou Y. \& Baldwin I.T. (2006): Silencing of a germin-like gene in Nicotiana attenuata improves performance of native herbivores. Plant Physiology 140: 1126-1136.

Manosalva P.M., Davidson R.M., Liu B., Zhu X., Hulbert S.H., Leung H., Leach J.E. (2009): A germin-like protein gene family functions as a complex quantitative trait locus conferring broadspectrum disease resistance in rice. Plant Physiology 149: 286-296.

Mansoori B. \& Smith C.J. (2005): Elicitation of ethylen by Verticillium albo-atrum in potato. Journal of Phytopathology 153: 143-149. 
Mauch F., Mauch-Mani B., Boller T. (1988): Antifungal hydrolases in pea tissue II. Inhibition of fungal growth by combinations of chitinase and B-1,3-glucanase. Plant Physiology 88: 936-942.

Maxwell K. \& Johnson G.N. (2000): Chlorophyll fluorescence - a practical guide. Journal of Experimental Botany 51: 659-668.

McDonell M.W., Simon M.N., Studier F.W. (1977): Analysis of restriction fragments of T7 DNA and determination of molecular weights by electrophoresis in neutral and alkaline gels. Journal of Molecular Biology 110: 119-146.

McFadden H.G., Chapple R., de Feyter R., Dennis E. (2001): Expression of pathogenesis-related genes in cotton stems in response to infection by Verticillium dahliae. Physiological and Molecular Plant Pathology 58: 119-131.

Melotto M., Underwood W., Jessica K., Kinya N., He S.Y. (2006): Plant stomata function in innate immunity against bacterial invasion. Cell 126: 969-980.

Membré N., Berna A., Neutelings G., David A., David H., Staiger D., Vásquez J.S., Raynal M., Delseny M., Bernier F. (1997): cDNA sequence, genomic organization and differential expression of three Arabidopsis genes for germin/oxalate oxidase-like proteins. Plant Molecular Biology 35: 459-469.

Membré N., Bernier F., Staiger D., Berna A. (2000): Arabidopsis thaliana germin-like proteins: common and specific features point to a variety of functions. Planta 211: 345-354.

Menzies J.D. \& Griebel G.E. (1967): Survival and saprophytic growth of Verticillium dahliae in uncropped soil. Phytopathology 57: 703-709.

Millar D.J., Whitelegge J.P., Bindschedler L.V., Rayon C., Boudet A.-M., Rossignol M. Borderies G., Bolwell G.P. (2009): The cell wall and secretory proteome of a tobacco cell line synthesising secondary wall. Proteomics 9: 2355-2372.

Minic Z., Jamet E., San-Clemente H., Pelletier S., Renou J.-P., Rihouey C., Okinyo D.P.O., Proux C., Lerouge P., Jouanin L. (2009): Transcriptomic analysis of Arabidopsis developing stems: a close-up on cell wall genes. BMC Plant Biology 9: 6. 
Miya A., Albert P., Shinya T., Desaki Y., Ichimura K., Shirasu K., Narusaka Y., Kawakami N., Kaku H., Shibuya N. (2007): CERK1, a LysM receptor kinase, is essential for chitin elicitor signaling in Arabidopsis. Proceedings of the National Academy of Sciences of the United States of America 104: 19613-19618.

Mohr P.G. \& Cahill D.M. (2007): Suppression by ABA of salicylic acid and lignin accumulation and the expression of multiple genes in Arabidopsis infected with Pseudomonas syringae pv. tomato. Functional \& Integrative Genomics 7: 181-191.

Mol L., Scholte K., Vos J. (1995): Effects of crop rotation and removal of crop debris on the soil population of two isolates of Verticillium dahliae. Plant Pathology 44: 1070-1074.

Mol L. \& Scholte K. (1995): Formation of microsclerotia of Verticillium dahliae Kleb. on various plant parts of two potato cultivars. Potato Research 38: 143-150.

Mol L. \& van Riessen H. W. (1995): Effect of plant-roots on the germination of microsclerotia of Verticillium dahliae. European Journal of Plant Pathology 101: 673-678.

Mullis K.B. \& Faloona F.A. (1987): Specific synthesis of DNA in vitro via a polymerasecatalyzed chain reaction. Methods in Enzymology 155: 335-350.

Murashige T. \& Skoog F. (1962): A revised medium for rapid growth and bioassays with tobacco tissue cultures. Physiologia Plantarum 15: 473-497.

Musgrave M.E. (2000): Realizing the potential of rapid-cycling Brassica as a model system for use in plant biology research. Journal of Plant Growth Regulation 19: 314-325.

Nakagawa T., Kurose T., Hino T., Tanaka K., Kawamukai M., Niwa Y., Toyooka K., Matsuoka K., Jinbo T., Kimura T. (2007): Development of series of Gateway binary vectors, pGWBs, for realiting efficient construction of fusion genes for plant transformation. Journal of Bioscience and Bioengineering 104: 34-41.

Nakamura S.-I., Akiyama C., Sasaki T., Hattori H., Chino M. (2008): Effect of cadmium on the chemical composition of xylem exudate from oilseed rape plants (Brassica napus L.). Soil and plant nutrition 54: 118-127. 
Narusaka Y., Narusaka M., Park P., Kubo Y., Hirayama T., Seki M., Shiraishi T., Ishida J., Nakashima M., Enju A., Sakurai T., Satou M., Kobayashi M., Shinozaki K. (2004): RCH1, a locus in Arabidopsis that confers resistance to the hemibiotrophic fungal pathogen Colletotrichum higginsianum. Molecular Plant-Microbe Interactions 17: 749-762.

Neumann M.J. \& Dobinson K.F. (2003): Sequence tag analysis of gene expression during pathogenic growth and microsclerotia development in the vascular wilt pathogen Verticillium dahliae. Fungal Genetics and Biology 38: 54-62.

Ossowski S., Schwab R., Weigel D. (2008): Gene silencing in plants using artificial microRNAs and other small RNAs. The Plant Journal 53: 674-690.

Pantelides I.S., Tjamos S.E., Paplomatas E.J. (2010): Ethylen perception via ETR1 is required in Arabidopsis infection by Verticillium dahliae. Molecular Plant Pathology 11: 191-202.

Pedras M.S., Okanga F.I., Zaharia I.L., Khan A.Q. (2000): Phytoalexins from crucifers: synthesis, biosynthesis, and biotransformation. Phytochemistry 53: 161-176.

Pedras M.S., Adio A.M., Suchy M., Okinyo D.P., Zheng Q.A., Jha M., Sarwar M.G. (2006): Detection, characterization and identification of crucifer phytoalexins using high-performance liquid chromatography with diode array detection and electrospray ionization mass spectrometry. Journal of Chromatography. A. 1133:172-183.

Pegg G.F. \& Brady B.L. (2002): Verticillium Wilts. Wallingford, UK: CAB Publishing.

Pieterse C.M.J., Leon-Reyes A., Van der Ent S., Van Wees S.C.M. (2009): Networking by small-molecule hormones in plant immunity. Nature Chemical Biology 5: 308-316.

Polle A., Chakrabarti K., Schurmann W., Rennenberg H. (1990): Composition and properties of hydrogen peroxide decomposing systems in extracellular and total extracts from needles of Norway spruce (Picea abies L., Karst.). Plant Physiology 94: 312-319.

Polle A., Wieser G., Havranek W.M. (1995): Quantification of ozone influx and apoplastic ascorbate content in needles of Norway spruce trees (Picea abies L., Karst.) at high altitude. Plant, Cell and Environment 18: 681-688.

Qu Z.-L., Zhong N.-Q., Wang H.-Y., Chen A.-P., Jian G.-L., Xia G.-X. (2006): Ectopic expression of the cotton non-symbiotic hemoglobin gene GhHb1 triggers defense response and increases disease tolerance in Arabidopsis. Plant \& Cell Physiology 47: 1058-1068. 
Rabilloud T., Strub J.M., Luche S., van Dorsselaer A., Lunardi J. (2001): A comparison between Sypro Ruby and ruthenium (II) tris (bathophenanthroline disulfonate) as fluorescent stains for protein detection in gels. Proteomics 1: 699-704.

Ramonell K., Berrocal-Lobo M., Koh S., Wan J.R., Edwards H., Stacey G., Somerville S. (2005): Loss-of-function mutations in chitin responsive genes show increased susceptibility to the powdery mildew pathogen Erysiphe cichoracearum. Plant Physiology 138: 1027-1036.

Ratzinger A., Riediger N., von Tiedemann A., Karlovsky P. (2009): Salicylic acid and salicylic acid glucoside in xylem sap of Brassica napus infected with Verticillium longisporum. Journal of Plant Research 122: 571-579.

Rep M., Dekker H.L., Vossen J.H., de Boer A.D., Houterman P.M., Speijer D., Back J.W., de Koster C.G., Cornelissen B.J.C. (2002): Mass spectrometric identification of isoforms of PR proteins in xylem sap of fungus-infected tomato. Plant Physiology 130: 904-917.

Riens B., Lohaus G., Heineke D., Heldt H.W. (1991): Amino acid and sucrose content determined in the cytosolic, chloroplastic, and vacuolar compartments and in the phloem sap of spinach leaves. Plant Physiology 97: 227-233.

Robb J., Powell D.A., Street P.F.S. (1989): Vascular coating: a barrier to colonization by the pathogen in Verticillium wilt of tomato. Canadian Journal of Botany 67: 600-607.

Roberts R.J. (1985): Restriction and modification enzymes and their recognition sequences. Nucleic Acids Research 13: 165-200.

Rodríguez-López M., Baroja-Fernández E., Zandueta-Criado A., Moreno-Bruna B., Muñoz F.J., Akazawa T., Pozueta-Romero J. (2001): Two isoforms of a nucleotide-sugar pyrophosphatase/phosphodiesterase from barley leaves (Hordeum vulgare L.) are distinct oligomers of hvglp1, a germin-like protein. FEBS Letters 490: 44-48.

Roháček K. (2002): Chlorophyll fluorescence parameters: the definitions, photosynthetic meaning, and mutual relationships. Photosynthetica 40: 13-29.

Rygulla W., Snowdon R.J., Eynck C., Koopmann B., von Tiedemann A., Lühs W., Friedt W. (2007): Broadening the genetic basis of Verticillium longisporum resistance in Brassica napus by interspecific hybridization. Phytopathology 11: 1391-1396. 
Samson F., Brunaud V., Balzergue S., Dubreucq B., Lepiniec L., Pelletier G., Caboche M., Lecharny A. (2002): FLAGdb/FST: a database of mapped flanking insertion sites (FSTs) of Arabidopsis thaliana T-DNA transformants. Nucleic Acids Research 30: 94-97.

Sanabria N., Goring D., Nürnberger T., Dubery I. (2008): Self/nonself perception and recognition in plants: a comparison of self-incompatibilty and innate immunity. New Phytologist 178: 503-514.

Sanger F., Nicklen S., Coulson A.R. (1977): DNA sequencing with chain-terminating inhibitors. Proceedings of the National Academy of Sciences of the United States of America 74: 54635467.

Schenk R.U. \& Hildebrandt A.C. (1972): Medium and techniques for induction and growth of monocotyledonnous and dicotyledonous plant cell cultures. Canadian Journal of Botany 50: 199204.

Schlesier B., Berna A., Bernier F., Mock H.-P. (2004): Proteome analysis differentiates between two highly homologues germin-like proteins in Arabidopsis thaliana ecotypes Col-0 and Ws-2. Phytochemistry 65: 1565-1574.

Schnathorst W.C. (1981): Life cycle and epidemiology of Verticillium. In: Mace M.E., Bell A.A., Beckmann C.H. (Editoren): Fungal Wilt Diseases of Plants. Academic Press, New York, S. 81-111.

Schneidereit A. (2005): Untersuchungen zur transkriptionellen Regulation des AtSUC2Promotors beim Sink-Source-Übergang im Blatt und Analyse der Gene AtINT2 und AtINT4. Dissertation, Universität Erlangen-Nürnberg.

Scholander P.F., Bradstreet E.D., Hemmingsen E.A., Hammel H.A.T. (1965): Sap pressure in vascular plants, negative hydrostatic pressure can be measured in plants. Science 148: 339-346.

Scholl R.L., May S.T., Ware D.H. (2000): Seed and molecular resources for Arabidopsis. Plant Physiology 124: 1477-1480.

Schopfer P. (1989): Experimentelle Pflanzenphysiologie. Band 2: Einführung in die Anwendungen. Springer, Berlin, S. 39-50. 
Schreiber L.R. \& Green R.J. (1963): Effects of root exudates on germination of conidia and microsclerotia of Verticillium albo-atrum inhibited by the soil fungistatic principle. Phytopathology 53: 260-264.

Schwab R., Ossowski S., Riester M., Warthmann N., Weigel D. (2006): Highly specific gene silencing by artificial microRNAs in Arabidopsis. The Plant Cell 18: 1121-1133.

Schweizer P., Christoffel A., Dudler R. (1999): Transient expression of members of the germinlike gene family in epidermal cells of wheat confers disease resistance. The Plant Journal 20: 541-552.

Schwessinger B. \& Zipfel C. (2008): News from the frontline: recent insights to PAMP-triggered immunity in plants. Current Opinion in Plant Biology 11: 389-395.

Sela-Buurlage M.B., Ponstein A.S., Vloemans S.A., Melchers L.S., Van den Elzen P.J.M., Cornelissen B.J.C. (1993): Only specific tobacco (Nicotinia tabacum) chitinases and B-1,3glucanases exhibit antifungal activity. Plant Physiology 101: 857-863.

Sharon N. \& Lis H. (2004): History of lectins: from hemagglutinins to biological recognition molecules. Glycobiology 14: 53-62.

Shenoy S.R., Kameshwari M.N., Swaminathan S., Gupta M.N. (2006): Major antifungal activity from the bulbs of Indian squill Urginea indica is a chitinase. Biotechnological Progress 22: 631637.

Shetty N.P., Jensen J.D., Knudsen A., Finnie C., Geshi N., Blennow A., Collinge D.B., Lyngs Jørgensen H.J. (2009): Effects of B-1,3-glucan from Septoria tritici on structural defence responses in wheat. Journal of Experimental Botany 60: 4287-4300.

Siebrecht S. (2000): Untersuchungen zur Dynamik des Nährstofftransports im Xylem von Pappeln unter besonderer Berücksichtigung der Stickstoffversorgung des Sprosses. Dissertation, Georg-August-Universität Göttingen.

Singh S., Braus-Stromeyer S.A., Timpner C., Tran V.T., Lohaus G., Reusche M., Knüfer J., Teichmann T., von Tiedemann A., Braus G. (2010): Silencing of Vlaro2 for chorismate synthase revealed that the phytopathogen Verticillium longisporum induces the cross-pathway control in the xylem. Applied Micobiology and Biotechnology 85: 1961-1976. 
Smit F. \& Dubery I.A. (1997): Cell wall reinforcement in cotton hypocotyls in response to a Verticillium dahliae elicitor. Phytochemistry 44: 811-815.

Smith P.K., Krohn R.I., Hermanson G.T., Mallia A.K., Gartner F.H., Provenzano M.D., Fujimoto E.K., Goeke N.M., Olson B.J., Klenk D.C. (1985): Measurement of protein using bicinchoninic acid. Analytical Biochemistry 150: 76-85.

Smith H.O. \& Wilcox K.W. (1970): A restriction enzyme from Hemophilus influenzae I. Purification and general properties. Journal of Molecular Biology 28: 379-391.

Solla A. \& Gil L. (2002): Xylem vessel diameter as a factor in resistance of Ulmus minor to Ophiostoma novo-ulmi. Forest Pathology 32: 123-134.

Southern E.M. (1979): Measurement of DNA length by gel electrophoresis. Analytical Biochemistry 100: 319-323.

Soyano T., Thitamadee S., Machida Y., Chua N.-H. (2008): Asymmetric leaves 2 - like 19/Lateral organ bounderies domain 30 and ASL20/LBD18 regulate tracheary element differentiation in Arabidopsis. The Plant Cell 20: 3359-3373.

Spoel S.H. \& Dong X. (2008): Making sense of hormone crosstalk during plant immune responses. Cell, Host and Microbe 3: 348-351.

Staiger D., Apel K., Trepp G. (1999): The Atger3 promoter confers circadian clock-regulated transcription with peak expression at the beginning of the night. Plant Molecular Biology 40: 873-882.

Stark C. (1961): Das Auftreten der Verticillium-Tracheomykosen in Hamburger GartenbauKulturen. Gartenbauwissenschaft 26: 493-528.

Steventon L.A., Okori P., Dixelius C. (2001): An investigation of the susceptibility of Arabidopsis thaliana to isolates of two species of Verticillium. Journal of Phytopathology 149: 395-401.

Subramanian S., Cho U.-H, Keyes C., Yu O. (2009): Distinct changes in soybean xylem sap in response to pathogenic and symbiotic microbe interactions. BMC Plant Biology 9: 119. 
Svenson C.H. \& Lerenius C. (1987): An investigation on the effect of Verticillium wilt (Verticillium dahliae Kleb.) on oilseed rape. Working group integrated control in oilseed rape. IOBC/WPRS (X/4): 30-34.

Takken F.L.W. \& Tameling W.I.L. (2009): To nibble at plant resistance proteins. Science 324: 744-746.

Talboys P.W. (1958): Association of tylosis and hyperplasia of the xylem with vascular invasion of the hop by Verticillium albo-atrum. Transactions of the British Mycological Society 41: 249260.

Tao Y., Xie Z., Chen W., Glazebrook J., Chang H.-S., Han B., Zhu T., Zou G., Katagiri F. (2003): The quantitative nature of Arabidopsis responses during compatible and incompatible interactions with the bacterial pathogen Pseudomonas syringae. The Plant Cell 15: 317-330.

Tappe H. (2008): Verticillium longisporum induced gene expression in Arabidopsis thaliana. Dissertation, Georg-August-Universität Göttingen.

Tena G., Asai T., Chiu W.-L., Sheen J. (2001): Plant mitogen-activated protein kinase signaling cascades. Current Opinion in Plant Biology 4: 392-400.

Thomma B.P., Nelissen I., Eggermont K., Broekaert W.F. (1999): Deficiency in phytoalexin production causes enhanced susceptibility of Arabidopsis thaliana to the fungus Alternaria brassicicola. The Plant Journal 19: 163-171.

Tian J., Zhang X., Liang B., Li S., Wu Z., Wang Q., Leng C., Dong J., Wang T. (2010): Expression of Baculovirus Anti-apoptosic genes p35 and op-iap in cotton (Gossypium hirsutum L.) enhances tolerance to Verticillium Wilt. PLoS ONE 5: e14218.

Tjamos S.E., Flemetakis E., Paplomatas E.J., Katinakis P. (2005): Induction of resistance to Verticillium dahliae in Arabidopsis thaliana by the biocontrol agent K-165 and pathogenesisrelated proteins gene expression. Molecular Plant-Microbe Interactions 18: 555-561.

Turner S., Gallois P., Brown D. (2007): Tracheary element differentiation. Annual Review of Plant Biology 58: 407-433. 
Tzima A.K., Paplomatas E.J., Rauyaree P., Ospina-Giraldo M.D., Kang S. (2010): VdSNF1, the sucrose non-fermenting protein kinase gene of Verticillium dahliae, is required for virulence and expression of genes involved in cell wall degradation. Molecular Plant-Microbe Interactions 1: 129-142.

Udvardi M.K., Czechowski T., Scheible W.-R. (2008): Eleven Golden Rules of Quantitative RTPCR. The Plant Cell 7: 1736-1737.

Użarowska A., Dionisio G., Sarholz B., Piepho H.-P., Xu M., Ingvardsen C.R., Wenzel G., Lübberstedt T. (2009): Validation of candidate genes putatively associated with resistance to SCMV and MDMV in maize (Zea mays L.) by expression profiling. BMC Plant Biology 9: 15.

Van Esse H. P., Fradin E.F., De Groot P. J., De Wit P.J.G.M., Thomma B.P.H.J. (2009) : Tomato transcriptional responses to a foliar and a vascular fungal pathogen are distinct. Molecular PlantMicrobe Interactions 22: 245-258.

Van Etten H.D., Mansfield J.W., Bailey J.A., Farmer E.E. (1994): Two Classes of Plant Antibiotics: Phytoalexins versus "Phytoanticipins". The Plant Cell 6: 1191-1192.

Van Loon L.C., Rep M., Pieterse C. M. J. (2006): Significance of inducible defense-related proteins in infected plants. Annual Review of Phytopathology 44: 135-162.

Vanneste S. \& Friml J. (2009): Auxin: a trigger for change in plant development. Cell 136: 10051016.

Veronese P., Narasimhan M.L., Stevenson R.A., Zhu J.-K., Weller S.C., Subbarao K.V., Bressan R.A. (2003): Identification of a locus controlling Verticillium disease symptom response in Arabidopsis thaliana. The Plant Journal 35: 574-587.

Wang D., Pajerowska-Mukhtar K., Hendrickson Culler A., Dong X. (2007): Salicylic acid inhibits pathogen growth in plants through repression of the auxin signaling pathway. Current Biology 17: 1784-1790.

Wang J.-Y., Cai Y., Gou J.-Y., Mao Y.-B., Xu Y.-H., Jiang W.-H., Chen X.-Y. (2004): VdNEP, an elicitor from Verticillium dahliae, induces cotton plant wilting. Applied and Environmental Microbiology 70: 4989-4995. 
Wang Q., Li F., Zhang X., Zhang Y., Hou Y., Zhang S., Wu Z. (2011): Purification and characterization of a CkTLP protein from Cynanchum komarovii seeds that confers antifungal activity. PLoS ONE 6: e16930.

West R.W., Yocum R.R., Ptashne M. (1984): Saccharomyces cerevisiae GALI-GALIO divergent promoter region: location and function of the upstream activating sequence UASG. Molecular and Cellular Biology 4: 2467-2478.

White J., Chang S.Y., Bibb M.J. (1990): A cassette containing the bar gene of Streptomyces hygroscopicus: a selectable marker for plant transformation. Nucleic Acids Research 18: 1062.

Wilhelm S. (1955): Longevity of the Verticillium wilt fungus in the laboratory and field. Phytopathology 45: 180-181.

Williams P.H. \& Hill C.B. (1986): Rapid-cycling populations of Brassica. Science 232: 13851389.

Williams J.S. \& Cooper R.M. (2003): Elemental sulphur is produced by diverse plant families as a component of defence against fungal and bacterial pathogens. Physiological and Molecular Plant Pathology 63: 3-16.

Williams J., Hall S.A., Hawkesford M.J., Beale M.H., Cooper R.M. (2002): Elemental sulfur and thiol accumulation in tomato and defense against a fungal vascular pathogen. Plant Physiology 128: 150-159.

Wong J.H., Ng T.B., Cheung R.C.F., Ye X.J., Wang H.X., Lam S.K., Lin P., Chan Y.S., Fang E.F., Ngai P.H.K., Xia L.X., Ye X.Y., Jiang Y., Liu F. (2010): Proteins with antifungal properties and other medicinal applications from plants and mushrooms. Applied Microbiology and Biotechnology 87: 1221-1235.

Woo E.-J., Dunwell J.M., Goodenough P.W., Marvier A.C., Pickersgill R.W. (2000): Germin is a manganese containing homohexamer with oxalate oxidase and superoxide dismutase activities. Nature Structural Biology 7: 1036-1040.

Young S.A., Guo A., Guikema J.A., White F.F., Leach J.E. (1995): Rice cationic peroxidase accumulates in xylem vessels during incompatible interactions with Xanthomonas oryzae pv. oryzae. Plant Physiology 107: 1333-1341. 
Zeise K. \& Seidel D. (1990): Zur Entwicklung und Schadwirkung der VerticilliumWelkekrankheit am Winterraps. Raps 8: 20-22.

Zeise K. \& von Tiedemann A. (2001): Morphological and physiological differentiation among vegetative compatibility groups of Verticillium dahliae in relation to $V$. longisporum. Journal of Phytopathology 149: 469-475.

Zeise K. \& von Tiedemann A. (2002a): Host specialization among vegetative compatibility groups of Verticillium dahliae in relation to Verticillium longisporum. Journal of Phytopathology 150: 112-119.

Zeise K. \& von Tiedemann A. (2002b): Application of RAPD-PCR for virulence type analysis within Verticillium dahliae and Verticillium longisporum. Journal of Phytopathology 150: 557563.

Zielenski D. \& Sadowski C. (1995): A preliminary study on Verticillium dahliae Kleb. in winter oilseed rape in Poland. In: Murphy D. (Editor): Proceedings of the $9^{\text {th }}$ International Rapeseed Conference, Cambridge. 4-7 July 1995. GciRC, Cambridge, UK, S. 649-651.

Zhang B., Ramonell K., Somerville S., Stacey G. (2002): Characterization of early, chitininduced gene expression in Arabidopsis. Molecular Plant-Microbe Interactions 15: 963-970.

Zhou Z. (2000): Untersuchungen zum Blatt- und Wurzelmetabolismus sowie zum Phloem- und Xylemtransport in Zusammenhang mit der Stickstoff-Effizienz bei Raps (Brassica napus L.). Dissertation, Georg-August-Universität Göttingen.

Zhou L., Hu Q., Johansson A., Dixelius C. (2006): Verticillium longisporum and Verticillium dahliae: infection and disease in Brassica napus. Plant Pathology 55: 137-144.

Zimmermann G., Bäumlein H., Mock H.-P., Himmelbach A., Schweizer P. (2006): The multigene family encoding germin-like proteins of barley. Regulation and function in basal host resistance. Plant Physiology 142: 181-192. 


\section{Anhang}

\section{Anhang A: Einfluss einer Infektion mit Verticillium longisporum auf die Aktivität des Photosystems II in Arabidopsis thaliana}

Messungen der Chlorophyllfluoreszenz mit einem pulsmoduliertem Fluoreszenzmesser (MINIPAM, Walz, Effeltrich, Deutschland) zur Charakterisierung des Einflusses von V. longisporum auf das Photosystem II offenbarten eine verringerte Quantenausbeute („Yield“) bei infizierten Pflanzen gegenüber Kontrollen (Floerl et al. 2010). Diese Unterschiede waren jedoch sehr gering. Anhand der Abbildung der Chlorophyllfluoreszenz mit einem IMAGING-PAM (Walz, Effeltrich, Deutschland) konnte gezeigt werden, dass bei heterogen im Pflanzengewebe auftretenden Pathogenen Beeinträchtigungen der Photosynthese lokal beschränkt sein können (Berger et al. 2004, Berger et al. 2007). Da auch V. longisporum als vaskuläres Pathogen in der biotrophen Phase seines Lebenszyklus nur auf einen bestimmten Teil innerhalb der Pflanze begrenzt vorkommt, wurden die Messungen der Chlorophyllfluoreszenz mit einem IMAGINGPAM wiederholt. Dazu wurden infizierte und nicht infizierte, im Kurztag angezogene Arabidopsis-Pflanzen wöchentlich gemessen. Hierbei wurde an 5 Pflanzen die Chlorophyllfluoreszenz zunächst nach Dunkeladaption detektiert. Anschließend wurde die Lichtintensität stufenweise über 20, 50, 100 und 500 bis $1000 \mu \mathrm{mol} \mathrm{m} \mathrm{m}^{-2} \mathrm{~s}^{-1}$ erhöht und die Messung wiederholt.

Die maximale Quantenausbeute im Dunkeln war ab 14 dpi bei infizierten Pflanze geringer als bei nicht infizierten Pflanzen (Abb. 42). Bei einer Lichtzufuhr von $20 \mu \mathrm{mol} \mathrm{m} \mathrm{m}^{-2} \mathrm{~s}^{-1}$ konnte dagegen bei den Kontrollpflanzen bei allen Zeitpunkten eine signifikant geringere Quantenausbeute gegenüber infizierten Pflanzen detektiert werden. Bei Erhöhung der Lichtzufuhr war wiederum die Quantenausbeute der infizierten Pflanze ab 14 dpi tendenziell geringer als die der Kontrollen. Bei einer Lichtintensität von $500 \mu \mathrm{mol} \mathrm{m} \mathrm{m}^{-2} \mathrm{~s}^{-1}$ war diese Verringerung signifikant.

Bei Betrachtung der Verteilung der Quantenausbeute anhand von Falschfarbenbildern (Abb. 43) werden keine weiteren Unterschiede aufgrund von dem putativ heterogenen Auftreten von $V$. longisporum innerhalb der Blattrosette erkennbar. 

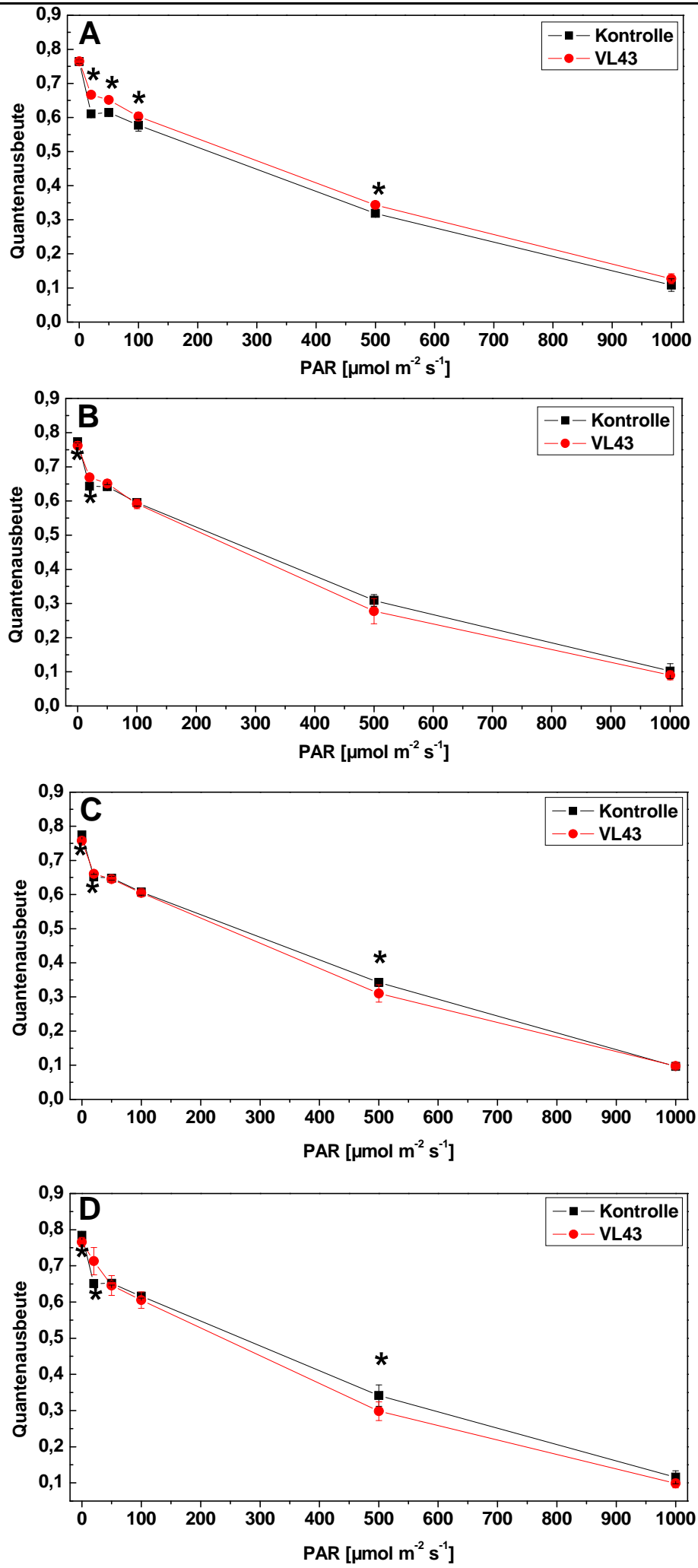

Abb. 42: Quantenausbeute von infizierten (rote Symbole) und nicht infizierten Pflanzen (schwarze Symbole) 7 dpi (A), 14 dpi (B), 21 dpi (C) und 28 dpi (D). Aufgetragen sind Mittelwerte mit Standardabweichung der Quantenausbeute $(n=5)$ in Abhängigkeit der Lichtintensität. Signifikante Unterschiede $(p \leq 0,05)$ zwischen den unterschiedlich behandelten Pflanzen sind durch Sterne gekennzeichnet. 

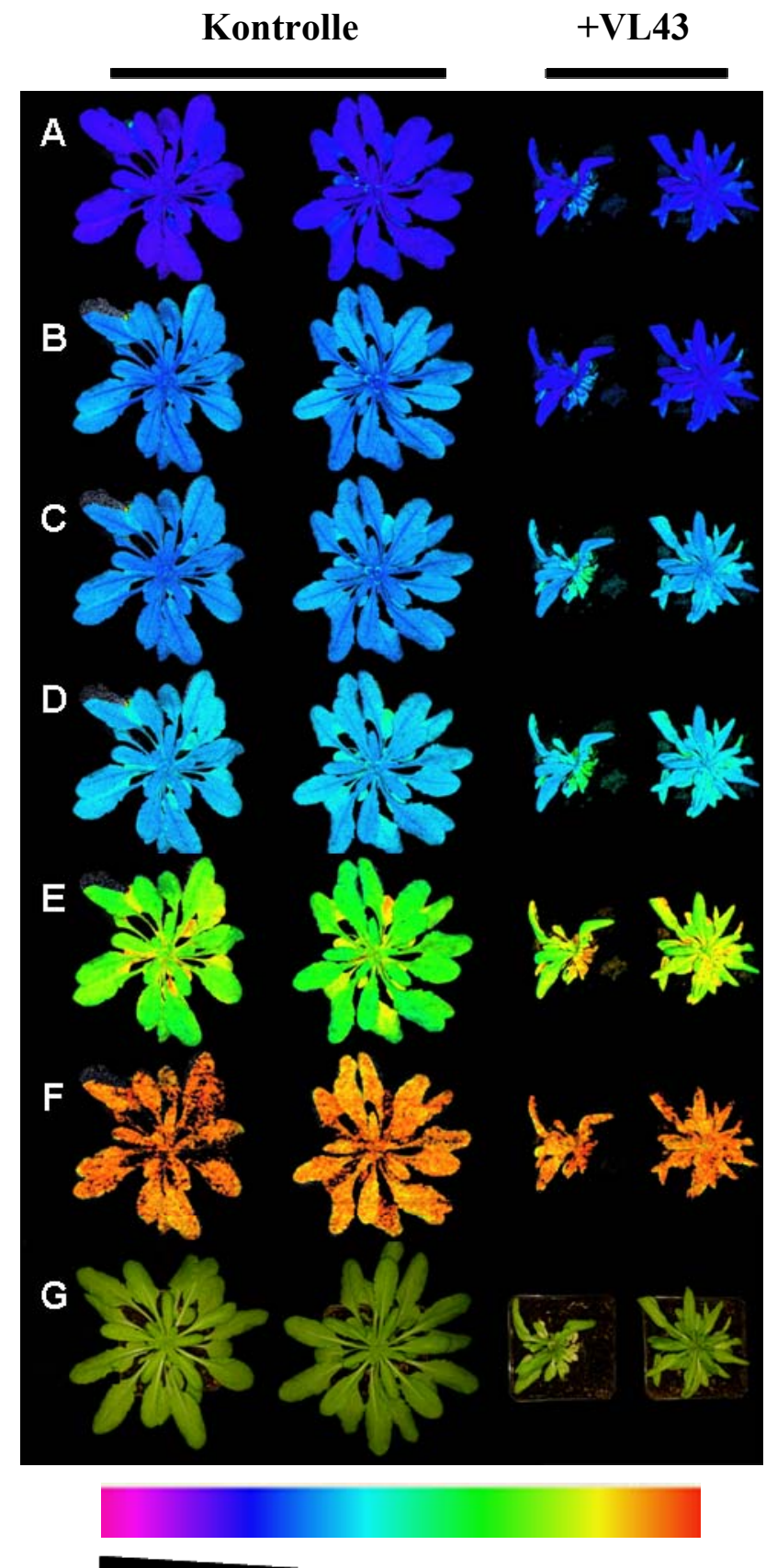

Abnehmende Quantenausbeute

Abb. 43: Messung der Quantenausbeute an infizierten ( + VL 43, rechts) und nicht infizierten Pflanzen (Kontrollen, links) 28 dpi. Abgebildet sind Falschfarbenbilder zur Darstellung der Quantenausbeute nach Dunkeladaption (A), bei Lichtintensitäten von 20 $\mu \mathrm{mol} \mathrm{m} \mathrm{s}^{-1}$ (B), $50 \mu \mathrm{mol} \mathrm{m} \mathrm{s}^{-1}$ (C), $100 \mu \mathrm{mol} \mathrm{m}^{-2} \mathrm{~s}^{-1}$ (D), $500 \mu \mathrm{mol} \mathrm{m} \mathrm{s}^{-1}$ (E) und 1000 $\mu \mathrm{mol} \mathrm{m}^{-2} \mathrm{~s}^{-1}$ (F) sowie Fotos der verwendeten Pflanzen (G). Gezeigt werden 2 repräsentative Pflanzen jeder Behandlung. 
Anhang B: Zusätzliche Bilder der GUS-Reporterpflanzen, Linie 3
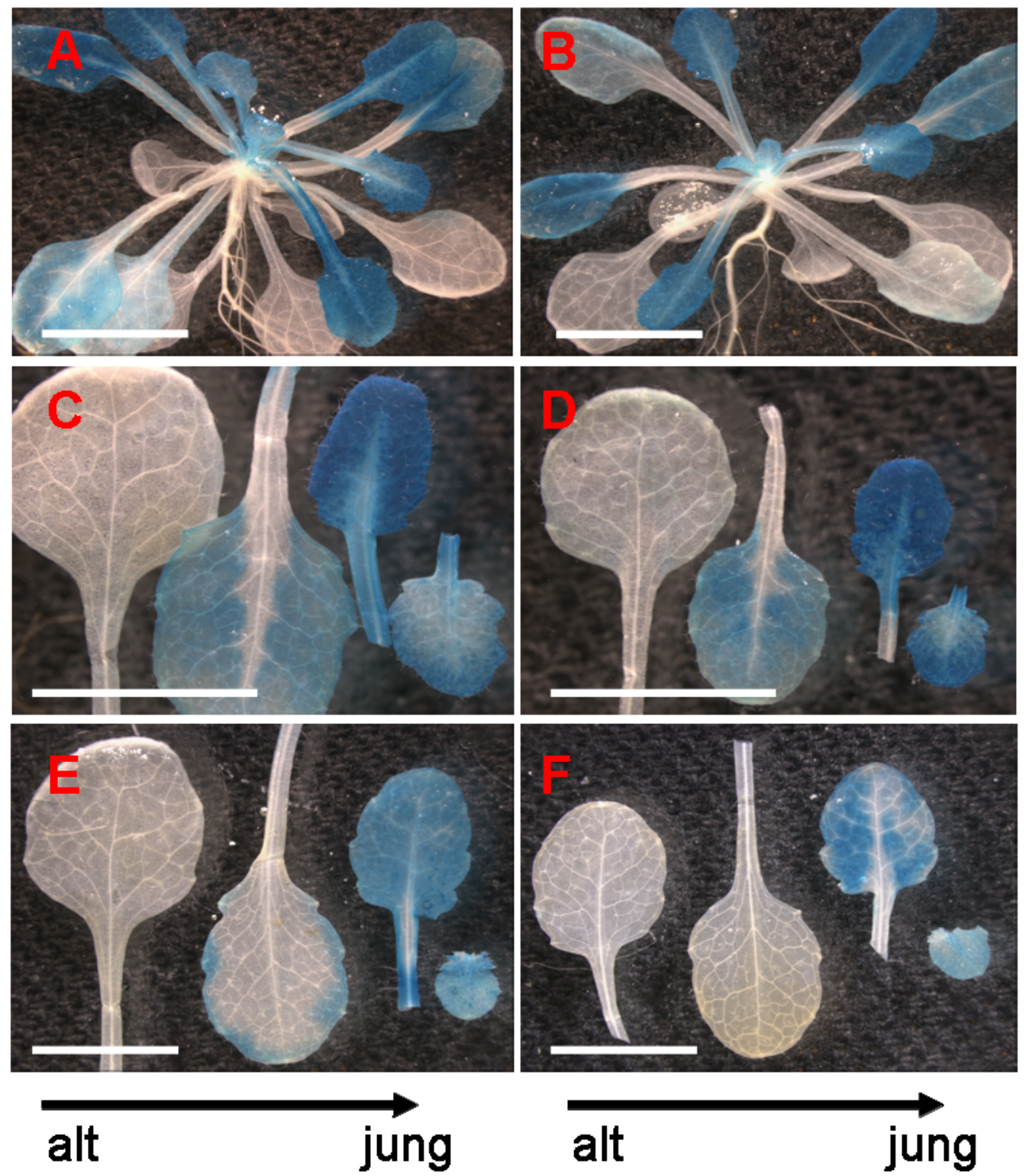

alt

jung

Abb. 44: Nachweis der B-Glucuronidase-Aktivität in vegetativen Pflanzenteilen zur Analyse der Expression von glp3 in mock inokulierten ( $A, C$ und $E$ ) und infizierten Pflanzen (B, D und F). Abgebildet sind Fotos repräsentativer junger Pflanzen der Linie 31 dpi (A und B) und detaillierte Aufnahmen von Blättern verschiedener Entwicklungsstadien 3 dpi (C und D; links: jeweils eines der ältesten Blätter, rechts: jüngstes Blatt) und 7 dpi (E und F) nach 3stündiger Inkubation in der Färbelösung. Der Längenstandard entspricht 0,5 cm. 


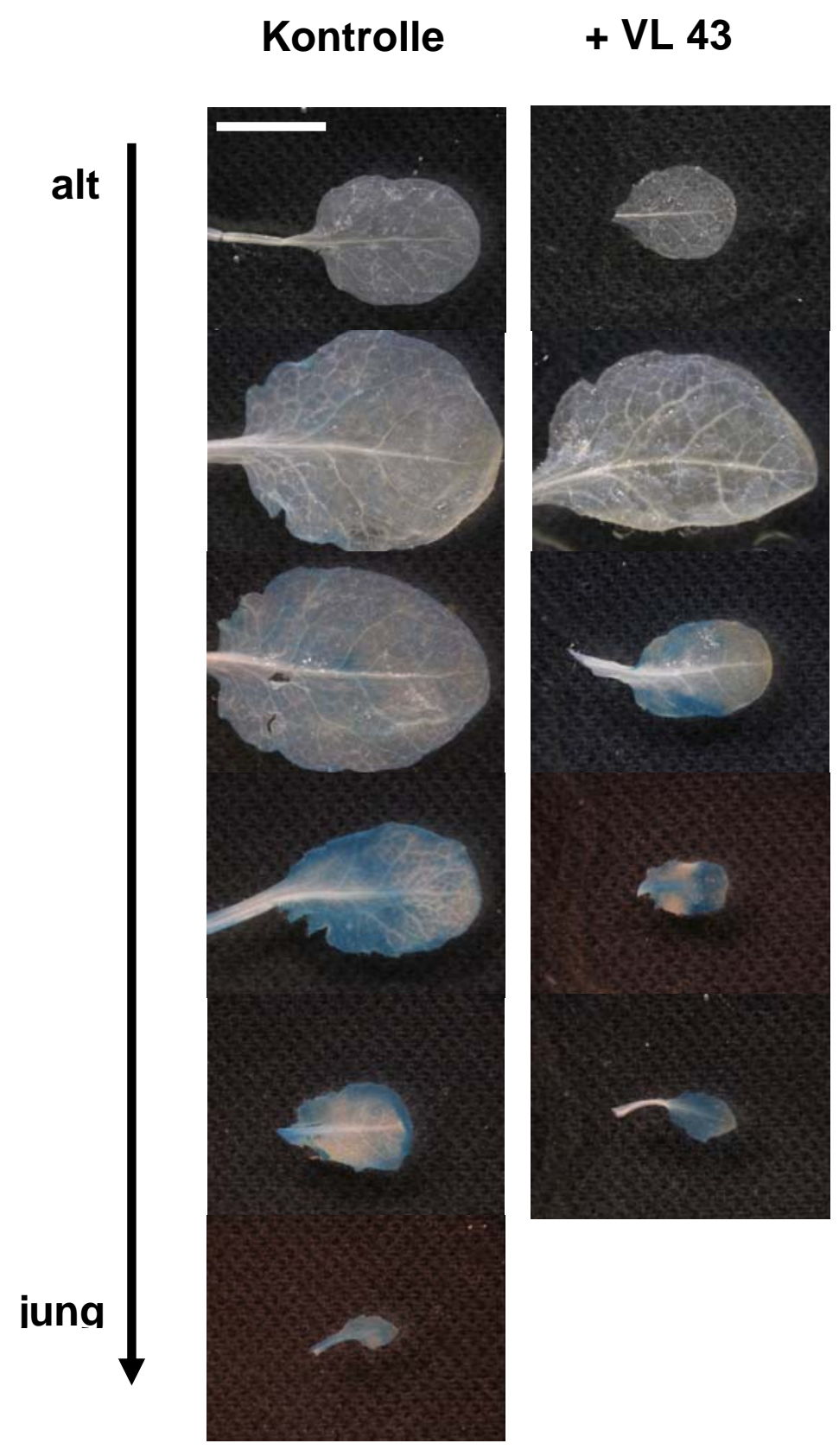

Abb. 45: Nachweis der B-Glucuronidase-Aktivität 21 dpi. Abgebildet sind Blätter repräsentativer Pflanzen der Linie 3 nach Infektion mit $V$. longisporum (rechts) und in uninfizierten Kontrollen (links) nach 3stündiger Inkubation in der Färbelösung. Der Längenstandard entspricht $0,5 \mathrm{~cm}$. 


\section{Anhang C: Querschnitte der VND7-Repressorlinien}
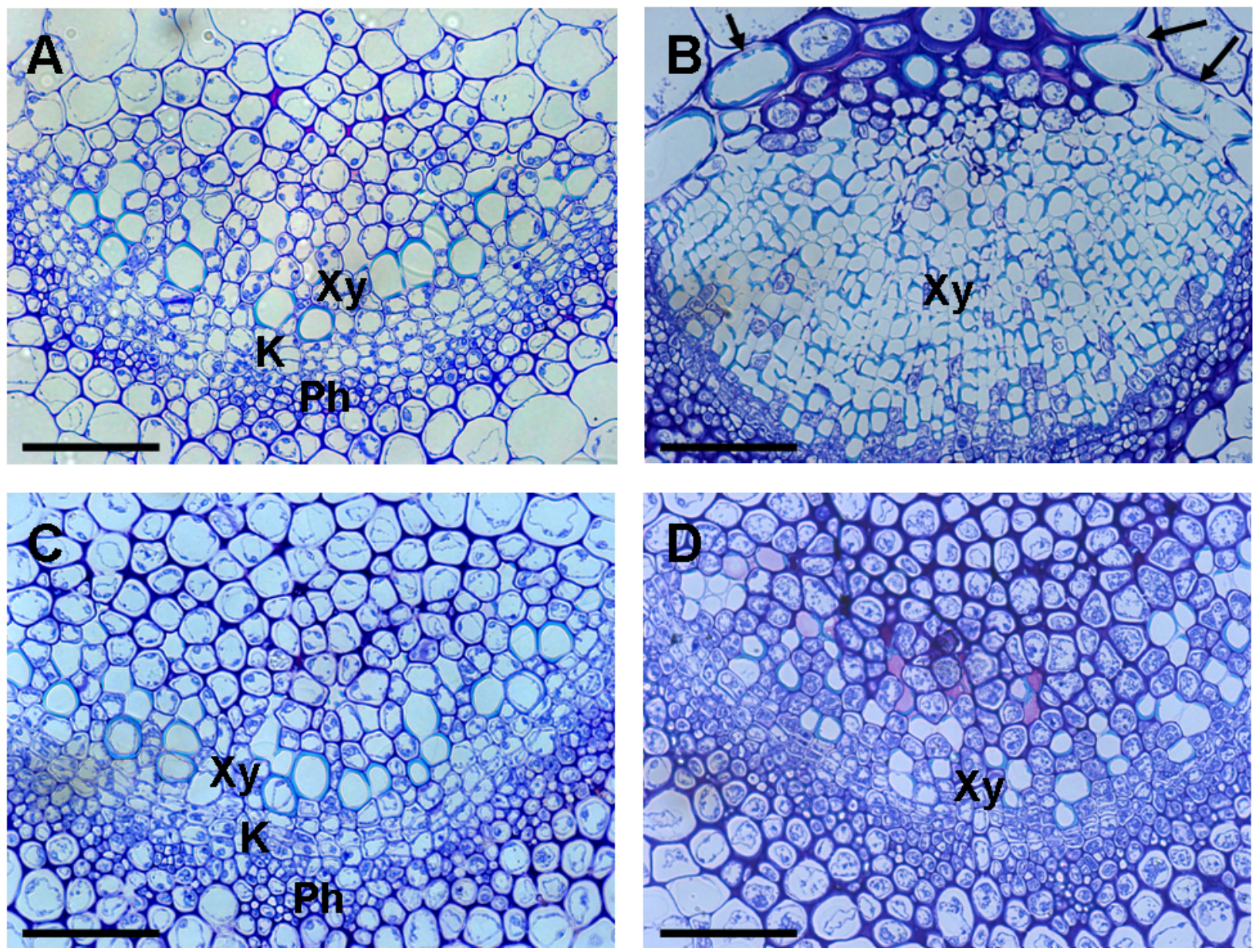

Abb. 46: Leitgewebe von Blättern mock inokulierter (A und $C$ ) und infizierter (B und D) Pflanzen des Wildtyps Col-0 (A und B) sowie der Linie pPer21::VND7-SRDX (C und D) im Querschnitt. Die Proben wurden in Stryrol-Methacrylat eingebettet. Die $1 \mu \mathrm{m}$ dicken Schnitte wurden mit Toluidinblau angefärbt. Lignifizierte Zellwände sind daher türkisblau, während Cytoplasma und unverholzte Primärwände durch eine violette Farbe gekennzeichnet sind. Bei den Bildern der infizierten Pflanzen des Wildtyp (B) sind die putativ transdifferenzierten Zellen zu sehen (Pfeile). In den infizierten Pflanzen der VNDRepressorlinie (D) fehlen diese Zellen. Xy: Xylem, Ph: Phloem, K: Kambiumzone. Die Längenstandards entsprechen $50 \mu \mathrm{m}$. 


\section{Anhang D: Veröffentlichungen im Rahmen dieser Arbeit}

Auf den sich anschließenden Seiten sind folgende Veröffentlichungen zu finden:

Floerl S., Druebert C., Majcherczyk A., Karlovsky P., Kües U., Polle A. (2008): Defence reactions in the apoplastic proteome of oilseed rape (Brassica napus var. napus) attenuate Verticillium longisporum growth but not disease symptoms. BMC Plant Biology 8: 129.

Floerl S., Druebert C., Aroud H.I, Karlovsky P., Polle A. (2010): Disease symptoms and mineral nutrition in Arabidopsis thaliana in response to Verticillium longisporum VL43 infection. Journal of Plant Pathology 92 (3): 695 - 702. 
Defence reactions in the apoplastic proteome of oilseed rape (Brassica napus var. napus) attenuate Verticillium longisporum growth but not disease symptoms

\author{
Saskia Floerl ${ }^{1}$, Christine Druebert ${ }^{1}$, Andrzej Majcherczyk ${ }^{2}$, Petr Karlovsky ${ }^{3}$, \\ Ursula Kües ${ }^{2}$ and Andrea Polle*1
}

\author{
Address: 'Büsgen-Institut, Abteilung: Forstbotanik and Baumphysiologie, Büsgenweg 2, 37077 Göttingen, Germany, 2Büsgen-Institut, Abteilung: \\ Molekulare Holzbiotechnologie und technische Mykologie, Büsgenweg 2, 37077 Göttingen, Germany and ${ }^{3}$ Department für \\ Nutzpflanzenwissenschaften, Abteilung: Molekulare Phytopathologie und Mykotoxinforschung, Grisebachstr. 6, 37077 Göttingen, Germany \\ Email: Saskia Floerl - sfloerl@gwdg.de; Christine Druebert - cdruebe@gwdg.de; Andrzej Majcherczyk - amajche@gwdg.de; \\ Petr Karlovsky - pkarlov@gwdg.de; Ursula Kües - ukuees@gwdg.de; Andrea Polle* - apolle@gwdg.de \\ * Corresponding author

\begin{abstract}
Background: Verticillium longisporum is one of the most important pathogens of Brassicaceae that remains strictly in the xylem during most stages of its development. It has been suggested that disease symptoms are associated with clogging of xylem vessels. The aim of our study was to investigate extracellular defence reactions induced by $V$. longisporum in the xylem sap and leaf apoplast of Brassica napus var. napus in relation to the development of disease symptoms, photosynthesis and nutrient status.

Results: V. longisporum (strain VL43) did not overcome the hypocotyl barrier until 3 weeks after infection although the plants showed massive stunting of the stem and mild leaf chlorosis. During this initial infection phase photosynthetic carbon assimilation, transpiration rate and nutrient elements in leaves were not affected in VL43-infected compared to non-infected plants. Proteome analysis of the leaf apoplast revealed 170 spots after 2-D-protein separation, of which 12 were significantly enhanced in response to VL43-infection. LS-MS/MS analysis and data base searches revealed matches of VL43-responsive proteins to an endochitinase, a peroxidase, a PR-4 protein and a $\beta$-I,3-glucanase. In xylem sap three up-regulated proteins were found of which two were identified as PR-4 and $\beta-1,3-$ glucanase. Xylem sap of infected plants inhibited the growth of $V$. longisporum.
\end{abstract}

Conclusion: $V$. longisporum infection did not result in drought stress or nutrient limitations. Stunting and mild chlorosis were, therefore, not consequences of insufficient water and nutrient supply due to VL43-caused xylem obstruction. A distinct array of extracellular PR-proteins was activated that might have limited Verticillium spreading above the hypocotyl. In silico analysis suggested that ethylene was involved in up-regulating VL43-responsive proteins. 


\section{Background}

Verticillium longisporum colonizes the xylem of Brassicacae [1] using carbohydrates, amino acids, and minerals present in the xylem sap as nutrient source. Xylem sap of oilseed rape also contains a vast spectrum of proteins including many enzymes putatively involved in defence; e.g. a disease resistance response protein (PR-1), chitinases (class I, IV), germin-like proteins (subfamily 1 ) and different peroxidases [2]. A comparison of various species suggested that xylem sap composition was conserved across species [3].

Despite the presence of constitutive defence systems in the extracellular compartment, xylem-invading and inhabiting fungi provoke additional reactions. For example, analyses of tomato xylem sap after infection with the xylemcolonising fungus Fusarium oxysporum revealed novel proteins including PR-1, PR-2, and PR-5 [4]. In rice, infection with the vascular pathogen Xanthomonas oryzae induced the accumulation of a basic peroxidase in the apoplast of mesophyll cells as well as in xylem vessels [5]. Vascular pathogens such as Cladosporium fulvum and Septoria tritici affected the leaf apoplast by increasing chitinases and 1,3$\beta$-glucanases or a germin-like protein with activity of a protease-inhibitor, respectively $[6,7]$. However, the example of Cladosporium fulvum, which inactivates chitinases by Avr4 and thereby, protects its cell walls from degradation shows that vascular fungi have developed specific means to disarm plant defences [8]

Recently, proteomic approaches have been introduced to obtain a comprehensive overview of proteins responsive in plants to pathogen attack. The apoplast, which includes the xylem sap, has received specific attention because it is the first compartment where recognition and defence may take place. When plants or cell cultures were challenged with pathogens or elicitors pronounced changes in the extracellular proteome were found such as accumulation of novel protease inhibitors, stimulation of defence proteins, modification in cell proteins, etc. [9-16]. V. longisporum is one of the most important diseases of oilseed rape (Brassica napus var. oleifera) locally causing yield losses in the range of 10 to $50 \%$ [17]. Activation of apoplastic defences has not been characterized in this species, although knowledge on these interactions may help to device strategies for improving plant resistance.

Verticillium-infections have frequently been described as wilting disease [18]. For example, V. dahliae infection resulted in partial vessel occlusion by deposits secreted by neighbouring parenchyma cells [19]. These obstructions may delay movement of the fungus physically and also because they may contain antifungal components, e.g. elemental sulphur [19-21]. Since these obstructions can be expected to affect water and nutrient transport, typical disease symptoms such as wilting, stunting, chlorosis and premature senescence, have been suggested to occur as consequences of water limitations and insufficient nutrient supply [22]. However, clear-cut evidence for this sequence of disease symptoms is still lacking for the $B$. napus - V. longisporum pathosystem. Since nutrient limitations and water stress can also affect the plant defence system, it is necessary to characterize the physiological stage of infected and non-infected to plants to distinguish between responses evoked by changes in the plant conditions and those related to fungal infection.

The major aim of our study was to identify proteins activated in response to $V$. longisporum in the leaf apoplast and xylem sap of Brassica napus and to investigate whether changes in the composition of extracellular fluid were effi cient in attenuating fungal proliferation. We have characterized these responses in relation to the development of disease symptoms, photosynthetic electron transport, gas exchange and nutrient status.

\section{Results}

Verticillium-induced stunting is not caused by decline in photosynthetic gas exchange or plant nutrition

Stunting of the stem became apparent about 14 days afte inoculation of oilseed rape plants with VL43 (Fig. 1). At $21 \mathrm{dpi}$ (days post infection), the infected plants were about two times shorter than non-infected plants and showed initial chlorotic symptoms on leaves but no wilting (Fig. 1A, B). During these initial stages of infection stem biomass production was more inhibited than that of leaves or roots (Fig. 2).

Photosynthetic $\mathrm{CO}_{2}$ assimilation or transpiration were not affected in VL43-infected plants until $21 \mathrm{dpi}$, indicat ing that the plants did not suffer from diminished water transport or stomatal limitations (Fig. 3A, B). However, the maximum quantum yield of PSII of infected plants was lower than that of non-infected plants $(-20 \%)$. This was probably the result of chlorophyll loss, which was about $17 \%$ compared with non-infected plants (Fig. 4A B). Overall, these reductions in chlorophyll and electron transport capacity were apparently too small to affect gross carbon assimilation.

Nutrient elements were measured in leaves between 2 and 4 weeks after VL43 infection to investigate whether VL43 infection had negative effects on nutrition. Potassium, calcium, magnesium, manganese, and iron showed agedependent changes in infected plants, which were not different from those found in non-infected plants (Table 1). The concentrations of the macro-nutrients $\mathrm{N}, \mathrm{P}$, and $\mathrm{S}$ were higher in VL43-infected plants than in controls at 28 dpi (Fig. 5). Overall, these analyses show that VL43 infec- 

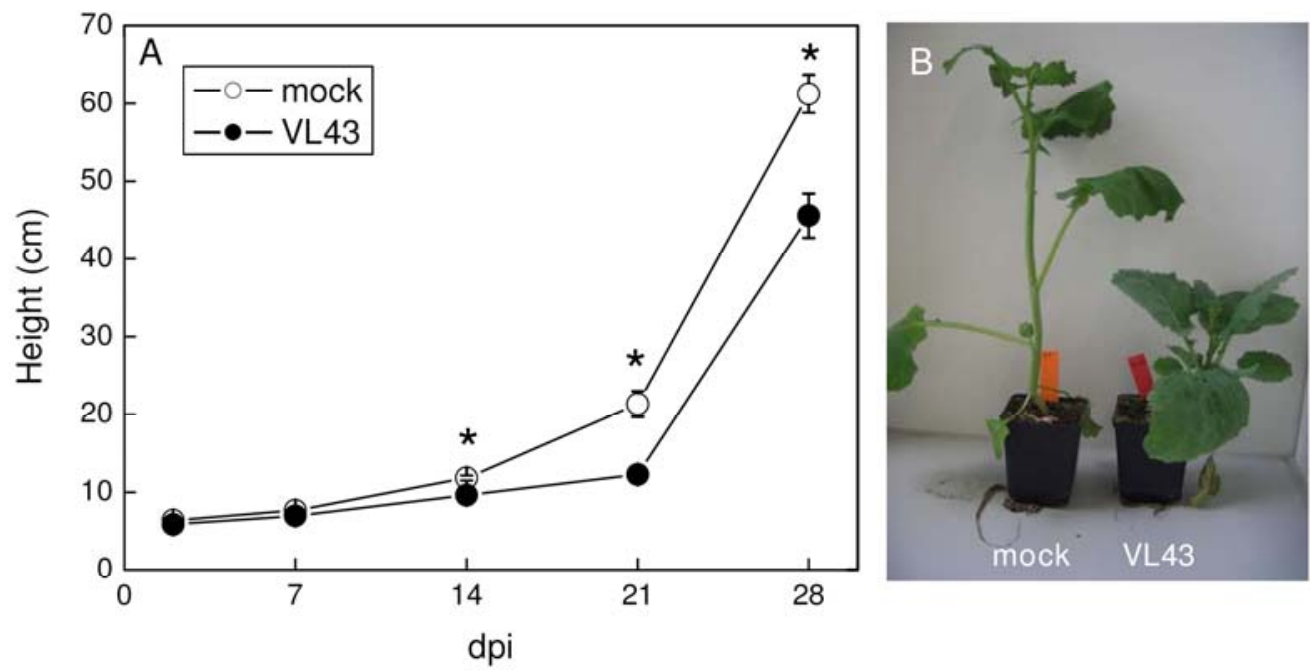

Figure I

Stunting symptoms in oilseed rape (Brassica napus var. napus) after infection with Verticillium longisporum (VL43). (A) Time course. White circles $=$ non-infected plants, black circles = VL43-infected plants. Data indicate means $(n=$ $20 \pm \mathrm{SE}$ ). Occasionally, SE is smaller than the symbols. * indicate significant differences between treated and non-treated plants at $P \leq 0.05$. (B) Typical phenotype of controls and infected plants $21 \mathrm{dpi}$.

tion did not cause nutrient limitations in stages of plant development where severe stunting occurred.

Verticillium-induced defences in xylem sap and apoplast Figure 6 shows SDS-PAGE gradient gels for an overview of changes occurring in the apoplastic washing fluid of leaves and in the xylem sap at $21 \mathrm{dpi}$. At earlier stages similar but less pronounced changes were found (not shown). Five apoplast and 3 xylem proteins were strongly increased compared with non-inoculated controls. These changes were not caused by unspecific effects because at this time point of infection, membranes were not destabilized by fungal action as indicated by low electrolyte leakage that was similar in infected plants to that of noninfected plants (Table 2). Furthermore, the estimated contamination of the apoplast with symplastic proteins was extremely low and not increased in infected plants (Table 2 ). In whole leaf extracts, separated by gradient PAGE, no changes in protein pattern were found, indicating that the influence of VL43 was only subtle (not shown). It is also notable that we have no evidence that at $21 \mathrm{dpi}$ VL43 had overcome the hypocotyl barrier. In stems, Verticillium DNA did not exceed the detection limit of $0.5 \mathrm{ng} \mathrm{g}^{-1}$ fresh mass (Table 2).

To study the observed changes in greater detail, apoplastic washing fluids were subjected to 2-D electrophoresis to obtain better resolution and to analyse changes in the protein patterns statistically. Silver stained gels showed $170 \pm$ 9 protein spots (Fig. 7). We analysed 31 major spots common to both VL43-infected and non-infected plants to check if the apoplastic washing fluid was enriched in typical secretory proteins. Only 19 of these spots yielded peptides. The predicted sequences corresponded mainly to extracellular enzymes involved in defence and cell wall metabolism (Table 3). Several spots that were represented by just one peptide could not be identified unambiguously here $($ spot $10,17,18$ = predicted aspartyl protease spot $11=$ predicted peroxidase, spot $12-15=$ predicted glucanase) but pointed also the presence of typical extracellular enzymes, which have already previously been identified in oilseed rape [2]. With the exception of one protein with unknown function (spot 9) and two spots for a putative $\alpha$-L-arabinofuranosidase (spots 5 and 7), all identified proteins contained a predicted target peptide for the secretory pathway. Whether the two putative $\alpha$-Larabinofuranosidase proteins were in fact mitochondrial proteins as suggested by TargetP analysis, is unlikely because the reliability of the prediction was low (RC4) and the Raphanus sativus enzyme, with which the highest homology existed, was shown to be localized in the cell wall fraction [23]. The protein with unknown functions in B. rapa var. pekinesis ( with a pectin esterase from $A$. thaliana. Since pectin este- 

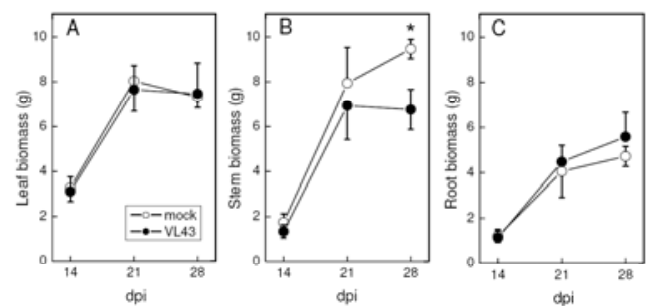

Figure 2

Time course of leaf, stem and root biomass production of oilseed rape (Brassica napus var. napus) after infection with Verticillium longisporum VL43. White cir cles $=$ non-infected plants, black circles $=$ VL43-infected plants. Data indicate means $(n=5 \pm S E)$. * indicate significant differences between treated and non-treated plants at $\mathrm{P} \leq$ 0.05 .

rases are known cell wall and xylem sap components $[2,3]$, the predicted chloroplastic localization is also unlikely. Overall, this supports that the washing fluid was enriched in soluble apoplastic proteins and contained only little unspecific contaminants

The total number of spots identified on silver stained gels was not significantly changed in VL43-infected compared with non-infected plants. However, the intensity of 12 spots was significantly increased in the apoplast of VL-43 challenged plants compared with non-infected controls,

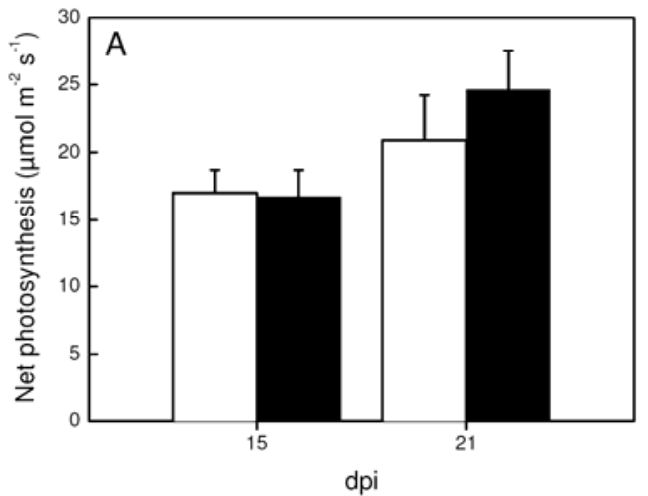

Figure 3

Net photosynthesis (A) and transpiration (B) of oilseed rape (Brassica napus var. napus) 15 and 21 dpi after infection with Verticillium longisporum VL43. White bars $=$ non-infected plants, black bars $=$ VL43-infected plants. Data indicate means ( $n=8 \pm S E$ ). Significant differences were not observed.

whereas no spots with decreased staining intensities were found. Of the 12 spots, 6 could be identified by LC-MS/ MS (Table 4) and corresponded to three different proteins, i.e., a basic $\beta$-1,3-glucanase ( 3 spots), a basic endochitinase CHB4 ( 2 spots) and a peroxidase. The factor by which the intensities increased ranged from 2.4 to 8.3 (Table 4). All proteins contained a predicted signal peptide for the secretory pathway supporting their apoplastic localisation (Table 4). To corroborate these results, differentially appearing spots from PAGE gels shown in Figure 6 were also identified. AVL1 was the basic glucanase corresponding to spots no. 21-23, AVL2 the basic endochitinase CHB4 corresponding to spots no. 34 and 51 and AVL9 the putative peroxidase corresponding to spot no. 54 in the 2-D gels (Fig. 7). AVL 5 was not identified. AVL 7 was a new protein identified as a PR4-type protein (Brassica rapa subsp. pekinensis, gi|73671284, accession number AF528181, protein score 108), which also contained a predicted signal peptide for the secretory pathway. Since the MW of the PR4-type protein was below 20 $\mathrm{kD}$, it was not resolved on the 2-D gels.

PAGE was also used to investigate the differentially appearing xylem sap proteins (Figure 6, Table 5). Among the three up-regulated protein bands, basic glucanase (XVL1) and PR4-type protein (XVL 3) were identified. XVL2 was not identified. However, its MW corresponded to that of AVL2, the endochitinase CHB4.

To find out whether the changes in the composition of the xylem were competent in attenuating VL43 growth, we



dpi 

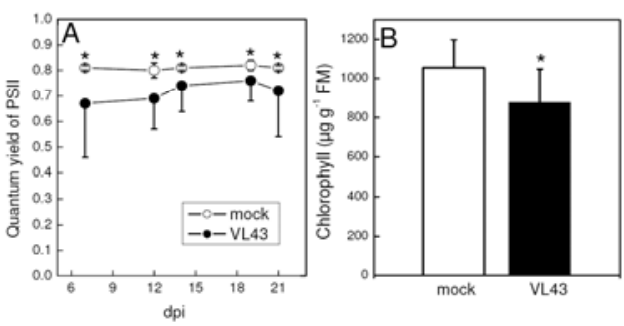

Figure 4

Quantum yield of photosynthesis (A) and chlorophyl concentration (B) of oilseed rape (Brassica napus var. napus) after infection with Verticillium longisporum

VL43. White symbols = non-infected plants, black symbols = VL43-infected plants. Data indicate means $(n=20$ for quantum yield of PSII and $n=9$ for chlorophyll, \pm SE). * indicate significant differences between treated and non-treated plants at $P \leq 0.05$.

isolated xylem sap from infected and non-infected oilseed rape and grew VL43 in pure xylem sap. Figure 8A shows that fungal growth was significantly inhibited in xylem sap of infected compared to that of non-infected plants, whereas the protein concentration was unaffected (Fig. $8 B)$.

\section{Discussion}

Stunting and defence responses are not caused by suppression of carbon assimilation or injury to nutrient or water supply

Stunting occurred before V. longisporum colonized aboveground plant parts as reported previously [1]. Our study clearly shows that neither these growth reductions nor beginning symptoms of chlorosis were the result of nutrient limitations or suppression of carbon assimilation. We have also no evidence that $V$. longisporum caused drought stress since the transpiration rate was unaffected in infected plants. This is in contrast to $V$. dahliae infections, which resulted in reduced stomatal opening in species like tomato, potato and egg plants and caused wilting symptoms [24-26]. Eynck et al. [1] observed that clogging of vessels after VL43 infection of oilseed rape occurred infrequently and only at late stages of infection. They assumed, therefore, that these rare obstructions would not affect gross water transport. Our data corroborate this idea.

Although the effect on carbon assimilation was either marginal or not present, both Verticillium pathogens caused chlorosis [this study, $[22,27,28]]$. Since chlorosis preceded fungal proliferation in leaves, it might have been caused by Verticillium toxins as suggested earlier [18]. However, chlorophyll loss is also a common symptom of nutrient deficiencies. Our study excludes the latter reason for $V$. longisporum infected oilseed rape. VL43 had also no effect on nutrient concentrations in Arabidopsis thaliana leaves at early stages of stunting [28]. Previous investigations with horticultural crops infected with $V$. dahliae neither revealed nutrient deficiencies [29-31]. Therefore, we conclude that chlorosis is not the consequence of insufficient nutrient supply to leaves. Notably, in our study the amounts of nutrient elements nitrogen, phosphorus and sulphur were higher in older leaves of VL43-infected oilseed rape than in those of non-infected controls. Increased phosphorus or nitrogen concentrations have also been reported in $V$. dahliae infected tomato, eggplant and in VL43-infected Arabidopsis [28,31] suggesting a yet unknown interference of Verticillium with $\mathrm{P}$ or $\mathrm{N}$ metabolism.

Vital functions related to nutrition, water supply and photosynthetic carbon assimilation were not compromised at least not during infection stages when Verticillium was still retained in the root system. Therefore, we presume that the observed up-regulation of defence proteins must have been a pathogen-specific effect rather than an unspecific general stress response.

The extracellular proteome and its role in defence against Verticillium longisporum

A previous proteomic study of oilseed rape xylem proteins revealed about 300 spots; 69 of these yielded peptide sequences and were putatively identified by matches with database entries as enzymes related to defence and cell wall re-modelling including, e.g., peroxidases, proteases, chitinases, $\beta$-1,3-glucanases, germin-like proteins, PR1 protein, thaumatin-like protein, lectins, glycine-rich proteins, polygalacturonases, etc. [2]. We detected 170 protein spots in the apoplastic proteome of rape leaves. Since the focus of our work was on $V$. longisporum-responsive proteins, we analyzed only some of the unregulated proteins to document that apoplastic washing fluids were enriched in proteins with a signal peptide for the secretion pathway (Table 3). Among the identified proteins we confirmed the presence of chitinases, peroxidases, proteases, glucanases, germins, and some proteins involved in cell wall modifications in the leaf apoplast of healthy oilseed rape. A similar composition has also been reported for the apoplast and some cell wall-associated proteins of Arabidopsis [32-34]. But some of the proteins present in leaf apoplast of oilseed rape or belonging to secreted proteins of Arabidopisis [this study, [28,35]] were not found in xylem saps $[2,3]$. Among them were $\alpha$-arabinofuranosidases that are members of a set of glycosidases required for degradation of polymeric substrates such as arabinan, arabinoxylan, and other polysaccharides, which are major components of plant cell wall hemicelluloses [36]. These enzymes provide many microorganisms with soluble car- 

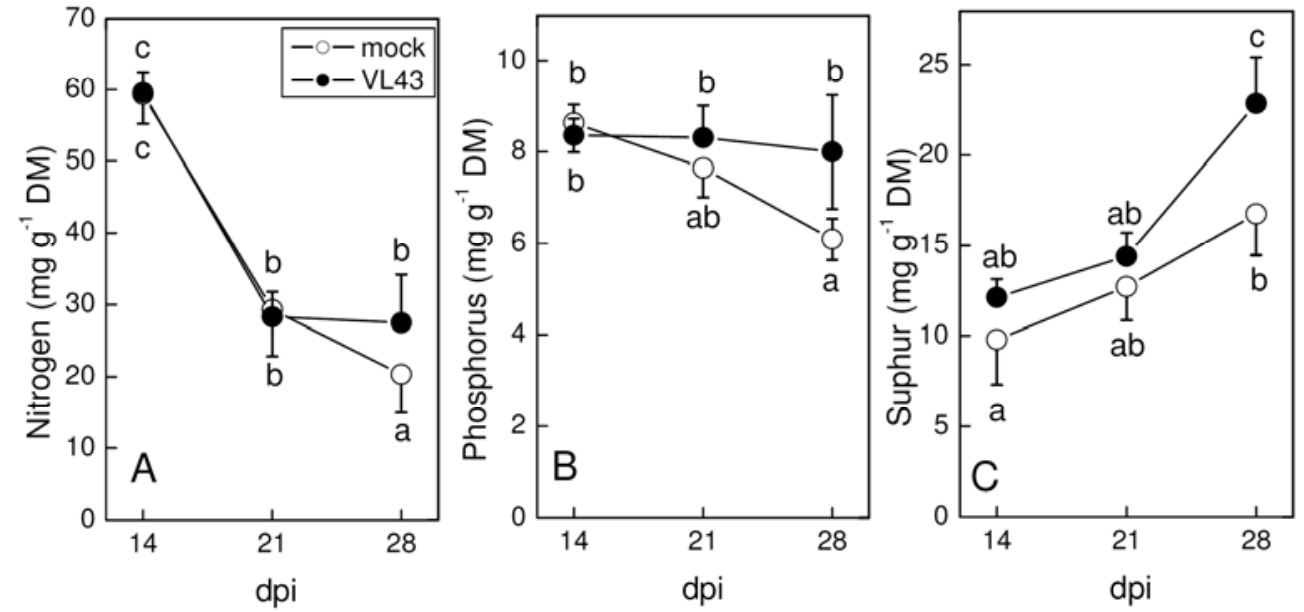

Figure 5

Nitrogen, phosphorus and sulphur concentrations in leaves of oilseed rape (Brassica napus var. napus) after infection with Verticillium longisporum VL43. White circles $=$ non-infected plants, black circles $=$ VL43-infected plants. Data indicate means $(n=5 \pm S E)$. Different letters indicate significant differences at $P \leq 0.05$.

bohydrates that can be used as carbon or energy sources [36]. Our study shows that these enzymes are part of the healthy apoplast and do not belong to the suite of primary responses to $V$. longisporum infection.

Table I: Nutrient elements in leaves of oilseed rape (Brassica napus var. napus) after infection with Verticillium longisporum VL43.

\begin{tabular}{llll}
\hline Element & dpi & Control & VL43 \\
\hline $\mathrm{K}\left(\mathrm{mg} \mathrm{g}^{-1}\right)$ & 14 & $46.5 \pm 3.7 \mathrm{~b}$ & $50.5 \pm 1.3 \mathrm{~b}$ \\
& 21 & $29.1 \pm 5.6 \mathrm{a}$ & $31.0 \pm 3.8 \mathrm{a}$ \\
$\mathrm{Ca}\left(\mathrm{mg} \mathrm{g}^{-1}\right)$ & 28 & $25.7 \pm 2.6 \mathrm{a}$ & $31.4 \pm 6.1 \mathrm{a}$ \\
& 14 & $30.0 \pm 2.4 \mathrm{a}$ & $27.5 \pm 2.3 \mathrm{a}$ \\
& 21 & $25.1 \pm 2.9 \mathrm{a}$ & $29.5 \pm 2.9 \mathrm{a}$ \\
$\mathrm{Mg}\left(\mathrm{mg} \mathrm{g}^{-1}\right)$ & 28 & $30.5 \pm 4.4 \mathrm{a}$ & $29.3 \pm 5.3 \mathrm{a}$ \\
& 14 & $4.1 \pm 0.2 \mathrm{c}$ & $4.2 \pm 0.2 \mathrm{bc}$ \\
$\mathrm{Mn}\left(\mu \mathrm{gg}^{-1}\right)$ & 21 & $3.1 \pm 0.4 \mathrm{a}$ & $3.3 \pm 0.3 \mathrm{ab}$ \\
& 28 & $3.2 \pm 0.5 \mathrm{a}$ & $3.4 \pm 0.5 \mathrm{abc}$ \\
& 14 & $57 \pm 7 \mathrm{a}$ & $62 \pm 8 \mathrm{a}$ \\
$\mathrm{Fe}\left(\mu \mathrm{gg} \mathrm{g}^{-1}\right)$ & 21 & $49 \pm 6 \mathrm{a}$ & $63 \pm 13 \mathrm{a}$ \\
& 14 & $62 \pm 7 \mathrm{a}$ & $48 \pm 6 \mathrm{a}$ \\
& 21 & $67 \pm 11 \mathrm{ab}$ & $105 \pm 15 \mathrm{~b}$ \\
& 28 & $72 \pm 9 \mathrm{ab}$ & $98 \pm 17 \mathrm{ab}$ \\
& & & $73 \pm 13 \mathrm{ab}$
\end{tabular}

Data indicate means $(n=5 \pm S E$ ). Different letters in blocks indicate significant differences at $\mathrm{P} \leq 0.05$.
Our proteomic analysis revealed that only $7 \%$ apoplastic proteins were differentially regulated in response to VL43 suggesting that Verticillium evoked very distinct responses. All identified VL43-induced apoplastic proteins ( $\beta-1,3$ glucanase, peroxidase, PR4-protein and endochitinase) are candidates already known to be involved in pathogen defence. For example, $\beta$-1,3-glucanases belong to the PR2 protein family and hydrolyse $\beta$-1,3-glucans, major structural compounds of fungal cell walls [37]. Rep et al. [4] have also found a basic and an acidic glucanase in the xylem sap of tomato after infection with the vascular fungus Fusarium oxysporum. Infections with $V$. dahliae caused increased expression and activities of glucanases and chitinases $[38,39]$. The PR4 protein identified here was homolog to that of a Pseudomonas syringae inducible PR4 protein of Brassica rapa $[40,41]$. The expression of this gene was induced in $B$. rapa by ethylene but not by salicylic acid or methyl jasmonate $[40,42]$. In A. thaliana, expression of an ethylene-dependent PR4 protein was also increased after V. longisporum infection [22]. Since Arabidopsis mutants deficient in ethylene signalling (ein 2, ein 4 , ein6) were more susceptible to $V$. longisporum, ethyleneassociated signalling pathway appear to be involved in mediating Verticillium resistance [22]. Indeed, Genevestigator analysis showed that the Arabidopsis homologues of the endochitinase (At2g43590) and $\beta$-1,3-glucanase (Atg57240) identified in our study were significantly 

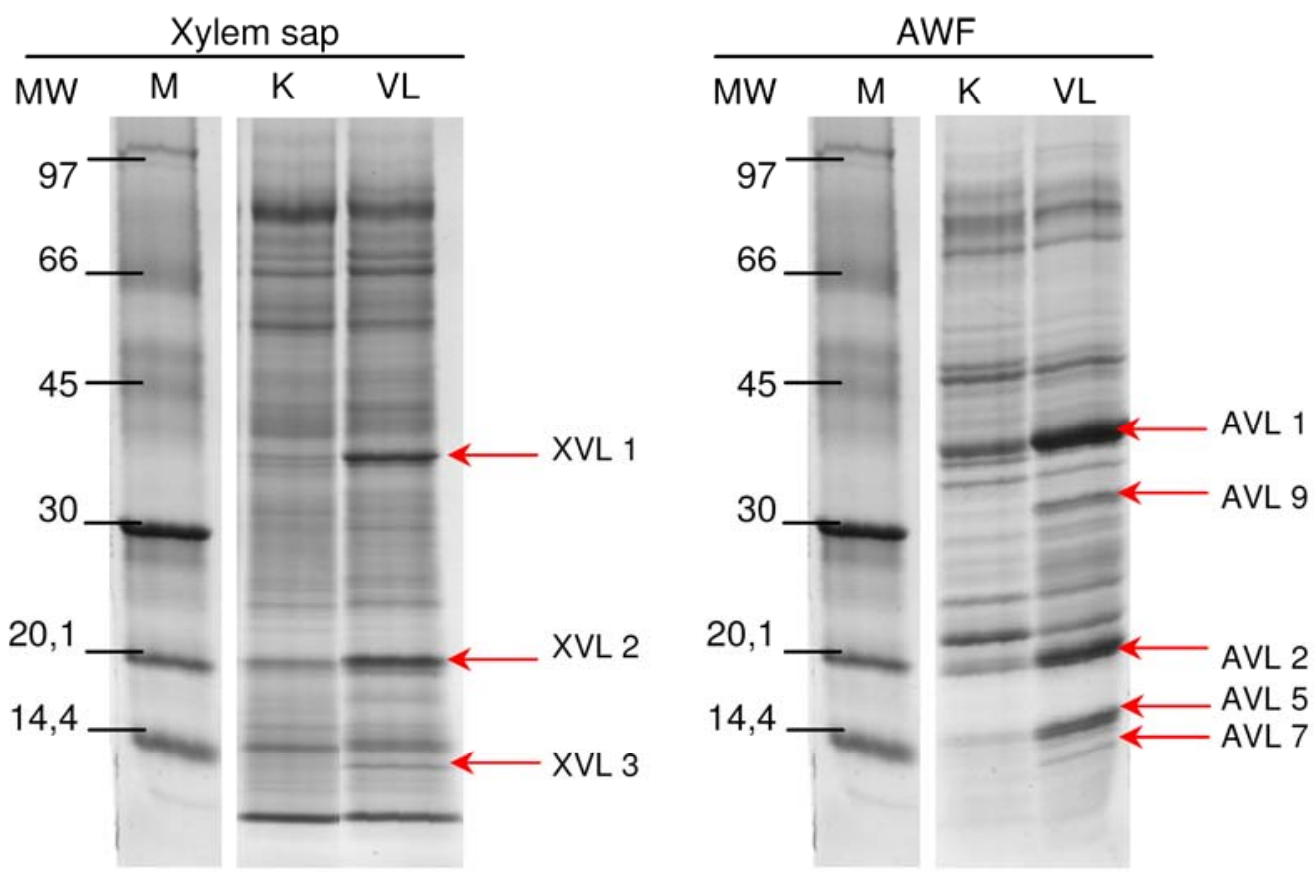

Figure 6

Protein patterns in leaf apoplastic washing fluids and in the xylem sap of oilseed rape (Brassica napus var. napus) of non-infected plants and 21 dpi after infection with Verticillium longisporum VL43. Each lane was loaded with $100 \mu \mathrm{g}$ protein. Proteins were separated by gradient SDS-PAGE and stained with Coomassie Blue.

increased after ethylene exposure. In other plant species, chitinases and glucanases were also induced by ethylene [43-45]. In summary, this suggests that ethylene plays a yet unresolved role in $V$. longisporum responses of oilseed rape.
Overall, current studies suggest that the PR-response to $\mathrm{V}$. longisporum is relatively conserved across different Brassicaceae [this study, $[22,28]]$. Some of these proteins (PR4, $\beta$-1,3-glucanase) appeared in xylem sap even before fungal infection had overcome the hypocotyl barrier. Moreo-

Table 2: Electrolyte leakage, fungal DNA, protein content and estimated contamination of apoplastic washing fluids of in leaves of oilseed rape (Brassica napus var. napus) after infection with Verticillium longisporum VL43.

\begin{tabular}{lccc}
\hline & mock & VL43 & P-Value \\
\hline Electrolyte leakage (\%) & $7.4 \pm 0.6$ & $9.8 \pm 1.4$ & 0.1545 \\
VL43-DNA (ng g- FM) & $<$ LOD & $<$ LOD* & \\
Leaf protein (mg g- FM) & $13.7 \pm 2.1$ & $13.2 \pm 1.6$ & 0.8491 \\
Apoplastic protein $\left(\mu g^{-1}\right.$ FM) & $13 \pm 1$ & $17 \pm 2$ & 0.1142 \\
Leaf MDH activity (nkat g- gM $^{-1}$ & $417.1 \pm 31.7$ & $444.4 \pm 17.9$ & 0.4742 \\
Apoplastic MDH (nkat g-1 FM) & $0.015 \pm 0.003$ & $0.038 \pm 0.022$ & 0.3439 \\
Contamination (\%) & $0.004 \pm 0.001$ & $0.008 \pm 0.005$ & 0.3940
\end{tabular}

Data indicate means $(n=5, \pm S E)$, "Limit of detection (LOD) was $0.5 \mathrm{ng} \mathrm{g} \mathrm{g}^{-1} \mathrm{FM}$ 
mock

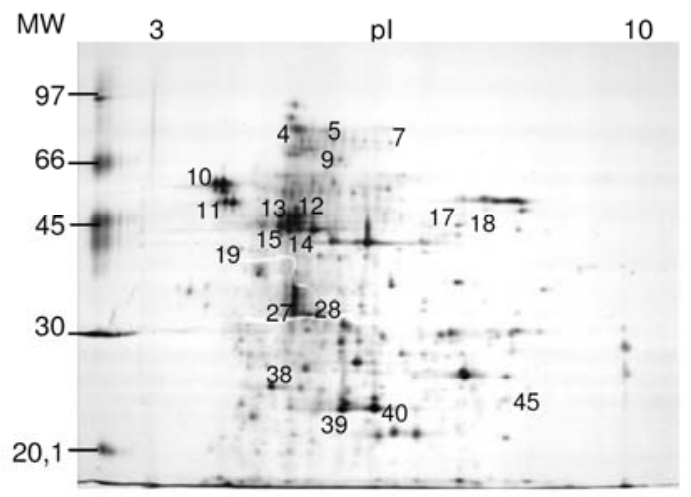

VL43

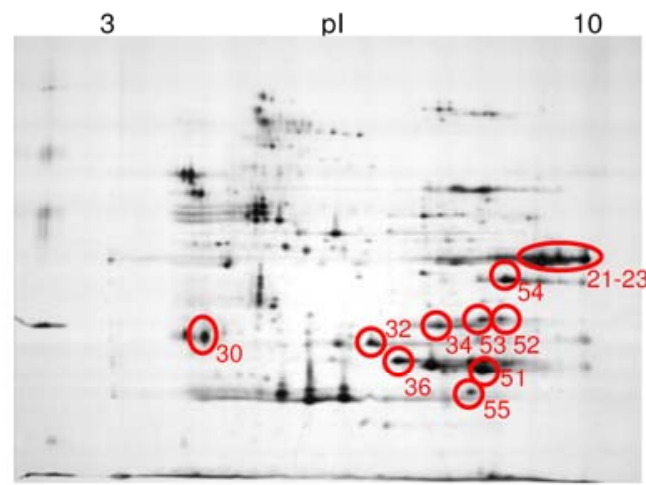

Figure 7

2-D-protein pattern in leaf apoplastic washing fluids of oilseed rape (Brassica napus var. napus) of non-infected plants and at 21 dpi after infection with Verticillium longisporum VL43. Each gel was loaded with $80 \mu \mathrm{g}$ protein and stained with silver. Circles indicate differentially appearing protein spots. Numbers indicate proteins for which peptides were obtained.

ver, fungal growth in xylem sap of infected plants was massively inhibited (Fig. 8). Therefore, we suggest that xylem sap proteins may play a crucial role in the control of $V$. longisporum. Since xylem elements consist of dead tissue, the sap proteins must either have been produced in roots or in parenchyma cells in the xylem such as ray cells. Further studies must show whether the biosynthesis of these proteins is stimulated in roots, how they are loaded into the xylem and whether they serve to retain the fungus underground.

Since the VL43-responsive proteins of xylem sap were also increased in the leaf apoplast, it is possible that they were transported with the ascent of sap into the leaf mesophyll, where they might have accumulated. However, the leaf apoplast of infected plants contained additional novel proteins (a peroxidase, an endochitinase and unidentified proteins) compared with the xylem sap. We suspect that the endochitinase found in leaf apoplast also originated from xylem sap because a protein with identical molecular weight was present in the latter. The increases in additional novel defence proteins in the leaf apoplast occurred before significant fungal proliferation in above-ground plant parts was apparent. This suggests that systemic signalling took place. It is currently unknown whether $V$. longisporum produced such signalling compounds, which might have been transported with the xylem sap. We can not exclude that the new xylem sap proteins themselves might have exerted signalling functions or that glucanase activities released elicitors from fungal cell walls which might have stimulated defence reactions in the leaf. This will require further analysis.

\section{Conclusion}

In conclusion our data show that $V$. longisporum-induced stunting of oilseed rape was not caused by nutrient limitations, reduced water supply or suppression of photosynthesis. Although $V$. longisporum had not yet overcome the hypocotyl barrier, proteomic analysis of the leaf apoplast revealed activation of pathogen defence enzymes ( $\beta-1,3-$ glucanase, peroxidase, PR4, and endochitinase). This suggests systemic signalling of $V$. longisporum infection. A subset of the defence enzymes identified in leaf apoplast was also increased in xylem sap. Since orthologs of these enzymes in other plant species were regulated by ethylene, this phytohormone appears also to be involved in mediating $V$. longisporum responses in oilseed rape. The xylem sap of infected plants suppressed fungal proliferation compared with that of non infected plants suggesting that the activation of apoplastic defences contributes to limit fungal spreading

\section{Methods}

Plant growth conditions and infection with Verticillium longisporum

Brassica napus var. napus (rapid-cycling rape provided by PH Williams, University of Wisconsin-Madison, Crucifer Genetics Cooperative) seeds were surface-sterilized for 15 min in a solution of 5\% Ca hypochloride and $0.02 \%$ Triton $\mathrm{X}-100$, washed in sterilized water, sown on root- 
Table 3: Major proteins in apoplastic washing fluids of leaves of oilseed rape (Brassica napus var. napus).

\begin{tabular}{|c|c|c|c|c|c|}
\hline Spot No & Similarity (Organism) Peptide & NCBI no. (ACC) & Protein score (Threshold) & MW & Target peptide \\
\hline 4 & $\begin{array}{l}\alpha \text {-L-arabinofuranosidase (Ath) } \\
\text { YVAIGNEDCGK } \\
\text { AFVSEYAVTGK }\end{array}$ & $\begin{array}{l}\text { gi| } 13937191 \\
\text { (At3g10740) }\end{array}$ & $113(56)$ & 75437 & $S(R C 2)$ \\
\hline 5 & $\begin{array}{l}\alpha \text {-L-arabinofuranosidase (Rs) } \\
\text { GQETPGEDPLLSSK }\end{array}$ & $\begin{array}{l}\text { gi|74355968 } \\
\text { (BAE44362) }\end{array}$ & 76 & 84750 & $M(R C 4)$ \\
\hline 7 & $\begin{array}{l}\alpha \text {-L-arabinofuranosidase (Rs) } \\
\text { GQETPGEDPLLSSK } \\
\text { LPMTWYPQSYVEK }\end{array}$ & $\begin{array}{l}\text { gi|74355968 } \\
\text { (BAE44362) }\end{array}$ & $195(56)$ & 84750 & $M(R C 4)$ \\
\hline 9 & $\begin{array}{l}\text { HP (pectin esterase) (Br) } \\
\text { TVQDAVNAAPDNNGVSK } \\
\text { ISEGVYEETVR } \\
\text { DITFQNTAGPDAHQAVAFR }\end{array}$ & $\begin{array}{l}\text { gi|72384433 } \\
\text { (homolog of At5g09770) }\end{array}$ & $84(56)$ & 60345 & $C(R C I)$ \\
\hline 27 & $\begin{array}{l}\text { Chitinase (Class IV) (Bn) } \\
\text { DLNEGDLLATPEK } \\
\text { AVNSMECTGGGVPSTAANR }\end{array}$ & $\begin{array}{l}\text { gi|l } 14486393 \\
\text { (AAK62048) }\end{array}$ & $103(56)$ & 31219 & $S(R C 4)$ \\
\hline 28 & $\begin{array}{l}\text { Chitinase (Class IV) (Bn) } \\
\text { GAIQLSWNYNYGPCGR } \\
\text { DLNEGDLLATPEK }\end{array}$ & $\begin{array}{l}\text { gi|l } 14486393 \\
\text { (AAK62048) }\end{array}$ & $90(56)$ & 31219 & $S(R C 4)$ \\
\hline 38 & $\begin{array}{l}\text { UP (basic secretory protein) (Ath) } \\
\text { WDQGYDVTAR }\end{array}$ & $\begin{array}{l}\text { gi| } 15226060 \\
\text { (At2g15130) }\end{array}$ & $81(56)$ & 25459 & $S(R C I)$ \\
\hline 39 & $\begin{array}{l}\text { Germin (GER 3, GLP3) (Ath) } \\
\text { NPDQVTENDFAFTGLGK }\end{array}$ & $\begin{array}{l}\text { gil } 1755154 \\
\text { (At5g20630) }\end{array}$ & $56(56)$ & 22020 & $S(R C I)$ \\
\hline 40 & $\begin{array}{l}\text { Germin (GER 3, GLP3) (Ath) } \\
\text { NPDQVTENDFAFTGLGK }\end{array}$ & $\begin{array}{l}\text { gi| } 1755154 \\
(\text { At5g20630) }\end{array}$ & $98(56)$ & 22020 & $S(R C I)$ \\
\hline 45 & $\begin{array}{l}\text { Germin (GER 3, GLP3) (Ath) } \\
\text { NPDQVTENDFAFTGLGK }\end{array}$ & $\begin{array}{l}\text { gi| } 1755154 \\
\text { (At5g20630) }\end{array}$ & $73(45)$ & 22020 & $S(R C I)$ \\
\hline
\end{tabular}

Spot numbers refer to spots in Figure 7. NCBI and accession number (ACC) of the proteins identified by comparing the peptide sequence with $\mathrm{NCBI}$ databank are indicated. $\mathrm{HP}=$ hypothetical protein, $\mathrm{UP}=$ unknown protein. Protein score, predicted molecular weight $(\mathrm{MW})$ and predicted target peptide with reliability class $(\mathrm{RC})$ are indicated. $\mathrm{C}=$ Chloroplast, $\mathrm{M}=$ Mitochondrium, $\mathrm{S}=$ Secretory pathway. Ath $=$ Arabidopsis thaliana, $\mathrm{Bj}=$ Brassica juncea, $\mathrm{Bn}=$ Brassica napus, $\mathrm{Br}=$ Brassica rapa, $\mathrm{Rs}=$ Raphanus sativus

medium [46], stored for 3 days at $4^{\circ} \mathrm{C}$ and then transferred to $20^{\circ} \mathrm{C}, 60 \%$ relative humidity, and a light intensity of $200 \mu \mathrm{mol} \mathrm{m}^{-2} \mathrm{~s}^{-1}$ photosynthetically active radiation with an $16 \mathrm{~h}$ light $/ 8 \mathrm{~h}$ dark cycle. Two weeks old plants were removed and planted into a soil-sand mixture (1:1) after cutting root tips. The plants were inoculated by applying $2 \times 10^{6}$ spores of $V$. longisporum in sterile water directly to the roots. Control plants were treated in the same way and mock-inoculated with sterile water. The plants were regularly watered with tap water and fertilized weekly with $10 \mathrm{ml}$ fertilizer solution $(10 \mathrm{~g}$ Flory Basisdünger, Euflor, München, Germany and $2.2 \mathrm{~g} \mathrm{NH}_{4} \mathrm{NO}_{3}$ in 11 tap water).

Plant height growth was measured weekly. Harvested plants were separated into roots, stems and leaves for biomass determination. Aliquots of fresh plant tissue were stored frozen at $-80^{\circ} \mathrm{C}$ and further aliquots were dried at $60^{\circ} \mathrm{C}$.

Collection of apoplastic washing fluid and of xylem sap Apoplastic washing fluids and xylem sap were extracted immediately after harvest. Leaves of five plants were pooled and used to prepare apoplastic washing fluid using the infiltration procedure of Polle et al. [47] with some modifications. Five biological replicates were pre- pared per treatment. The leaves were detached and the midrib was removed. The leaves were briefly washed in distilled water, placed in infiltration solution $(100 \mathrm{mM}$ $\mathrm{KCl}, 0.01 \%$ Triton-X 100 ) and subjected to vacuum infiltration $(-80 \mathrm{kPa}, 5 \mathrm{~min})$. Subsequently the atmospheric pressure was slowly restored. The leaves surface was quickly blotted between paper towels. The leaves were rolled and placed in centrifugation tubes with a perforated bottom. The tubes were inserted into larger centrifugation tubes over a reaction vial. The whole set-up was centrifuged at $900 \mathrm{~g}\left(8 \mathrm{~min}, 4^{\circ} \mathrm{C}\right.$, Rotana $96 \mathrm{R}$, Hettich, Tuttlingen, Germany) in a swing rotor. During centrifugation the infiltration solution was released from the leaves and collected in the reaction vial. The solution was weighed and stored at $-20^{\circ} \mathrm{C}$. The composition of the infiltration solution had been optimized by varying the $\mathrm{KCl}$ and Triton $\mathrm{X}$ 100 concentrations to obtain maximum protein with minimum contamination (see below). For proteome analysis five biological replicates per treatment were analysed.

Xylem sap was collected using a Scholander pressure chamber [48]. Plants were removed from the pots, the soil-sand mixture was carefully removed by washing in water and after covering the roots with aluminium foil, they were placed inside the pressure chamber. The stem 
Table 4: Differentially expressed proteins in apoplastic washing fluids of leaves of oilseed rape (Brassica napus var. napus) after infection with Verticillium longisporum VL43.

\begin{tabular}{|c|c|c|c|c|c|c|c|}
\hline Spot no & Similarity (Organism) Peptide & $\mathrm{NCBI}(\mathrm{ACC})$ & Protein score (threshold) & MW & Target peptide & Factor & $P$ \\
\hline \multirow[t]{2}{*}{21} & $\begin{array}{l}\text { basic glucanase }(\mathbf{B j}) \\
\text { LYDPNQEVLSALR } \\
\text { YISVGNEVQPDPTSR } \\
\text { GISGFPPSSGTFTPEFR }\end{array}$ & $\begin{array}{l}g i \mid 86371164 \\
(A B C 94638)\end{array}$ & $223(56)$ & 30722 & $S(R C I)$ & 3.9 & 0.037 \\
\hline & $\begin{array}{l}\text { B-1,3-glucanase (Ath) } \\
\text { LASSQAEADTWVR } \\
\text { GISGFPPSSGTFTPEF }\end{array}$ & $\begin{array}{l}g i \mid 6735303 \\
(\text { At3g57240) }\end{array}$ & $91(56)$ & 37632 & $S(R C I)$ & & \\
\hline \multirow[t]{2}{*}{22} & $\begin{array}{l}\text { basic glucanase }(\mathbf{B j}) \\
\text { IASSQAEADTWVR } \\
\text { LYDPNQEVLSALR } \\
\text { YISVGNEVQPSDPTSR } \\
\text { GISGFPPSSGTFTPEFR } \\
\text { NLFHALVDTVYAALEK } \\
\text { GSNIDLLLDVPNPDLQR } \\
\text { LDYALFTSPSTVVNDGSNAYR }\end{array}$ & $\begin{array}{l}\text { gi|8637II64 } \\
(\mathrm{ABC} 94638)\end{array}$ & $405(56)$ & 30722 & $S(R C I)$ & 3.1 & 0.001 \\
\hline & $\begin{array}{l}\text { B-I,3-glucanase (Ath) } \\
\text { LASSQAEADTWVR } \\
\text { GISGFPPSSGTFTPEFR } \\
\text { TYVNNLIQTVK }\end{array}$ & $\begin{array}{l}g i \mid 6735303 \\
(A+3 g 57240)\end{array}$ & $180(56)$ & 37632 & $S(R C I)$ & & \\
\hline 23 & $\begin{array}{l}\text { } \beta \text {-1,3-glucanase (Ath) } \\
\text { LASSQAEADTWVR } \\
\text { GISGFPPSSGTFTPEFR } \\
\text { TYVNNLIQTVK } \\
\text { GSNIELVLDVPNPDLQR }\end{array}$ & $\begin{array}{l}g i \mid 6735303 \\
(\text { At3g57240) }\end{array}$ & $222(56)$ & 37632 & $S(R C I)$ & 4.8 & 0.049 \\
\hline 30 & not identified & & & & & 5.8 & 0.007 \\
\hline 32 & not identified & & & & & 8.3 & 0.000 \\
\hline 34 & $\begin{array}{l}\text { basic endochitinase (CHB4) (Bn) } \\
\text { DSFINAANTFPNFANSVTR } \\
\text { AINGMECNGGNSGAVNAR }\end{array}$ & $\begin{array}{l}\text { gi|584929 } \\
(\mathrm{Q} 06209)\end{array}$ & $95(56)$ & 29684 & $S(R C I)$ & 7.7 & 0.009 \\
\hline 36 & not identified & & & & & 4.8 & 0.014 \\
\hline 51 & $\begin{array}{l}\text { basic endochitinase (CHB4) (Bn) } \\
\text { DSFINAANTFPNFANSVTR } \\
\text { AINGMECNGGNSGAVNAR } \\
\text { DYCGQLGVDPGNLS }\end{array}$ & $\begin{array}{l}\text { gi|584929 } \\
(\mathrm{Q} 06209)\end{array}$ & $159(44)$ & 29684 & $S(R C I)$ & 4.2 & 0.020 \\
\hline 52 & not identified & & & & & 3.5 & 0.045 \\
\hline 53 & not identified & & & & & 4.4 & 0.005 \\
\hline \multirow[t]{2}{*}{54} & $\begin{array}{l}\text { Korean horseradish peroxidase (Rs) } \\
\text { MGDISPLTGSSGEIR }\end{array}$ & $\begin{array}{l}\text { gi|l15।8388 } \\
(X 91172)\end{array}$ & $94(44)$ & 33993 & $S(R C 3)$ & 2.4 & 0.040 \\
\hline & $\begin{array}{l}\text { Peroxidase (Ath) } \\
\text { MGDISPLTGSSGEIR }\end{array}$ & $\begin{array}{l}g i \mid 15239075 \\
(A+5 g 05340)\end{array}$ & $94(44)$ & 34650 & $S(R C I)$ & & \\
\hline 55 & not identified & & & & & 3.6 & 0.005 \\
\hline
\end{tabular}

Data indicate means of 5 gels per treatment. Spot numbers refer to spots in Figure 7. NCBI and accession number (ACC) of the proteins were identified by comparing the peptide sequence with NCBI databank. Protein score, predicted molecular weight $(\mathrm{MW})$ and predicted target peptide with reliability class (RC) are indicated. Factor indicates mean intensity of spots in apoplastic washing fluid of VL43-infected plants/mean intensity of spot in apoplastic washing fluid of control plants. P-values were calculated using ProteinWeaver software. Ath $=$ Arabidopsis thaliana, $\mathrm{Bj}=\mathrm{Brassica}$ juncea, $\mathrm{Bn}=$ Brassica napus, $\mathrm{Rs}=$ Raphanus sativus,

was cut above the hypocotyl and the cut surface was rinsed with $\mathrm{ddH}_{2} \mathrm{O}$. After closing the chamber, the roots were exposed to $0.2 \mathrm{MPa}$ for 10 to $15 \mathrm{~min}$. Xylem sap exuding through the cut surface was collected with a pipette tip. Sap of 15 plants per treatment was pooled as one biological replicate and stored at $-20^{\circ} \mathrm{C}$. For proteome analysis five biological replicates were analysed.

\section{Fungal culture and growth test}

Verticillium longisporum isolate VL43 (isolated from Brassica napus), was maintained on potato dextrose agar at $4^{\circ} \mathrm{C}$. For sporulation, fungal hyphae were transferred to
$250 \mathrm{ml}$ liquid potato dextrose medium (PDB medium Scharlau, Barcelona, Spain) with $0.2 \mathrm{mg} / \mathrm{ml}$ streptomycin sulphate (Sigma, Steinheim) as described by Fahleson et al. [49]. The culture was incubated at $22^{\circ} \mathrm{C}$ by horizontal shaking $(80 \mathrm{rpm})$ for $14 \mathrm{~d}$ in darkness. For inoculation the fungal suspension was filtered and diluted to a suspension of $2 \times 10^{6}$ conidia per millilitre.

To test fungal growth xylem sap was collected as described above from 30 control and 30 infected plants, respectively and used for 13 growth assays in uninfected and 15 growth assays in infected saps, respectively. Fungal 
Table 5: Differentially regulated proteins in xylem sap of oilseed rape (Brassica napus var. napus) after infection with Verticillium ongisporum VL43.

\begin{tabular}{|c|c|c|c|c|c|}
\hline Spot No & $\begin{array}{l}\text { Similarity (Organism) } \\
\text { Peptide }\end{array}$ & NCBI (ACC) & Protein score (Threshold) & MW & Target peptide \\
\hline \multirow[t]{2}{*}{ XVL I } & $\begin{array}{l}\text { basic glucanase }(\mathbf{B j}) \\
\text { IASSQAEADTWVR } \\
\text { LYDPNQEVLSALR } \\
\text { YISVGNEVQPSDPTSR } \\
\text { GISGFPPSSGTFTPEFR } \\
\text { NLFHALVDTVYAALEK } \\
\text { GSNIDLLLDVPNPDLQR } \\
\text { LDYALFTSPSTYVNDGSNAYR }\end{array}$ & $\begin{array}{l}\text { gi|| I 18763538 } \\
\text { (ABC94638) }\end{array}$ & $510(44)$ & 30722 & $S(R C I)$ \\
\hline & $\begin{array}{l}\beta-1,3 \text {-glucanase (Ath) } \\
\text { LASSQAEADTWVR } \\
\text { GISGFPPSSGTFTPEFR } \\
\text { TYVNNLIQTVK } \\
\text { GSNIELVLDVPNPDLQR }\end{array}$ & $\begin{array}{l}\text { gi|6735303( } \\
\text { At3g57240) }\end{array}$ & $222(45)$ & 37632 & $S(R C I)$ \\
\hline XVL 2 & not identified & & & & \\
\hline$X V L 3$ & $\begin{array}{l}\text { PR4-Typ protein (Br) } \\
\text { VTNTGTQAQATVR } \\
\text { QIDTDGQGYAR } \\
\text { ATYHFYNPAQNGWDLYR }\end{array}$ & $\begin{array}{l}\text { gi|7367। } 284 \\
\text { (AF528।8I) }\end{array}$ & $162(44)$ & 15950 & $\mathrm{~S}(\mathrm{RC} 2)$ \\
\hline
\end{tabular}

Spot numbers refer to Fig. 6. NCBI and accession number of the proteins identified by comparing the peptide sequence with NCBI databank are indicated. Protein score, predicted molecular weight $(\mathrm{MW})$ and predicted target peptide with reliability class $(\mathrm{RC})$ are indicated. Ath $=$ Arabidopsis thaliana, $\mathrm{Bj}=$ Brassica juncea, $\mathrm{Br}=$ Brassica rapo

spore solution with $1.8 \times 10^{6}$ spores in PDB medium was centrifuged and resuspended in $\mathrm{dd}_{2} \mathrm{O}$ water. $10 \mu \mathrm{l}$ of this spore solution were diluted 1:10 with sterile water, filled up with $900 \mu \mathrm{l}$ xylem sap to a final volume of $1 \mathrm{ml}$ and incubated in a sterile $2 \mathrm{ml}$ reaction tube at $22^{\circ} \mathrm{C}$ by shaking ( $80 \mathrm{rpm})$ for 3 days in darkness. Subsequently, the suspension was centrifuged and the pellet was used for DNA extraction [50]. For this purpose, the pellet was milled (MM 2, Retsch, Haan, Germany), suspended in $400 \mu \mathrm{l}$ extraction buffer $(200 \mathrm{mM}$ Tris- $\mathrm{HCl}, \mathrm{pH} 7.5,250$ $\mathrm{mM} \mathrm{NaCl}, 25 \mathrm{mM}$ EDTA, 0,5\% sodium dodecylsulfate), and centrifuged $(20.000 \mathrm{~g}, 3 \mathrm{~min}, 5417 \mathrm{R}$ Eppendorf centrifuge, Hamburg, Germany) after mixing. $300 \mu \mathrm{l}$ of the supernatant was transferred to a new tube, mixed with $300 \mu \mathrm{l}$ isopropanol and incubated for $2 \mathrm{~min}$ at room temperature. The sample was centrifuged $(20000 \mathrm{~g}, 5 \mathrm{~min})$. The supernatant was discarded and the pellet was dried for 5 - $10 \mathrm{~min}$ at $37^{\circ} \mathrm{C}$ in a Speed Vac (Eppendorf Concentrator 5301, Hamburg, Germany). The pellet was resuspended in $100 \mu \mathrm{TE}$ buffer $(10 \mathrm{mM}$ Tris- $\mathrm{HCl} \mathrm{pH} 7,5 ; 1$ $\mathrm{mM}$ EDTA) used for fungal DNA determination was described below.

Quantification of Verticillium longisporum DNA by realtime PCR

Frozen hypocotyl was ground in liquid nitrogen to a fine powder. For DNA extraction from plant tissue the DNeasy Plant Mini Kit from Qiagen (Hilden, Germany) was used. The amount of fungal DNA was determined by real-time
PCR with primers 5'-cagcgaaacgcgatatgtag -3' and 5'-ggcttgtagggggtttaga-3', which are specific for Verticillium spp [1]. BIOTaq DNA polymerase (Bioline, Luckenwalde, Germany) in standard polymerase buffer with $0.01 \%(\mathrm{v} / \mathrm{v})$ Tween-20 and $3 \mathrm{mM} \mathrm{MgCl}$, was used, $10 \mathrm{nM}$ fluorescein (BioRad, Hercules, CA, USA) was added as internal fluorescence standard and the fluorescence of SYBR Green I (100,000-times diluted solution purchased from Invitrogen, Karlsruhe, Germany) was recorded using $490 \pm 10$ $\mathrm{nm}$ for excitation and $530 \pm 15 \mathrm{~nm}$ for emission. PCR consisted of a $2 \mathrm{~min}$ denaturation step at $94^{\circ} \mathrm{C}$ followed by 36 cycles of $20 \mathrm{~s}$ at $94^{\circ} \mathrm{C}, 30 \mathrm{~s}$ at $59^{\circ} \mathrm{C}$ and $40 \mathrm{~s}$ at $72^{\circ} \mathrm{C}$. The amount of $V$. longisporum DNA was estimated from a calibration curve constructed with purified fungal DNA dissolved in plant matrix.

\section{Photosynthesis and Chlorophyll fluorescence}

Chlorophyll fluorescence was measured on dark-adapted leaves using the Mini PAM system (Walz, Effeltrich, Germany). The quantum yield of photochemistry was calculated as described by Maxwell and Johnsen [51]:

$\Phi=\left(\mathrm{F}_{\mathrm{m}}-\mathrm{F}_{\mathrm{o}}\right) / \mathrm{F}_{\mathrm{m}}$, with $\mathrm{F}_{\mathrm{m}}$ and $\mathrm{F}_{\mathrm{o}}$ referring to maximum and background fluorescence, respectively, in darkness.

Photosynthesis and transpiration were measured in gas exchange system (HCM 1000, Walz, Effeltrich, Germany) at saturating light of $800 \mu \mathrm{mol} \mathrm{m} \mathrm{m}^{-2} \mathrm{~s}^{-1}$ of photosynthetic active radiation $\left(20^{\circ} \mathrm{C}, 60 \%\right.$ air humidity). 


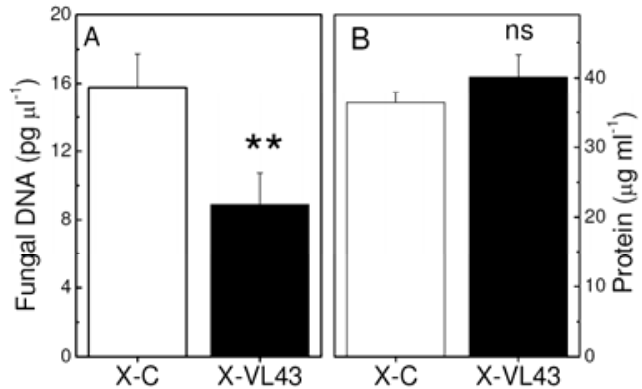

Figure 8

Fungal growth (A) and protein content (B) in xylem sap of non-infected $(X-C)$ and VL43-infected (XVL43) oilseed rape (Brassica napus var. napus). Data indicate means $(n=13$ for non-infected and 15 for infected xylem sap, $\pm \mathrm{SE}$ ). **k indicate significant differences between treated and non-treated plants at $P \leq 0.01$, ns $=$ not significant.

\section{Chlorophyll concentration}

Frozen leaf material was milled in liquid nitrogen and extracted in $80 \%$ acetone. After centrifugation the pigment concentration of the supernatant was determined spectrophotometrically (Beckman DU 640, Beckman Coulter, Krefeld, Germany) at $646 \mathrm{~nm}$ and $663 \mathrm{~nm}$. The chlorophyll concentration was determined as sum of chlorophyll a and b after Lichtenthaler and Wellburn [52].

\section{Nutrient elements}

Dry leaf material was milled to a fine powder (MM2 Ret sch, Haan Germany). Aliquots of the powder were extracted with $65 \% \mathrm{HNO}_{3}[53]$ and subjected to induc tively-coupled optical emission spectroscopy (Spectroflame, Spectro Analytical Instruments, Kleve Germany). For carbon and nitrogen determination, leaf powder was weighed into tin capsules and measured in a CNS-elemental analyser (Carlo Erba Instruments, Rodano, Italy).

\section{Electrolyte leakage}

Leaf disks $(10 \mathrm{~mm})$ were excised from leaf blades avoiding major veins. 25 disks were immersed in $20 \mathrm{ml}$ of distilled water. The conductivity $(\mathrm{C})$ was determined immediately $\left(\mathrm{C}_{0}\right)$ and after $24 \mathrm{~h}\left(\mathrm{C}_{24}\right)$ with a conductivity meter (LF315/SET, WTW Wissenschaftliche Technik, Weilheim, Germany). The samples were autoclaved $\left(5 \mathrm{~min}, 121^{\circ} \mathrm{C}\right)$ to destroy the tissues and measured after cooling to room temperature $(\mathrm{C}$ was calculated as

$$
\operatorname{REL}(\%)=\left[\left(\mathrm{C}_{\mathrm{t}}-\mathrm{C}_{0}\right) / \mathrm{C}_{\max }\right]^{*} 100
$$

\section{Contamination measurements}

To determine contamination of apoplastic fluids with cellular components, malate dehydrogenase activity was determined as symplastic marker enzyme [54]. The enzyme activity was measured spectrophotometrically at $340 \mathrm{~nm}$ as the consumption of NADH with oxalacetate as substrate. Malate dehydrogenase activity was also measured in leaf extracts prepared as described previously [47] Crude extracts were filtered over Sephadex G-25 (NAP5, Amersham Biosciences, Uppsala, Sweden) before enzyme determination.

Preparation of protein extracts for gel electrophoresis Xylem sap was filtered, $(0.2 \mu \mathrm{m}$ pore size, Sarstedt, Nümbrecht, Germany) freeze-dried, dissolved in $500 \mu \mathrm{ldd} \mathrm{H}_{2} \mathrm{O}$ (double deionised water) and filtered over a Sephadex G25 column.

Apoplastic washing fluids and whole leaf extracts were subjected to acetone/trichloracetic acid (TCA) precipitation ( 5 volumes $10 \% \mathrm{w} / \mathrm{v}$ TCA, $0.14 \% \mathrm{v} / \mathrm{v} 2$-mercaptoethanol in acetone with 1 volume of plant extract) overnight at $-20^{\circ} \mathrm{C}$. Subsequently, the samples were centrifuged $\left(20000 \mathrm{~g}, 4^{\circ} \mathrm{C}, 20 \mathrm{~min}\right)$. The supernatant was discarded. The pellet was washed three times with $200 \mu \mathrm{l}$ acetone containing $0.07 \% 2$-mercaptoethanol and dried. The pellet was dissolved in $380 \mu \mathrm{l}$ rehydration buffer $(8 \mathrm{M}$ urea containing $0.5 \% \quad \mathrm{w} / \mathrm{v}$ CHAPS (3-[(3-cholamidopropyl)dimethylammoniol-1-propanesulfonate), $15 \mathrm{mM}$ DTT (DL-dithiothreitol), 0.2\% v/v IPG Buffer pH 3-10 (Amersham Bioscience, Freiburg, Germany) and $0.2 \% \mathrm{v} / \mathrm{v}$ Bromphenol Blue [55] and shaken for $30 \mathrm{~min}$ at room temperature to dissolve proteins. The extract was centrifuged for $5 \mathrm{~min}\left(12000 \mathrm{~g}, 4^{\circ} \mathrm{C}\right)$ and the supernatant was used for protein separation on 2-D gels.

For 1-D gels protein pellets obtained by TCA/acetone precipitation were dissolved in $\mathrm{dd}_{2} \mathrm{O}$ water. For gel electrophoretic separation $5 \mu$ l loading buffer (4\% w/v SDS, 20\% v/v glycerol, $0.2 \mathrm{M}$ DTT, $0.002 \% \mathrm{w} / \mathrm{v}$ Bromphenol Blue in $0.5 \mathrm{M}$ Tris- $\mathrm{HCl}, \mathrm{pH} 6.8$ ) was added. Before application to gels samples were incubated for $3 \mathrm{~min}$ at $70^{\circ} \mathrm{C}$.

The protein concentration of the extracts was quantified by the bicinchoninic acid (BCA) method using the BCA protein quantification kit (Uptima, Montlucon, France) and bovine serum albumin as the standard.

Separation of proteins by I-D or 2-D gel electrophoresis

Proteins were separated by sodium dodecyl sulphate (SDS) - polyacrylamide gel electrophoresis (PAGE, [56]) in a gradient from 7.5 to $20 \%$ (electrophoresis unit, Biorad, München, Germany). Each lane was loaded with 1.8 $\mu \mathrm{g}$ protein (for silver staining) or 50 to $100 \mu \mathrm{g}$ protein (for 
Coomassie staining). Molecular weight markers were used from Amersham (LMW 17-0446-01, Amersham Biosciences, Freiburg, Germany).

For 2-D electrophoresis, $80 \mu \mathrm{g}$ protein in $350 \mu \mathrm{l}$ rehydration buffer was used for isoelectric focusing on immobilized $\mathrm{pH}$ gradient strips (Immobiline DryStrip, $\mathrm{pH}$ 3-10, length $18 \mathrm{~cm}$, Amersham Bioscience, Freiburg, Germany). Isoelectric focusing (IPGphor isoelectric focusing system, Amersham Bioscience, Freiburg, Germany) was performed under the following conditions: rehydration $12 \mathrm{~h}$ at $20 \mathrm{~V}$, followed by $2 \mathrm{~h}$ at $150 \mathrm{~V}, 1 \mathrm{~h}$ at $200 \mathrm{~V}, 1 \mathrm{~h}$ at 500 $\mathrm{V}, 1.000 \mathrm{Vh}$ at $1.000 \mathrm{~V}$, and finally by $60.000 \mathrm{Vh}$ at 80.00 $\mathrm{V}$. The focused samples were stored at $-20^{\circ} \mathrm{C}$.

Prior to the second separation step, IEF focusing strips were incubated two times for $15 \mathrm{~min}$ in equilibration buffer ( $6 \mathrm{M}$ urea, $30 \% \mathrm{w} / \mathrm{v}$ glycerol, $2 \% \mathrm{w} / \mathrm{v}$ SDS in 0.05 $\mathrm{M}$ Tris-HCl buffer $\mathrm{pH} 8.8$ ) after Görg and Weis [55] containing $1 \%$ DTT in the first equilibration step and $4 \%$ iodoacetamide in the second one. In the second dimension proteins were separated on 12\% SDS-PAGE [56] using an EttanDalt-six electrophoresis unit (Amersham Biosciences, Freiburg, Germany) operating at $600 \mathrm{~V}$ (400 $\mathrm{mA}, 13 \mathrm{~W})$ for $30 \mathrm{~min}$ and followed by $3000 \mathrm{~V}(400 \mathrm{~mA}$, $100 \mathrm{~W}$ ) for $4.5 \mathrm{~h}$.

Gels were stained with colloidal Coomassie Blue [57] or with silver [58] and scanned with a FluorS-Multimager (Biorad, München, Germany)

\section{Protein identification}

Protein spots of interest were cut and digested in-gel after Havlis et al. [59]. Gel pieces were washed twice with $\mathrm{ddH}_{2} \mathrm{O}$ for $15 \mathrm{~min}$ and washed once with $50 \%$ methanol $(15 \mathrm{~min})$ at room temperature. The gel pieces were dehydrated in pure acetonitrile for $20 \mathrm{~min}$ and solvent was removed under vacuum. Gel pieces were soaked for 60 min in a solution of $2 \mu \mathrm{M}$ modified trypsin (Promega, Mannheim, Germany) in $50 \mathrm{mM}$ ammonium bicarbonate buffer $\mathrm{pH} 8$ at $4^{\circ} \mathrm{C}$. Trypsin solution not taken up by gel pieces was removed. The digestion was carried out for 30 $\min$ at $58^{\circ} \mathrm{C}$ and stopped by addition of $200 \mu \mathrm{l} 5 \%(\mathrm{v} / \mathrm{v})$ formic acid. Peptides were extracted for $300 \mathrm{~min}$ at room temperature on a shaker and extraction was repeated with $200 \mu \mathrm{l} \mathrm{50 \%} \mathrm{(v/v)} \mathrm{acetonitrile} \mathrm{in} \mathrm{5 \%} \mathrm{(v/v)} \mathrm{formic} \mathrm{acid.}$ Combined supernatants were dried in a vacuum centri fuge (SPD SpeedVac, Thermo Savant, Holbrook, USA) Peptides were dissolved in $5 \mu \mathrm{l}$ of $0.1 \%$ formic acid and 4 $\mu \mathrm{l}$ samples were used for separation on $180 \mu \mathrm{m}$ capillary column packed with $218 \mathrm{MS}-\mathrm{C} 18$ phase (Vydac, Columbia, USA) and analysed by ESI-LC-MS (HP 1100 Agilent, Palo Alto, USA; Esquire 3000, Bruker Daltonik, Bremen Germany). Mass spectra were analysed by Data Analysis software (Bruker Daltonik, Bremen, Germany) and proteins identified by online searching of MSDB, NCBInr and EST databases using Mascot software (Matrix Science, Boston, USA). Settings for peptide searches were: ion charge $2+$ and $3+$, monoisotopic ions, carbamidomethyl-C as fixed modification, oxidation- $\mathrm{M}$ as variable modification, missed cleavage 1, peptide tolerance 1.4 Da, MS/MS tolerance $0.4 \mathrm{Da}$, standard scoring using significance threshold $\mathrm{p}<0.05$. To obtain information whether the identified proteins contained a target sequence for the secretory pathway, the programme TargetP (version 1.1) was used, which predicts the subcellular localisation of eukaryotic proteins [60]. TargetP also indicates reliability classes (1 to 5) of the predicted localisation. Small values indicate high reliability.

\section{Statistical analysis}

To compare gels from Verticillium-treated and non-inoculated plants five gels, each loaded with one biological replicate per treatment were run and silver stained. The gels were scanned and stored as TIFF-files. Gels belonging to one treatment were analysed as a group by Proteomweaver software (Version 3.1.07, Definitions Cognitionware, München, Germany). Protein spots were identified automatically, adjusted manually where necessary and merged by Pair Matching or Multi Matching. The grouped gels were normalized using standard settings of the programme and compared. Protein intensities of matching spots were statistically analysed by Student's Ttest to identify significant differences at $\mathrm{P} \leq 0.05$.

Genevestigator analysis was conducted with the software developed by Zimmermann et al. [61].

Biometric and physiological data are shown as means $( \pm$ $\mathrm{SE}$ ). The number of replicates is indicated in the figure legends. For statistical analysis ANOVA or Student's T-test were applied using Statgraphics (Centurion XV, St Louis, MO, USA).

\section{Authors' contributions}

SF conducted rape infection experiments, extracted and analysed the proteome. CD conducted Verticillium growth experiments in xylem sap. AM and UK made the LC-MS/ MS available and helped with protein separation and identification. PK contributed data on Verticillium DNA. AP suggested experiments and wrote the manuscript. All authors have read and approved the manuscript.

\section{Acknowledgements}

We are grateful to A. von Tiedemann for the donation of the VL43-strain of Verticillium longisporum and to Monika Franke-Klein and Christine Kettner for excellent technical assistance. We thank the DFG for providing financial support (Po362/15-1/2) via FOR 546 


\section{References}

I. Eynck C, Koopmann B, Grunewaldt-Stoecker G, Karlovsky P, von Tiedemann A: Differential interactions of Verticillium longisporum and V. dahliae with Brassica napus detected with molecII $18: 259-274$.

2. Kehr J. Buhtz A, Giavalisco P: Analysis of xylem sap proteins from Brassica napus. BMC Plant Biol 2005, 5: II.

3. Buhtz A, Kolasa A, Arlt K, Walz C, Kehr J: Xylem sap protein Weng different plant species. composition is conserve
Planta 2004, 219:610-618.

4. Rep M. Dekker HL, Vossen JH, de Boer AD, Houterman PM. Speijer D, Back JW, de Koster CG, Cornelissen BJC: Mass spectrometric identification of isoforms of PR proteins in xylem
gus-infected tomato. Plant Physiol 2002, 130:904-917.

5. Young SA, Guo A. Guikema JA. White FF, Leach JE: Rice cationic peroxidase accumulates in xylem vessels during incompatible interactions with Xanthomonas oryzae pv oryzae. Plant

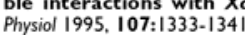

6. Joosten MHAJ. De Wit PJGM: Identification of several pathogen esis-related proteins in tomato leaves inoculated with Cladosporium fulvum (syn. Fulvia fulva) as 1,3- $\beta$-glucanases and chitinases. Plant Physiol 1989, 89:945-951.

7. Segarra Cl. Casalongue CA, Pinedo ML, Ronchi VP. Conde RD: A germin-like protein of wheat leaf apoplast inhibits serine proteases. J Exp Bot 2003, 54:1335-1341.

8. Burg HA Van den, Harrison S]. Joosten MHAJ. Vervoort I, de Witt PJGM: Cladosporium fulvum Avr4 protects fungal cell walls against hydrolysis by plant chitinases accumulation durin infection. Mol Plant Microbe Interac 2006, 19: 1420-1430.

9. Ndimba BK, Chivasa S, Hamilton JM, Simon W]. Slabas AR: Proteomic analysis of changes in the extracellular matrix of Arobidopsis cell suspension cultures induced by fungal elicitors. Proteomics 2003, 3:1047-1059.

10. Smolka MB, Martins D. Winck FV, Santoro CE, Castellari RR, Ferrar F. Brum I Jr, Galembeck E, Della Coletta Filho H. Machado MA Marangoni S, Novello JC: Proteome analysis of the plant pathogen Xylella fastidiosa reveals major cellular and extracellular proteins and a peculiar codon bias distribution. Proteomics 2003, 3:224-237.

1I. Gau AE, Koutb M, Piotrowski M, Kloppstech K: Accumulation of ble cultivar of apple (Malus domestica cv. Elstar) after infection by Venturia inaequalis and constitutive expression of PR genes in the resistant cultivar Remo. Eur J Plant Pathol 2004. genes in the

12. Chivasa S, Simon W], Yu X-L, Yalpani N, Slabas AR: Pathogen elicxtracellular matrix proteome. Proteomics 2005, 5:4894-4904.

13. Houterman PM, Speijer D. Dekker HL, De Koster CG, Cornelissen BJC, Rep M: The mixed xylem sap proteome of Fusarium oxysporum-infected tomato plants. Mol Plant Pathol 2007. 8:215-221.

14. Kaffarnik FAR, Jones AME, Rathjen JP. Peck SC: Effector protein of the bacterial pathogen Pseudomonas syringae alter the extracellular proteome of the host plant, Arabidopsis thaliana. Mol Cell Proteomics 2008.

15. Bolton MD, van Esse HP, Vossen JH, de Jonge R, Stergiopoulos Stulemeijer IJE, Berg GCM van den, Borrás-Hidalgo O. Dekker HL, de Koster CG, de Wit PJGM:

16. Joosten MAHJ, Thomma BPHJ: The novel Cladosporium fulvum ysin motif effector Ecp6 is a virulence factor with orthologues in other fungal species. Mol Microbiol 2008, 69:119-136.

17. Daebeler F. Amelung D, Zeise K: Verticillium Welke an Winterraps - Auftreten und Bedeutung. Nachrichtenblatt Pflanzenschutzdienst DDR 1988, 42:71-73

18. Fradin EF. Thomma BPHJ: Physiology and molecular aspects of Verticillium wilt diseases caused by $V$. dahliae and V. alboatrum. Mol Plant Pathol 2006, 7:71-86.

19. Benhamou N: Immunocytochemistry of plant defense mecha nisms induced upon microbial attack. Microsc Res Tech 1995. 3I:63-78.

20. Gold J. Robb J: The role of the coating response in Craigella tomatoes infected with Verticillium dahliae, race-I and race2. Physiol Mol Plant Pathol 1995, 47:141-157.
21. Williams JS, Hall SA, Hawkesford MJ, Beale MH, Cooper RM: Elemental sulfur and thiol accumulation in tomato and defense against a
128:150-159.

22. Johansson A, Staal J. Dixelius C: Early responses in the Arabidopsis-Verticillium longisporum pathosystem are dependent on NDRI, JA- and ET-associated signals via cytosolic NPRI and RFOI. Mol Plant Microbe Interac 2006, 19:958-969.

23. Kotake T, Tsuchiya K. Aohara T, Konishi T, Kaneko S, Igarashi K, Samejima M. Tsumuraya $Y$ : An $\alpha$-L-arabinofuronosidase/ $/ \beta$-D xylosidase from immature seeds of radish (Raphanus sativus L.). J Exp Bot 2006, 57:2353-2362

24. Bowden RL, Rouse DI, Sharkey TD: Mechanism of photosynthesis decrease by Verticillium dahliae in potato. Plant Physiol 1990 94: 1048-1055.

25. Saeed IAM, MacGuidwin AE, Rouse DI, Sharkey TD: Limitation to photosynthesis in Pratylenchus penetrans - and Verticillium dahliae-infected potato. Crop Sci 1999, 39:1340-1346.

26. Sadras VO, Quiroz F, Echarte L, Escande A. Pereyra VR: Effect of Verticillium dahliae on photosynthesis, leaf expansion and senescence of field-grown sunflower. Ann Bot 2000 86: $1007-1015$

27. Flörl S: Identifizierung und Charakterisierung extrazellulärer Proteine unter dem Einfluss von Verticillium longisporum in Arabidopsis thaliana und Raps (Brassica napus). In Thesis University of Göttingen; 2007

28. Veronese P, Narasimhan ML, Stevenson RA, Zhu JK, Weller SC, Subbarao KV, Bressan RA: Identification of a locus controlling Verticillium disease symptom response in Arabidopsis thaliana. Plant / 2003, 35:574-58

29. Walker JC, Gallegly ME, Bloom JR, Scheffer RP: Relation of plant nutrition to disease development. Verticillium wilt of tomato. Am J Bot 1954, 41:760-762.

30. Sivaprakasam K, Rajagopa CK: Effect of nitrogen on incidence of Verticillium wilt disease of egg plant caused by Verticillium dahliae Kleb. Plant and Soil 1974, 40:217-220.

31. Karagiannidis N, Bletsos F, Stavropoulos N: Effect of Verticillium wilt (Verticillium dahliae Kleb.) and mycorrhiza (Glomus mosseae) on root colonization, growth and nutrient uptake in tomato and eggplant seedlings. Sci Hort 2002, 94: 145-156.

32. Bayer EM, Bottrill AR, Walshaw J. Vigouroux M, Naldrett MJ. Thoma CL. Maule AJ: Arabidopsis cell wall proteome defined using multidimensional protein identification technology. Proteom ics 2006, 6:30I-3II.

33. Boudart G, Jamet E, Rossignol M, Lafitte C, Borderies G, Jauneau A Esquerre-Tugaye MT. Pont-Lezica R: Cell wall proteins in apoplastic fluids of Arabidopsis thaliana rosettes: Identification by mass spectrometry and bioinformatics. Proteomics 2005

34. Slabas AR. Ndimba B. Simon W]. Chivasa S: Proteomic analysis of the Arabidopsis cell wall reveals unexpected proteins with

. new cellular locations. Biochem Soc Transac 2004, 32:524-528.

Charmont S, Jamet E, Pont-Lezica R, Canut H: Proteomic analysis of secreted proteins from Arabidopsis thallana seedlings: improved recovery following rem

36. Saha BC: $\alpha$-L-arabinofuranosidases: biochemistry, molecular biology and application in biotechnology. Biotechnol Adv 2000, 18:403-423.

37. Doxey AC, Yaish MWF, Moffatt BA, Griffith M, McConkey B]: Functional divergence in the Arabidopsis $\beta-1,3$-glucanase gene family inferred by phylogenetic reconstruction of expression family inferred by phylogenetic reconstr.

38. MFFadden HG Chapple R, de Feyter R. Dennis E: Expression of pathogenesis-related genes in cotton stems in response to infection by Verticillium dahliae. Physiol Mol Plant Pathol 2001. 58:119.131.

39. Dubery IA, Slater V: Induced defence responses in cotton leaf disks by elicitors from Verticillium dahliae. Phytochem 1997. 44:1429.1434.

40. Park Y-S, Jeon MH, Lee S-H. Moon JS, Cha J-S, Kim HY, Cho T-J: Activation of defense responses in chinese cabbage by a nonhost pathogen, Pseudomonas syringae pv. tomato. J Biochem Mol Biol pathogen, Pseud

41. Ryang S-H, Chung S-Y, Lee S-H, Cha J-S, Kim HY, Cho T-1: Isolation of pathogen-induced chinese cabbage genes by subtractive 
hybridization employing selective adaptor ligation. Biochem Biophys Res Comm 2002, 299:352-359.

42. Park Y-S, Cho T-J: Isolation and characterization of methyl jasmonate-inducible genes in chinese cabbage. Kor J Biol Sci 2003 . 7:337-343.

43. Broglie KE, Gaynor J]. Broglie RM: Ethylene-regulated gene expression: molecular cloning of the genes encoding an endochitinase from Phaseolus vulgaris. Proc Natl Acad Sci USA 1986, 83:6820-6824.

44. Mauch F, Staehelin LA: Functional implications of the subcellular localization of ethylene-induced chitinase and $\beta-1,3-g l u-$ canase in bean leaves. Plant Cell 1989, 1:447-457.

45. Petruzzelli L, Kunz C, Waldvogel R, Meins F Jr, Leubner-Metzger G Distinct ethylene- and tissue-specific regulation of $\beta-1,3$-glucanases and chitinases during pea seed germination. Plant 1999. 209: 195-20

46. Murashige T, Skoog F: A revised medium for rapid growth and bio assays with tobacco tissue cultures. Physiol Plant 1962 15:473-497.

4. Polle A, Chakrabarti K, Schurmann W, Rennenberg H: Composition and properties of hydrogen peroxide decomposing systems in extracellular and total extracts from needles of Norway spruce (Picea abies L, Karst). Plant Physiol 1990, 94:312-319.

48. Scholander PF, Hammel HT, Bradstre ED, Hemmings EA: Sap pressure in vascular plants - Negative hydrostatic pres

49. Fahleson J. Lagercrantz U. Hu Q. Steventon LA. Dixelius C: Estimation of genetic variation among Verticillium isolates using tion of genetic variation among Verticillium is
AFLP analysis. Eur J Plant Pathol 2003, 109:361-371.

50. Schneidereit A: Untersuchungen zur transkriptionellen Regulation des AtSUC2-Promotors beim Sink-Source-Übergan im Blatt und Analyse der Gene AtINT2 und AtINT4 In Thesis University of Erlangen-Nürnberg; 2005.

51. Maxwell K. Johnson GN: Chlorophyll fluorescence - a practical guide. J Exp Bot 2000, 51:659-668.

52. Lichtenthaler HK. Wellburn AR: Determinations of total carotenoids and chlorophylls $a$ and $b$ of leaf extracts in different solnoids and chlorophylls a and b of leaf ex
vents. Biochem Soc Trans 1983, I I:59|-592.

53. Heinrichs H, Brumsack HJ. Loftfield N, König N: Verbessertes Druckaufschlußsystem für biologische und anorganische Materialien. Zeitschr Pflanzenernähr Bodenk 1986, 149:350-353.

54. Bergmeyer HU, Rozalskis $\mathrm{G}: \mathbf{K}_{m}$ of malate dehydrogenase from pig heart with oxaloacetate as substrate. Zeitschrift fur klinische Chemie und klinische Biochemie 1975, 13:509.

55. Görg A, Weiss W: Two-dimensional electrophoresis with Immobilized pH gradients. In Proteome research: Two-dimension gel electrophoresis and identification methods Edited by: Rabilloud J. Berlin Heidelberg: Springer Verlag; 2000:57-106.

56. Laemmli UK: Cleavage of structural proteins during the assembly of the head of bacteriophage T4. Nature 1970 , 227:680-685

57. Neuhoff V: Colloid Coomassie Blue staining of proteins and peptides in polyacrylamide gels. Biol Chem Hoppe-Seyler 1990. 37I:AIO-AII.

58. Blum H, Beier H, Gross HI: Improved silver staining of plantproteins, RNA and DNA in polyacrylamide gels. Electrophoresis 1987, 8:93-99.

59. Havlis J. Thomas H, Sebela M. Shevchenko A: Fast-response proteomics by accelerated in-gel digestion of proteins. Anal Chen 2003, 75:1300-1306

60. Emanuelsson O, Nielsen H, Brunak S, von Heijne G: Predicting subcellular localization of proteins based on their $\mathrm{N}$-terminal amino acid sequence. I Mol Biol 2000, 300: 1005-1016.

61. Zimmermann P. Hirsch-Hoffmann M, Hennig L., Gruissem W: GENEVSTIGATOR. Arabidopsis microarray
Publish with Bio Med Central and every scientist can read your work free of charge

-BioMed Central will be the most significant development for disseminating the results of biomedical research in our lifetime. Sir Paul Nurse, Cancer Research UK

Your research papers will be:

- available free of charge to the entire biomedical community

- peer reviewed and published immediately upon acceptance

- cited in PubMed and archived on PubMed Central

- yours - you keep the copyright

Submit your manuscript here:

BioMedcentral

Page 15 of 15

(page number not for citation purposes) 


\title{
DISEASE SYMPTOMS AND MINERAL NUTRITION IN ARABIDOPSIS THALIANA IN RESPONSE TO VERTICILLIUM LONGISPORUM VL43 INFECTION
}

\author{
S. Floerl ${ }^{1}$, C. Druebert ${ }^{1}$, H.I. Aroud ${ }^{2}$, P. Karlovsky ${ }^{2}$ and A. Polle ${ }^{1}$ \\ ${ }^{1}$ Institut für Forstbotanik, Abteilung: Forstbotanik and Baumphysiologie, Büsgenweg 2, 37077 Göttingen, Germany \\ ${ }^{2}$ Department für Nutzpflanzenwissenschaften, Abteilung: Molekulare Phytopatbologie und Mykotoxinforschung. \\ Grisebacbstr. 6, 37077 Göttingen, Germany
}

\section{SUMMARY}

Verticillium longisporum is one of the most important pathogens of Brassicaceae. The goal of the present study was to characterize the development of $V$. longisporum (strain VL43) stress symptoms caused to Arabidopsis thaliana in relation to plant nutrition. Significant growth inhibition became apparent between 2 and 3 weeks after VL43 inoculation but was not accompanied by reduced leaf water content or wilting. The leaves of VL43-infected plants showed reduced chlorophyll content $(-20 \%)$ but only marginal effects on photosynthetic electron transport of PS II $(-2 \%)$ compared with controls. VL43-infection did not have negative effects on nutrient element concentration in leaf tissues during a five-week observation period. Measurements of fungal nutrient content in simulated xylem medium suggested that nutrient intake by VL43 was negligible compared to that of plant tissues. Therefore, growth retardation induced by VL43 infection is not a consequence of nutrient depletion.

Key words: Brassicaceae, chlorosis, nutrients, photosynthesis, soil pathogen, stunting.

\section{INTRODUCTION}

Verticillium species are soil-borne fungi with worldwide distribution, causing vascular diseases in many plant species including a vast range of economically important crops and trees. $V$. dabliae is probably the most frequent and widespread pathogen. However, $V$. longisporum, which occurs predominately in crucifers (Zeise and Tiedemann, 2002), is one of the most important disease agents of oilseed rape in Europe, whereas $V$. dabliae is not, or little pathogenic to Brassica napus (Karapapa et al., 1997; Eynck et al., 2007). V. longisporum has probably evolved by parasexual hybridization between a strain of $V$. albo-atrum and a strain of $V$.

Corresponding author: A. Polle
Fax: +49.551 .3922705

E-mail: apolle@gwdg.de dabliae (Karapapa et al., 1997). Typical disease symptoms of Verticillium infections are wilting, stunting, chlorosis and premature senescence (Fradin and Thomma, 2006).

All crucifer isolates of Verticillium produce thickwalled melanised microsclerotia which can survive for more than a decade in the soil. Their germination is stimulated by root exudates following which the fungus penetrates host roots and spreads systemically in the xylem (Fradin and Thomma, 2006). Until the very late stages of infection, Verticillium species remain strictly xylem-localized. Spreading in the xylem results in partial vessel occlusion by deposits secreted by neighbouring parenchyma cells (Benhamou, 1995). These obstructions may block transport through the vessels, thus delaying the fungus movement. Since obstructions can be expected to affect water and nutrient transport, disease symptoms such as wilting, stunting and chlorosis have been suggested to occur as the consequence of nutrient limitations or drought stress due to reduced water transport in the xylem (Johansson et al., 2006). In fact, young, still symptomless leaves of potato plants infected by Verticillium dabliae displayed lower carbon assimilation than non-infected plants as the result of stomatal limitations (Bowden et al., 1990). However, the effect was age-dependent and affected only some leaf areas (Saeed et al., 1999). Data on plant nutritional status during Verticillium sp. infections are scarce (Karagiannidis et al., 2002; Floerl et al., 2008). To understand disease symptoms, which may lead to massive yield loss, it is important to know whether this pathogen compromises vital functions such as plant mineral nutrition and photosynthesis.

The goal of the present study was to provide a comprehensive characterization of the development of Verticillium-induced stress symptoms during the growth of Arabidopsis and to find out whether these symptoms were caused by effects on nutrition and photosynthesis. For this purpose, growth reduction, chlorosis, photosynthetic electron transport, and changes in macro- and micro-nutrients were measured in Arabidopsis thaliana (ecotype Col-0) infected with $V$. longisporum strain VL43 from Brassica napus (Zeise and Tiedemann, 2002). Since VL43 present in leaves also sequesters nutrients, we determined optimum fungal nutrition in a synthetic 
medium and used these data to assess the upper limit of nutrients incorporated by the pathogen.

\section{MATERIALS AND METHODS}

Arabidopsis growth conditions. Seeds of Arabidopsis thaliana (ecotype Columbia-0) were sown on MS-medium (Murashige and Skoog, 1962) and stored for 3 days at $4^{\circ} \mathrm{C}$, then transferred to $20^{\circ} \mathrm{C}, 60 \%$ relative humidity, and a light intensity of $120 \mu \mathrm{mol} \mathrm{m} \mathrm{m}^{-2} \mathrm{~s}^{-1}$ photosynthetically active radiation with an $8 \mathrm{~h}$ light $/ 16 \mathrm{~h}$ dark cycle. After four weeks, seedlings were used for infection.

Fungal culture. Stock cultures of V. longisporum were stored in potato dextrose medium (PDB, Scharlau, Spain) with $20 \%$ glycerol at $-80^{\circ} \mathrm{C}$. For sporulation, the cultures were grown on potato dextrose agar at $22^{\circ} \mathrm{C}$ for 4 weeks, then transferred to $250 \mathrm{ml}$ liquid potato dextrose medium (Scharlau, Spain) with $0.2 \mathrm{mg} \mathrm{ml}^{11}$ streptomycin sulphate (Sigma, Germany) as described by Fahleson et al. (2003). The culture was incubated at $22^{\circ} \mathrm{C}$ with horizontal shaking $(80 \mathrm{rpm})$ for 14 days in darkness. The fungal suspension was filtered and centrifuged for $10 \mathrm{~min}$ at $900 \mathrm{~g}$. The pellet was diluted to $2 \times 10^{6}$ conidia $/ \mathrm{ml}$ and used for inoculation.

Infection of Arabidopsis with V. longisporum and assessment of disease symptoms. Four-week-old Arabidopsis plants were removed from the agar and their root tips were cut. During planting, the roots were placed into a small hole in the soil and were drenched with $10 \mathrm{ml}$ of $V$. longisporum suspension containing $2 \times 10^{6}$ conidia $/ \mathrm{ml}$. Control plants were treated in the same way and mock-inoculated with sterile water. The plants (40 per treatment and experiment) were grown under the same conditions specified above, watered with tap water and fertilized twice a week with Wuxal (Aglucon, Germany).

Consequences of infection were monitored by measuring the leaf area development of the plants. For this purpose, the rosettes of all plants were photographed regularly (Digital-Camera: Casio QV R52) for 35 days post inoculation and the projected area of each rosette was recorded using Image $J$ (http://rsb.info.nih.gov/ ij/index.html). During the experimental period whole rosettes were harvested regularly ( $\mathrm{n}=6$ plants per sampling date) and stored at $-80^{\circ} \mathrm{C}$ for further analysis.

Quantification of Verticillium longisporum DNA in plant tissue. Leaves were ground in liquid nitrogen to a fine powder and DNA was extracted using DNeasy Plant Mini Kit (Qiagen, Germany). The amount of fungal DNA was determined by real-time PCR with the Verticillium sp.-specific primers 5'-CAGCGAAACGCGATATGTAG-3' and '5'-GGCTTGTAGGGGGTT. TAGA-3' (Eynck et al., 2007). Calibration curves were

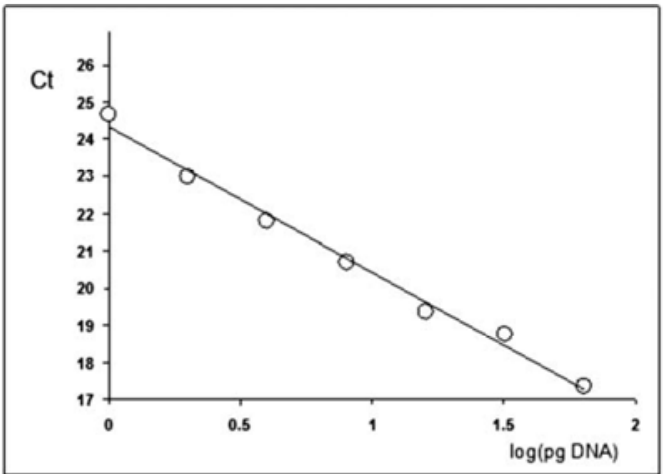

Fig. 1. Real-time PCR assay for Verticillium longisporum. Calibration curves were constructed by plotting threshold cycle values $(\mathrm{Ct})$ against the amount of template DNA as described (Eynck et al., 2007).

constructed with purified fungal DNA dissolved in a solution of plant DNA extracted from non-infected plants (matrix standards, Fig. 1).

Determination of specific DNA content of $V$. longisporum mycelium. $V$. longisporum was grown in simulated xylem sap (Neumann and Dobinson, 2003) for up to 28 days at $22^{\circ} \mathrm{C}$ without shaking. Mycelium was harvested by filtration, rinsed briefly with tap water and freezedried. DNA was extracted using the CTAB protocol (Brandfass and Karlovsky, 2006). The DNA preparation obtained was diluted 100 - to 500 -fold and the content of $V$. longisporum DNA was determined by real-time PCR (Eynck et al., 2007) using preparations of pure fungal DNA as standards. To assess the completeness of fungal DNA extraction, the pellet obtained after centrifugation of mycelium lysate and the interlayer formed after chloroform/isopropanol extraction were re-extracted with buffer $(100 \mathrm{mM} \mathrm{NaCl}, 10 \mathrm{mM}$ Tris-HCl, 1 mM EDTA, $\mathrm{pH}$ 8.0) and checked for DNA presence by agarose electrophoresis. No detectable DNA was found, showing that the extraction of DNA from fungal mycelium was complete.

Chlorophyll fluorescence. Chlorophyll fluorescence was measured in ambient light $\left(120 \mu \mathrm{mol} \mathrm{m} \mathrm{m}^{-2} \mathrm{~s}^{-1}\right.$ of photosynthetic active radiation, $20^{\circ} \mathrm{C}, 60 \%$ relative air humidity) and on dark-adapted leaves using the Mini PAM system (Walz, Germany). The quantum yield of photochemistry was calculated as described by Maxwell and Johnson (2000):

$$
\phi=\left(\mathrm{F}_{\mathrm{m}}-\mathrm{F}_{\mathrm{o}}\right) / \mathrm{F}_{\mathrm{m}}
$$

with $\mathrm{F}_{\mathrm{m}}$ and $\mathrm{F}_{\mathrm{o}}$ referring to maximum and background fluorescence, respectively, in darkness and with

$$
\phi_{\text {(acute) }}=\left(\mathrm{F}_{\mathrm{m}}-\mathrm{F}_{\mathrm{t}}\right) / \mathrm{F}_{\mathrm{m}}
$$

with $\mathrm{F}_{\mathrm{m}}$ and $\mathrm{F}_{\mathrm{t}}$ referring to maximum and background fluorescence in the light, respectively. Initially 40 plants 
per treatment were measured. At each date six plants were removed for biochemical analysis, resulting in decreasing " $\mathrm{n}$ " during the time course of the experiment. At the final date $n=6$ plants were measured per treatment.

Chlorophyll concentration. Frozen leaf material was milled in liquid nitrogen and extracted in $80 \%$ acetone After centrifugation $(10,000 \mathrm{~g}, 10 \mathrm{~min})$ the pigment concentration of the supernatant was determined spectrophotometrically (Beckman DU 640) at $646 \mathrm{~nm}$ and $663 \mathrm{~nm}$. The chlorophyll concentration was determined as the sum of chlorophyll $\mathrm{a}$ and $\mathrm{b}$ (Lichtenthaler and Wellburn, 1983).

Water content and nutrient elements. Leaves were harvested, weighed and dried at $60^{\circ} \mathrm{C}$. The water content was determined as (fresh mass-dry mass) $\times 100 /$ fresh mass. In addition to plant tissues, freeze-dried fungal tissues obtained after growth in simulated xylem medium (see above) were used for nutrient analyses. The dry material was milled to a fine powder (MM2 Retsch, Germany). Aliquots of the powder were extracted with $\mathrm{HNO}_{3}$ (Heinrichs et al., 1986) and subjected to inductively coupled optical emission spectroscopy (Spectroflame, Spectro Analytical Instruments, Germany). For carbon and nitrogen, leaf powder was weighed into tin capsules and measured in a CNS-elemental analyser (Carlo Erba Instruments, Italy).

To assess nutrient partitioning between plant and $V$. longisporum in infected leaves, we calculated the amount of an element $\left(\mathrm{E}_{\mathrm{f}}\right)$ per fungal $\mathrm{DNA}_{\mathrm{f}}$ for pure fungal cultures:

\section{$\mathrm{E}_{\mathrm{f}} / \mathrm{DNA}_{\mathrm{f}}\left(\mathrm{mg} \mathrm{\mu g}^{-1}\right)=\left(\mathrm{mg}\right.$ of $\mathrm{E}_{\mathrm{f}} / \mathrm{g}$ of fungal dry mass $) /$ ( $\mu \mathrm{g}$ of $\mathrm{DNA}_{\mathrm{f}} / \mathrm{g}$ of fungal dry mass).}

This calculation was conducted at each harvest date, yielding three mean values for each element. These data were used to calculate the relative fraction of $\mathrm{E}$ associated with the fungus in infected leaves:

Fraction of $\mathrm{E}_{\mathrm{f}}$ of total $\mathrm{E}$ in infected leaves $(\%)=$ $\left[\left(\mathrm{E}_{\mathrm{f}} / \mathrm{DNA}_{\mathrm{f}}\right) \times \mathrm{DNA}_{\mathrm{f}}\right.$ in plant $\left.\times 100\right] /$ (mg of total E/g of leaf dry mass).

Element and fungal DNA amounts in Arabidopsis were used for the harvest dates $21,28,35$ days post inoculation yielding, with three values for $\mathrm{E}_{\mathfrak{f}} / \mathrm{DNA}_{\mathrm{f}}$, a total of nine estimates per element, which were presented as box plots to show the range covered by these assessments.

Osmotic pressure. Aliquots of dry leaf powder were extracted with distilled water. After centrifugation at $900 \mathrm{~g}$ for $25 \mathrm{~min}$ the osmolality (osmol kg-1) of the supernatant was determined in a Cryo-osmometer (Osmomat 030, Ganotec, Germany). The osmotic pressure $(\mathrm{MPa})$ was calculated as:

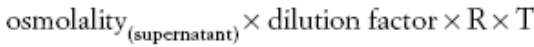

with $\mathrm{R}=0.00831\left(\mathrm{~L} \times \mathrm{MPa} \times \mathrm{mol}^{-1} \mathrm{~K}^{-1}\right)$ and $\mathrm{T}=295 \mathrm{~K}$ (absolute temperature).

Statistical analyses. Data are shown as means. The number of biological replicates was $n=6$, if not indicated differently in the figure legends. Statistical analysis (ANOVA, multiple range test) was performed using Statgraphics (Centurion XV, USA).

\section{RESULTS}

Verticillium infection causes growth reduction, chlorosis of leaf tissues, affects PSII activity but not plant water relations. Infection with $V$. longisporum VL43 caused a drastic reduction in projected rosette area compared with controls (Fig. $2 \mathrm{~A}, \mathrm{~B}$ ). The difference in time course between expansion and fresh mass was mainly caused by the fact that the VL 43 coloniza-
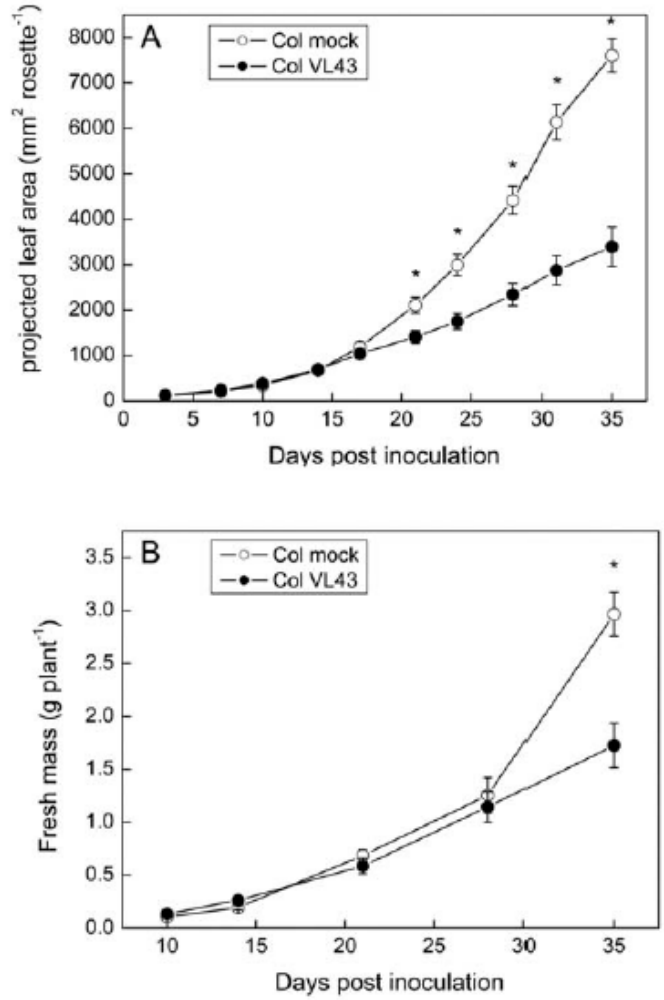

Fig. 2. Development of projected rosette area (A) and fresh mass of rosette (B) after infection with Verticillium longisporum and of mock-inoculated Arabidopsis thaliana plants. The projected leaf area and fresh mass was determined per plant. Data are means $(n=6, \pm S E)$. Stars indicate significant differences between treatments at $\mathrm{P} \leq 0.05$. 
tion initially resulted mainly in stunting of Arabidopsis plants because petiole elongation was severely inhibited.

In both controls and VL43-infected plants, the amount of chlorophyll declined with plant age; however, this effect was more pronounced in infected plants (Fig. 3). Overall, on a fresh mass basis infected plants contained $20 \%$ less chlorophyll than non-infected plants. Quantum yield of photochemistry ( $\phi)$ was determined to obtain information on photosystem II activity. Very small but significant reduction in $\phi$ was found in response to VL43 infection in ambient light $(-2 \%)$ and in darkness $(-1 \%$, Fig. 4). The influence of VL43 infec-

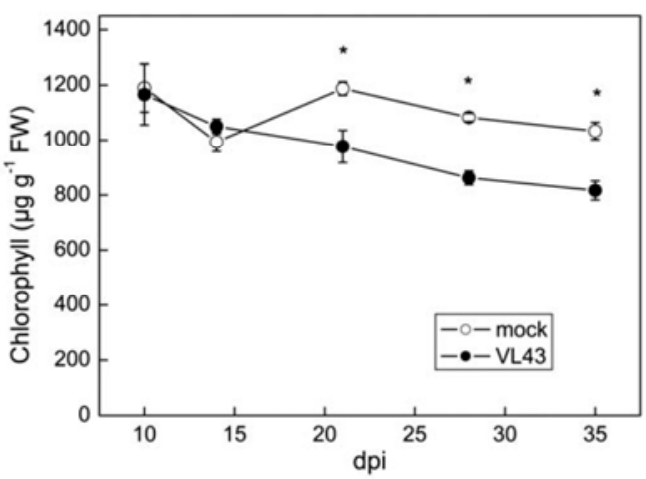

Fig. 3. Chlorophyll content in leaves of Arabidopsis thaliand after infection with Verticillium longisporum and in mock-inoculated controls. Data are means $(n=6, \pm$ SE). Stars indicate significant differences between treatments at $\mathrm{P} \leq 0.05$.


Fig. 4. Chlorophyll fluorescence of leaves of Arabidopsis
thaliana after infection with Verticillium longisporum and of mock-inoculated controls. The maximum quantum yield of photosystem II was measured on dark-adapted leaves (circles) and the acute quantum yield was measured in ambient light 120 $\mu \mathrm{mol} \mathrm{m} \mathrm{m}^{-2} \mathrm{~s}^{-1}$ of photosynthetic active radiation (triangles). Stars indicate significant differences between treatments at $\mathrm{P} \leq 0.05$.
Table 1. Water relations in Arabidopsis thaliana leaves. Data are means of $\mathrm{n}=8( \pm \mathrm{SE})$ plants measured at 25 days post inoculation after infection with Verticillium longisporum strain 43 .

\begin{tabular}{lll}
\hline & Mock- inoculated & VL43-infected \\
\hline Relative water content $(\%)$ & $91.7 \pm 0.7$ & $93.3 \pm 0.8^{\text {s*x }}$ \\
Osmotic pressure (MPa) & $0.893 \pm 0.014$ & $0.843 \pm 0.018^{*}$ \\
\hline
\end{tabular}

Significant differences between treatments are marked as

* $(\mathrm{P}<0.05)$ and औरे $(\mathrm{P} \leq 0.01)$

tion on PSII activity was, thus, much lower than that on chlorophyll content. Neither effect was detectable in old plants.

To find out whether the water relations were disturbed, we determined leaf water content and osmotic pressure at 25 days post inoculation. No evidence of drought stress was obtained since VL43-infected plants contained slightly more water and osmotic pressure was lower than in non-infected plants (Table 1).

Verticillium does not have any negative effects on Arabidopsis nutrient relations. Concentrations of macro- and micro-nutrients in the leaves were measured regularly after VL43 infection of Arabidopsis. Among the major nutrient elements $\mathrm{P}, \mathrm{N}, \mathrm{K}$, and $\mathrm{S}$, no pronounced age-dependent nor VL43-induced decreases were observed (Fig. 5A-D). The $\mathrm{C} / \mathrm{N}$ ratio of the leaves was also unaffected and amounted 5.4 throughout the whole time course of the experiment (data not shown). In VL43-infected plants the concentration of phosphorus was higher than in non infected plants (Fig. 5B). Other nutrient elements showed small and inconsistent changes in response to VL43. Calcium was accumulated with increasing age to an about $10 \%$ higher concentration than that of controls (Fig. 5E). The magnesium concentration of infected plants was initially lower than that of non-infected plants, but this difference disappeared three weeks post infection (Fig. 5F), when stunting symptoms became pronounced (Fig. 2A). The manganese content fluctuated with age ranging from 90 to $150 \mu \mathrm{g} \mathrm{g}^{-1}$ dry mass (Fig. 5G). Although the time courses of these fluctuations in infected and non-infected plants were different, the amplitudes were similar (Fig. $5 G)$. The iron concentration decreased until 4 weeks post infection. There were no differences between infected and non-infected plants (Fig. 5H)

When the element concentrations in VL43 mycelium grown in xylem sap-simulating medium were determined, the content of $\mathrm{N}, \mathrm{P}, \mathrm{S}, \mathrm{K}$, and $\mathrm{Mn}$ decreased during cultivation, whereas $\mathrm{Mg}$ increased (Fig. 5). Young fungal mycelium contained higher concentrations of $\mathrm{P}$ than Arabidopsis leaves (Fig. 5B). The concentrations of most other elements were lower in VL43 than in Arabidopsis (Fig. 5).

To assess the fraction of elements present in VL43 in 

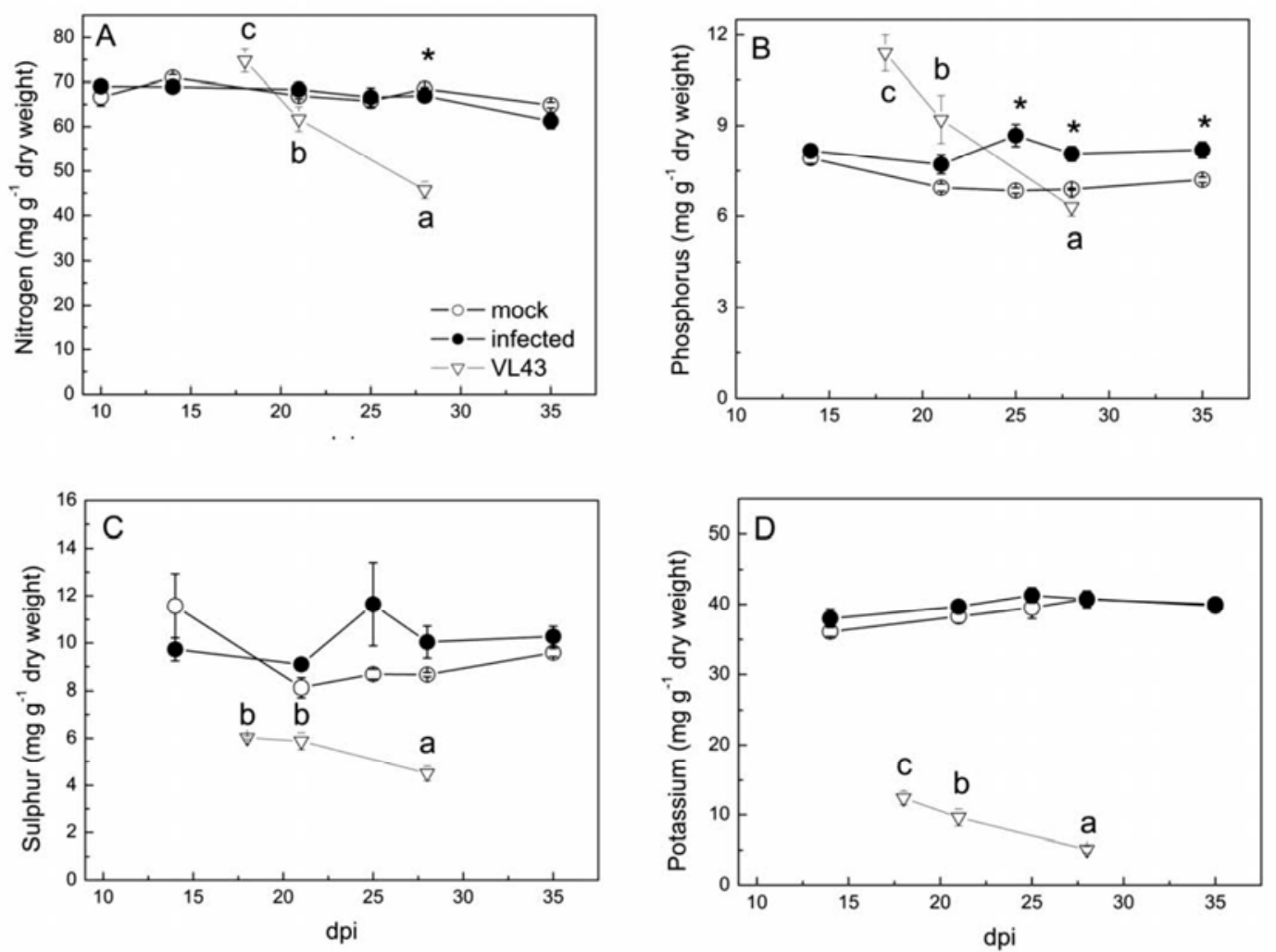

Fig. 5A-D. Nitrogen (A), phosphorus (B), sulphur (C) and potassium concentrations (D) in the leaves of Arabidopsis thaliana after infection with Verticillium longisporum (full circles) and in mock-inoculated controls (open circles) and in fungal tissues grown in pure culture (open triangles). Data are means $(\mathrm{n}=6, \pm \mathrm{SE}$ ). Stars indicate significant differences between treatments at $\mathrm{P} \leq 0.05$ for plants and letters indicate differences due to increasing culture time in V. longisporum.

infected leaves and thus not available for the plant, we determined the amount of fungal DNA in fungal tissues grown in simulated xylem medium as well as in plant leaves (Fig. 6). The amount of fungal biomass in infected plant leaves contributed approximately $0.001 \%$ to their dry mass. With this figure and the known nutrient content of fungal mycelium, the fraction of mineral nutrients sequestered by the fungus within plant tissue was estimated (Fig. 7). The mean fractions of nutritional elements present in the fungus in infected leaves were $0.0008 \pm 0.0003 \%$ of the total leaf contents, except for iron whose fractions was slightly higher $(0.006 \%)$. Even if we assume that fungal nutrient demand in planta exceeded the demand of mycelium grown in vitro by one or two orders of magnitudes, the effect of fungal consumption of mineral nutrients on the plant would be negligible. Therefore, we found no evidence that fungal infection caused nutrient deficiencies in Arabidopsis.

\section{DISCUSSION}

In the present study we documented that the growth reduction in Arabidopsis, which became very pronounced between two and three weeks post inoculation with $V$. longisporum, was not caused by foliar nutrient deficiencies but was mainly related to decreased elongation of the petioles. This finding does not support the hypothesis that insufficient supply with nitrogen or other major nutrients might have affected plant growth. This agrees with previous findings showing that VL43 infection did not cause nutrient deficiencies in oilseed rape (Floerl et al., 2008). One might argue that in infected leaves the fungus may bind significant amounts of nutrients and that despite high total foliar nutrient concentrations the availability for the plant may be limited. To obtain an estimate for the amount of nutrients sequestered by the fungus in the leaf tissue, we deter- 

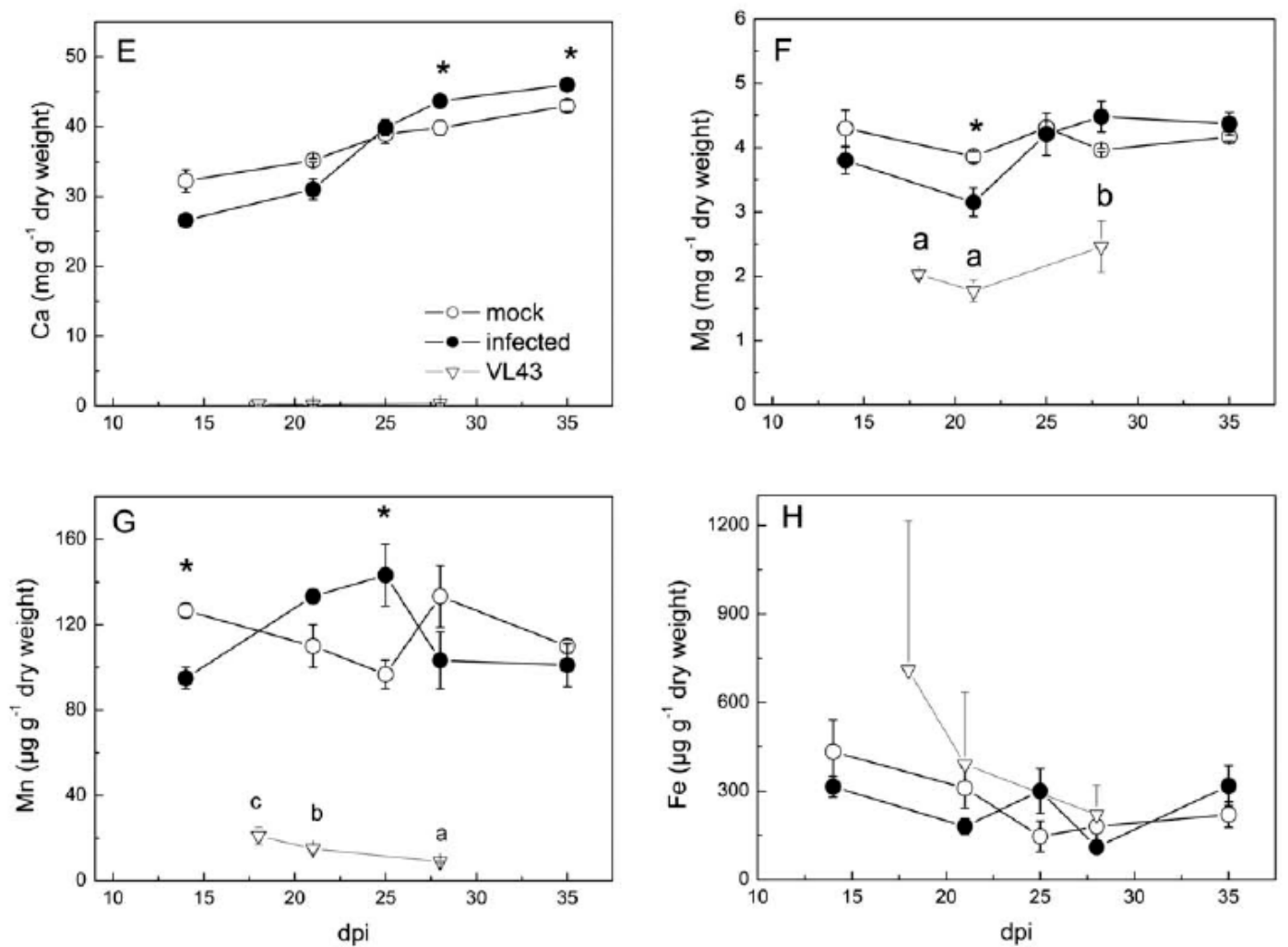

Fig. 5E-H. Calcium (E), magnesium (F), manganese (G) and iron concentrations $(\mathrm{H})$ in the leaves of Arabidopsis thaliana after infection with Verticillium longisporum (full circles) and in mock-inoculated controls (open circles) and in fungal tissues grown in pure culture (open triangles). Data are means $(n=6, \pm S E$ ). Stars indicate significant differences between treatments at $\mathrm{P} \leq 0.05$ for plants and letters indicate differences due to increasing culture time in V. longisporwm.

mined the content of mineral elements in fungal mycelium grown in a medium with a composition similar to xylem sap. Although culture conditions in vitro differ from the situation in planta, the data provide a reasonable estimate for the maximum amounts of mineral nutrients withheld off the plant by the fungus.

Nitrogen deficiencies have been shown to cause chlorosis in Arabidopsis (Hanaoka et al., 2002). Since there was no evidence that fungal proliferation sequestered a significant fraction of nitrogen, $\mathrm{N}$ limitation was not the cause of chlorophyll loss observed during Verticillium infection.

Potassium acts in plants as a major osmolyte and is critically involved in cell expansion growth (OToole et al., 1980). Our data do not support K deficiency as a cause of stunting of VL43-infected plants.

Surprisingly, VL43-infected plants displayed increased phosphorus concentrations. Since this effect was also observed in tomato and eggplants infected with
V. dabliae (Karagiannidis et al., 2002), it seems that Verticillium infection influences the metabolism of phosphorus. Notably, microarray analysis revealed induction of the inorganic phosphate transporter gene LePT2 in $\mathrm{V}$. dabliae-infected tomato roots (Van Esse et al., 2009). Whether this effect is relevant for fungal infection or plant physiology is unknown. However, it has been shown that plants well supplied with nutrients, especially nitrogen and phosphorus, are more susceptible to $V$. dabliae infection than starved plants (Sivaprakasam and Rajagopalan, 1972), whereas iron deficiency increases Verticillium infection of tomatoes (Macur et al., 1991). These reports underline the importance of interactions between fungal infection and plant nutritional status, but our data do not support that Verticillium infection itself reduces plant nutrition.

It is possible that the observed chlorophyll loss was the result of phytotoxin action. Evidence for the role of phytotoxins in Verticillium-plant interactions has been 


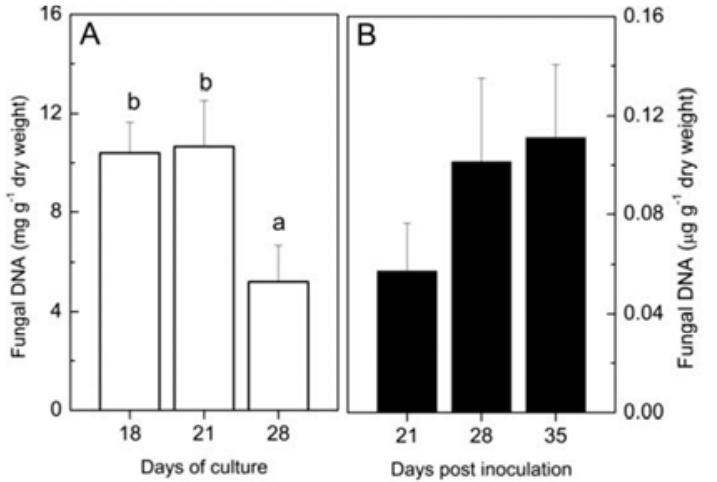

Fig. 6. Changes of fungal DNA during cultivation in artificial medium (A) and in Arabidopsis thaliana leaves (B). Data are means $(n=4$ for the fungal cultures and $n=6$ for plant tissues, \pm SE). Significant differences at $\mathrm{P} \leq 0.05$ are indicated by letters.

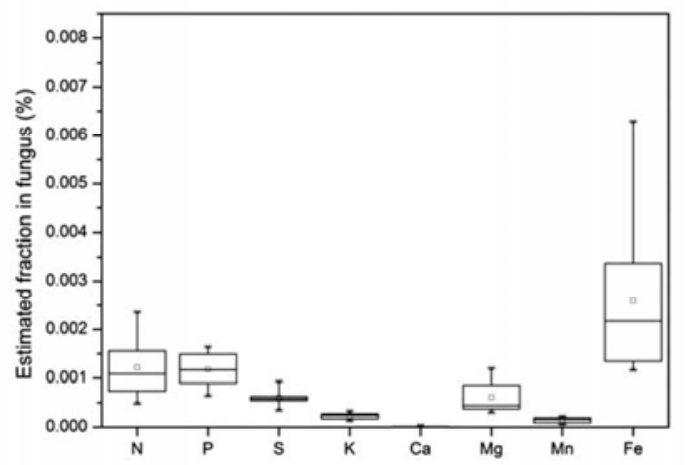

Fig. 7. Assessment of element partitioning in infected leaves of Arabidopsis thaliana between Verticillium longisporum and plant tissue. All possible combinations of element concentrations per fungal tissue and plant were calculated and are shown as box plots with maximum and minimum values $(\mathrm{x})$ and mean (open square) and mediam (horizontal line in box).

provided by numerous studies (Fradin and Thomma, 2006). For example, Mansoori et al. (1995) isolated a heat stable toxin $(\mathrm{MW}<1000)$ from the culture fluid of $V$. dabliae, which caused chlorosis and necrosis of leaf discs. Others reported that a protein-lipopolysaccharide complex produced by Verticillium sp. acted as phytotoxin (Fradin and Thomma, 2006). Since the toxins were isolated from culture fluids, it is unclear whether they are also formed in infected plants.

Phytotoxin production by $V$. longisporum has not been reported. Fungal phytotoxins often disrupt the integrity of photosynthetic electron transport (Kshirsagar et al., 2001). Our data indicate that the loss in chlorophyll had only small impact on the quantum yield of
PSII. The slightly stronger decrease of quantum yield in light than in darkness in VL43-infected plants might have been the result of small effects on stomatal opening as reported by others (Bowden et al., 1990; Saeed et al., 1999; Sadras et al., 2000) and was not indicative for direct injury of PSII or $\mathrm{CO}_{2}$ assimilatory enzymes. In fact, microarray analysis of $V$. dabliae responsive genes in tomato revealed increased transcript abundance of several genes in involved in photosynthesis (Robb et al., 2007). These data contrast those of Veronese et al. (2003) who showed significant loss in Rubisco transcripts in Arabidopsis infected with $V$. dabliae. Although $V$. dabliae is non-pathogenic to several cultivars of oilseed rape (Karapapa et al., 1997; Eynck et al., 2007), it caused significant stunting and chlorosis in Arabidopisis. However, the response varied between different ecoptypes, cv. Columbia being among the most sensitive ones (Veronese et al., 2003).

In conclusion, our data show that $V$. longisporum, one of the most important pathogens of Brassicaeae, infects also $A$. thaliana. While VL43 caused strong stunting of the stem of oil seed rape (Floerl et al., 2008), it suppresses leaf expansion in Arabidopsis which, according to our results, is not caused by nutrient depletion.

\section{ACKNOWLEDGEMENTS}

We are grateful to A. von Tiedemann for providing V. longisporum strain VL43 and to M. Franke-Klein for excellent technical assistance. We thank the German Science Foundation for financial support to FOR 546 (PO362/15-1,15-2).

\section{REFERENCES}

Benhamou N., 1995. Ultrastructural and cytochemical aspects of the response of eggplant parenchyma cells in direct contact with Verticillium-infected xylem vessels. Physiology and Molecular Plant Patbology 46: 321-338.

Bowden R.L., Rouse D.I., Sharkey T.D., 1990. Mechanism of photosynthesis decrease by Verticillium dabliae in potato, Plant Physiology 94: 1048-1055.

Brandfass C., Karlovsky P., 2006. Simultaneous detection of Fusarium culmorum and $F$, graminearum in plant material by duplex PCR with melting curve analysis. BMC Microbiology 6: 4 .

Eynck C., Koopmann B., Grunewaldt-Stoecker G., Karlovsky P., Tiedemann A., 2007. Differential interactions of Verticillium longisporum and $V$. dabliae with Brassica napus detected with molecular and histological techniques. European Journal of Plant Patbology 118: 259-274.

Fahleson J., Lagercrantz U., Hu Q., Steventon L.A., Dixelius C., 2003. Estimation of genetic variation among Verticillium isolates using AFLP analysis. European Journal of Plant Pathology 109: 361-371. 
Floerl S., Drübert C., Majcherczyk A., Karlovsky P., Kües U., Polle A., 2008. Defence reactions in the apoplastic pro teome of oilseed rape (Brassica napus var. napus) attenuate Verticillium longisporum growth but not disease symptoms. BMC Plant Biology 8: 129

Fradin E.F., Thomma B.P.H., 2006. Physiology and molecular aspects of Verticillium wilt diseases caused by $V$. dabliae and V. albo-atrum. Molecular Plant Patbology 7: 71-86.

Hanaoka H., Noda T., Shirano Y., Kato T., Hayashi H., Shibata D., Tabata S., Ohsumi Y., 2002. Leaf senescence and starvation-induced chlorosis are accelerated by the disruption of an Arabidopsis autophagy gene. Plant Physiology 129: 1181-1193.

Heinrichs H., Brumsack H.J., Loftfield N., König N., 1986. Verbessertes Druckaufschlusssystem für biologische und anorganische Materialien. Zeitschrift für Pflanzenernäbung und Bodenkunde 149: 350-353.

Johansson A., Goud J.-K., Dixelius C., 2006. Plant host range of Verticillium longisporum and microsclerotia density in Swedish soils. European Journal of Plant Patbology 114: 139-149.

Karagiannidis N., Bletsos F., Stavropoulos N., 2002. Effect of Verticillium wilt (Verticillium dabliae Kleb.) and mycorrhiza (Glomus mosseae) on root colonization, growth and nutrient uptake in tomato and eggplant seedlings. Scientia Horticulturae 94: 145-156.

Karapapa V.K., Bainbridge B.W., Heale J.B., 1997. Morphological and molecular characterization of Verticillium longisporum comb. nov., pathogenic to oilseed rape. Mycological Research 101: 1281-1294.

Kshirsagar A., Reid A.J., McColl S.M., Saunders V.A., Whalley A.J.S., Evans H.E., 2001. The effect of fungal metabolites on leaves as detected by chlorophyll fluorescence. New Pbytologist 151: 451-457.

Lichtenthaler H.K., Wellburn A.R., 1983. Determinations of total carotenoids and chlorophylls a and b of leaf extracts in different solvents. Biochemical Society Transactions 11: 591-592.

Macur R.E., Mathre D.E., Olsen R.A.. 1991. Interactions between iron nutrition and Verticillium wilt resistance in tomato. Plant and Soil 134: 281-286.

Mansoori B., Milton J.M., Smith C.J., 1995. Isolation and par- tial purification of a phytotoxin related to pathogenic Ver ticillium species. Journal of Pbytopatbology 143: 33-36.

Maxwell K., Johnson G.N., 2000. Chlorophyll fluorescence - a practical guide. Journal of Experimental Botany 51: 659-668.

Murashige T., Skoog F., 1962. A revised medium for rapid growth and bioassays with tobacco tissue cultures. Physiologia Plantarum 15: 473-497.

Neumann M.J., Dobinson K.F., 2003. Sequence tag analysis of gene expression during pathogenic growth and microsclerotia development in the vascular wilt pathogen Verticillium dabliae. Fungal Genetics and Biology 38: 54-62.

O'Toole J.C., Treharne K., Turnipseed M., Crookston K. Ozbun J., 1980. Effect of potassium nutrition on leaf anatomy and net photosynthesis of Phaseolus vulgaris L. New Phytologist 84: 623-630.

Robb J., Lee B., Nazar R.N., 2007. Gene suppression in a tolerant tomato-vascular pathogen interaction. Planta 226: 299-309.

Sadras V.O., Quiroz F, Echarte L., Escande A., Pereyra V.R. 2000. Effect of Verticillium dabliae on photosynthesis, leaf expansion and senescence of field-grown sunflower. $A n$ nals of Botany 86: 1007-1015.

Saeed I.A.M., MacGuidwin A.E., Rouse D.I., Sharkey T.D., 1999. Limitation to photosynthesis in Pratylenchus penetrans- and Verticillium dabliae-infected potato. Crop Science 39: 1340-1346.

Sivaprakasam K., Rajagopalan C.K.S., 1974. Effect of nitrogen on the incidence of Verticillium wilt disease of egg plant caused by Verticillium dabliae Kleb. Plant and Soil 40: 217. 220.

van Esse H.P., Fradin E.F., de Groot PJ., de Wit P.J.G.M., Thomma B.P.H.J., 2009. Tomato transcriptional responses to a foliar and a vascular fungal pathogen are distinct. Molecular Plant Microbe Interactions 22: 245-258

Veronese P., Narasimhan M.L., Stevenson R.A., Zhu J.K., Weller S.C., Subbarao K.V., Bressan R.A., 2003. Identification of a locus controlling Verticillium disease symptom response in Arabidopsis thaliana. Plant Journal 35: 574-587.

Zeise K., von Tiedemann A., 2002. Host specialization among vegetative compatibility groups of Verticillium dabliae in relation to Verticillium longisporum. Journal of Phytopathology 150: 112-119. 


\section{Danksagung}

An dieser Stelle möchte ich mich bei allen bedanken, die mich während meiner Doktorarbeit unterstützt haben.

Als Erstes möchte ich mich bei Frau Prof. Dr. Andrea Polle für die Überlassung des interessanten Dissertationsthemas, die damit verbundene Betreuung dieser Doktorarbeit und die vielen Anregungen zur experimentellen Durchführung sowie zur Gestaltung dieser Arbeit bedanken.

Des Weiteren möchte ich mich bei Frau Prof. Dr. Christiane Gatz für Übernahme des Korreferates und die Teilnahme an meinem Thesis Commitee bedanken.

Bei Dr. Thomas Teichmann, Prof. Dr. Petr Karlovsky, Prof. Dr. Jan Schirawski und Prof. Dr. Stefanie Pöggeler möchte ich mich dafür bedanken, dass sie sich als weitere Prüfer für die Disputation zur Verfügung gestellt haben.

Für die Finanzierung dieser Arbeit, die im Rahmen der Forschergruppe 546 durchgeführt wurde, bedanke ich mich bei der DFG. In dem Zusammenhang möchte ich mich auch bei allen Mitgliedern der Verticillium-Forschergruppe 546 für die gute Zusammenarbeit und den Informationsaustausch während der monatlichen Treffen bedanken. Im Besonderen möchte ich der AG Karlovsky für die zahlreichen qRT-PCR-Messungen und die Zusammenarbeit im Hinblick auf die Xylemsaft-Wachtumsversuche bedanken. Der AG Teichmann danke ich für die gute Koorperation bei dem „Projekt Transdifferenzierung“. Von der AG Tiedemann haben wir VL43 und Raps bekommen. Dafür einen ganz herzlichen Dank. Weiterhin möchte ich der AG Gatz und der AG Dröge-Laser für diverse Vektoren, E.colis und Arabidopsis-Samen danken. Außerdem möchte ich mich bei Martin Fulda und der AG Feußner für die Ratschläge bei den Hefe-Experimenten danken. Bei Stefanie Götze und Mareike Possienke aus der AG Feußner bedanke ich mich für die nette Zusammenarbeit während der gemeinschaftlichen Arabidopsis-Versuche.

Aus der Abteilung Forstbotanik möchte ich vor allem Saskia Flörl herzlich danken. Durch ihre gute Vorarbeit ist dieses Projekt erst möglich geworden. Außerdem hat sie mich zu Beginn meiner Arbeit in die Geheimnisse und Tricks der Verticillium-Infektion eingewiesen. Danke hierfür! Bei Monika Franke-Klein möchte ich mich für die Hilfe beim Retschen, Xylemsaft-Pressen, Ernten und für diverse Extraktionen und Messungen bedanken. Marianne Smiatacz danke ich ebenfalls für die Hilfe bei einigen Ernten und für das Xylemsaft-Pressen, außerdem für die Erledigung der zahllosen „kleinen“ Dinge für die 
Allgemeinheit. Merle Fastenrath danke ich für die große Hilfe bei der Anatomie und bei den GUS-Ernten. Im Zusammenhang mit der Anatomie möchte ich mich auch ganz herzlich bei Andrea Olbrich, Jasmin Seven, Karin Lange, Christa Lang und Frau Dr. Rosemarie Heyser für den Austausch vieler nützlicher Tips bedanken. Prof. Dr. Gertrud Lohaus danke ich für die Aminosäure-Messungen. Ein besonderer Dank geht an Mona Quambusch, die mir während ihrer Zeit als HiWi bei vielen Arbeiten geholfen hat. Christine Kettner, Gisbert Langer-Kettner, Sabine Elend, Viktoria Pfander, Thomas Klein und Gabi Lehmann haben mich ebenfalls unterstützt. Danke hierfür! Bernd Kopka danke ich für die Hilfe bei Computerproblemen und für das Drucken diverser Poster.

Für die nette Arbeitsatmosphäre, viele gemeinschaftliche Mensa-Gänge und Mittagspausen in der Sonne danke ich Andrea Olbrich, Christa Lang, Jasmin Seven, Kerttu Valtanen, Peter Hawighorst, Dennis Janz, Lara Danielsen, Franziska Biedermann, Katharina Platner, Annette Naumann und Caroline Carsjens. Meiner Bürokollegin Rodica Pena danke ich für die vielen aufmunternden Gespräche zwischendurch. Ihr, Christa Lang und Lara Danielsen danke ich auch für die vielen hilfreichen Statistik-Diskussionen. Allen anderen aus der Abteilung danke ich für die Hilfsbereitschaft und die nette, internationale Atmosphäre.

Ein großes Dankeschön möchte ich an meine Freunde und meine Familie, besonders an meine Eltern, richten, die mich während der ganzen Doktorarbeit immer wieder aufgemuntert und unterstützt haben.

Mein größter Dank gilt meinem Schatz Christoph Weiste, der mich während der gesamten Zeit der experimentellen Arbeit und vor allem während des anstrengenden Zusammenschreibens trotz eigener Doktorarbeit so liebevoll unterstützt hat. Danke. 


\section{Lebenslauf}

\section{Persönliche Daten}

Name: Christine Drübert

Geburtsdatum: $\quad 22.09 .1980$

Geburtsort: Volkmarsen

\section{Schulbildung}

$1987-1991$

Kugelsburgschule, Volkmarsen (Grundschule)

$1991-2000$

Christian-Rauch-Schule, Bad Arolsen (Gymnasium)

Abschluss: Allgemeine Hochschulreife

$2000-2001 \quad$ Freiwilliges Ökologisches Jahr

\section{Wissenschaftlicher Werdegang}

Okt. 2001 - Jan. $2007 \quad$ Studium der Biologie an der Georg-August-Universität Göttingen; Abschluss: Diplom-Biologin

Febr. 2004 - Dez. 2004

März 2006 - Dez. 2007

April 2007 - Sept. 2007

seit Okt. 2007
Auslandspraktikum und Mitarbeit an einer Publikation im Rahmen eines Forschungsprojektes

Anfertigung der Diplomarbeit mit dem Titel „Einfluss des Kohlenstoffhaushaltes auf die Mykorrhizierung bei Buchen (Fagus sylvatica L.)“ in der Abteilung Forstbotanik und Baumphysiologie des Büsgen-Instituts der Universität Göttingen

Wissenschaftliche Hilfskraft in der Abteilung Forstbotanik und Baumphysiologie des Büsgen-Instituts der Universität Göttingen

Wissenschaftliche Mitarbeiterin in der Abteilung Forstbotanik und Baumphysiologie des Büsgen-Instituts der Universität Göttingen; Anfertigung der Dissertation „Funktionelle Charakterisierung von aoplastischen Proteinen in Brassica napus und Arabidopsis thaliana nach Infektion mit Verticillium longisporum“ 


\section{Publikationen}

Floerl S., Druebert C., Aroud H.I, Karlovsky P., Polle A. (2010): Disease symptoms and mineral nutrition in Arabidopsis thaliana in response to Verticillium longisporum VL43 infection. Journal of Plant Pathology 92 (3): 695-702.

Druebert C., Lang C., Valtanen K., Polle A. (2009): Beech carbon productivity as driver of ectomycorrhizal abundance and diversity. Plant, Cell and Environment 32 (8): 9921003.

Floerl S., Druebert C., Majcherczyk A., Karlosky P., Kües U., Polle A. (2008) : Defence reactions in the apoplastic proteome of oilseed rape (Brassica napus var. napus) attenuate Verticillium longisporum growth but not disease symptoms. BMC Plant Biology 8: 129.

Gradstein S.R, Tan B.C., Zhu R.-L., Ho B.-C., King C., Drübert C., Pitopang R. (2005): A catalogue of the bryophytes of Sulawesi, Indonesia. Journal of the Hattori Botanical Laboratory 98: 213-257. 